\title{
Simulation of Ductile Fracture in Pipeline Steels under Varying Constraint Conditions
}

by

\author{
Shreya Parmar
}

A thesis submitted to the Faculty of Graduate and Postdoctoral Affairs in partial fulfillment of the requirements for the degree of

Masters in Applied Science

in

Aerospace Engineering

Carleton University

Ottawa, Ontario

(C) 2014, Shreya Parmar 


\section{Abstract}

This study has two major objectives: (1) to study the effect of non-singular T-stress (or constraint) variations on crack tip opening angle (CTOA) of pipeline steels using modified boundary layer (MBL), and (2) to simulate ductile crack propagation in pipeline steels using drop weight tear test (DWTT) and comparing these FE simulations with experimental results. Three sets of materials: (1) TH steel, Tvergaard and Hutchinson (1992), (2) C2 steel or X70 steel, and (3) C4 steel or X100 steel are used in this work. TH steel, C2 steel and C4 steel are modeled using four, three and six traction-separation (TS) laws respectively. The surface based cohesive zone modeling is used for the models of TH steel and C2 steel, while models of C4 steel are computed using element based cohesive modeling. In this work, we use following three models to study the ductile crack growth: (1) small scale yielding (SSY), (2) MBL, and (3) DWTT. All finite element simulations are conducted in the FE program ABAQUS-6.11.

From the results of MBL of all three steels, it was concluded that the effect of T-stress on CTOA is negligible. The extracted steady state CTOA from SSY and DWTT of TH steel (TH_1-TH_4) were ranged from $1.5^{\circ}-5.6^{\circ}$ and $1.6^{\circ}-5^{\circ}$ respectively, that showed good agreement among these two specimens. From DWTT simulations of $\mathrm{C} 2$ and $\mathrm{C} 4$ steel, the values of the obtained CTOA of C2_2 steel and C4_3 steel were $11.9^{\circ}$ and $9.3^{\circ}$ respectively. To validate the DWTT results of $\mathrm{C} 2$ and $\mathrm{C} 4$ steel, the CTOA results were compared with the experimental results. The values of experimental CTOA of DWTT for $\mathrm{C} 2$ and $\mathrm{C} 4$ steel were $12.4^{\circ}$ and $10.4^{\circ}$ respectively (S-SSM). The numerical CTOA of SSY and DWTT were in good agreement with the experimental data. Reasonable 
agreements were also achieved when comparing the load vs. load-line displacement curves between experiments and simulations for $\mathrm{C} 2$ and $\mathrm{C} 4$ steels. 


\section{Acknowledgement}

This research work could not have been accomplished without the support of many people. Foremost, I am thankful to God for blessing me for everything. I would like to express my deep gratitude to Professor Xin Wang, my research supervisor, for his continuous guidance and encouragement during critical times of this entire journey. I would also like to thank the entire fracture arrest project team of CANMET-MTL; Dr. Tyson Bill, Su Xu and Simha Hari for their advices and direction.

I also wish to acknowledge CANMET-MTL and Carleton University for financial support throughout this thesis work. I also thank the Department of Mechanical and Aerospace Engineering for the academic help. I would like to convey my appreciation to all my friends and colleagues for their supports.

My grateful thank is also extended to my grandfather Mr. Alabhai Parmar, for his motivations from my childhood to till now, without him, I would not have been at this position of my life. Finally, I wish to thank my parents; Mr. Vijay Parmar \& Mrs. Parul Parmar and my dearest brother Mr. Parth Parmar for their inspiration, love and prayers. 


\section{Table of Contents}

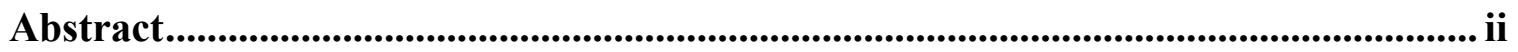

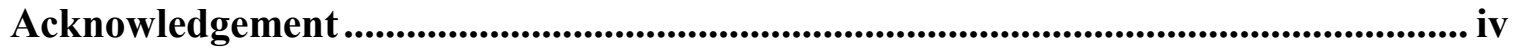

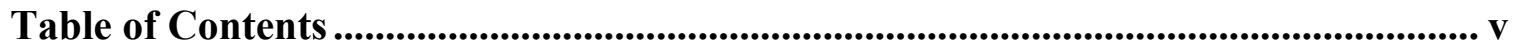

List of Tables .......................................................................................................... viii

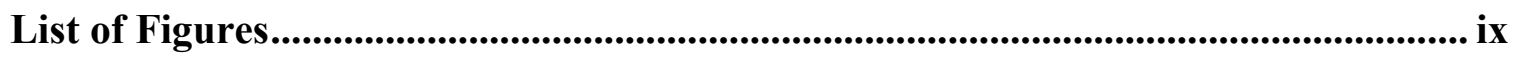

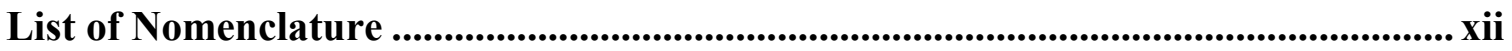

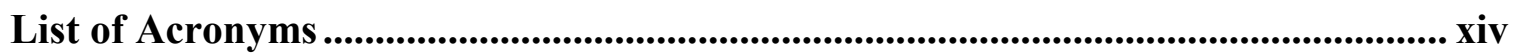

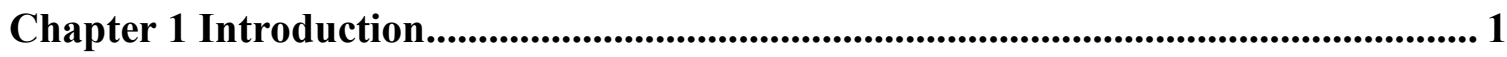

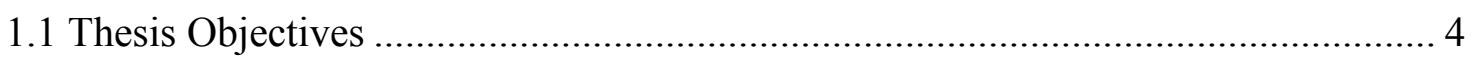

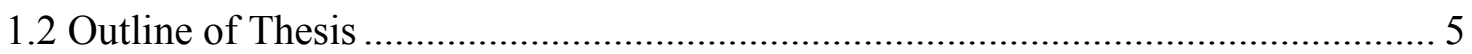

Chapter 2 Literature Review and Background..........................................................8 8

2.1 Overview of Cohesive Zone Modeling for Pipe-line Steel .................................... 8

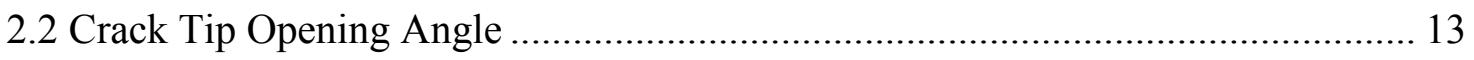

2.2.1 Calibration of CTOA from Experimental data ........................................... 14

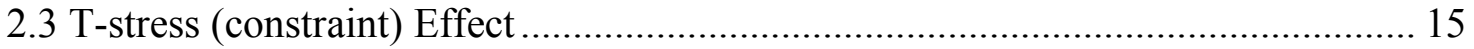

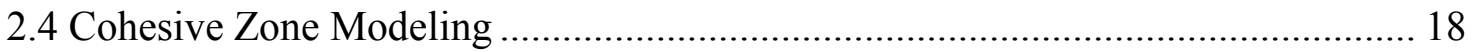

2.4.1 Role of Micromechanics in Cohesive Zone Modeling ................................... 18

2.4.2 Traction-Separation Based Modeling in ABAQUS ....................................... 18

2.4.3 Element Based CZM and Surface Based CZM ............................................ 24

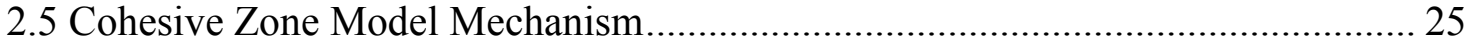

2.6 Explicit and Implicit Numerical Method ....................................................... 27

Chapter 3 FE Simulation of Ductile Crack Propagation in TH Steel ........................ 35

3.1 FE Simulation of Small Scale Yielding Model .................................................. 35

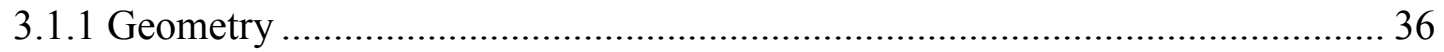

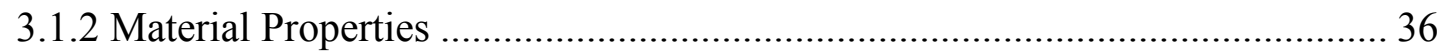

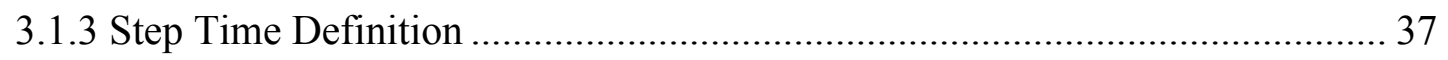

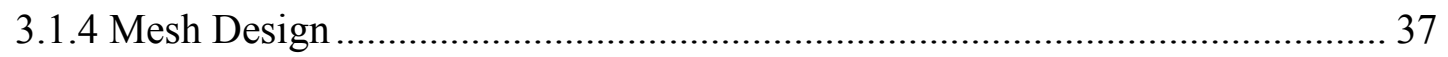

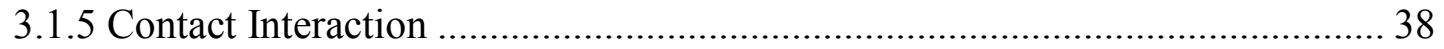




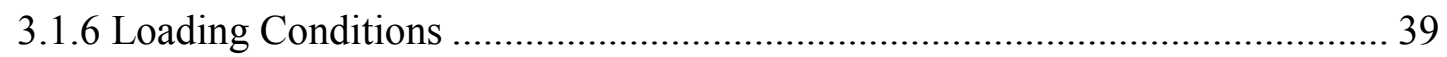

3.2 FE Simulation of Modified Boundary Layer Model............................................ 39

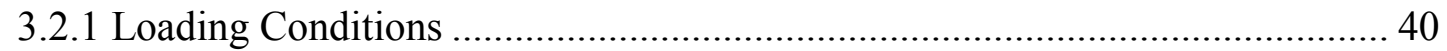

3.3 FE Simulation of Drop-Weight Tear Test (DWTT) .............................................. 40

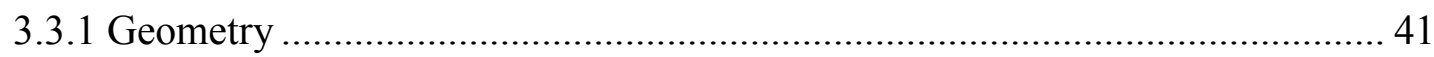

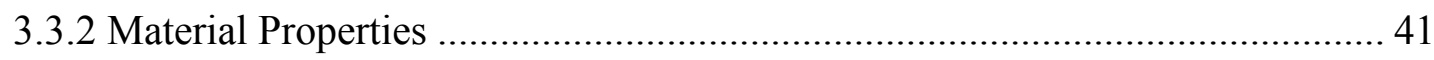

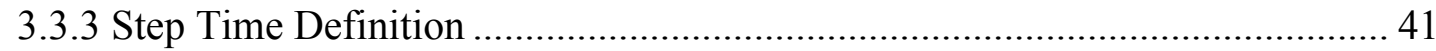

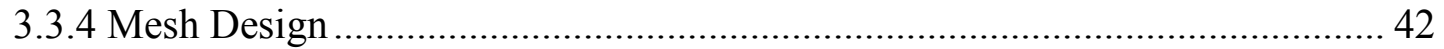

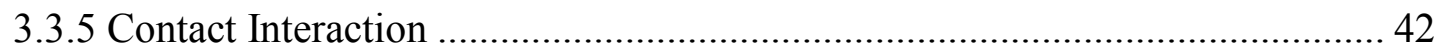

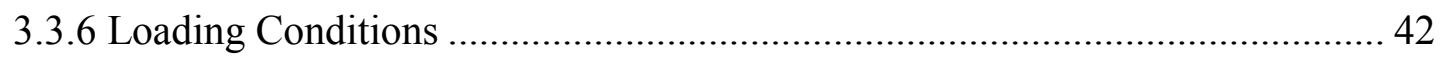

3.4 FE Simulation of Single Edge Notched Specimen in Tension (SENT) .................. 43

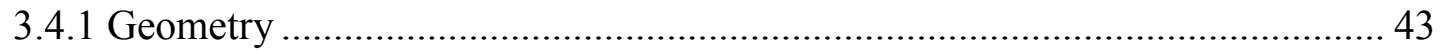

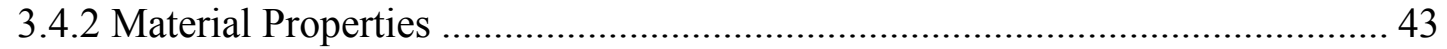

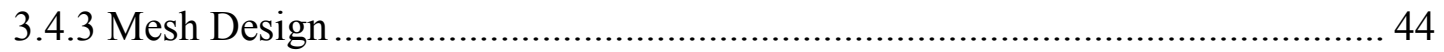

3.4.4 Step Time Definition and Contact Interaction............................................... 44

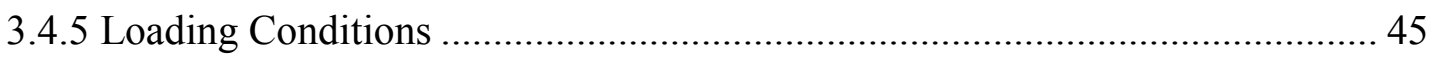

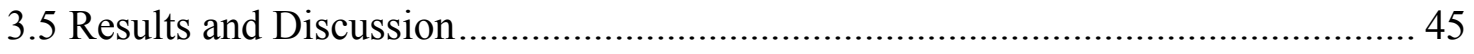

3.5.1 Small Scale Yielding Model......................................................................... 45

3.5.2 Modified Boundary Layer Model.................................................................. 47

3.5.3 Drop-Weight Tear Test............................................................................. 48

3.5.4 Single Edge Notched Specimen in Tension (SENT) ....................................... 50

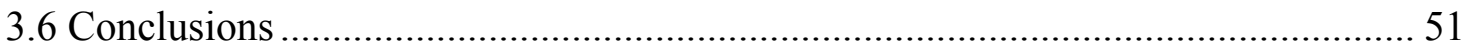

Chapter 4 FE Simulation of Ductile Crack Propagation in C2 Steel........................... 77

4.1 FE Simulation of the Small Scale Yielding Model ................................................. 77

4.2 FE Simulation of the Modified Boundary Layer Model ....................................... 78

4.3 FE Simulation of the Drop-Weight Tear Test ......................................................... 79

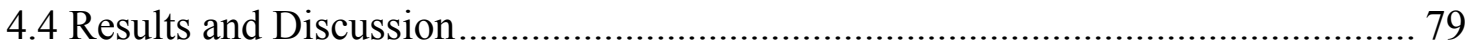

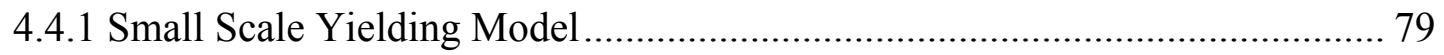

4.4.2 Modified Boundary Layer Model ............................................................... 80

4.4.3 Drop-Weight Tear Test........................................................................... 81

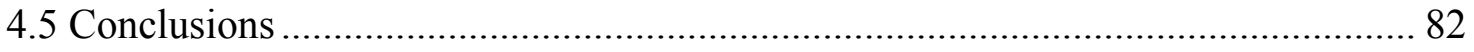


Chapter 5 FE Simulation of Ductile Crack Propagation in C4 Steel.

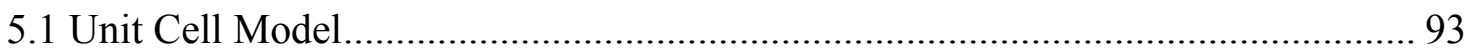

5.2 FE Simulation of Small Scale Yielding Model .................................................. 94

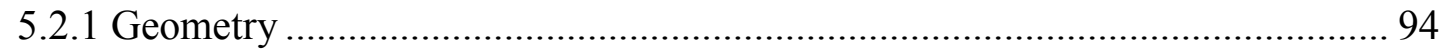

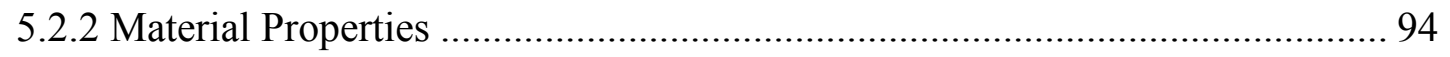

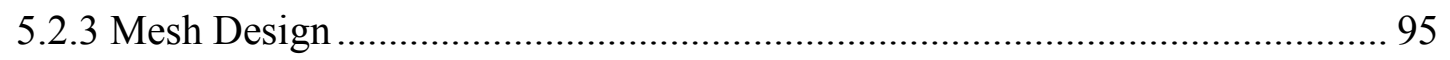

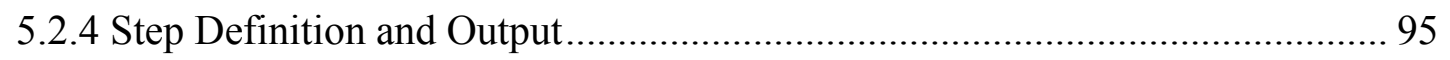

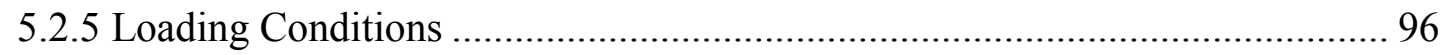

5.3 FE Simulation of Modified Boundary Layer Model .......................................... 97

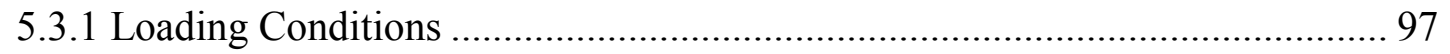

5.4 Drop-Weight Tear Test Model-Experimental and Numerical Analysis ................ 97

5.4.1 Experimental Set up and Data Collection of DWTT ..................................... 98

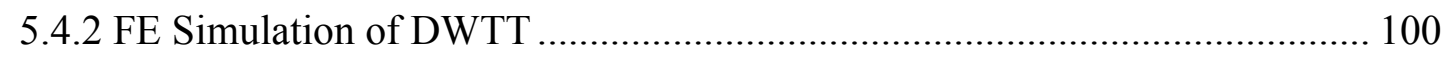

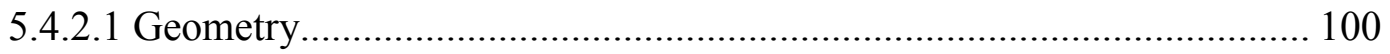

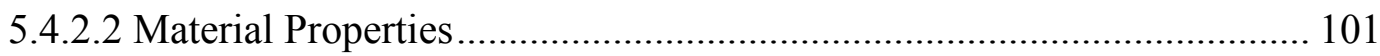

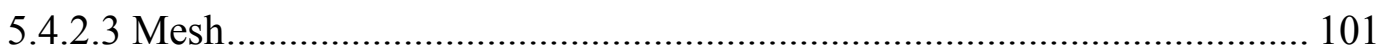

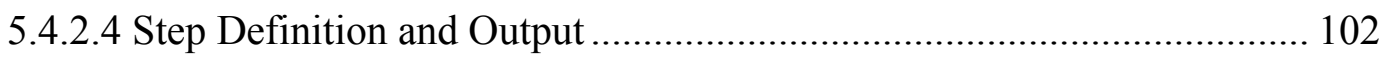

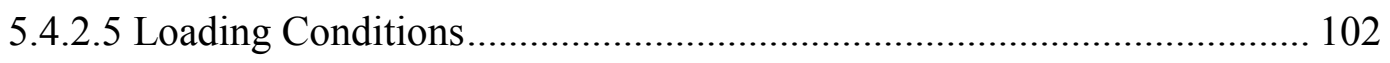

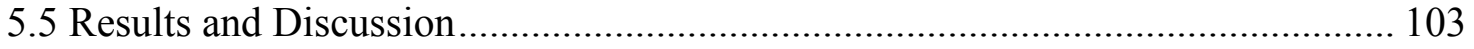

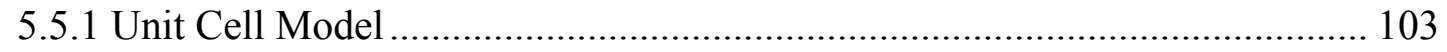

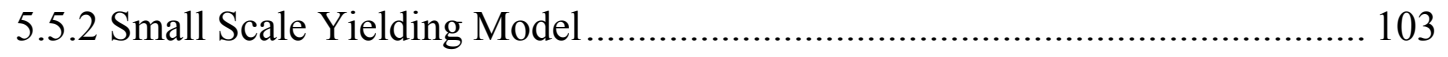

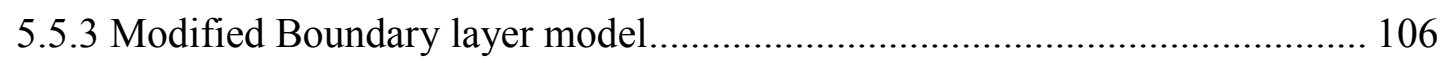

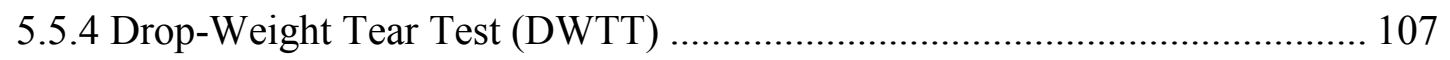

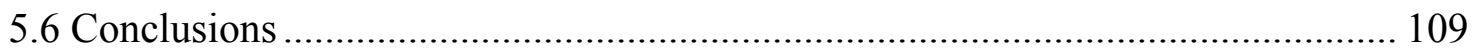

Chapter 6 Conclusions and Future Work ........................................................................ 130

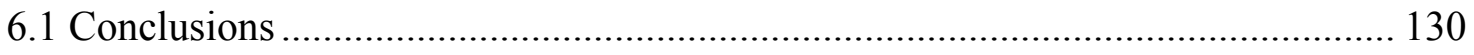

6.2 Recommendations for Future Work ............................................................. 132

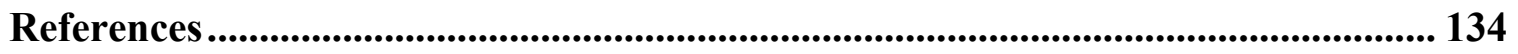




\section{List of Tables}

Table 3.1: Stress vs. plastic strain data - TH steel (input in ABAQUS)) ........................... 53

Table 3.2: Cohesive properties of four sets of TH steel ................................................. 54

Table 3.3: Model parameters - TH steel ................................................................ 54

Table 4.1: Stress vs. plastic strain data - C2 steel (input in ABAQUS) .......................... 84

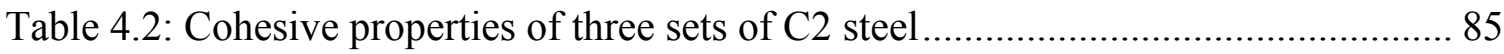

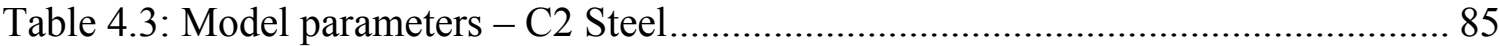

Table 5.1: Chemical composition of pipe steel C4 (X100) (wt \%), (Xu et al., 2010b)... 111 Table 5.2: Average transverse tensile and charpy properties of pipe steel C4 (X100),.. 111 Table 5.3: Stress vs. plastic strain data- C4 steel (input in ABAQUS) ......................... 112 Table 5.4: Cohesive properties of three sets of C4 steel (used in unit cell, SSY and MBL) 113

Table 5.5: Cohesive properties of three sets of C4 steel (used in unit cell and DWTT) 113

Table 5.6: Model parameters - C4 steel ..................................................................... 114 


\section{List of Figures}

Figure 1.1: Schematic of drop-weight tear test (DWTT) ............................................. 7

Figure 2.1: Cohesive Zone models: various separation laws, (Zerbst, et al., 2009) : (a)

Dugdale (1960); (b) Barenblatt (1962); Hillerborg et al. (1976),brittle materials; (c) Needlemen (1987); Tvergaard (1990), ductile materials,polynomial equations; (d) Rose et al. (1981);Needleman (1990), exponential equation; (e) Tvergaard and Hutchinson (1992),

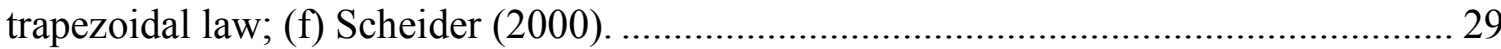

Figure 2.2: Modified boundary layer (MBL) model, (Ding \& Wang, 2012) .................... 29

Figure 2.3: Full specimen of drop-weight tear test (DWTT), (Xu et al., 2011) ............... 30 Figure 2.4: Load vs. load-line displacement plots of shallow-notched DWTT specimens,

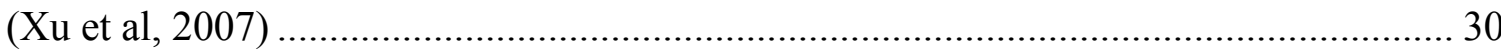

Figure 2.5: Plots of LnPPi vs. $y-y i \mathrm{~S}$ relations and data range for determination of the

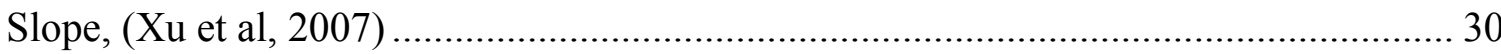

Figure 2.6: Definitions of the crack tip opening angle (CTOA), (Zerbst, et al., 2009) .... 31 Figure 2.7: Embedded cohesive process zone and typical traction-separation (TS) curve, (Li \& Chandra, 2003).

Figure 2.8: Typical bilinear traction-separation response (ABAQUS User'smanual- 6.11)

Figure 2.9: (a) Exponential TS law (b) Traction stresses as a function of separation with

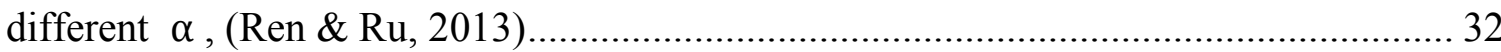
Figure 2.10: Typical element based cohesive zone model-independent meshes with tie

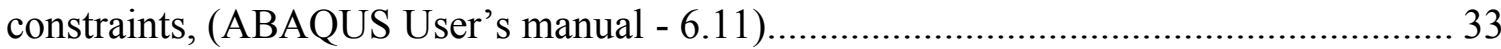
Figure 2.11: Typical surface based cohesive zone model-contact interaction with tie constraint, (ABAQUS User's manual - 6.11) ……………........................................... 33 Figure 2.12: Simplified scheme of cohesive zone model, (Salvini \& Mannucci, 2003). 34 Figure 2.13: Standard Newton-Raphson (NR) method, (Ivanco, 2011) ……………….... 34

Figure 3.1: True stress-strain curve - TH steel, (Dunbar, 2011) ..................................... 55

Figure 3.2: Bilinear traction-separation laws - TH steel ................................................5 55

Figure 3.3: Geometry of SSY and MBL model -TH steel .......................................... 56

Figure 3.4: Mesh design -SSY and MBL model - TH steel .......................................... 57

Figure 3.5: Mesh design near crack tip - SSY and MBL model - TH steel .................... 58 Figure 3.6: Contact interaction - surface based cohesive behavior-SSY and MBL model-

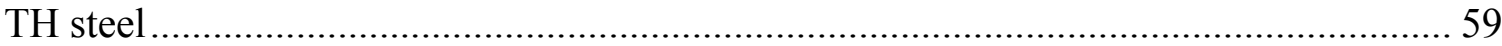

Figure 3.7: Loading conditions- SSY and MBL model-TH steel........................................... 60

Figure 3.8: Geometry of DWTT specimen - TH steel ........................................................... 61

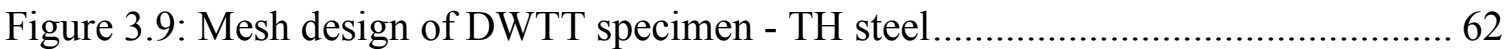

Figure 3.10: Loading conditions of DWTT specimen - TH Steel ..................................... 63

Figure 3.11: Geometry of single edge notched specimen in tension (SENT) - TH Steel. 64

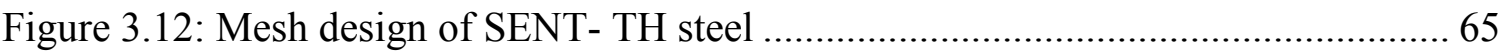




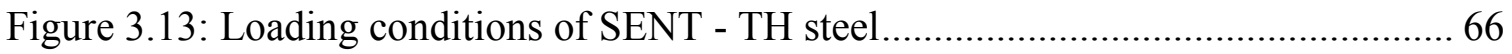

Figure 3.14: Normalized resistance curves of SSY models - TH steel.............................. 67

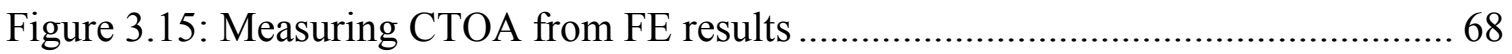

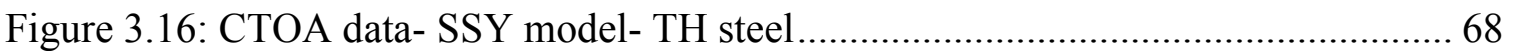

Figure 3.17: Normalized resistance curves - MBL model ( $\sigma \sigma \mathrm{y}=2.4, \sigma y \mathrm{E}=$

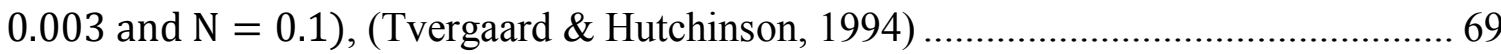

Figure 3.18: Normalized resistance curves - MBL model - TH_1 steel........................... 70

Figure 3.19: CTOA data -MBL model - TH_1 steel ................................................... 70

Figure 3.20: Normalized resistance curves -MBL model - TH_2 steel............................ 71

Figure 3.21: CTOA data -MBL model - TH_2 steel ................................................... 71

Figure 3.22: Normalized resistance curves -MBL model - TH_3 steel........................... 72

Figure 3.23: CTOA data -MBL model - TH_3 steel .................................................. 72

Figure 3.24: Normalized resistance curves -MBL model - TH_ 4 steel........................... 73

Figure 3.25: CTOA data-MBL model - TH_4 steel .................................................... 73

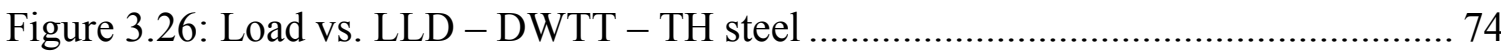

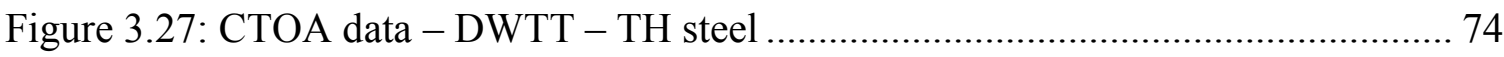

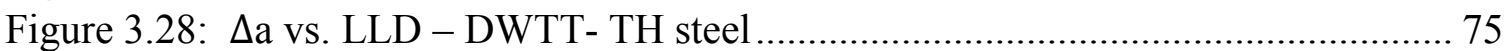

Figure 3.29: CTOA comparison (SENT and DWTT) - TH_1 steel................................ 75

Figure 3.30: CTOA comparison (SENT and DWTT) - TH_2 steel................................. 76

Figure 3.31: CTOA comparison (SENT and DWTT) - TH_3 steel................................. 76

Figure 4.1: True stress-strain curve - C2 steel, (Dunbar, 2011) ....................................... 86

Figure 4.2: Exponential traction-separation laws $\alpha=1-\mathrm{C} 2$ steel ................................. 86

Figure 4.3: Normalized resistance curves of SSY models - C2 steel............................. 87

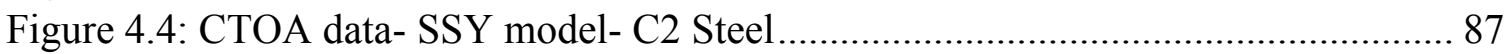

Figure 4.5: Normalized resistance curves -MBL model - C2_1 steel ............................ 88

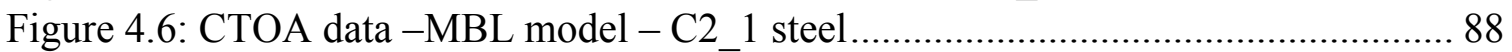

Figure 4.7: Normalized resistance curves -MBL model - C2_2 steel ............................. 89

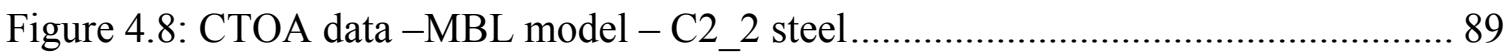

Figure 4.9: Load vs. LLD - DWTT - C2 steel ............................................................. 90

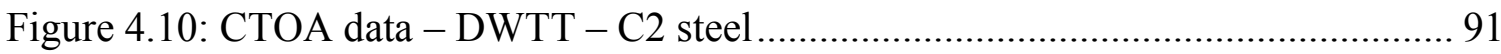

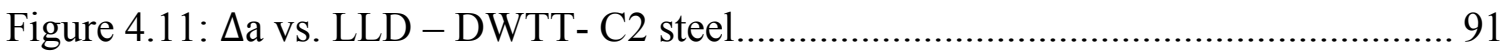

Figure 5.1: Bilinear traction-separation laws - C4 steel (used in unit cell, SSY and MBL)

Figure 5.2: Exponential traction-separation laws $\alpha=1$ - $\mathrm{C} 4$ steel (used in unit cell and DWTT).

Figure 5.3: True stress-strain curve - C4 steel ............................................................ 116

Figure 5.4: Geometry and boundary condition of unit cell model - C4 steel ................. 116

Figure 5.5: Geometry of SSY and MBL model-C4 steel............................................ 117

Figure 5.6: Geometry of mesh near crack tip - SSY and MBL model - C4 steel ........... 117

Figure 5.7: Boundary conditions - SSY and MBL model - C4 steel .............................. 118 
Figure 5.8: Mesh design - SSY and MBL model - C4 steel ....................................... 118

Figure 5.9: Mesh design near crack tip - SSY and MBL model - C4 steel ................... 119

Figure 5.10: Experimental DWTT set up-C4 steel, (Xu et al., 2010b) ......................... 120

Figure 5.11: Experimental Load vs. LLD-corrected for compliance.............................. 120

Figure 5.12: Geometry of DWTT specimen - C4 steel.............................................. 121

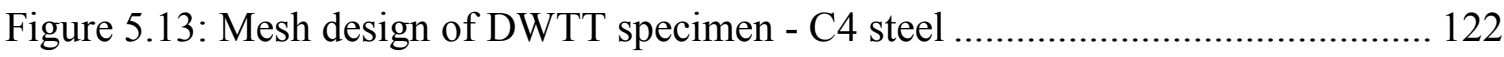

Figure 5.14: Mesh design near crack tip of DWTT specimen - C4 steel........................ 123

Figure 5.15: Loading conditions of DWTT specimen - C4 steel................................... 124

Figure 5.16: Traction-separation laws of unit cell analysis - C4 steel .......................... 125

Figure 5.17 Normalized resistance curves of SSY models - C4 Steel........................... 126

Figure 5.18: CTOA data - SSY model - C4 steel .................................................... 126

Figure 5.19: Normalized resistance curves -MBL model - C4_A steel ....................... 127

Figure 5.20: CTOA data -MBL model - C4_A steel.............................................. 127

Figure 5.21: Plane strain simulation and experimental data of DWTT - C4 steel......... 128

Figure 5.22: Load vs. LLD - DWTT - C4 steel........................................................ 128

Figure 5.23: CTOA data - DWTT - C4 steel........................................................... 129

Figure 5.24: $\Delta$ a vs. LLD - DWTT - C4 steel ........................................................... 129 


\section{List of Nomenclature}

a

$a_{0}$

$A_{0}$

B

D

E

$\mathrm{K}_{\mathrm{ii}}$

$\mathrm{K}_{\mathrm{r}}$

$\mathrm{K}_{0}$

P or F

$R_{0}$

r

$\mathrm{r}_{\mathrm{p}}$

S

$\mathrm{T}_{0}$

$\mathrm{u}_{\mathrm{x}}, \mathrm{u}_{\mathrm{y}}$

V

W

$r, \theta$

$\mathrm{x}, \mathrm{y}$

$t_{i}$

$t_{i}^{0}$

$t_{\mathrm{n}}^{0}$ or $\widehat{\sigma}$

$t_{y}$

$\varepsilon_{\mathrm{i}}$
Crack length

Initial crack length

Radius of the small-scale yielding model

Thickness of the specimen

Damage function

Young's modulus

Stiffness vector of cohesive elements $(i=n, s, t)$

Applied stress intensity factor

Critical stress intensity factor

Load

Estimated plastic zone size

Radius of the small scale yielding model and modified boundary layer model

Plastic rotation factor

Specimen span between anvil contact points

Original thickness of cohesive element

Displacements in the $\mathrm{x}$ and $\mathrm{y}$ directions

Half crack flank opening (CTOD)

Width of specimen

Polar co-ordinates

Cartesian co-ordinates

Nominal traction stress vector of cohesive elements $(i=n, s, t)$

Peak values of nominal stress of cohesive elements $(i=n, s, t)$

Peak or maximum traction in normal direction

Normalized T-stress

Nominal strain vector of cohesive elements $(i=n, s, t)$ 


$\begin{array}{ll}\mu & \text { Shear modulus } \\ \mathrm{w}_{\mathrm{f}} & \text { Work of fracture } \\ \delta & \text { Separation or displacement } \\ \delta_{\mathrm{n}}^{0} & \text { Effective displacement at damage initiation or at peak traction } \\ \delta_{\mathrm{n}}^{\text {max }} & \text { Maximum value of the effective displacement attained during the loading } \\ & \text { history of the cohesive element } \\ \delta_{\mathrm{n}}^{\mathrm{f}} \text { or } \delta_{\mathrm{c}} & \text { Effective displacement at complete failure } \\ \Delta_{0} & \text { The size of the smallest elastic-plastic elements adjacent to the cohesive } \\ \sigma_{\mathrm{y}} & \text { layer } \\ \nu & \text { Yield stress } \\ \alpha & \text { Poisson's ratio } \\ \mathrm{G}_{\mathrm{c}}, \Gamma_{0}, \mathrm{E}_{\mathrm{D}} & \text { Fracture energy (work of separation) } \\ \xi & \text { Slope of Ln (P/P }\end{array}$




\section{List of Acronyms}

$\begin{array}{ll}\text { ASTM } & \text { American Society for Testing and Materials } \\ \text { CTOA } & \text { Crack-tip opening angle } \\ \text { CTOD } & \text { Crack tip opening displacement } \\ \text { CVN } & \text { Charpy V-notch energy } \\ \text { CZM } & \text { Cohesive zone model } \\ \text { DWTT } & \text { Drop-weight tear test } \\ \text { LLD } & \text { Load-line displacement } \\ \text { SE(B) } & \text { Single-edge bend specimen } \\ \text { S-SSM } & \text { Simplified single-specimen method for measuring CTOA } \\ \text { SSY } & \text { Small scale yielding } \\ \text { MBL } & \text { Modified boundary layer } \\ \text { UTS } & \text { Ultimate tensile strength } \\ \text { R-curve } & \text { Crack growth resistance curve } \\ \text { SENT } & \text { Single edge notched specimen in tension } \\ \text { V.C. } & \text { Viscosity Coefficient } \\ & \end{array}$




\section{Chapter 1}

\section{Introduction}

Damage and failure tolerance analysis plays a major role for the health and life prediction of oil and gas transmitting pipelines. The common cause of the failure of the pipelines can be internal and external surface flaws, manufacturing defects, weld cracks, lack of fusion, blunt corrosion, fatigue, stress corrosion cracking, dents and weld seams, high stresses due to internal pressure of fluid, etc. (Ruggieri \& Dotta, 2011). Therefore, the safety operations have become necessary to avoid costly leaks and ruptures of the material. To prevent structure from all these failures, the pressurized pipelines are made from high strength and high toughness steels like X70 and X100. In high toughness steel, it shows significant amount of ductility before a crack starts to propagate and the crack grows in a stable manner before it completely fails. Recently, deformation based engineering methodology, crack tip opening angle (CTOA) is widely used to study stable crack extension in ductile material.

The CTOA is considered as a material property to measure the toughness of the material. For tougher material, higher CTOA is required to propagate the crack. After showing the significant ductility, the crack starts to grow at significant CTOA in high toughness steel, this CTOA is called critical crack tip opening angle $\left(\mathrm{CTOA}_{c}\right)$. The critical crack tip opening angle $\left(\mathrm{CTOA}_{c}\right)$ is higher in the beginning, which will drop down quickly along 
the crack growth to a steady state CTOA (Rice \& Sorensen, 1978 and Newman, et al., 2003).

To investigate the failure behavior of axially flawed pipelines, the full scale burst test should be performed, that is very expensive. Thus, the specimen is machined from the full thickness flattened pipe section and CTOA are measured from this machined specimen. The CTOA measured from machined specimens like the modified double cantilever beam (MDCB), compact tension test, single edge notched specimen in tension (SENT), drop weight tear test (DWTT) and modified DWTT (M-DWTT) are transformable to full pipeline geometry (Horsley, 2003). Even though, the CTOA can be measured experimentally using different techniques, the two techniques: Optical Method and Simplified Single-Specimen Method (S-SSM) were used by Xu, et al., (2010b) to measure the CTOA of DWTT specimen of high strength steels: C2 (X70) and C4 (X100). The schematic of DWTT specimen is illustrated in Figure 1.1.

The focus of this study is to determine CTOA of the high strength steel using cohesive zone model $(\mathrm{CZM})$ technique. The main purpose of cohesive zone models is to analyze fracture and failure mechanics of an engineering structure (De Borst, 2003). The cohesive zone model is inserted in front of the crack tip in a form of discretize line (surface based CZM) and discretize elements (element based CZM) in models of the present thesis. The traction-separation relationship is also introduced to analyze the degrading mechanism of a fracture process zone. The shape of the traction-separation (TS) law plays a dominant role in the propagation of a crack and numerical stability as well.

Every TS law has different peak traction and fracture energy. To analyze the effect of these various TS laws on the crack growth resistance curve and also on CTOA, the small 
scale yielding models are examined. The plastic zone size of small scale yielding is very small as compared with the dimension of the model. Thus, the small scale yielding can still be analyzed by linear elastic fracture mechanics near the crack tip (De Borst, 2003). In addition, the effect of T-stress (constraint) on the crack tip opening angle (CTOA) and the crack growth resistance curves (R-curves) are studied. The T-stress is applied on the modified boundary layer model using the William series. Numerically, the modified boundary layer (MBL) can be described as a state of stress near the crack tip. In other words, the MBL is a new numerical generation of small scale yielding model with varying level of remote boundary conditions to study stationary and propagating cracks in ductile/brittle fracture (Larsson \& Carlsson, 1973). In the William series, MBL is the combination of the singular and non-singular stress terms as:

$$
\sigma_{i j}=\frac{K_{I}}{(2 \pi r)^{1 / 2}} f_{i j}(\theta)+T_{i j 0}+\text { higher order terms }
$$

where, $K_{I}$ is the stress intensity factor of mode $I, r$ and $\theta$ are the polar co-ordinates, $f_{i j}$ is the normalized universal function of angle theta. The first term of the Equation 1.1 will be singular as $r \rightarrow 0$ near the crack tip. The second term, T-stress (tension or compression) is known as the non-singular stress of HRR field, which is acting parallel to the crack plane.

After calibrating a crack growth resistance curve (R-curve) and CTOA from SSY and MBL, the drop weight tear tests (DWTT) are simulated. The load vs. load line displacement (LLD) plots and crack length vs. LLD are produced from numerical analysis to evaluate the crack growth. The numerical load vs. LLD curves are compared with the experimental load vs. LLD provided by Xu (2010a, 2013) for C2 steel and C4 steel. The CTOA data is also generated from a FE simulation of DWTT. The CTOA data 
of DWTT specimens are compared with the experimental CTOA data obtained by Xu et al., (2010b) and also with CTOA data measured for small scale yielding (SSY) model.

Three high strength and high toughness steels are used in this work. The first material is ideal steel, which is known as TH steel as it was introduced by Tvergaard and Hutchinson (1992). The other two steels are commercial pipe steels: C2 (X70) and C4 (X100), these two steels were characterized by $\mathrm{Xu}$, et al., (2010b). As each TS law has different peak traction and fracture energy values, several TS laws are introduced for all three steels. Four, three and six Traction-Separation laws are used for TH steel, C2 steel and C4 steel respectively. All the FE simulation are conducted using FE program ABAQUS/Standard6.11 simultaneously ABAQUS/Explicit-6.11.

\subsection{Thesis Objectives}

The main aim of this thesis is to find CTOA through FE simulations and to examine the effect of constraint (T-stress) on CTOA. As explained above, three steels: TH, C2 and C4 were used. Three different models: SSY, MBL, DWTT were simulated using CZM with various TS laws.

The objectives of the thesis work are summarized as follows:

1. FE analysis of small scale yielding (SSY) model, modified boundary layer (MBL) model and drop weight tear test (DWTT) specimen for TH steel, C2 steel and $\mathrm{C} 4$ steel.

2. Establish the surface based cohesive zone model and element based cohesive zone model to study the damage and failure mechanism. 
3. Study the effect of T-stress (or constraint) on crack tip opening angle (CTOA) and crack growth resistance curve (R-curve).

4. Comparison of the simulated load vs. LLD curves of DWTT for C2 and C4 steels with experimental load vs. LLD.

5. Comparison between experimental CTOA results and the numerical CTOA results obtained from SSY and DWTT for C2 and C4 steels.

\subsection{Outline of Thesis}

The basic introduction, objectives and outline of the thesis are described in Chapter 1 . Chapter 2 reviews the literature regarding the measurement techniques of CTOA, effect of T-stress (constraint), mechanism of cohesive zone modeling (CZM) and different numerical schemes (implicit and explicit). Chapter 3 describes the implementation of surface based cohesive zone modeling on the small scale yielding (SSY) model, modified boundary layer (MBL) model, drop weight tear test (DWTT) specimen and single edge notched specimen in tension (SENT) of TH steel. The validation of surface based cohesive model is described in Chapter 3 by comparing it with the element based cohesive model of Tvergaard \& Hutchinson (1992). In Chapter 4, the FE models of SSY, MBL and DWWT of $\mathrm{C} 2$ steel are produced using the same procedures described in Chapter 3, but the material properties and TS laws are different for $\mathrm{C} 2$ steel. The numerical results of DWTT for C2 steel; load vs. LLD and CTOA results are compared with experimental results provided by Xu, et al., (2010a,2010b). All models in Chapter 3 and Chapter 4 are analyzed in ABAQUS/Standard-6.11. Chapter 5 gives the detailed investigation of C4 steel. The unit cell model, SSY model, MBL model and DWTT 
model for $\mathrm{C} 4$ steel are studied for six different TS laws of element based cohesive zone model. Same as Chapter 4, the load vs. LLD curve and CTOA of C4 steel are compared with the experimental load vs. LLD and CTOA provided by Xu, et al., (2010b,2013). Chapter 6 summaries the conclusions and recommendations for future work. 


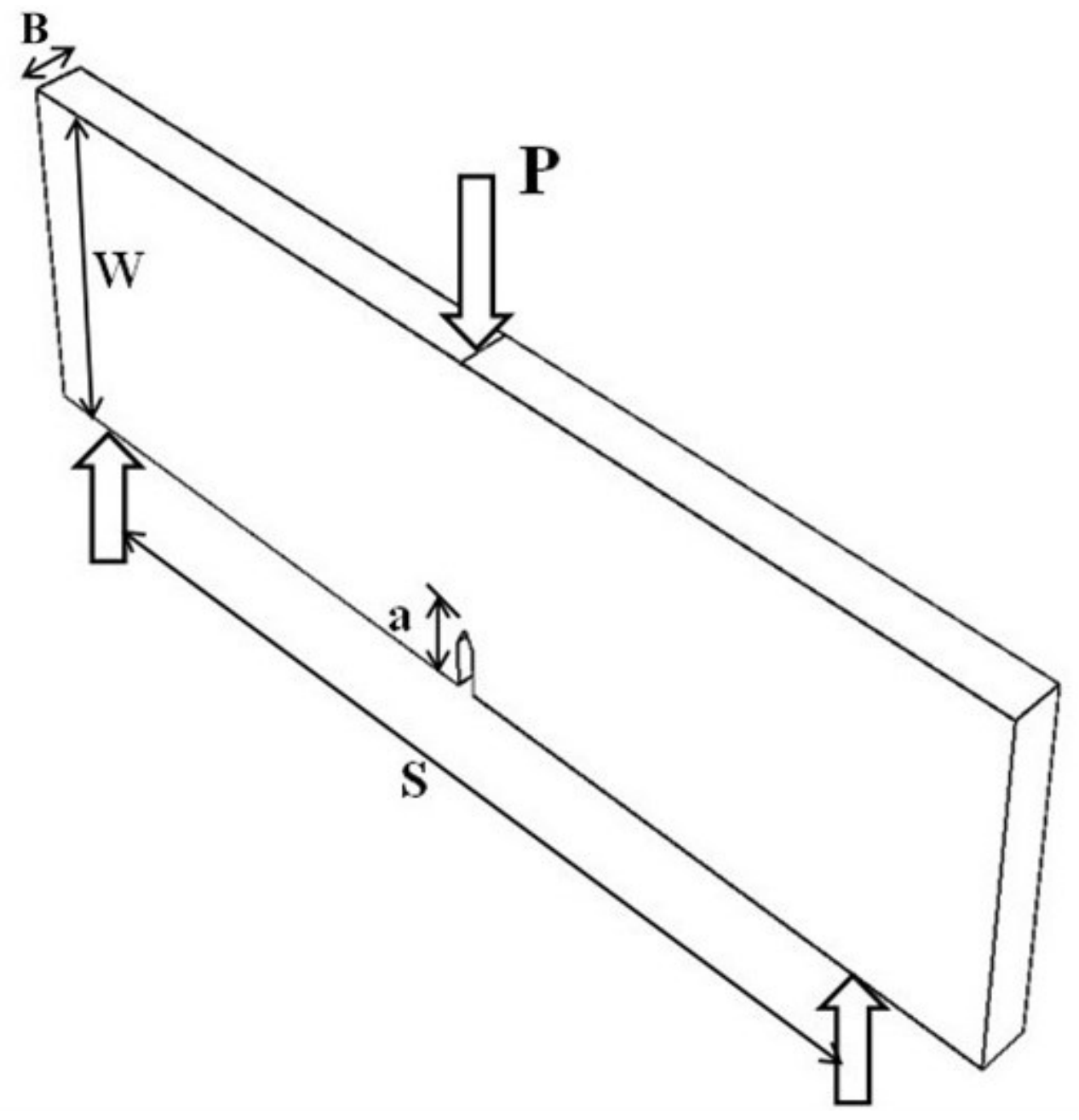

Figure 1.1: Schematic of drop-weight tear test (DWTT) 


\section{Chapter 2}

\section{Literature Review and Background}

Recently, the deformation based engineering methodology is used to study the stable crack extension in ductile materials. The J-integral, resistance (R) curve, crack tip opening displacement (CTOD) and crack tip opening angle (CTOA) are taken in to consideration on deformation based techniques (Ruggieri \& Dotta, 2011). Among these techniques, CTOA is widely used to characterize the fully plastic fracture (Darcis, et al., 2008). In this chapter, the introduction of CTOA and the numerical and experimental techniques to calibrate CTOA will be explained.

In this chapter, an overview of cohesive zone modeling for pipeline steel will also be summarized. The cohesive zone modeling is a technique to study the crack propagation and CTOA. The T-stress (or constraint) and its effect on stress field at crack tip will also be illustrated.

\subsection{Overview of Cohesive Zone Modeling for Pipe-line Steel}

Enormous investigations have been done on the development of cracks in ductile and brittle fracture of solids. In Linear Elastic Fracture Mechanics (LEFM), the crack field is characterized by many terms like stress intensity factor, energy release rate or fracture energy, fracture toughness etc. The strain energy release rate is directly proportional to path dependent J-integral $\left(\mathcal{G}=\mathrm{J}_{\mathrm{c}}\right)$ when cracks start to propagate in non-linear elastic 
material (Li \& Chandra, 2003). Hence, the role of J-integral becomes dominant. However, in most engineering materials, $\mathcal{G}=\mathrm{J}_{\mathrm{c}}$ criterion is satisfied until the crack starts to grow, after that strain energy release rate $(\mathcal{G})$ increases along the crack length. In this situation cohesive zone modeling is widely used to analyze crack propagation. The CZM is useful for ductile crack propagation by avoiding the singularity at the crack tip and it is easy to implement in numerical methods of finite element analysis for non-linear study of large metallic structure.

Dugdale studied the problem of steel sheets containing slits (Dugdale, 1960). He investigated the extent of yielding ahead of the slit as a function of applied loading. From his experiment, he measured the plastic zone length at different values of applied tensile stress at different locations of slits. The main vision of his work was to study localized inelasticity of the material using the strip yield model.

The concept of CZM was proposed by Barenblatt (1962), which is based on the Griffith's theory of fracture. To analyse finite strength of brittle material was the aim of Barenblatt's work. He also proved that the cohesive stress distribution is higher at the crack tip but decreases rapidly away from the crack tip. The CZM was based on two hypotheses: (1) the length over which the cohesive forces act is small compared to the crack size, and (2) the distribution of displacements over the cohesive zone region is independent of material and boundary conditions.

In early research on CZM, the size of cohesive zone was smaller than crack size and geometry of the specimen (Rice, 1968). The application of CZM in the finite element analysis to model failure in concrete was addressed by Hillerborg, et al., (1976) and Petersson (1981). Further, the CZM was implemented for metallic materials to study 
fracture behavior by many researchers such as Needleman (1987); Tvergaard \& Hutchinson (1992,1994); Tijssens (2000); Siegmund \& Brocks (2000); Deshpande, et al. (2003); Cornec, et al. (2003); Dunbar (2011); Carpinteri, et al. (2012). The CZM was also employed in composites, fiber metal laminates and weld specimen by Harper \& Hallett (2010), Yamaguchi, et al. (2009) and Yang (2006) respectively.

The traction-separation laws of CZM play major roles in studying the fracture process zone. The shapes of the cohesive zone laws vary according to traction-separation laws. Several traction-separation laws are summarized in Figure 2.1, (Zerbst, et al., 2009). As shown in Figure 2.1, three parameters are used to define traction-separation laws: (1) the maximum cohesive strength $t_{n}^{0}$ or $\widehat{\sigma},(2)$ the final separation $\delta_{n}^{f}$ or $\delta_{c}$, and (3) the work done for separation (fracture energy, $\Gamma_{0}$ ).

The cohesive zone models are widely used to study the small scale yielding (SSY) of different materials to examine the failure phenomenon. The SSY is used to study the linear elastic crack problem of elastic-plastic material (Tvergaard \& Hutchinson, 1992), (Trädegård, et al., 1998). The size of the plastic zone is determined for various configurations of SSY analysis using different traction-separation laws. The trapezoidal TS law was used for SSY modeling by Tvergaard \& Hutchinson (1992) to study the crack growth resistance in TH steel (TH steel is ideal steel, which was introduced by Tvergaard \& Hutchinson). SSY without T-stress (constraint) is often referred as “standard small scale yielding” (Ding \& Wang, 2012).

T-stress is the non-singular stress term acting parallel to the crack plane of elastic-plastic crack tip fields. Tvergaard \& Hutchinson (1994) also investigated T-stress (constraint) effect on crack growth resistance of SSY. The effect of constraint on SSY is also known 
as modified boundary layer (MBL). The typical representation of $\mathrm{MBL}$ is shown in Figure 2.2.

Dunbar (2011) used the bilinear TS law to produce SSY model of TH steel and C2 (X70) steels to analyze the crack growth resistance and crack tip opening angle (CTOA). The element based cohesive zone modeling is used in the models of Tvergaard \& Hutchinson (1992,1994), Dunbar (2011).

There are different methods available to measure the fracture toughness of the steel like the Charpy V-notch impact test, the Izod impact test, drop weight tear test (DWTT) etc. The size of specimens of the Charpy test and the Izod test are comparatively smaller than DWTT specimen (Anderson, 2011) and therefore the length of fracture ligament is not long enough to reach steady state fracture (Dunbar, 2011). Thus, the DWTT method is suitable to allocate the fracture behavior to real pipe lines application, (Zerbst, et al., 1995), (Erdelen-Peppler, et al., 2014). Figure 2.3 illustrates a typical DWTT specimen. The different models of DWTT for pipeline steels were analyzed by many authors, which are described below:

The finite element simulations of two dimensional DWTT of TH steel and X70 steel were carried out by Dunbar (2011) in the FE solver ABAQUS/Explicit. Four sets and three sets of bilinear TS laws were used for TH steel and X70 steel respectively. The recorded data of load vs. load line displacement (LLD) plot and CTOA were compared to the experimental data. The ratio of cohesive strength and yield strength $\left(\widehat{\sigma} / \sigma_{y}\right)$ was assumed between 3 to 4 for both TH and X70 steel. The fracture energies for TH steel and X70 steel were ranged from 12 to $16 \mathrm{MPa} \cdot \mathrm{mm}$ and 30 to $35 \mathrm{MPa} \cdot \mathrm{mm}$ respectively. 
The numerical method to simulate the high speed fractures of pipeline steel X70 (C2) using three dimensional DWTT model was proposed by Shim, et al. (2013). The quasistatic FE simulation was done by Shim, et al. in ABAQUS/Implicit. The load vs. LLD plot, load vs. crack-mouth opening displacement (CMOD) plot and CTOA in FE simulations were compared with experimental data. The main goal of his work was to reproduce experimental data using the appropriate parameters of the TS law proposed by Cornec, et al., (2003). The parameters of the TS law to define element based cohesive behavior were: the maximum cohesive strength to yield strength ratio $\left(\widehat{\sigma} / \sigma_{\mathrm{y}}\right)=1.6$ and fracture energy $\left(\Gamma_{0}\right)=437.817 \mathrm{MPa} \cdot \mathrm{mm}$. In the analysis of Dunbar (2011) and Shim, et al., (2013), the element based cohesive models were used for DWTT.

The FE dynamic analysis of the three dimensional DWTT of commercial pipeline steel X100 (C4) was done by Cerrone, et al., (2014) using ABAQUS/Implicit. The load-time plot was compared with the experimental results. The Park-Paulino-Roesler (PPR) based cohesive zone model was used along the predefined crack path of DWTT specimen. The cohesive parameters for TS law were found using recommendations from the work of Scheider, et al., (2006). The range of cohesive strength( $(\widehat{\sigma})$ was $(2-3) \cdot \sigma_{\mathrm{y}}$ and fracture energy approximated as $240 \mathrm{MPa} \cdot \mathrm{mm}$ and $1400 \mathrm{MPa} \cdot \mathrm{mm}$.

In this thesis work surface based cohesive zone model will be used to analyse the crack growth resistance and CTOA in the SSY model of TH steel and C2 (X70) steel. In addition, the effect of T-stress on CTOA and the crack growth resistance will be studied. 
The surface based cohesive model will be used in this work for the FE simulation of DWTT of TH and C2(X70) steels. Finally, the full investigation of X100 (C4) steel will be done using experimental data provided by Xu (2010b, 2013), CANMET MTL.

\subsection{Crack Tip Opening Angle}

The crack tip opening angle can be used to describe stable crack extension. The value of CTOA becomes almost constant for the stable crack propagation in steady state (Wang \& Shuai, 2012). Usually, CTOA is the geometric angle that the two separated fractured surfaces form in correspondence to the virtual crack tip (Salvini \& Mannucci, 2003) but also it can be identified in following different ways as below (Zerbst, et al., 2009) :

In Figure 2.6: a, the surfaces are straight and the angle between them is the CTOA. In reality these faces are not straight. These crack fronts faces are curved that depends on loading condition and geometry of the component. Hence, Figure 2.6: b represents the standard definition of the crack tip opening angle. This angle is measured at distance " $d$ " behind from the current crack tip. The value of " $\mathrm{d}$ " has been chosen as $1 \mathrm{~mm}$ according to ASTM standards for both experimental determination and structural assessment. Figure 2.6: c illustrates the zig-zag pattern of the two faces. Thus, at every step $\Psi_{\mathrm{i}}$ will be the angle enclosed by lines $\mathrm{L}_{1}$ and $\mathrm{L}_{2}$. The points on upper and lower faces are chosen in the range of $0.5 \mathrm{~mm}$ to $1.5 \mathrm{~mm}$ behind from the current crack tip and after that the average has been taken of these measured angles $\Psi_{\mathrm{i}}$ between those points to determine CTOA.

The CTOA is commonly used as a measuring parameter of fracture toughness of oil-gas pipeline steel (Wang \& Shuai, 2012). The measurement of CTOA using modified double cantilever beam (MDCB) for high strength pipeline steels was addressed by Darcis, et al., 
(2008) and $\mathrm{Xu}$, et al., (2010b). The DWTT specimen was also used to determine CTOA of oil-gas transmission pipeline steels by Rudland, et al., (2003) and Xu, et al., (2010,2011). Additionally, the measurement of CTOA for compact tension (CT) specimen was accomplished by Jadhav \& Maiti (2010).

\subsubsection{Calibration of CTOA from Experimental data}

There have been many methods developed to measure the CTOA from the experimental set up to characterize crack propagation in material. Within the present section, there are mainly two methods discussed here: the optical method and simplified single specimen method.

\section{Optical Method}

The optical method is a commonly used surface based method to evaluate CTOA. The same procedure is followed as discussed in Section 2.2, Figure 2.6: c for the optical method. High speed camera monitoring is required to capture the images of DWTT (Xu et al., 2008).

Moreover, the optical method is not suitable for pipe mill test on account of it is time consuming to analyse images and it will not give the values of CTOA throughout the thickness (Xu et al., 2013). Additionally, the CTOA measured from the optical method is higher than the CTOA measured from the S-SSM method. As in the optical method, the CTOA is measured on surface only while in S-SSM, the crack tunnelling effect of the three dimensional specimen is considered. 


\section{Simplified Single-Specimen Method (S-SSM)}

The simplified single-specimen method was presented by Xu, et al., (2007). To evaluate CTOA, the single-specimen method of Martinelli and Venzi (1996) was simplified by $\mathrm{Xu}$, et al., (2007). In this method, the CTOA is calibrated from load vs. load line displacement (LLD) curve of DWTT. The example of load vs. LLD is presented in Figure 2.4 (Xu, et al., 2007). The CTOA from S-SSM can be calculated as follow:

$$
\text { CTOA }=\frac{8 \mathrm{r}_{\mathrm{p}}}{\xi} \frac{180}{\pi}
$$

where, $r_{p}$ is the rotation factor and $\xi$ is the slope of $\mathrm{Ln}\left(\mathrm{P} / \mathrm{P}_{\max }\right) v s .\left(\mathrm{Y}-\mathrm{Y}_{\max }\right) / \mathrm{S}$.

Here, $\mathrm{P}_{\max }$ and $\mathrm{Y}_{\max }$ represent the maximum values of force and force-line displacement and $\mathrm{S}$ is the span between the anvil contact points. The values of $r_{p}$ are recommended 0.57 and 0.54 for high strength steel and low strength steel respectively (Xu, et al., 2007, 2009). As shown in Figure 2.5 ( $\mathrm{Xu}$ et al, 2007), the slope $(\xi)$ of $\operatorname{Ln}\left(\mathrm{P} / \mathrm{P}_{\max }\right)$ vs. $\left(\mathrm{Y}-\mathrm{Y}_{\max }\right) / \mathrm{S}$ is generally determined in the steady state region corresponds to Ln (P/P $\left.\mathrm{P}_{\max }\right)$ values between -0.51 and -1.21 (Xu, et al., 2009).

The crack tip opening angles (CTOA) were measured using the optical method and the simplified single-specimen method for C2 steel as well as C4 steel by Xu, et al., (2010b). These measured CTOA from DWTT will be compared with the CTOA obtained from the FE simulations of DWTT for C2 and C4 steels.

\subsection{T-stress (constraint) Effect}

The T-stress is used widely in fracture mechanics nowadays. For HRR field, mainly Jintegral is the governing parameter to define the stress/strain field around crack tip under high constraint conditions. Despite for low constraint, J-integral will lose its all control on 
crack tip stress/strain field eventually and also it will swerve from HRR field as well. Hence, it has become necessary to introduce other parameters along with J-integral to identify stress/strain field near crack tip. A two-parameter methodology was introduced to overcome this problem. First parameter is known as CTOD, which measures the degree of crack tip deformation and the other parameter is characterized as T-stress, which will depict the degree of crack tip constraint or in other words, it enumerates the level of deviation of stress/strain field from HRR field, (Wang, 2009). The T-stress is a non-singular stress which acts parallel to crack plane on elastic plastic crack tip field. Zero and positive T-stress is J-dominance while negative T-stress is loss of J-dominance (Tvergaard \& Hutchinson, 1994).

An asymptotic expansion of the stresses about the crack tip can be given by the William series expansion as (Du \& Hancock, 1991),

$$
\sigma_{i j}=A_{i j}(\theta) r^{-\frac{1}{2}}+B_{i j}(\theta)+C_{i j}(\theta) r^{\frac{1}{2}}+\cdots
$$

As shown from the Equation 2.2, it has been observed that the stress field will become dominant in the first term of the series as stress distribution will become singular at the crack tip. But the stress will be non-singular in the finite second term of the series. This uniaxial stress is known as the T-stress which is acting parallel to the crack plane. Thus, the remote traction under plane strain condition can be given by,

$$
\left[\begin{array}{ll}
\sigma_{11} & \sigma_{12} \\
\sigma_{21} & \sigma_{22}
\end{array}\right]=\frac{\mathrm{K}_{\mathrm{I}}}{\sqrt{2 \pi \mathrm{r}}}\left[\begin{array}{ll}
\mathrm{f}_{11}(\theta) & \mathrm{f}_{12}(\theta) \\
\mathrm{f}_{21}(\theta) & \mathrm{f}_{22}(\theta)
\end{array}\right]+\left[\begin{array}{ll}
\mathrm{T} & 0 \\
0 & 0
\end{array}\right]
$$

where, $K_{I}$ is stress intensity factor of mode I, $r$ and $\theta$ are the polar coordinates as shown in Figure 2.2, $\mathrm{T}$ is the $\mathrm{T}$-stress and $\mathrm{f}_{\mathrm{ij}}$ is the normalized universal function of angle theta. 
The plastic zone size at the crack tip is very affected by $\mathrm{T}$-stress in fracture or fatigue of the cracked structure. The positive T-stress develops more constraints at the crack tip, as a result it will reduce the size of the plastic zone. While the negative T-stress develops less constraint, thus it will increase the size of the plastic zone.

The stress field near the crack tip can be given as (Nazarali \& Wang, 2011) :

$$
\begin{aligned}
& \sigma_{11}=\frac{\mathrm{K}_{\mathrm{I}}}{\sqrt{2 \pi \mathrm{r}}} \cos \left(\frac{\theta}{2}\right)\left[1-\sin \left(\frac{\theta}{2}\right) \sin \left(\frac{3 \theta}{2}\right)\right]+\mathrm{T} \\
& \sigma_{22}=\frac{\mathrm{K}_{\mathrm{I}}}{\sqrt{2 \pi \mathrm{r}}} \cos \left(\frac{\theta}{2}\right)\left[1+\sin \left(\frac{\theta}{2}\right) \sin \left(\frac{3 \theta}{2}\right)\right]
\end{aligned}
$$

The normalized T-stress $\left(\mathrm{t}_{\mathrm{y}}\right)$ with respect to yield stress $\left(\sigma_{\mathrm{y}}\right)$ can be given by,

$$
\mathrm{t}_{\mathrm{y}}=\frac{\mathrm{T}}{\sigma_{\mathrm{y}}}
$$

The hydrostatic triaxiality stress state near the crack tip field is influenced by the sign and magnitude of the T-stress (Toshio \& Parks, 1992). The negative T-stress will reduce the crack tip triaxiality while the positive T-stress will magnify the crack tip triaxiality. The T-stress relies on loading conditions, geometry and relative length of crack. Thus, single edge notched specimen in Tension (SENT) is the example of the negative T-stress whereas DWTT is illustrative of positive T-stress.

Hence, the T-stress effect on CTOA as well as on crack growth resistance curves of small scale yielding models and modified boundary layer models will be studied for TH steel, C2 steel and C4 steel. 


\subsection{Cohesive Zone Modeling}

\subsubsection{Role of Micromechanics in Cohesive Zone Modeling}

The pre-defined crack path can be predicted due to physical behavior of micro-void nucleation, growth and coalescence in a material (Li \& Chandra, 2003). The role of the cohesive zone model at the crack tip can be described by a typical crack tip process zone as illustrated in Figure 2.7. It can be seen from the Figure 2.7 that the process zone is the part of the active plastic zone, which has been correlated with the typical tractionseparation law. The area under the TS curve is known as energy release rate $\left(\Gamma_{0}\right)$. The Figure 2.7 is mainly divided in two parts and three correspondence points $\mathrm{A}, \mathrm{B}$ and $\mathrm{C}$. Point $\mathrm{C}$ represents that the separation has not occurred yet. Thus the value of displacement is "zero" at point $\mathrm{C}$ and it is characterized as the crack tip. At point B, the material starts to damage and can take maximum stress. The point $\mathrm{A}$ is described as the point where the maximum displacement takes place in between two surfaces of the material. In other words, it is the point at which the material will not be able to take more traction and hence the value of traction is "zero" at this point. The material is completely damaged at point $\mathrm{A}$.

\subsubsection{Traction-Separation Based Modeling in ABAQUS}

It is possible to introduce cohesive behavior in ABAQUS. The constitutive behavior of the cohesive elements can be defined in three different ways; (1) continuum-based modeling, (2) traction-separation based modeling, and (3) modeling of gaskets and laterally unconstrained adhesive patches. Among all, traction-separation based modeling 
would be used for situations where the interface between two parts can be considered to have zero thickness. While modeling the crack propagation along the known crack path, the traction-separation based modeling used with almost zero thickness of cohesive behavior, which is controlled by damage variable D, (ABAQUS User's manual- 6.11). There are different shapes of Traction-Separation used depending on application and methodology of researchers. In this thesis, mainly two TS laws named bilinear and exponential are used for the FE simulations.

In ABAQUS for cohesive behavior, the TS based modeling assumes initially linear elastic behavior followed by the initiation and evolution of damage (ABAQUS User's manual- 6.11).

\section{Linear Elastic Traction-Separation Behavior}

The initial elastic behavior can be defined as,

$$
\mathrm{t}=\left\{\begin{array}{c}
\mathrm{t}_{\mathrm{n}} \\
\mathrm{t}_{\mathrm{s}} \\
\mathrm{t}_{\mathrm{t}}
\end{array}\right\}=\left[\begin{array}{lll}
\mathrm{K}_{\mathrm{nn}} & \mathrm{K}_{\mathrm{ns}} & \mathrm{K}_{\mathrm{nt}} \\
\mathrm{K}_{\mathrm{ns}} & \mathrm{K}_{\mathrm{ss}} & \mathrm{K}_{\mathrm{st}} \\
\mathrm{K}_{\mathrm{nt}} & \mathrm{K}_{\mathrm{st}} & \mathrm{K}_{\mathrm{tt}}
\end{array}\right]\left\{\begin{array}{c}
\varepsilon_{\mathrm{n}} \\
\varepsilon_{\mathrm{s}} \\
\varepsilon_{\mathrm{t}}
\end{array}\right\}=\mathrm{K} \varepsilon
$$

where, $t$ is the nominal traction stress vector, $\mathrm{K}$ is the stiffness matrix, $\varepsilon$ is the nominal strain vector and the subscripts $\mathrm{n}, \mathrm{s}, \mathrm{t}$ indicate normal, shear and tangential direction respectively. The nominal strains can be defined as,

$$
\varepsilon_{\mathrm{i}}=\frac{\delta_{\mathrm{i}}}{\mathrm{T}_{0}}, \mathrm{i}=\mathrm{n}, \mathrm{s}, \mathrm{t}
$$

where, $\delta_{\mathrm{i}}$ is the element separation and $\mathrm{T}_{0}$ is the original thickness of the cohesive element. The default value of $\mathrm{T}_{0}$ is taken 1, (ABAQUS User's manual- 6.11).

In present work, $\mathrm{K}_{\mathrm{nn}}, \mathrm{K}_{\mathrm{ss}}, \mathrm{K}_{\mathrm{tt}}$ are defined while $\mathrm{K}_{\mathrm{ns}}, \mathrm{K}_{\mathrm{nt}}, \mathrm{K}_{\mathrm{st}}$ are taken zero using uncoupled traction-separation laws and mode I crack growth in two dimensional FE 
simulations. The value of $\mathrm{K}_{\mathrm{nn}}$ is taken 10,000,000 MPa in most of the TS laws (Dunbar, 2011). The values of $K_{s s}$ and $K_{t t}$ are equal to $K_{n n} / 2(1+v)$, where Poisson's ratio $v$ is equal to 0.3 . Hence, $\mathrm{K}_{\mathrm{ss}}$ and $\mathrm{K}_{\mathrm{tt}}$ are $3,846,154 \mathrm{MPa}$ for most TS laws in this work.

Each failure mechanism consists of three criteria: (1) damage initiation, (2) damage evolution, and (3) maximum degradation and element removal.

\section{Damage Initiation}

The degradation of the material starts at the point when the stress or strain reaches the user defined damage initiation criterion. There are four different damage initiation criteria available in ABAQUS. They are known as the maximum nominal stress criterion (MAXS), the maximum nominal strain criterion (MAXE), the quadratic nominal stress criterion (QUADS) and the quadratic nominal strain criterion (QUADE), (ABAQUS User's manual- 6.11). The maximum nominal stress criterion (MAXS) is used in this thesis, in which damage is assumed to begin when the maximum nominal stress ratio reaches to 1 . This can be illustrated as,

$$
\max \left\{\frac{\left\langle\mathrm{t}_{\mathrm{n}}\right\rangle}{\mathrm{t}_{\mathrm{n}}^{0}}, \frac{\mathrm{t}_{\mathrm{s}}}{\mathrm{t}_{\mathrm{s}}^{0}}, \frac{\mathrm{t}_{\mathrm{t}}}{\mathrm{t}_{\mathrm{t}}^{0}}\right\}=1
$$

where, the Macaulay's bracket $\left\langle t_{n}\right\rangle$ indicates that the damage will not be initiated by a pure compressive stress.

The nominal stress $t_{n}^{0}$ is chosen in between the range of (3-4) $\sigma_{y}$, (Dunbar, 2011) and (Tvergaard \& Hutchinson, 1992). The values of shear strength $\left(\mathrm{t}_{\mathrm{s}}^{0}, \mathrm{t}_{\mathrm{t}}^{0}\right)$ are set to $0.75 \cdot \mathrm{t}_{\mathrm{n}}^{0}$ as shear strength is approximately $3 / 4$ of yield strength. The values of $t_{s}^{0}, t_{t}^{0}$ will not affect the model as all models are under mode I opening and loading, which will occur due to $\mathrm{t}_{\mathrm{n}}^{0}$ only. 


\section{Damage Evolution}

As shown in Figure 2.8 and Figure 2.9, the degradation of the material begins once it reaches the damage initiation criterion. A scalar damage variable (D) represents the damage mechanism of the material. The stress components are influenced by the damage as follow,

$$
\begin{aligned}
& t_{n}=\left\{\begin{aligned}
&(1-D) \overline{t_{n}}, \quad \overline{t_{n}} \geq 0 \\
& \overline{t_{n}}, \quad \text { otherwise (no damage to compressive stiffness) }
\end{aligned}\right. \\
& t_{s}=(1-D) \overline{t_{s}} \\
& t_{t}=(1-D) \bar{t}_{t}
\end{aligned}
$$

where, $\overline{\mathrm{t}_{\mathrm{n}}}, \overline{\mathrm{t}_{\mathrm{S}}}$ and $\overline{t_{t}}$ are the stress components predicted by the elastic traction-separation behavior for the current strains without damage. For mode I opening and from the Equations 2.7, 2.8 and 2.10, it can be written as,

$$
\mathrm{t}_{\mathrm{n}}=(1-\mathrm{D}) \mathrm{K}_{\mathrm{nn}} \delta_{\mathrm{n}}^{\max }
$$

where, $\delta_{\mathrm{n}}^{\max }$ is the maximum value of the effective displacement attained during the loading history. The damage scalar D will start to grow from $\delta_{\mathrm{n}}^{0}$ and will increase eventually with $\delta_{\mathrm{n}}^{\max }$ and will reach a maximum value of 1 at $\delta_{\mathrm{n}}^{\mathrm{f}}$. The scalar damage variable can be defined as,

For bilinear damage evolution (ABAQUS User's manual- 6.11),

$$
\mathrm{D}=\frac{\delta_{\mathrm{n}}^{\mathrm{f}}\left(\delta_{\mathrm{n}}^{\max }-\delta_{\mathrm{n}}^{0}\right)}{\delta_{\mathrm{n}}^{\max }\left(\delta_{\mathrm{n}}^{\mathrm{f}}-\delta_{\mathrm{n}}^{0}\right)}
$$

For exponential damage evolution (Ren \& $\mathrm{Ru}, 2013)$,

$$
\mathrm{D}=1-\frac{\delta_{\mathrm{n}}^{0}}{\delta_{\mathrm{n}}^{\max }} \cdot\left[1-\left(\frac{\delta_{\mathrm{n}}^{\max }-\delta_{\mathrm{n}}^{0}}{\delta_{\mathrm{n}}^{\mathrm{f}}-\delta_{\mathrm{n}}^{0}}\right)^{\alpha}\right]
$$

where, $\delta_{\mathrm{n}}^{\mathrm{f}}$ is the effective displacement at complete failure, $\delta_{\mathrm{n}}^{0}$ is the effective displacement at damage initiation and $\alpha$ is a non-dimensional material parameter that defines the rate of damage evolution. 
The fracture energy is equal to the area under the traction-separation curve. The fracture toughness of the cohesive zone model in terms of fracture energy can be expressed to represent the traction-separation law as:

For bilinear damage evolution, from Figure 2.8,

$$
\mathrm{G}_{\mathrm{c}}=\Gamma_{0}=\frac{1}{2} \mathrm{t}_{\mathrm{n}}^{0} \delta_{\mathrm{n}}^{\mathrm{f}}
$$

For exponential damage evolution, from Figure 2.9,

$$
\mathrm{G}_{\mathrm{c}}=\Gamma_{0}=\int_{0}^{\delta_{\mathrm{n}}^{\mathrm{f}}} \mathrm{t}_{\mathrm{n}} \mathrm{d} \delta=\left(1-\frac{1}{\alpha+1}\right) \mathrm{K}_{\mathrm{nn}} \delta_{\mathrm{n}}^{0} \delta_{\mathrm{n}}^{\mathrm{f}}+\left(\frac{1}{\alpha+1}-\frac{1}{2}\right) \mathrm{K}_{\mathrm{nn}} \delta_{\mathrm{n}}^{0^{2}}
$$

If $\alpha$ is inserted as 1 in Equation 2.17, then from Equation 2.17 and 2.16, it can be written that,

$$
\Gamma_{0_{\text {bilinear }}}=\Gamma_{0_{\text {exponential }}}
$$

Thus, the maximum separation can be found as,

$$
\delta_{\mathrm{n}}^{\mathrm{f}}=\frac{2 \Gamma_{0}}{\mathrm{t}_{\mathrm{n}}^{0}}
$$

Both types of damage evolution; bilinear and exponential are applied to FE models in present work to solve convergence issues, despite mathematically it can be concluded from Equation 2.18 that the fracture energies $\left(\Gamma_{0}\right)$ for bilinear and exponential are same. The fracture energy $\left(\Gamma_{0}\right)$ and maximum separation $\left(\delta_{\mathrm{n}}^{\mathrm{f}}\right)$ are calculated from Equation 2.16 and 2.19 respectively for bilinear and exponential TS evolution respectively.

\section{Damage Stabilization}

Usually, the softening behavior and stiffness degradation of the material models causes the convergence difficulties. These convergence difficulties can be overcome using the viscous regularization of the constitutive equations. The viscous regularization improves the convergence issues of delamination and debonding problems mainly in 
ABAQUS/Standard, (ABAQUS User's manual- 6.11). The viscous regularization produces the tangent stiffness matrix of the softening material to be positive for sufficiently small time increments which will help in convergence problem without affecting the results. The damage behavior of the viscous material for traction-separation laws can be assigned as,

$$
t_{n}=\left(1-D_{v}\right) \bar{t}_{n}
$$

where, $\mathrm{D}_{v}$ is the viscous stiffness degradation variable.

The procedure of viscous regularization can be expressed by the evolution equation as,

$$
\dot{D_{v}}=\frac{1}{\mu}\left(D-D_{v}\right)
$$

where, $\mu$ is the viscosity parameter representing the relaxation time of the viscous system, $\mathrm{D}$ is the degradation variable evaluated in the inviscid model.

Generally, the smaller value of viscosity parameter than the characteristic time increment helps to improve the numerical convergence of FE model. Thus, the value of viscosity parameter is selected $10^{-5}$ while the value of the characteristic time increment is chosen 0.01 .

\section{TS laws and EPFM}

The Traction-Separation law and Elastic-Plastic fracture mechanics (EPFM) can be correlated to find critical stress intensity factor as, (Dunbar, 2011):

$$
\mathrm{K}_{0}=\sqrt{\frac{E \Gamma_{0}}{\left(1-v^{2}\right)}}
$$

where, $\mathrm{K}_{0}$ is the critical stress intensity factor, E is Young's modulus, $v$ is Poisson's ratio and $\Gamma_{0}$ is the fracture energy. 
The fracture energy for bilinear TS law and exponential TS law (with $\alpha=1$ ) can be calculated as:

$$
\Gamma_{0}=\frac{1}{2} \widehat{\sigma} \delta_{\mathrm{c}}
$$

By inserting Equation 2.23 in Equation 2.22, the critical stress intensity factor can be calculated by equation (2.24) and this will begin the crack propagation,

$$
\mathrm{K}_{0}=\sqrt{\frac{\mathrm{E} \cdot \widehat{\sigma} \cdot \delta_{\mathrm{c}}}{2 \cdot\left(1-v^{2}\right)}}
$$

\subsubsection{Element Based CZM and Surface Based CZM}

\section{Element Based Cohesive Zone Modeling}

There are two dimensional as well as three dimensional cohesive elements library available in ABAQUS-Standard/Explicit. The element called COH2D4 (a 4-node two dimensional cohesive element) is appropriate to model two dimensional crack growth. The typical representation of element based CZM is illustrated in Figure 2.10. The cohesive elements are tied with surrounding structures using surface-to-surface tie constraint, thus the three different parts will act as a one part. The surrounding structures' surfaces are selected as master surfaces, which are in contact with cohesive elements. The top and bottom surfaces of cohesive elements are kept as slave surfaces due to their softer material and finer mesh discretization, (ABAQUS User's manual- 6.11). Hence, the crack will grow further once the cohesive elements degradation and removal takes place. 


\section{Surface Based Cohesive Zone Modeling}

In surface based CZM, the cohesive elements are not required. As cohesive behavior is introduced using contact interaction (ABAQUS/CAE interaction module) rather than using cohesive elements. The cohesive behavior is established in between the two parts of the surrounding material. As shown in Figure 2.11, the bottom surface of the top part and the top surface of the bottom surface are chosen as the master surface and slave surface respectively for surface-to-surface contact. Using contact interaction and tie constraint the two parts will act as a one part. The surfaces can be selected either way because of the similarity of mesh discretization and material. Therefore, the cracks will propagate further once the load carrying capacity of surfaces vanishes, which is more realistic than element based CZM.

In this thesis, the element based CZM is used for the models of C4 steel and the surface based CZM is used for the models of TH steel and C2 steel.

\subsection{Cohesive Zone Model Mechanism}

In this topic, the cohesive zone modeling for the simulation of crack propagation has been described. As shown in the Figure 2.12, the cohesive zone is situated behind the virtual crack tip. The stress distribution is applied in terms of load (F) on each node laying under the cohesive zone. The stress is maximum at the virtual crack tip, where the resistance to the separation of crack flanks is maximum. The stress reduces to zero at the distance $(\Delta)$. The delta $(\Delta)$ represents the size of the fracture process zone. The stress distribution can be defined in terms of power law of the half crack flank opening $(V)$ and evolutionary parameter $(\alpha)$ as, (Salvini \& Mannucci, 2003) : 


$$
\left\{\begin{array}{c}
\mathrm{V}=\mathrm{V}_{0}\left(1-\alpha^{k}\right) \\
\alpha=\frac{\sigma_{\mathrm{C}}}{\sigma_{\mathrm{C} 0}}
\end{array}\right.
$$

The parameter $\alpha$ is the ratio of the actual stress $\left(\sigma_{\mathrm{C}}\right)$ and the higher $\operatorname{stress}\left(\sigma_{\mathrm{C} 0}\right)$ that keeps the flanks closed immediately ahead of the virtual crack tip and $k$ is the non-dimensional parameter.

The energy dissipated in the fracture process zone $(\Delta)$ can be calculated by,

$$
\frac{\mathrm{dE}_{\mathrm{D}}}{\mathrm{da}}=2 \mathrm{~B} \int_{0}^{\Delta}\left[\sigma_{\mathrm{c}}(\mathrm{x}) \frac{\mathrm{dV}(\mathrm{x})}{\mathrm{da}}\right] \mathrm{dx}
$$

where, $\mathrm{B}$ is the specimen thickness, $\mathrm{V}$ is the half opening of crack flank, $\sigma_{\mathrm{c}}$ is the cohesive strength, $\mathrm{a}$ is the crack size and $\mathrm{x}$ is the distance from the crack tip. Hence, work of fracture with respect to specimen thickness can be expressed as, (Salvini \& Mannucci, 2003):

$$
\mathrm{W}_{\mathrm{f}}=\frac{1}{\mathrm{~B}} \frac{\mathrm{dE}_{\mathrm{D}}}{\mathrm{da}}=\frac{2}{\mathrm{~B} \Delta} \mathrm{F}_{0} \mathrm{~V}_{0} \frac{\mathrm{k}}{\mathrm{k}+1}
$$

where, $\mathrm{F}_{0}$ and $\mathrm{V}_{0}$ are the actual force and actual half opening of crack flanks respectively. Now, the crack tip opening angle can be given mathematically from Figure 2.12 as,

$$
\mathrm{CTOA}=\lim _{\mathrm{x} \rightarrow 0^{-}}\left\{2 \arctan \left[\frac{1}{2} \frac{\mathrm{d}}{\mathrm{da}} \operatorname{CTOD}(\mathrm{x})\right]\right\}
$$

where, CTOD is the half crack tip opening displacement, which is also known as $\mathrm{V}(\mathrm{x})$. Therefore, Equation 2.27 can be represented as,

$$
\mathrm{w}_{\mathrm{f}}=\frac{2}{\mathrm{~B} \Delta} \mathrm{F}_{0} \mathrm{~V}_{0} \frac{\mathrm{k}}{\mathrm{k}+1}=\frac{\mathrm{F}_{0}}{\mathrm{~B} \Delta} \Delta \operatorname{tg}\left(\frac{\mathrm{CTOA}}{2}\right) \approx \sigma_{0} \Delta \mathrm{CTOA}
$$

where, the value of parameter $k$ is generally assumed 1 , (Salvini \& Mannucci, 2003), $\sigma_{0}$ is the effective flow stress of the material.

To calculate the work of fracture from Equation 2.29, $\sigma_{0}$ is taken as the averaged value of yield strength and tensile strength. The size of fracture process zone $\Delta$ can be calibrated by the numerical analysis of DWTT doing several trials, until a good relation occurs with 
the Load vs. LLD curve. The correlation of $\Delta$ or $\delta$ with fracture energy can be found in Section 2.3.2, Equation 2.19. The CTOA can be found experimentally as well as numerically as explained in Section 2.2.

\subsection{Explicit and Implicit Numerical Method}

The finite element problem can be solved using two types of numerical approaches; (1) implicit numerical scheme, and (2) explicit numerical scheme. The most commonly used Newton-Raphson method and central difference method are adopted by default in ABAQUS/Standard (implicit) and ABAQUS/Explicit, respectively among all numerical schemes.

\section{Implicit Method}

The implicit scheme works upon the Newton-Raphson method. The Newton-Raphson method is an iterative process as shown in Figure 2.13, (Ivanco, 2011). The iterations are done by trial and error until it reaches the closest value of the applied boundary conditions (Force). The updated value of the displacement in Figure 2.13 can be found by equation,

$$
\mathrm{d}_{\mathrm{i}+1}=\mathrm{d}_{\mathrm{i}}+\Delta \mathrm{d}_{\mathrm{i}}
$$

where, $d_{i+1}$ is the displacement at $i+1$ iteration, $d_{i}$ is the displacement at $i$ iteration and $\Delta \mathrm{d}_{\mathrm{i}}$ is the difference between these two iterations.

The implicit methods are more appropriate for static analysis, where displacement is not a function of time. The implicit method is accurate but it consumes more computational time in order to solve the inversion of large stiffness matrices (McHugh, 2007). 


\section{Explicit Method}

The explicit method is based on the central difference method and does not suffer from the convergence problem as it is not iterative. The explicit method is suitable for dynamic analysis, as displacement is a function of time. The velocity and acceleration will come into consideration since the displacement is a function of the time. Thus, the solution of displacement is based on the equation, (McHugh, 2007);

$$
\begin{aligned}
& \dot{\mathrm{d}}_{\mathrm{i}+\frac{1}{2}}=\dot{\mathrm{d}}_{\mathrm{i}-\frac{1}{2}}+\frac{\Delta \mathrm{t}_{\mathrm{i}+1}+\Delta \mathrm{t}_{\mathrm{i}}}{2} \ddot{\mathrm{d}}_{\mathrm{i}} \\
& \mathrm{d}_{\mathrm{i}+1}=\mathrm{d}_{\mathrm{i}}+\Delta \mathrm{t}_{\mathrm{i}+1} \dot{\mathrm{d}}_{\mathrm{i}+\frac{1}{2}}
\end{aligned}
$$

where, $\dot{d}$ is a velocity and $\ddot{d}$ is an acceleration. The subscript (i) represents the increment

numbers and $\mathrm{i} \pm \frac{1}{2}$ indicates the value of variables midway between the variables. Although the explicit process is designed for the dynamic analysis, the explicit method is widely used for non-linear quasi static analysis.

ABAQUS/Standard (implicit) is used for TH steel and C2 steel. The analysis of high strength $\mathrm{C} 4$ steel is done using ABAQUS/Explicit to avoid numerical convergence issues. 

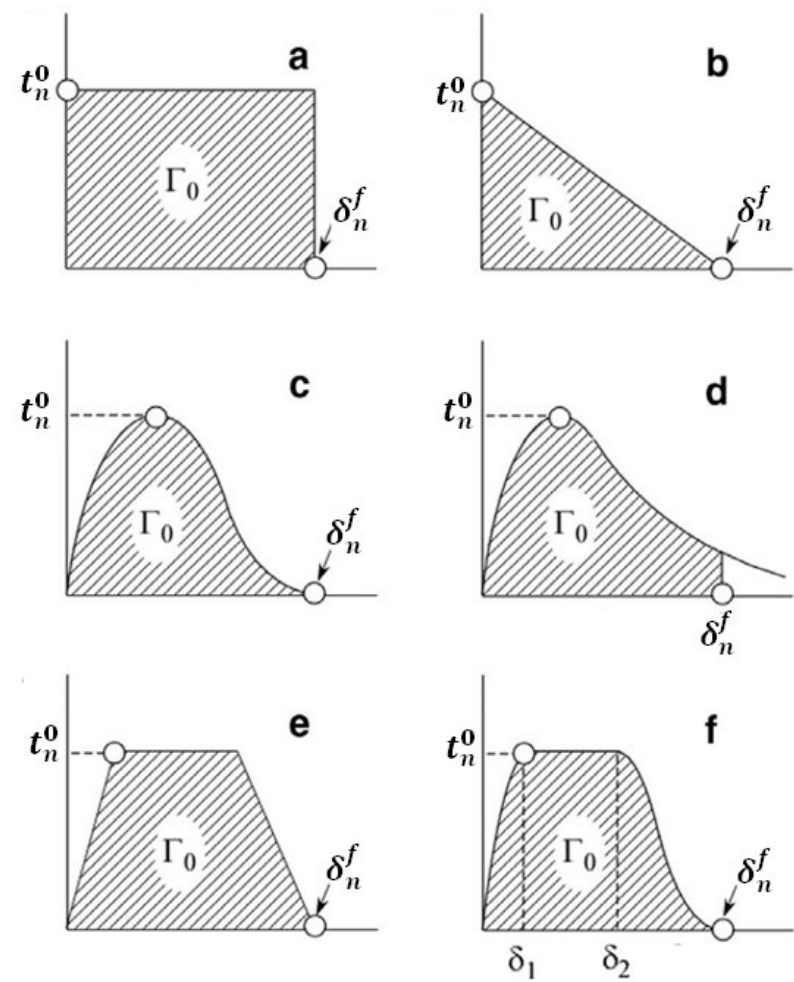

Figure 2.1: Cohesive Zone models: various separation laws, (Zerbst, et al., 2009) : (a) Dugdale (1960); (b) Barenblatt (1962); Hillerborg et al. (1976),brittle materials; (c) Needlemen (1987); Tvergaard (1990), ductile materials,polynomial equations; (d) Rose et al. (1981);Needleman (1990), exponential equation; (e) Tvergaard and Hutchinson (1992), trapezoidal law; (f) Scheider (2000).

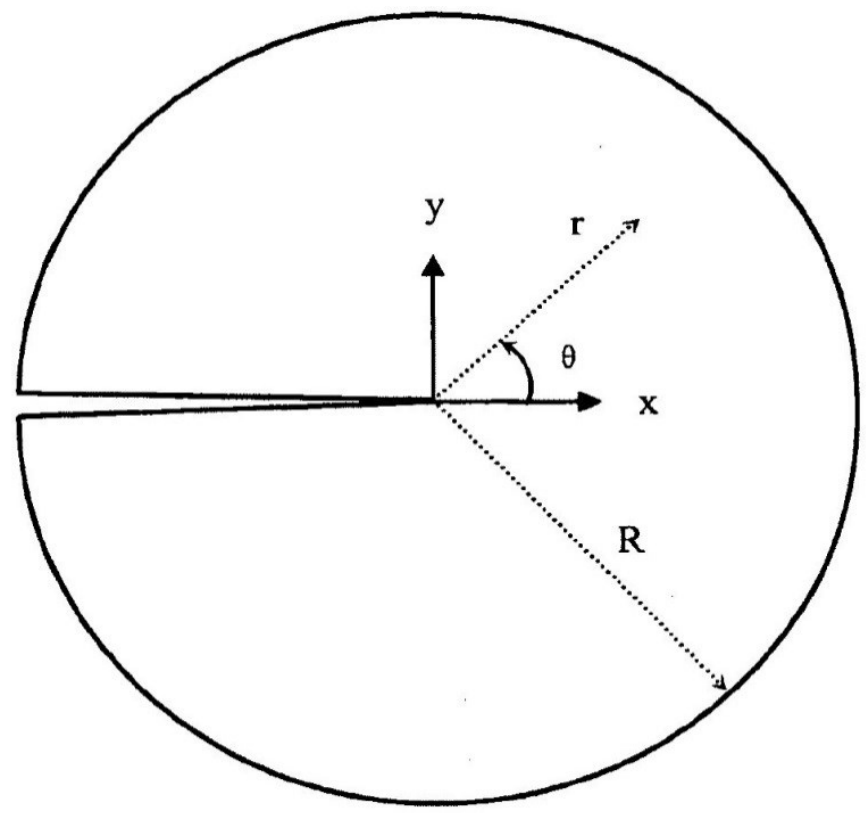

Figure 2.2: Modified boundary layer (MBL) model, (Ding \& Wang, 2012) 


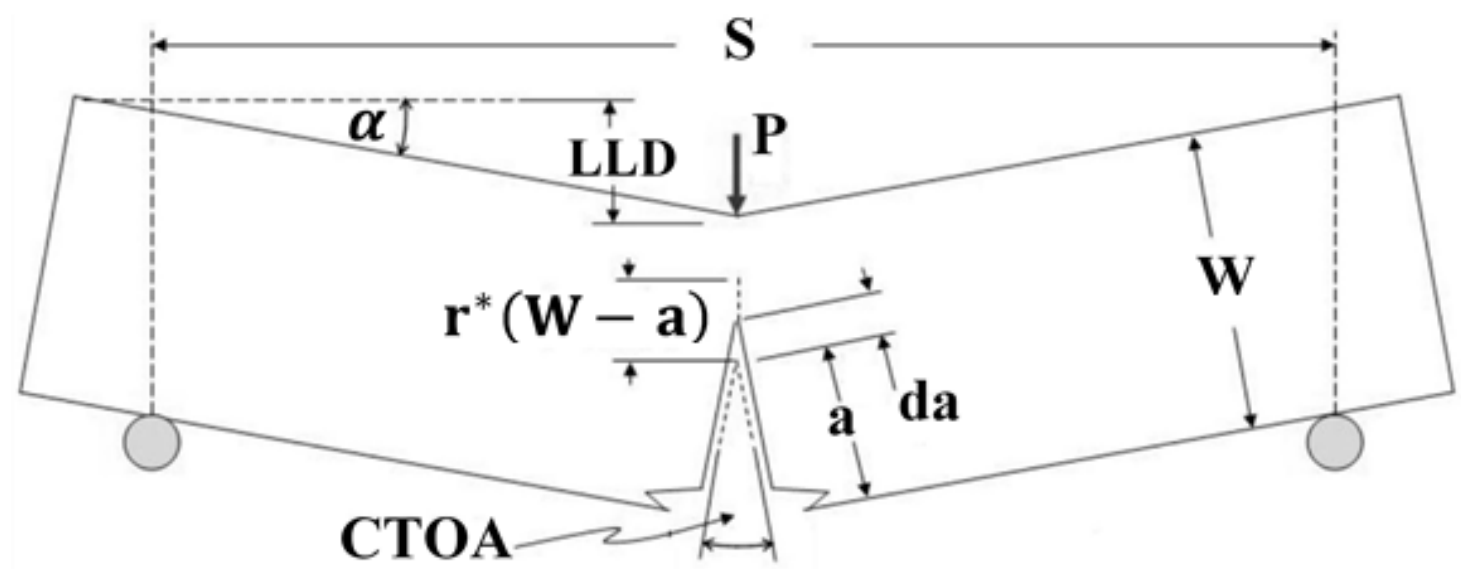

Figure 2.3: Full specimen of drop-weight tear test (DWTT), (Xu et al., 2011)

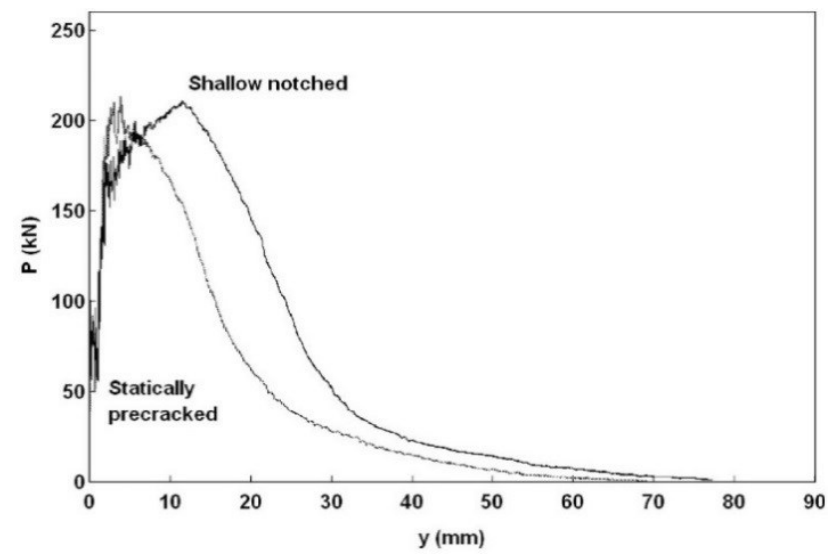

Figure 2.4: Load vs. load-line displacement plots of shallow-notched DWTT specimens, (Xu, et al., 2007)

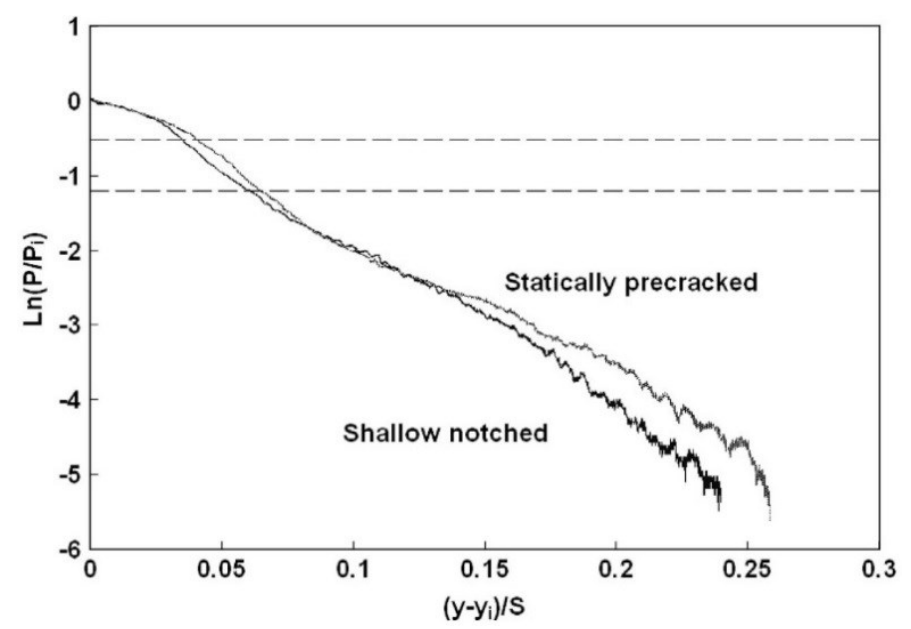

Figure 2.5: Plots of $\operatorname{Ln}\left(P / P_{i}\right)$ vs. $\left(y-y_{i}\right) / S$ relations and data range for determination of the Slope, (Xu, et al., 2007) 
a

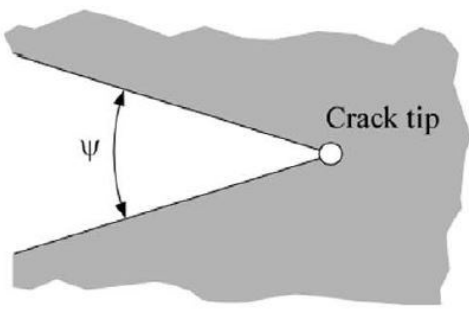

b

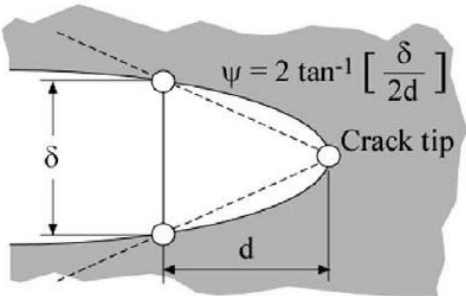

C

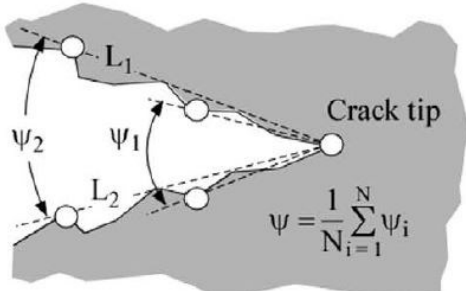

Figure 2.6: Definitions of the crack tip opening angle (CTOA), (Zerbst, et al., 2009)

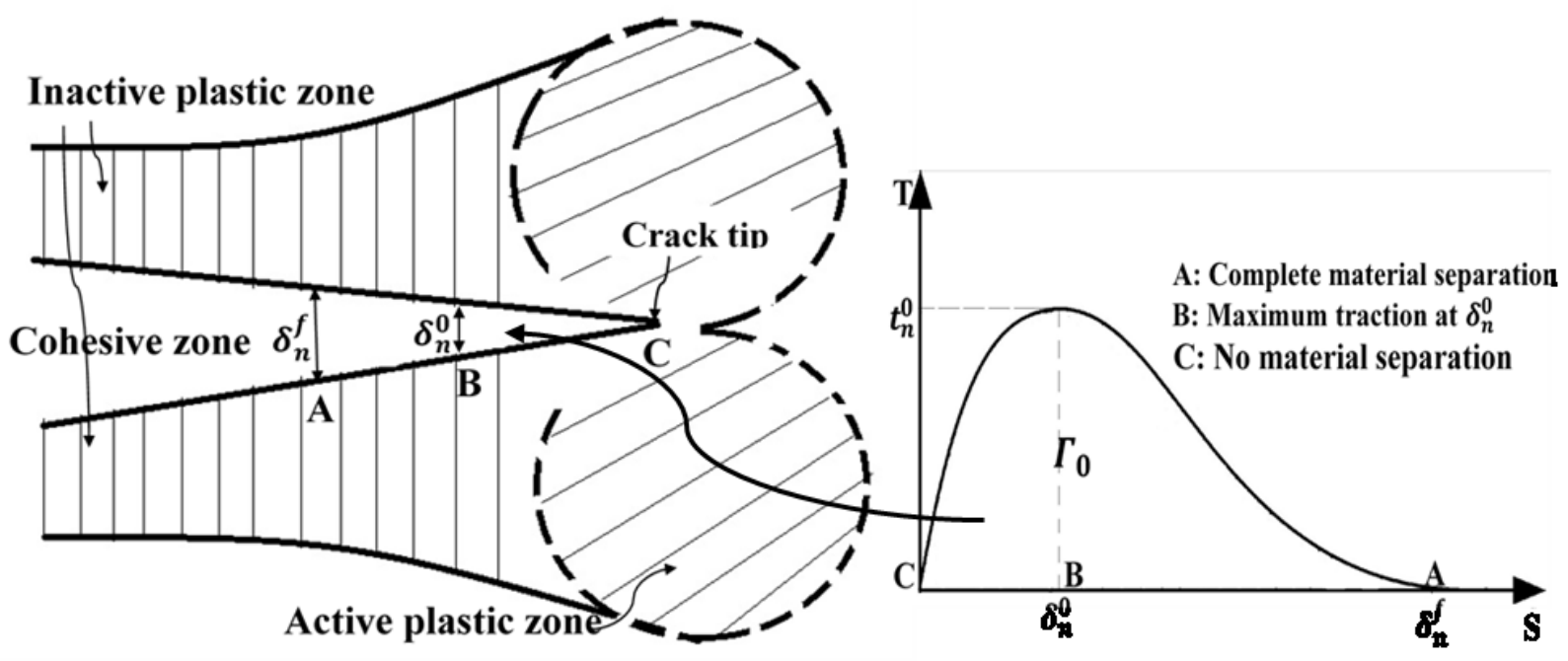

Figure 2.7: Embedded cohesive process zone and typical traction-separation (TS) curve, (Li \& Chandra, 2003). 


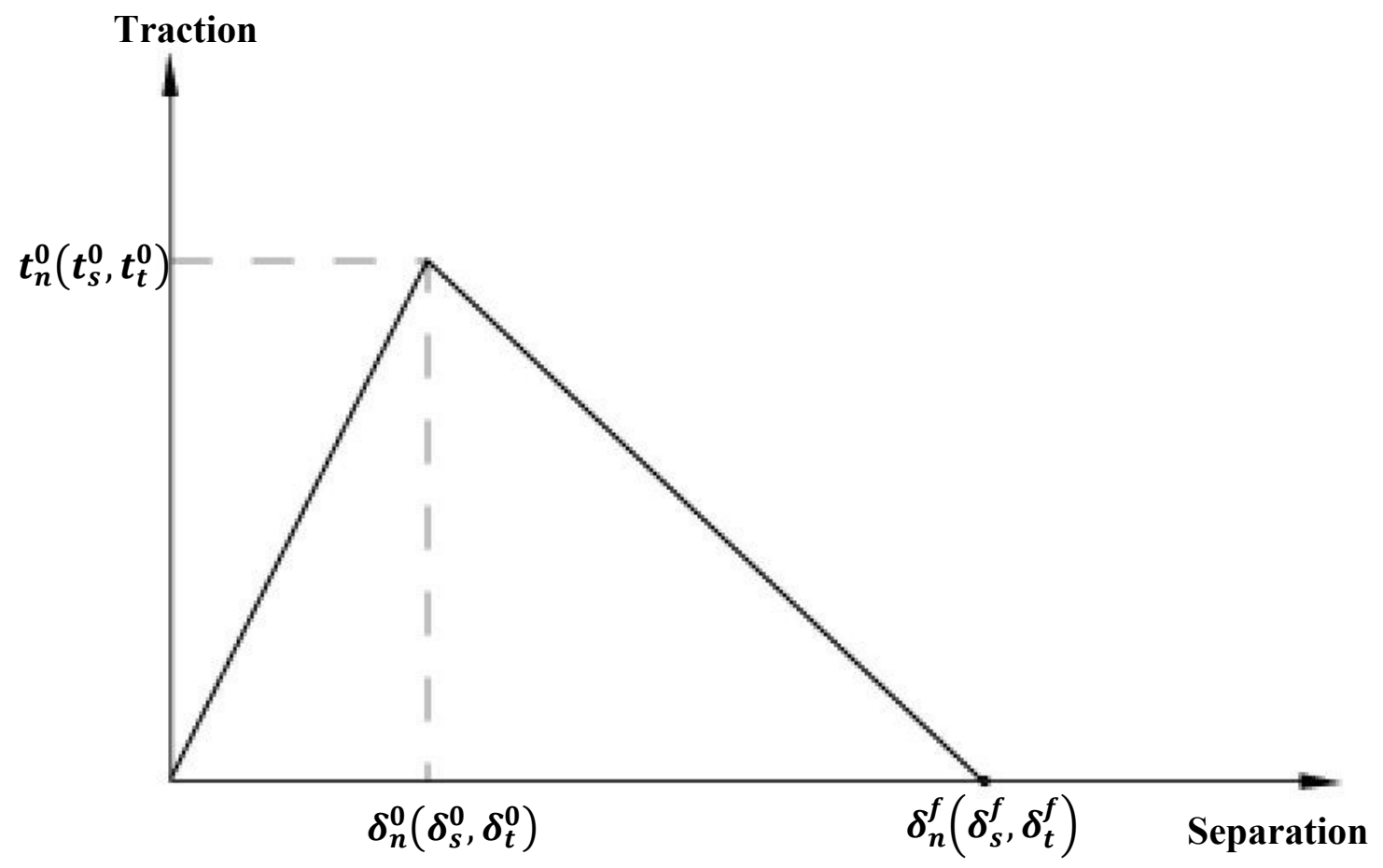

Figure 2.8: Typical bilinear traction-separation response (ABAQUS User's manual- 6.11)

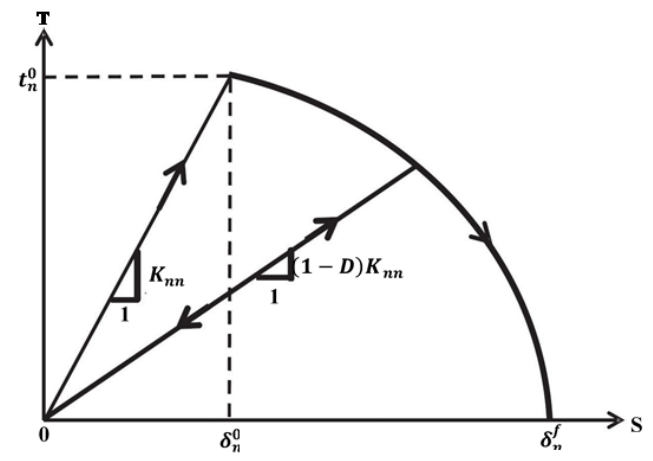

(a)

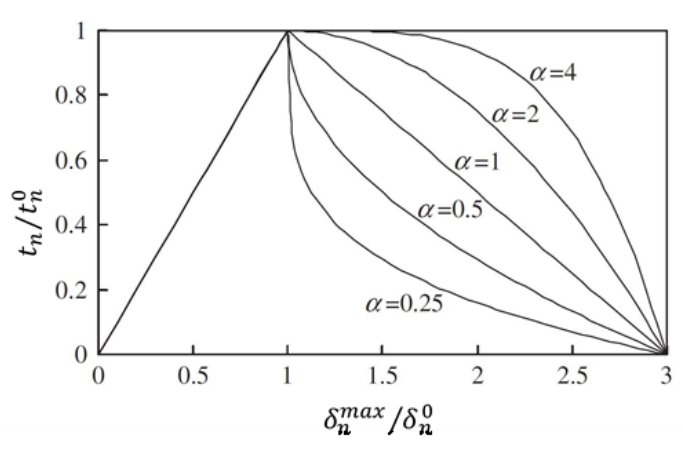

(b)

Figure 2.9: (a) Exponential TS law (b) Traction stresses as a function of separation with different $\alpha$, (Ren \& Ru, 2013) 


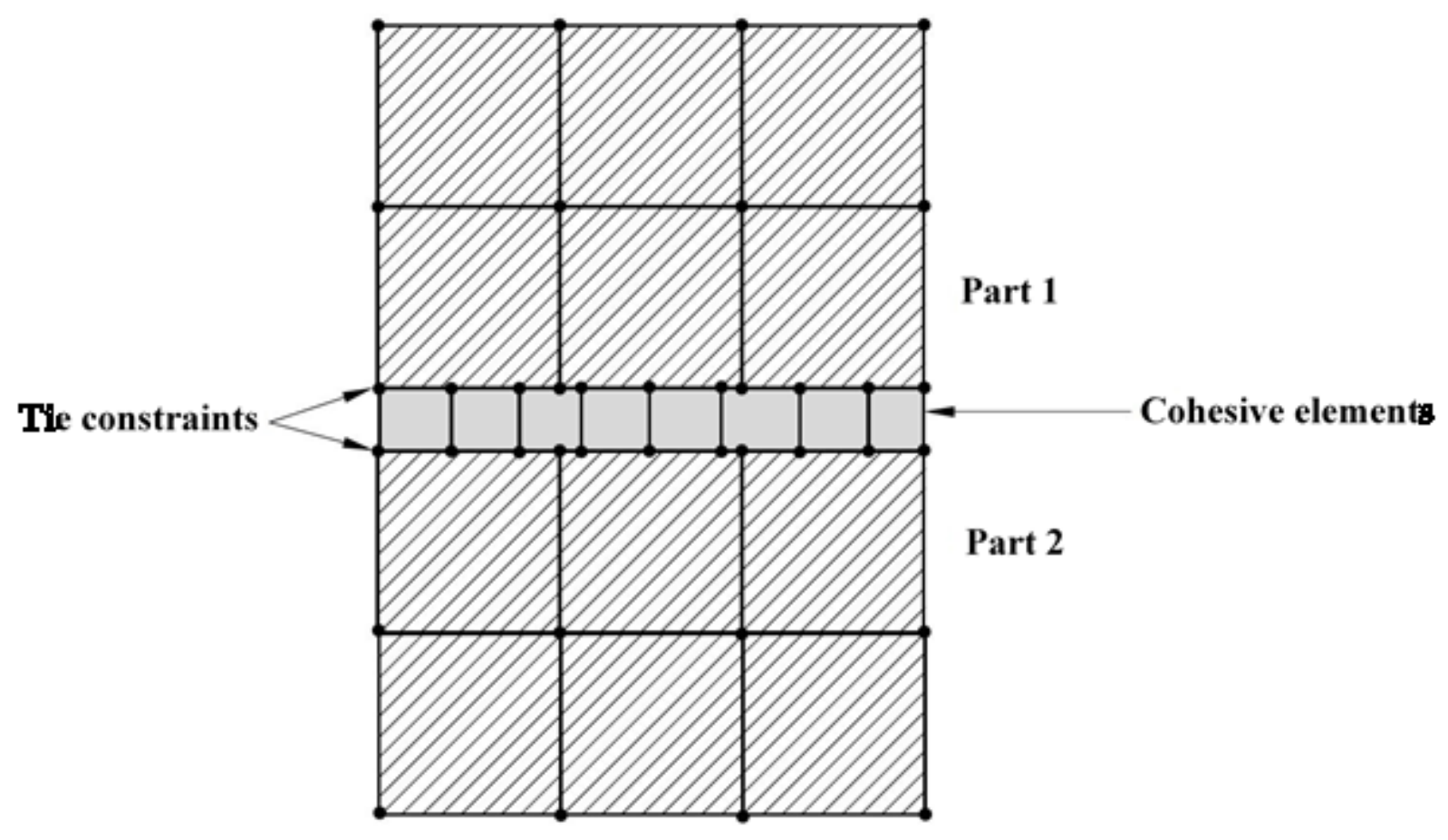

Figure 2.10: Typical element based cohesive zone model-independent meshes with tie constraints, (ABAQUS User's manual - 6.11)

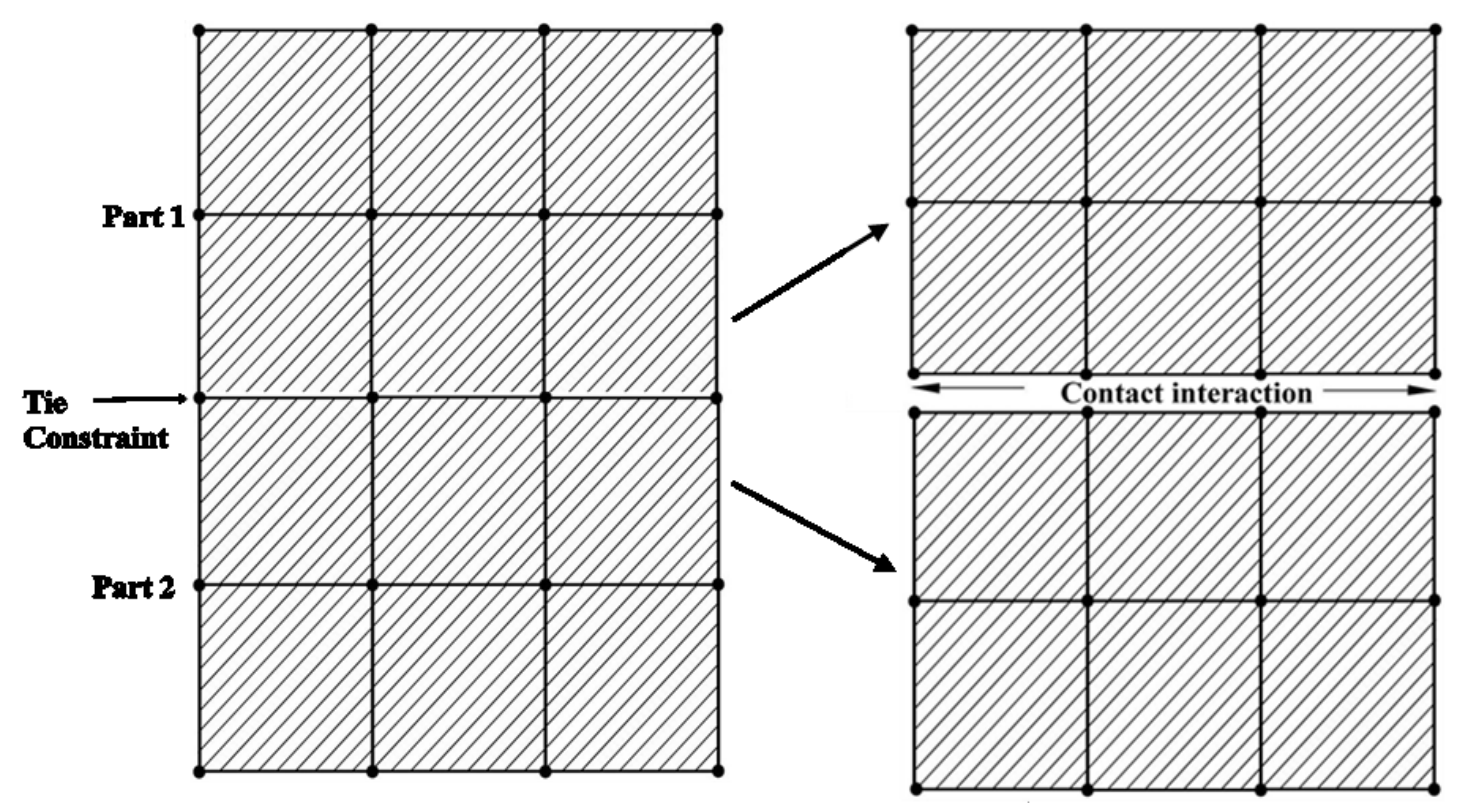

Figure 2.11: Typical surface based cohesive zone model-contact interaction with tie constraint, (ABAQUS User's manual - 6.11) 


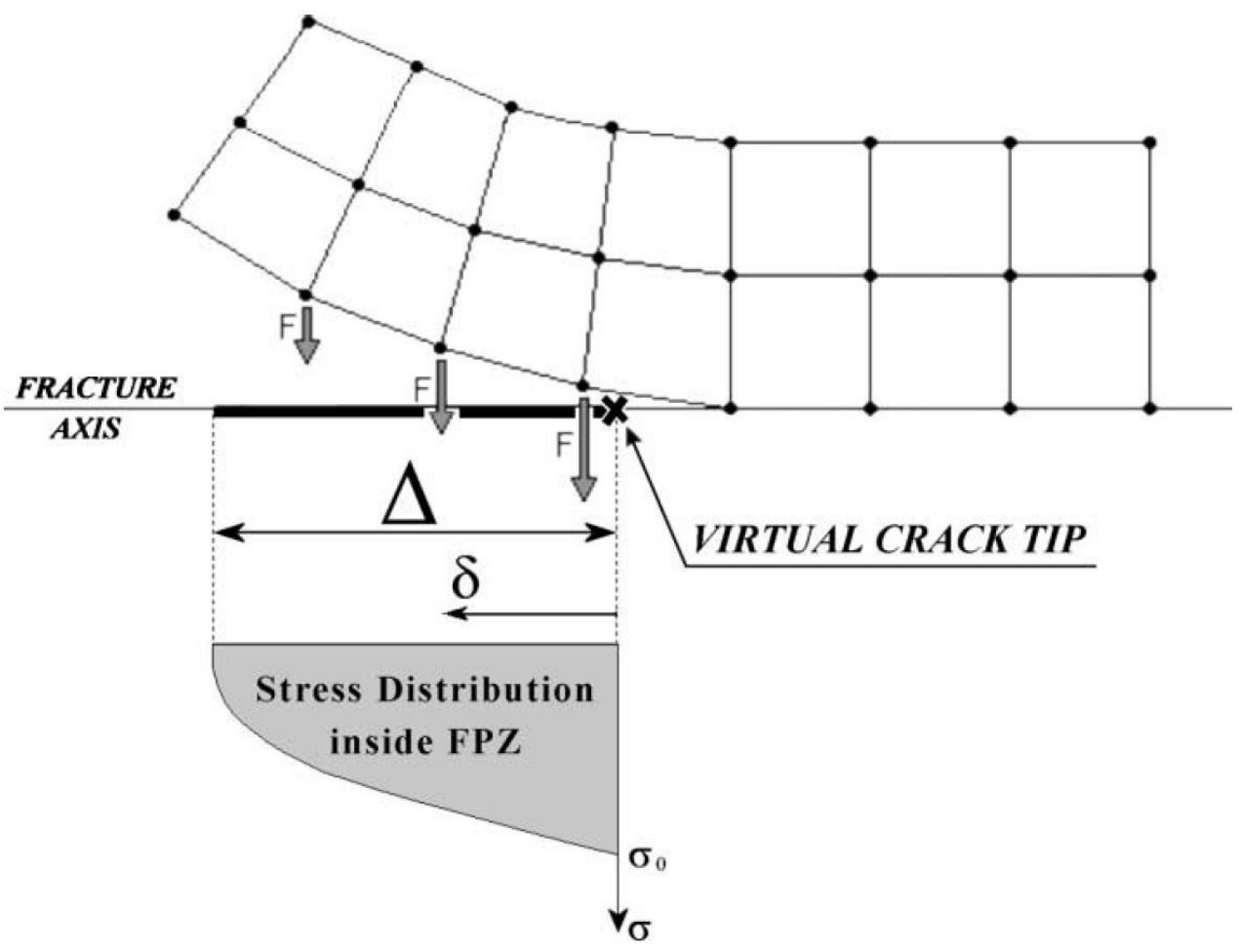

Figure 2.12: Simplified scheme of cohesive zone model, (Salvini \& Mannucci, 2003)

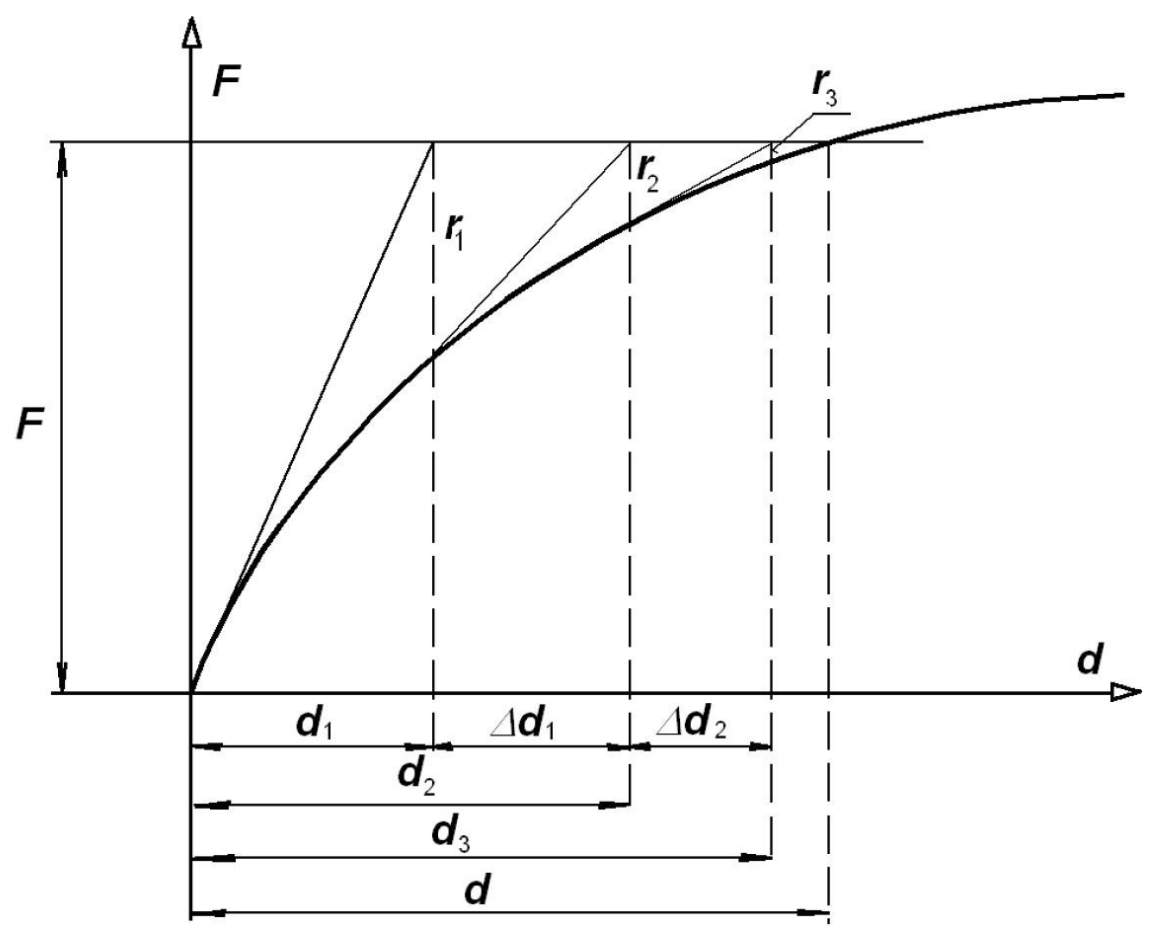

Figure 2.13: Standard Newton-Raphson (NR) method, (Ivanco, 2011) 


\section{Chapter 3}

\section{FE Simulation of Ductile Crack Propagation in TH Steel}

Computational analysis is performed on high strength, high toughness TH steel. TH steel was introduced by Tvergaard and Hutchinson in 1992 (Tvergaard \& Hutchinson, 1992). The TH steel has a yield strength of $600 \mathrm{MPa}$, a Young's modulus of 200,000 MPa and a Poisson's ratio of 0.3 . The true stress-strain data of TH steel can be found from Figure

\section{1.}

In this chapter, numerical solutions of small scale yielding (SSY) model, modified boundary layer (MBL) model, drop weight tear test (DWTT) and single edge notched specimen in tension (SENT) have been obtained with the finite element program ABAQUS/Standard -6.11-2. Each model has been studied for four sets of TH steels: TH_1, TH_2, TH_3 and TH_4. The four sets of TH steel are different from each other in terms of fracture toughness and peak traction as shown in Table 3.3 and Figure 3.2. Results of crack growths characteristics and CTOA are obtained for different specimens.

\subsection{FE Simulation of Small Scale Yielding Model}

In spite of the small scale yielding model is controlled by stress intensity, the material still behaves in a linear elastic way at the crack tip. Hence, in the small scale yielding model, the size of the plastic zone region needs to be small enough compared with the 
dimension of the model to study the elastic dominated region by LEFM (linear elastic fracture mechanics).

The crack growth resistance curves and crack tip opening angle (CTOA) are plotted from FE simulation of SSY. The crack growth resistance curves are compared with the results presented by Tvergaard \& Hutchinson (1992).

\subsubsection{Geometry}

The mode I crack model of the small scale yielding is generated using commercial finite element program ABAQUS/Standard-6.11-2. As illustrated in Figure 3.3, the top semicircle is produced with radius $200 \mathrm{~mm}$. The bottom semi-circle was imposed by mirroring the top half to design the whole model. A Cartesian co-ordinate system, X-Y, is selected and the crack tip of the model is chosen at the origin of the co-ordinate system. The bottom-right surface of the top semi-circle and top-right surface of the bottom semi-circle are partitioned to introduce cohesive behavior. These surfaces are both situated at greater than and equal to zero on the $\mathrm{X}$-axis and zero on the $\mathrm{Y}$-axis.

\subsubsection{Material Properties}

The values of yield strength, Young's Modulus and Poisson's ratio of TH steel are 600 MPa, 200,000 MPa and 0.3 respectively. The stress-plastic strain data are provided in Table 3.1 (Dunbar, 2011), the values of which are used in ABAQUS/Standard. 


\subsubsection{Step Time Definition}

The quasi-static implicit model is set for static, using a general time step for the time period of 1 second. The geometric non-linearity (Nlgeom) option is used to model the non-linearity accurately. The maximum number of increments is specified to 2000 . The initial time increment is assigned to 0.01 , the minimum time increment to $1 \times e^{-8}$ and the maximum time increment to 0.01 .

\subsubsection{Mesh Design}

The mesh design for the whole model is shown in Figure 3.4 and Figure 3.5. The crack tip is enclosed by the uniform square elements of size $\Delta_{0}$. From trial and error, a size of $\Delta_{0}$ is assigned as $0.05 \mathrm{~mm} \times 0.05 \mathrm{~mm}$, as the calculated R-curves were found to converge at this value of $\Delta_{0}$. A rectangular region around the crack tip has a total length of $\mathrm{B}_{0}=$ $360 \Delta_{0}$ and height of about $\mathrm{H}_{0}=40 \Delta_{0}$ as demonstrated in Figure 3.5. The model was meshed with the help of the three different meshing techniques. The structured (quaddominated) technique was used to generate the mesh nearer to the crack tip and sweep (quad-dominated) away from the crack tip. The free (quad) meshing technique was used to connect the gap between rectangular structured technique and circular swept technique. The outer edge of the whole circle was divided into 72 equal parts to introduce nodes at five degree intervals. Thus, the whole model consisted of 183,980 CPE4R elements (a four node bilinear plane strain quadrilateral elements with reduced integration and hourglass control) and 184,552 nodes. 


\subsubsection{Contact Interaction}

The interaction property and interaction contact are produced to introduce a contact pair for surface based cohesive behavior as shown in Figure 3.6. The simulations are carried out for the four types of TH steel: TH_1, TH_2, TH_3, and TH_4. Cohesive parameters for all four sets of TH steel are in Table 3.2 and Figure 3.2 to introduce bilinear TS law in ABAQUS/Standard (Dunbar, 2011).

The cohesive parameters are introduced in the interaction properties' contact type module. The uncoupled stiffness coefficients $\left(\mathrm{K}_{\mathrm{nn}}, \mathrm{K}_{\mathrm{ss}}, \mathrm{K}_{\mathrm{tt}}\right)$ are employed and initiated at $\mathrm{K}_{\mathrm{nn}}=\mathrm{K}_{\mathrm{ss}}=\mathrm{K}_{\mathrm{tt}}=0$ as the model is evaluated for opening crack separation mode $\mathrm{I}$. The maximum nominal stress criterion and fracture energy criterion are picked for damage initiation and damage evolution respectively. A value of viscosity coefficient is set equal

to $10^{-5}$ for stabilization. The ratio of maximum traction and yield strength i.e. $\widehat{\sigma} / \sigma_{y}$ are taken as 3, 3.5, 3.6 and 3.75 respectively for materials, TH_1, TH_2, TH_3 and TH_4. The fracture energies for all four models are 12.15 MPa $\cdot \mathrm{mm}, 14.175 \mathrm{MPa} \cdot \mathrm{mm}, 14.58$ $\mathrm{MPa} \cdot \mathrm{mm}$ and $15.1875 \mathrm{MPa} \cdot \mathrm{mm}$ respectively.

The surface-to-surface contact is used from the interaction module to tie master surface (bottom-right surface of a top semi-circle) and the slave surface (top-right surface of bottom semi-circle).

From the mesh, slave nodes (top-right nodes of bottom semi-circle) are selected and small sliding is picked in sliding formulation in interaction module in ABAQUS/Standard to model crack growth. 


\subsubsection{Loading Conditions}

To apply the desired stress intensity, the outer edge of the circle is divided into 72 parts. Stress intensity is applied in terms of displacement in X-direction and Y-direction at each five degree node by using the following equations,

$$
\begin{aligned}
& \mathrm{u}_{\mathrm{x}}=\frac{\mathrm{K}_{\mathrm{r}}}{2 \mu} \sqrt{\frac{\mathrm{r}}{2 \pi}} \cos \left(\frac{\theta}{2}\right)\left[\mathrm{k}-1+2 \sin ^{2}\left(\frac{\theta}{2}\right)\right] \\
& \mathrm{u}_{\mathrm{y}}=\frac{\mathrm{K}_{\mathrm{r}}}{2 \mu} \sqrt{\frac{\mathrm{r}}{2 \pi}} \sin \left(\frac{\theta}{2}\right)\left[\mathrm{k}+1-2 \cos ^{2}\left(\frac{\theta}{2}\right)\right]
\end{aligned}
$$

where, $K_{r}$ is the maximum far-field stress intensity factor, $\mu$ is the shear modulus, equals $[\mathrm{E} / 2(1+v)], \mathrm{r}$ is the radius of the semicircle and $\theta$ is the measured counter clockwise angle, $\mathrm{k}=3-4 v, v$ is the Poisson's ratio.

The value of $\mathrm{K}_{\mathrm{r}}$ is chosen $5 \cdot \mathrm{K}_{0}^{\mathrm{TH}}{ }^{4}$ (Dunbar, 2011). As shown in Figure 3.7, if a model is symmetric along the $\mathrm{X}$-axis, displacement in $\mathrm{X}$-direction $\left(\mathrm{u}_{\mathrm{x}}\right)$ would be the same for the regions $0^{\circ}$ to $180^{\circ}$ and $180^{\circ}$ to $360^{\circ}$. Nevertheless, $\mathrm{u}_{\mathrm{y}}$ will be equal and opposite in signs in both regions as from the Equation 3.2, as "sine" is an odd function.

\subsection{FE Simulation of Modified Boundary Layer Model}

T-stress is applied on the small scale yielding model with the help of the William series expansion.

The crack growth resistance curves and CTOA are recorded from FE simulation to analyze the effect of T-stress on modified boundary layer (MBL) model.

The geometry, material properties, step time definition, mesh design and contact interaction are the same as discussed in Section 3.1.1 to Section 3.1.5. Only boundary 
conditions of the model will be changed due to addition of T-stress effect in the William series.

\subsubsection{Loading Conditions}

Far field displacement field is applied on the MBL model. The remote boundary conditions are a combination of stress intensity factor as well as T-stress. The desired displacements in $\mathrm{X}$-direction and $\mathrm{Y}$-direction at each five degree node are given by using the following equations,

$$
\begin{aligned}
& \mathrm{u}_{\mathrm{x}}=\frac{\mathrm{K}_{\mathrm{r}}}{2 \mu} \sqrt{\frac{\mathrm{r}}{2 \pi}} \cos \left(\frac{\theta}{2}\right)\left[\mathrm{k}-1+2 \sin ^{2}\left(\frac{\theta}{2}\right)\right]+\frac{1-v}{2} \operatorname{Tr} \cos \theta \\
& \mathrm{u}_{\mathrm{y}}=\frac{\mathrm{K}_{\mathrm{r}}}{2 \mu} \sqrt{\frac{\mathrm{r}}{2 \pi}} \sin \left(\frac{\theta}{2}\right)\left[\mathrm{k}+1-2 \cos ^{2}\left(\frac{\theta}{2}\right)\right]+\frac{(-v)}{2} \operatorname{Tr} \sin \theta
\end{aligned}
$$

where, $K_{r}$ is the maximum far-field stress intensity factor, $\mu$ is the shear modulus, equals $[\mathrm{E} / 2(1+v)], r$ is the radius of the semicircle and $\theta$ is the measured counter clockwise angle, $\mathrm{k}=3-4 v, v$ is the Poisson's ratio, and $\mathrm{T}$ is the non-singular stress acting parallel to the crack plane.

To propagate the crack through cohesive layers, the value of $\mathrm{K}_{\mathrm{r}}$ is chosen $10 \cdot \mathrm{K}_{0}^{\mathrm{TH}}{ }_{-} 4$. The numerical simulations are conducted for various normalized $\mathrm{T}$-stress values i.e. $\mathrm{T} / \sigma_{\mathrm{y}}=$ $-0.5,+0.5,-0.8,+0.8,-1,+1$.

\subsection{FE Simulation of Drop-Weight Tear Test (DWTT)}

The two dimensional, elastic-plastic finite element model of drop weight tear test of TH steel is analysed with ABAQUS/Standard-6.11-2.

The load vs. LLD, CTOA data and $\Delta a$ vs. LLD are plotted to study the crack growth. 


\subsubsection{Geometry}

The two dimensional drop weight tear test model is demonstrated in Figure 3.8. A finite element analysis program ABAQUS/Standard 6.11-2 is used to produce the FEA model. The top half part is created first and the bottom half part was drawn with the help of the mirror tool to create the full model. The Cartesian coordinate system is used and it is symmetric along the X-axis. The width, height and thickness of the model are $76 \mathrm{~mm}$, $305 \mathrm{~mm}$ and $13.7 \mathrm{~mm}$ respectively. The thickness of the model will be taken in to consideration only in the calculation part as this is the two dimensional model. The span between two 'anvils' is $254 \mathrm{~mm}$. The crack tip is introduced on the middle line at the 15 $\mathrm{mm}$ from the origin. The two sets of two edges are created beyond the crack tip. The one edge (bottom edge of the top part) is tied with another edge (top edge of the bottom part) with the help of surface-to-surface tie constraint in the interaction module.

\subsubsection{Material Properties}

The TH steel with yield strength of $600 \mathrm{MPa}$, Young's modulus value of 200,000 $\mathrm{MPa}$ and Poisson's ratio of 0.3 is used. The stress - plastic strain data are found in Table 3.1.

\subsubsection{Step Time Definition}

The quasi-static implicit model is set for static, using a general time step for the time period of 1 second. The geometric non-linearity (Nlgeom) option is kept on. The maximum number of increments is specified to 20000. The initial time increment is assigned to 0.01 , the minimum time increment to $1 \times e^{-8}$ and the maximum time increment to 0.01 . 


\subsubsection{Mesh Design}

The mesh of the full model is illustrated in Figure 3.9. Two different mesh techniques are used to generate the mesh of the model. The structured mesh technique with element shape quad dominated is used for the area near crack tip. The free mesh technique with element shape quad and advancing front algorithm is applied on the rest of the model. The size of the element is $0.05 \mathrm{~mm} \times 0.05 \mathrm{~mm}$ near the crack tip area and the approximate global element size of the model is $5 \mathrm{~mm}$. The mesh is again refined at the 'anvils' along the $6 \mathrm{~mm}$ of length. Thus, the model comprised total number of 176,143 linear quadrilateral elements of type CPE4R (a four node bilinear plane strain quadrilateral elements with reduced integration and hourglass control) and 177,806 nodes.

\subsubsection{Contact Interaction}

The same steps are followed as in Section 3.1.5 for contact interaction.

\subsubsection{Loading Conditions}

The 2D elastic-plastic drop-weight tear test specimen with boundary conditions is illustrated in Figure 3.10. The 'anvils' are designed along the length of $6 \mathrm{~mm}$ on both side of the model. The 'anvils' are fixed from displacing and rotating in X-direction. Node A is fixed in Y-direction as well to prevent rigid body motion of the model in global coordinate system. A ramped displacement field is applied from the 'tup'. The span of the 'tup' is selected along $24 \mathrm{~mm}$. The ramped displacement of amount $1.5 \mathrm{~mm}, 2.5 \mathrm{~mm}, 6$ $\mathrm{mm}$ and $10 \mathrm{~mm}$ are employed for $\mathrm{TH} \_1, \mathrm{TH}_{-} 2, \mathrm{TH} \_3$ and $\mathrm{TH} \_4$ material respectively. 


\subsection{FE Simulation of Single Edge Notched Specimen in Tension (SENT)}

The FE simulation of single edge notched specimen in tension (SENT) for TH_1, TH_2 and TH_3 is carried out with ABAQUS/Standard-6.11-2. The FE model of TH_4 was not converged due to numerical instabilities.

The main purpose of this section is to determine the CTOA of SENT and compare it with the CTOA of DWTT specimen.

\subsubsection{Geometry}

The geometry and cartesian coordinate system of 2D plane strain SENT are illustrated in Figure 3.11. The model is divided into two halves to introduce surface based cohesive behavior. Both parts are the same in dimensions as the model is symmetric along the $\mathrm{X}$ axis. The ratio of height to width $(\mathrm{H} / \mathrm{W})$ and relative crack length $(\mathrm{a} / \mathrm{W})$ are 5 and 0.1974 respectively. Hence, the total length $(2 \mathrm{H})$ of the specimen and initial crack length of the model are $760 \mathrm{~mm}$ and $15 \mathrm{~mm}$ respectively. The two halves of the model are tied a with surface-to-surface tie constraint.

\subsubsection{Material Properties}

The same material properties as used for SSY, MBL and DWTT are used here for SENT, i.e. the values of yield strength, young's modulus and Poisson's ratio of TH steel are 600 MPa, 200,000 MPa and 0.3 respectively. The stress-plastic strain data are provided in Table 3.1, (Dunbar, 2011) . 


\subsubsection{Mesh Design}

Figure 3.12 demonstrates the typical 2D mesh of the SENT. Mainly two mesh techniques are used to mesh the SENT. The structured mesh technique (quad dominated) is used around the crack tip and the free mesh technique (quad dominated) is applied for the rest of the model. The mesh is refined around the crack tip keeping element size $0.05 \mathrm{~mm} \times 0.05 \mathrm{~mm}$. The element size for the rest of the model is $2 \mathrm{~mm} \times 2 \mathrm{~mm}$. The element type CPE4R (a four node bilinear plane strain quadrilateral elements with reduced integration and hourglass control) is employed for the full model.

\subsubsection{Step Time Definition and Contact Interaction}

Same number of increments and increment size as for SSY (Section 3.1.3) are used for the SENT. The cohesive and damage properties for TH_1, TH_2 and TH_3 are provided in Table 3.2. The cohesive and damage properties of $\mathrm{TH}_{-} 1$ and $\mathrm{TH}_{-} 2$ are the same as in Table 3.2. Nevertheless, the elastic moduli or in other words the stiffness of the TH_3 material is reduced to propagate crack little far. As TH_3 is tougher than TH_1 and TH_2, it was difficult to grow the crack. Therefore, after trials of different combinations of cohesive and damage parameters, the final values of $\mathrm{K}_{\mathrm{nn}}, \mathrm{K}_{\mathrm{ss}}, \mathrm{K}_{\mathrm{tt}}$ are chosen 1,000,000 $\mathrm{MPa}, 384,615 \mathrm{MPa}$ and 384,615 $\mathrm{MPa}$ respectively for $\mathrm{TH}_{-} 3$ material. The remaining cohesive parameters for TH_3 are same as listed in Table 3.2. The rest of the settings for the contact interaction properties are the same as explained in Section 3.1.5. 


\subsubsection{Loading Conditions}

The loading conditions of 2D mode I plane strain SENT is displayed in Figure 3.13. The uniaxial remote tensile loading is applied on model. The remote displacement field of 6 $\mathrm{mm}$ is implemented along the width on both upper and lower side of the model. The displacement is applied on nodes rather than edge to avoid distortion of mesh. The node $\mathrm{A}$ is constrained from displacing in $\mathrm{X}$-direction and $\mathrm{Y}$-direction to avoid rigid body motion in global coordinate system.

\subsection{Results and Discussion}

\subsubsection{Small Scale Yielding Model}

Four sets of TH steel are characterized by different values of $\widehat{\sigma} / \sigma_{\mathrm{y}}$. The values of $\widehat{\sigma} / \sigma_{\mathrm{y}}$ are 3, 3.5, 3.6 and 3.75 for $\mathrm{TH}_{-} 1, \mathrm{TH}_{-} 2, \mathrm{TH}_{-} 3$ and $\mathrm{TH} \_4$ respectively. The surface based cohesive behavior is introduced between two surfaces as shown in Figure 3.6. The bilinear traction-separation law is used throughout all simulations.

\section{Crack Growth Resistance Curves (R-curves)}

The normalized crack growth resistance curve is plotted as shown in Figure 3.14. As discussed later in Chapter 5, Section 5.5.2, applied far field stress intensity $\left(\mathrm{K}_{\mathrm{r}}\right)$ is normalized by critical stress intensity $\left(\mathrm{K}_{0}\right)$, and crack extension $(\Delta \mathrm{a})$ is normalized by plastic zone size $\left(R_{0}\right)$. The displacement in the $\mathrm{X}$-direction at node $0^{\circ}$ is recorded for several intervals of time steps. The applied stress intensity $\left(\mathrm{K}_{\mathrm{r}}\right)$ is then found by inserting recorded displacement in Equation 3.1. The critical stress intensity $\left(\mathrm{K}_{0}\right)$ and plastic zone size $\left(\mathrm{R}_{0}\right)$ can be found from Equation 5.7 and Equation 5.8. The calculated 
values of $K_{0}$ and $R_{0}$ can be found in Table 3.3. The crack extension $(\Delta \mathrm{a})$ is the travelling of the original crack tip to the current crack tip. The two surfaces are separated behind the current crack tip. These surfaces will be detached from each other when it reaches the critical displacement of $\delta_{\mathrm{c}}=0.0135 \mathrm{~mm}$ and maximum traction $(\widehat{\sigma})$ becomes zero for further crack growth. Hence, the crack extension $(\Delta \mathrm{a})$ is measured by calculating the distance between the original crack tip and the current crack tip.

In Figure 3.14, the resulting curves from Tvergaard \& Hutchinson (1992) and numerical results of $K_{r} / K_{0}$ and $\Delta a / R_{0}$ are plotted as well. It can be seen from Figure 3.14 that the numerical plot shows good agreement with the plot of Tvergaard \& Hutchinson (1992). The trend of R-curves of all four materials attains crack growth in initiation and then enters into a stable growth state. The plastic zone size $\left(R_{0}\right)$ is higher for high toughness material as shown in Table 3.3. Therefore, the R-curve for TH_4 material is steepest as depicted in Figure 3.14.

\section{Crack Tip Opening Angle (CTOA)}

As discussed in Section 2.2, the crack tip opening angle (CTOA) is measured from $1 \mathrm{~mm}$ behind the current crack tip, refer to Figure 3.15. The current crack tip is the meeting point of two separated surfaces which have diminished their load carrying capacity. The CTOA is calculated using following equation,

$$
\text { CTOA }=\tan ^{-1} \frac{\text { CTOD }}{1}
$$

The crack tip opening displacement (CTOD) is the vertical distance between two separated surfaces. The CTOD is measured $1 \mathrm{~mm}$ behind the current crack tip. To find the steady state CTOA, the trend lines are fitted on the CTOA results using a power law fit 
in Tecplot 3602011 (post-processing simulation results plot tool). Figure 3.16 shows that the CTOA is greater for the tougher material. Hence, TH_1 has the smallest steady state CTOA $1.56^{\circ}$ and TH_4 has the highest steady state CTOA $5.65^{\circ}$. The CTOA of TH_2 and TH_3 are $3.30^{\circ}$ and $4.16^{\circ}$ respectively.

CTOA of SSY models are compared with the DWTT model for all four sets of TH steel later.

\subsubsection{Modified Boundary Layer Model}

The plane strain FE simulation of modified boundary layer model has been analysed. The stress intensity $\left(\mathrm{K}_{\mathrm{r}}\right)$ and T-stress are applied in terms of displacement field in boundary conditions. All four sets of TH steel, TH_1, TH_2, TH_3 and TH_4 are studied for different values of normalized T-stress. The various values of $T / \sigma_{y}$ are taken as $\pm 0.5, \pm 0.8$ and \pm 1 . The bilinear traction-separation laws are used same as small scale yielding model. The R-curve plot and CTOA data are studied to identify the effect of Tstress on modified boundary layer model. The same procedures, explained in Section 3.5.1, are followed to predict R-curves and CTOA data.

\section{Crack Growth Resistance Curves (R-curves)}

The normalized crack growth resistance curves for TH_1, TH_2, TH_3 and TH_4 for $T / \sigma_{y}= \pm 0.5, \pm 0.8, \pm 1$ are plotted in Figures $3.18,3.20,3.22$ and 3.24 . It can be investigated that negative T-stress affect significantly to resistance curves. It can be observed from Figures 3.18, 3.20, 3.22 and 3.24, that $T / \sigma_{y}<0$ is differed significantly from $\mathrm{T}=0(\mathrm{SSY})$ but $\mathrm{T} / \sigma_{\mathrm{y}}>0$ differ slightly from $\mathrm{T}=0$ (SSY). 
The negative T-stress will increase the plastic zone size and hence the crack growth resistance curve (Tvergaard \& Hutchinson, 1994). Thus, the steepest curves for $\mathrm{T} / \sigma_{\mathrm{y}}=-1$ become gradually less steep for $\mathrm{T} / \sigma_{\mathrm{y}}=-0.8$ and -0.5 . It was previously observed by Du \& Hancock (1991) that there is a high constraint condition near the crack tip stress for positive T-stress and less constraint condition for negative T-stress. It makes sense, as a highly constrained condition will prevent growth of the plastic zone. Hence, the crack will grow with the smaller size of the plastic zone, since the R-curves of $\mathrm{T} / \sigma_{\mathrm{y}}>0$ are closer to ideal small scale yielding $(\mathrm{T}=0) \mathrm{R}$-curves. The trend of $\mathrm{R}$-curves for negative and zero T-stress are same as found in Figure 3.17 (Tvergaard \& Hutchinson, 1994).

\section{Crack Tip Opening Angle (CTOA)}

The crack tip opening angles of $\mathrm{TH}_{-} 1, \mathrm{TH}_{-} 2, \mathrm{TH}_{-} 3$ and $\mathrm{TH} \_4$ steels with $\mathrm{T} / \sigma_{\mathrm{y}}= \pm 0.5 \pm 0.8, \pm 1$ are measured. The CTOA is calculated as mentioned in Section 3.5.1. The CTOA are plotted in Figures 3.19, 3.21, 3.23 and 3.25.

In all cases, it can be seen that the CTOA are all most same for $\mathrm{T} / \sigma_{\mathrm{y}}<0, \mathrm{~T}=0$ and $\mathrm{T} / \sigma_{\mathrm{y}}>0$ for four sets of $\mathrm{TH}$ steel. Therefore, the steady state values of CTOA for TH_1, TH_2 TH_3 and TH_4 are $1.56^{\circ}, 3.30^{\circ}, 4.16^{\circ}$ and $5.65^{\circ}$ respectively.

\subsubsection{Drop-Weight Tear Test}

The elastic-plastic 2D FE model of the drop weight tear test contains surface based cohesive behavior. The same bilinear traction-separation laws are used as in small scale 
yielding model for TH_1, TH_2, TH_3 and TH_4. The amount of applied displacement of all four materials is explained in Section 3.3.6 over a time period of 1 second.

\section{Load vs. Load Line Displacement (Load vs. LLD)}

The obtained curves of Load vs. LLD are shown in Figure 3.26. The load at each displacement is calculated as explained later in Chapter 5, Section 5.5.4. The maximum load bearing capacity can be predicted from the cohesive strength and how long this load can be carried is predicted from fracture energy. The higher the fracture energy, the longer the specimen endures the impact of load (Cerrone, et al., 2014). Thus, material TH_4 has the highest load carrying capacity in comparison with the remaining three materials: TH_1, TH_2 and TH_3. The tougher material can experience more load. The maximum load sustained by TH_1, TH_2, TH_3 and TH_4 are $67.5 \mathrm{kN}, 158.9 \mathrm{kN}$, $191.8 \mathrm{kN}$ and $205.6 \mathrm{kN}$ respectively.

\section{Crack Tip Opening Angle (CTOA)}

The crack tip opening angle is calculated using same procedure mentioned in Section 3.5.1. The CTOA data for TH_1, TH_2, TH_3 and TH_4 are plotted in Figure 3.27.

Figure 3.27 shows that the range of the steady state CTOA of DWTT agrees well with the steady state CTOA of small scale yielding model. The steady state CTOA of DWTT of TH_1, TH_2, TH_3 and TH_4 are $1.6^{\circ}, 2.6^{\circ}, 3.2^{\circ}, 5.16^{\circ}$ respectively, which are quite similar range with CTOA of SSY as described in Section 3.5.1 that $1.56^{\circ}, 3.30^{\circ}, 4.16^{\circ}$ and $5.65^{\circ}$ respectively. 


\section{Crack Growth Rate ( $\triangle a$ vs. $L L D)$}

The plot of $\Delta a$ vs. LLD is presented in Figure 3.28. It can be seen from Figure 3.28 that the crack grows all the way through $56 \mathrm{~mm}$ for all four materials. The crack develops faster for $\mathrm{TH}_{-}$1, TH_2, and $\mathrm{TH}_{-} 3$ in comparison with $\mathrm{TH} \_$. Hence it can be stated that TH_1, TH_2 and TH_3 are more brittle and TH_4 will break in a ductile manner as it is the toughest material among all four sets of TH steel.

\subsubsection{Single Edge Notched Specimen in Tension (SENT)}

The CTOA are calculated from the FE simulation of 2D mode I SENT. The CTOA are calculated by following the same procedure as explained in Section 3.5.1.

The computed CTOA are plotted along with the CTOA of DWTT in Figure 3.29, Figure 3.30 and Figure 3.31. It can be anticipated that the trend of CTOA are similar for both SENT as well as DWTT. The crack is not propagated as far as DWTT due to numerical convergence problem in software. The crack did not propagate at all for material TH_4 due to numerical instability after a number of trial and error. It can be observed that the CTOA of SENT of TH_1, TH_2 and TH_3 will converge with the CTOA of DWTT of all three materials if crack is able to propagate further more. The crack is extended until $7.3 \mathrm{~mm}, 7.25 \mathrm{~mm}$ and $4.85 \mathrm{~mm}$ for TH_1, TH_2 and TH_3 material respectively. Generally, the SENT represents negative T-stress and DWTT model characterises positive T-stress. But from the results, it can be predicted that, there are no significant changes of CTOA owing to the T-stress. 


\subsection{Conclusions}

The main purpose of this chapter was to evaluate the T-stress effect on CTOA. The four different models of TH steel; SSY, MBL, DWTT and SENT are studied for four sets of TH steel: TH_1, TH_2, TH_3 and TH_4.

It can be observed that resistance curves of small scale yielding model for TH_1, TH_2, TH_3 and TH_4 agree well with published results of Tvergaard \& Hutchinson (1992). The crack tip opening angles (CTOA) of SSY are high for high toughness material and low for low toughness material. Thus, TH_4 has the highest steady state CTOA and TH_1 has the lowest steady state CTOA.

The behavior (trends) of resistance curves (R-curves) of MBL match well with the published results by Tvergaard \& Hutchinson (1994). The CTOA with positive and negative $\mathrm{T}$-stress, i.e. $\mathrm{T} / \sigma_{\mathrm{y}}= \pm 0.5, \pm 0.8, \pm 1$ do not differ significantly along with CTOA of SSY for all four sets of material of TH steel. In all, it has been concluded that the effect of T-stress on CTOA is negligible.

The computed results of DWTT for Load vs. LLD, $\Delta a$ vs. CTOA and LLD vs. $\Delta a$ are plotted for TH_1, TH_2, TH_3 and TH_4. The CTOA results of DWTT shows good agreement with the CTOA of SSY.

Lastly, the CTOA of SENT are comparable with CTOA of DWTT. Even though the positive T-stress is observed in DWTT and SENT experiences negative T-stress, the CTOA of both cases are not dependent on T-stress. The simulation of SENT is not converged due to numerical issues. 
In conclusion, all FE simulations of models SSY, MBL, DWTT and SENT of TH steel give quite promising results. The viscosity coefficient (damage stabilization factor) of value $10^{-5}$ plays a major role for numerical convergence of the solution. 


\begin{tabular}{|c|c|c|c|}
\hline Stress(MPa) & Plastic strain & Stress(MPa) & Plastic strain \\
\hline 600 & 0 & 910 & 0.190206919 \\
\hline 610 & 0.000539216 & 920 & 0.212519725 \\
\hline 620 & 0.001164143 & 930 & 0.237125475 \\
\hline 630 & 0.001886684 & 940 & 0.264231277 \\
\hline 640 & 0.002720164 & 950 & 0.294060429 \\
\hline 650 & 0.003679475 & 960 & 0.326853488 \\
\hline 660 & 0.004781227 & 970 & 0.362869405 \\
\hline 670 & 0.006043921 & 980 & 0.402386711 \\
\hline 680 & 0.007488126 & 990 & 0.445704781 \\
\hline 690 & 0.009136673 & 1000 & 0.493145151 \\
\hline 700 & 0.011014872 & 1010 & 0.545052911 \\
\hline 710 & 0.013150733 & 1020 & 0.60179817 \\
\hline 720 & 0.015575209 & 1030 & 0.663777594 \\
\hline 730 & 0.018322462 & 1040 & 0.731416024 \\
\hline 740 & 0.02143014 & 1050 & 0.80516817 \\
\hline 750 & 0.024939677 & 1060 & 0.8855204 \\
\hline 760 & 0.028896621 & 1070 & 0.972992606 \\
\hline 770 & 0.03335097 & 1080 & 1.068140168 \\
\hline 780 & 0.038357548 & 1090 & 1.171556007 \\
\hline 790 & 0.043976393 & 1100 & 1.283872744 \\
\hline 800 & 0.05027318 & 1110 & 1.405764953 \\
\hline 810 & 0.057319668 & 1120 & 1.537951527 \\
\hline 820 & 0.065194174 & 1130 & 1.681198149 \\
\hline 830 & 0.073982086 & 1140 & 1.836319877 \\
\hline 840 & 0.083776396 & 1150 & 2.004183852 \\
\hline 850 & 0.094678281 & 1160 & 2.185712122 \\
\hline 860 & 0.106797705 & 1170 & 2.381884595 \\
\hline 870 & 0.120254072 & 1180 & 2.593742129 \\
\hline 880 & 0.135176909 & 1190 & 2.822389747 \\
\hline 890 & 0.151706591 & 1200 & 3.069 \\
\hline 900 & 0.169995117 & & \\
\hline
\end{tabular}

Table 3.1: Stress vs. plastic strain data $-\mathrm{TH}$ steel (input in ABAQUS)) 


\begin{tabular}{|c|c|c|c|c|c|c|c|c|}
\hline \multicolumn{7}{|c|}{ TH Steel } \\
\hline Material & \multicolumn{2}{|c|}{ MaxS Damage (MPa) } & $\begin{array}{c}\text { Fracture } \\
\text { Energy } \\
\mathbf{\Gamma}_{\mathbf{0}} \\
\text { (MPa-mm) }\end{array}$ & \multicolumn{2}{|c|}{ Elastic Moduli (MPa) } & $\begin{array}{c}\text { Viscosity } \\
\text { Coefficient }\end{array}$ \\
\hline & Normal & 1st & 2nd & Linear & $\mathbf{K}_{\text {nn }}$ & $\mathbf{K}_{\text {ss }}$ & $\mathbf{K}_{\text {tt }}$ & \\
\hline TH_1 & 1800 & 1350 & 1350 & 12.15 & 10000000 & 3846150 & 3846150 & $10^{-5}$ \\
\hline TH_2 & 2100 & 1575 & 1575 & 14.175 & 10000000 & 3846150 & 3846150 & $10^{-5}$ \\
\hline TH_3 & 2160 & 1620 & 1620 & 14.58 & 10000000 & 3846150 & 3846150 & $10^{-5}$ \\
\hline TH_4 & 2250 & 1687.5 & 1687.5 & 15.1875 & 10000000 & 3846150 & 3846150 & $10^{-5}$ \\
\hline
\end{tabular}

Table 3.2: Cohesive properties of four sets of TH steel

\begin{tabular}{|c|c|c|c|c|c|}
\hline Material & $\widehat{\boldsymbol{\sigma}} / \boldsymbol{\sigma}_{\mathbf{y}}$ & $\begin{array}{c}\boldsymbol{\Gamma}_{\mathbf{0}} \\
(\mathbf{M P a} \cdot \mathbf{m m})\end{array}$ & $\begin{array}{c}\boldsymbol{\delta}_{\mathbf{c}} \\
(\mathbf{m m})\end{array}$ & $\begin{array}{c}\mathbf{K}_{\mathbf{0}} \\
(\mathbf{M P a} \cdot \sqrt{\mathbf{m m}})\end{array}$ & $\begin{array}{c}\mathbf{R}_{\mathbf{0}} \\
(\mathbf{m m})\end{array}$ \\
\hline TH_1 & 3 & 12.15 & 0.0135 & 1634.1 & 0.787 \\
\hline TH_2 & 3.5 & 14.175 & 0.0135 & 1765 & 0.918 \\
\hline TH_3 & 3.6 & 14.58 & 0.0135 & 1790.1 & 0.944 \\
\hline TH_4 & 3.75 & 15.188 & 0.0135 & 1827 & 0.984 \\
\hline
\end{tabular}

Table 3.3: Model parameters - TH steel 


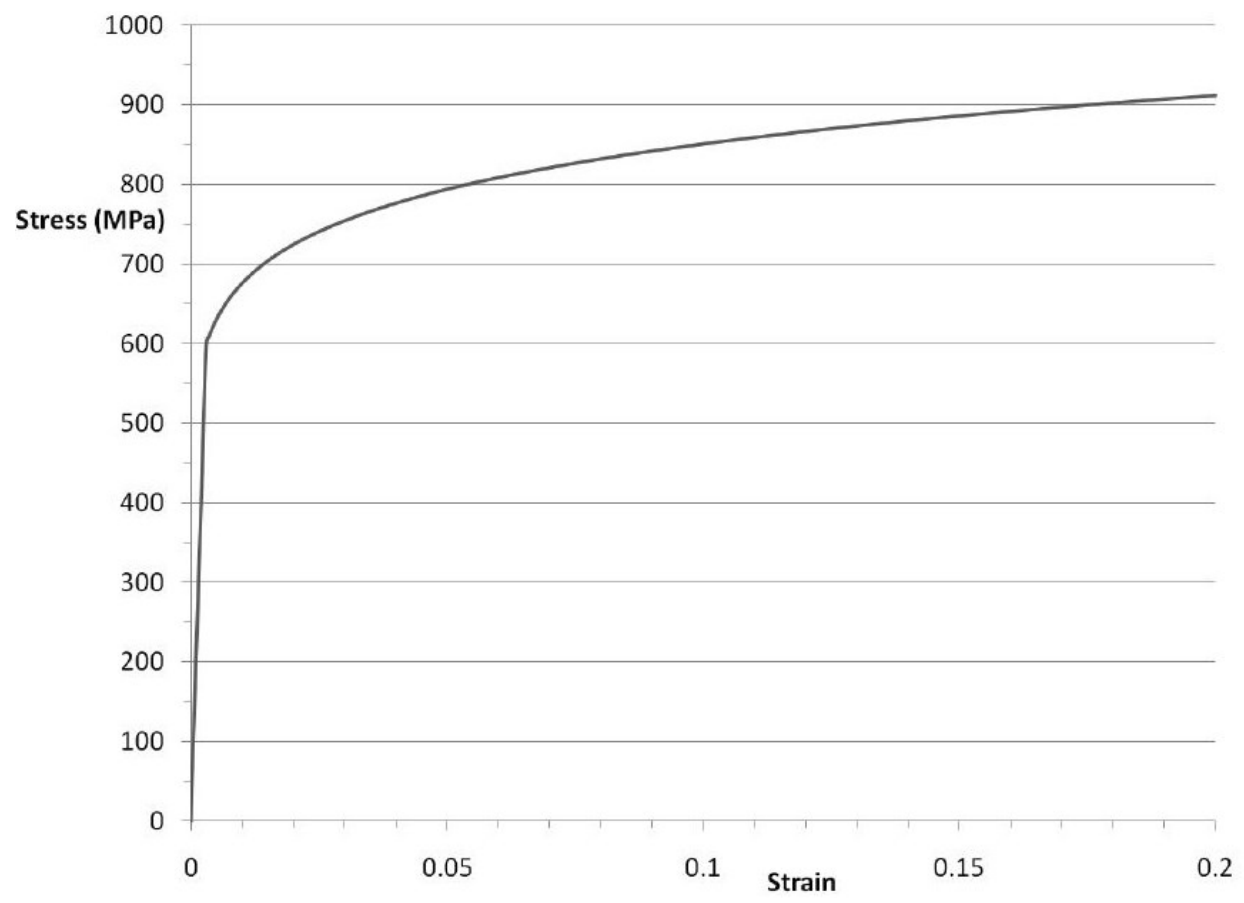

Figure 3.1: True stress-strain curve - TH steel, (Dunbar, 2011)

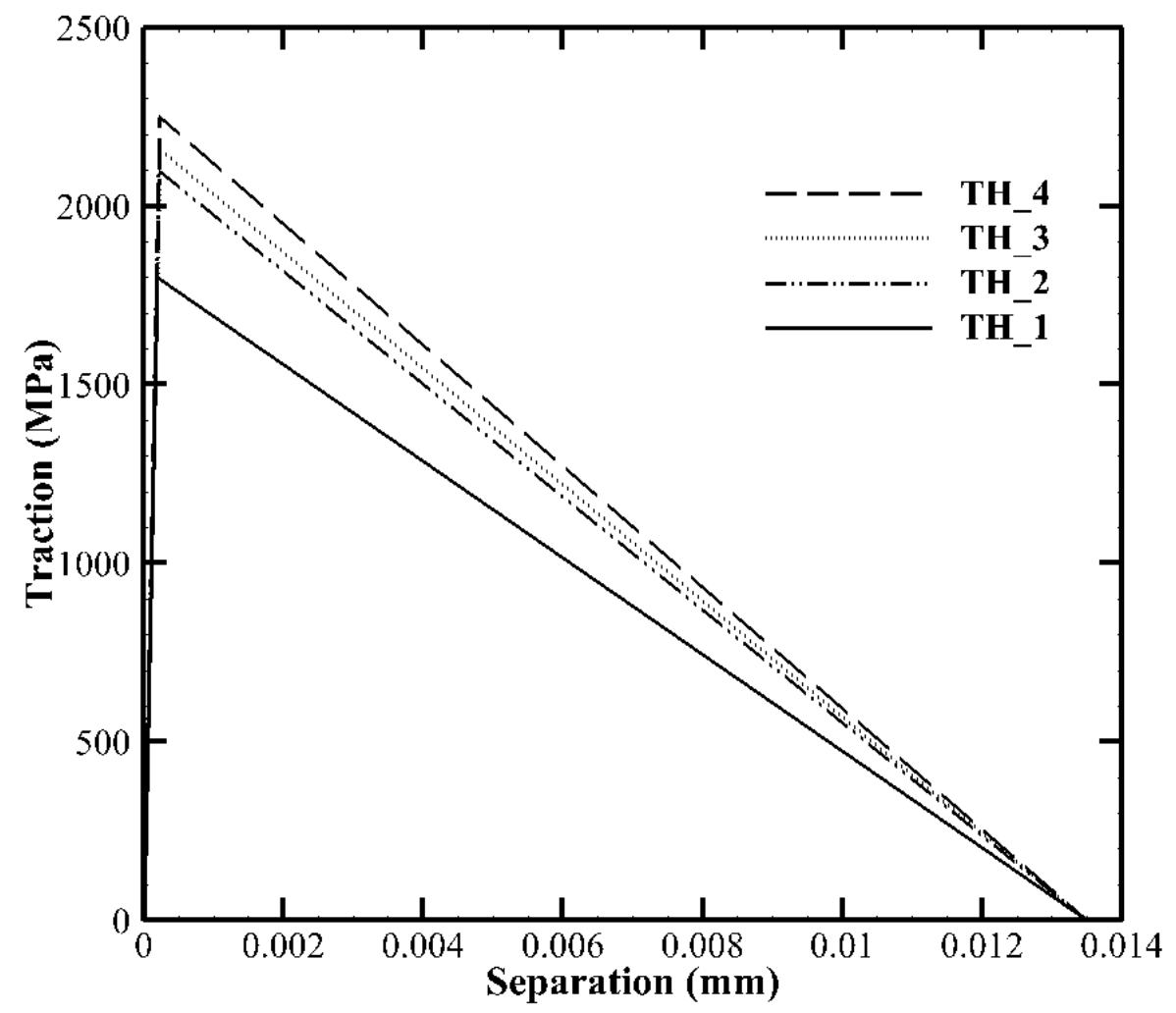

Figure 3.2: Bilinear traction-separation laws - TH steel 


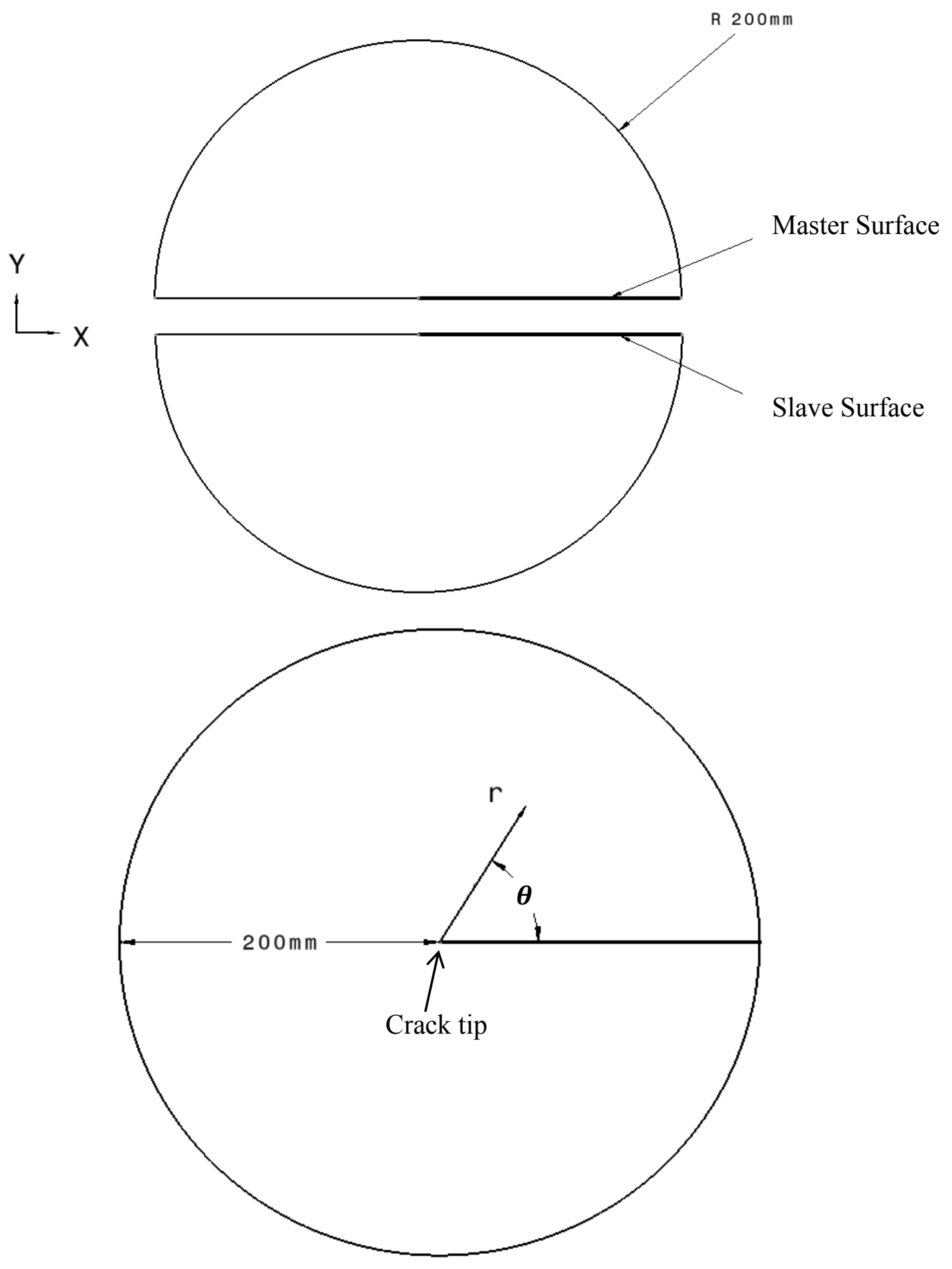

Figure 3.3: Geometry of SSY and MBL model -TH steel 


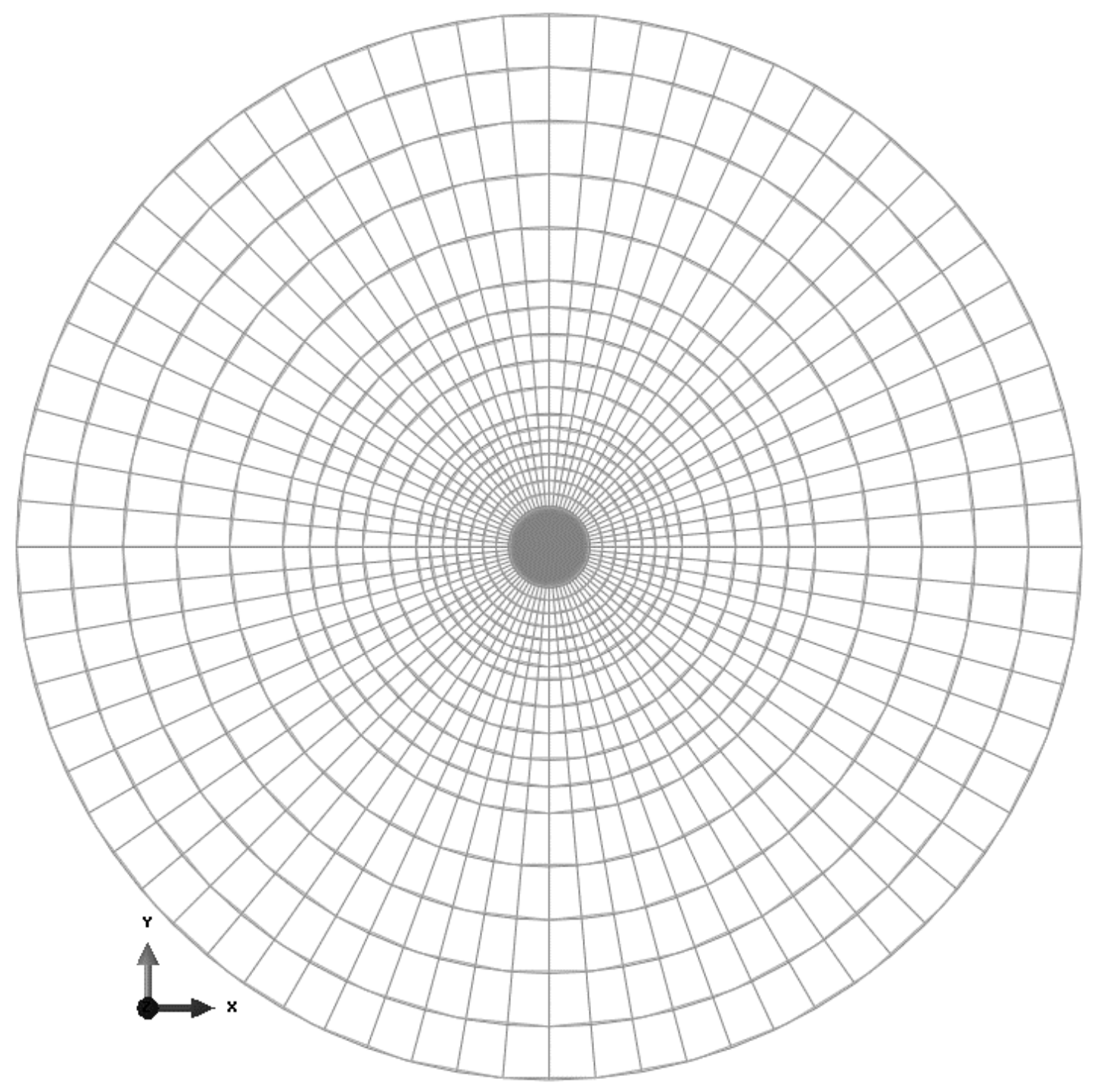

Figure 3.4: Mesh design -SSY and MBL model - TH steel 

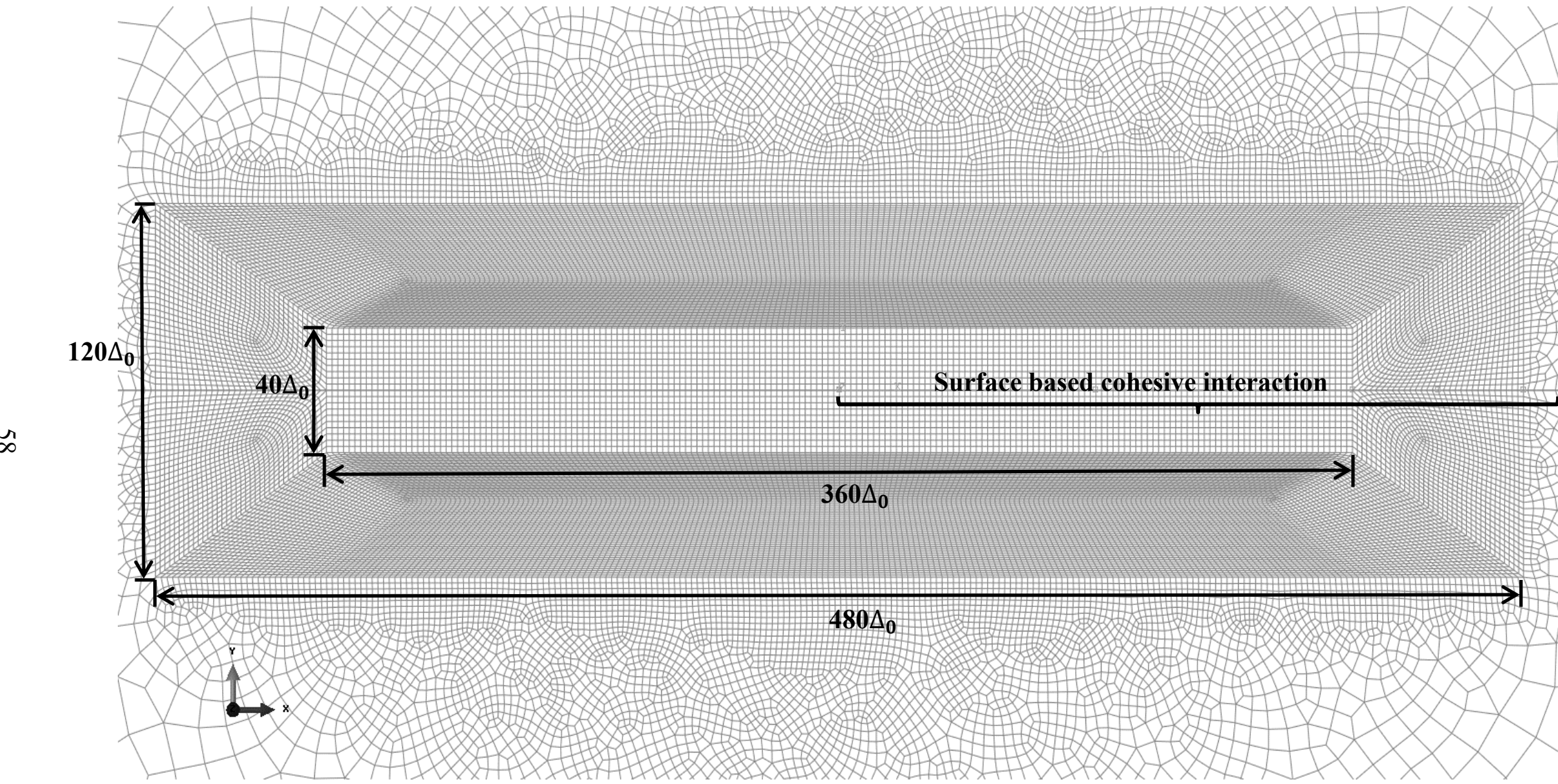

Figure 3.5: Mesh design near crack tip - SSY and MBL model - TH steel 


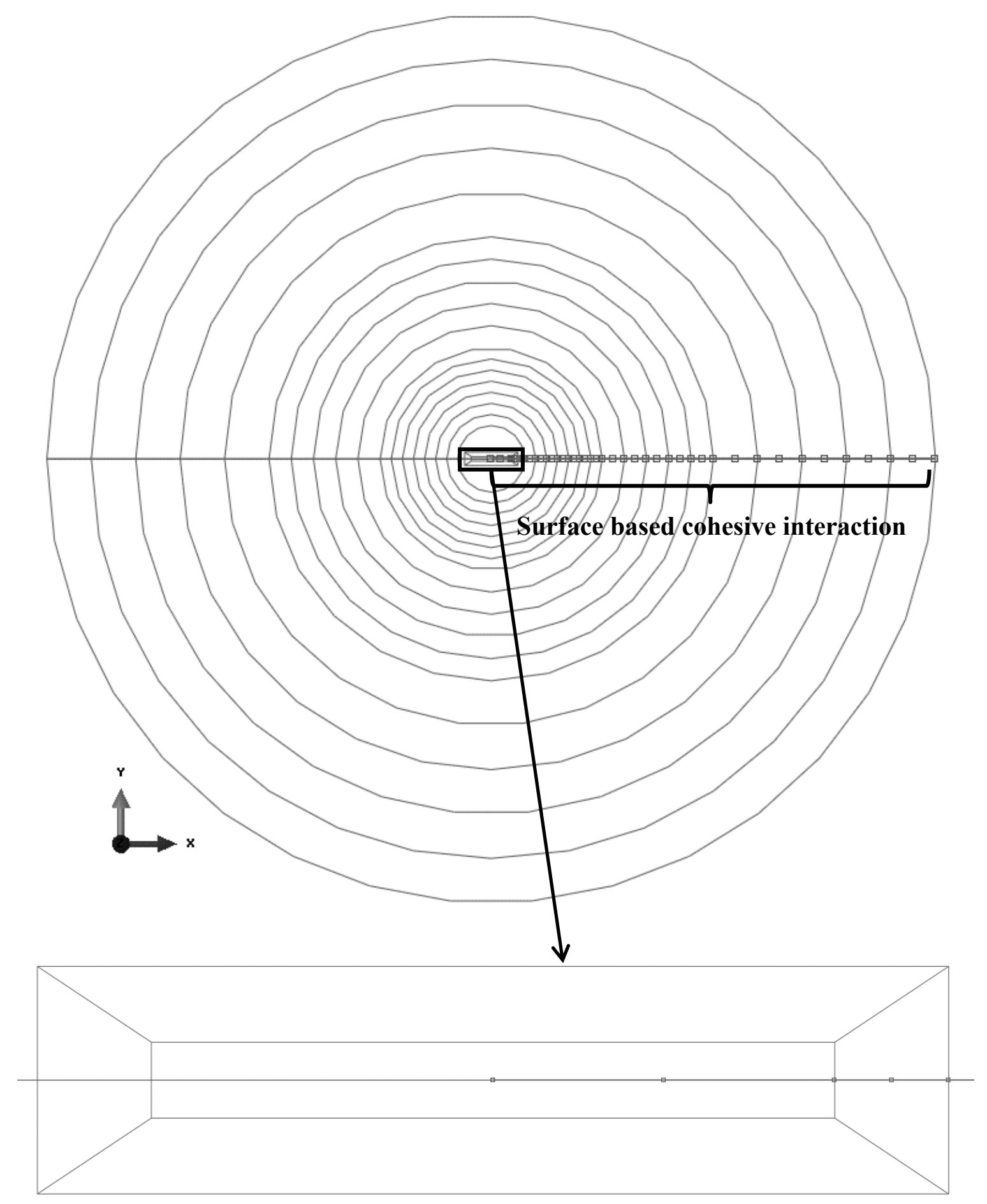

Figure 3.6: Contact interaction - surface based cohesive behavior-SSY and MBL modelTH steel 


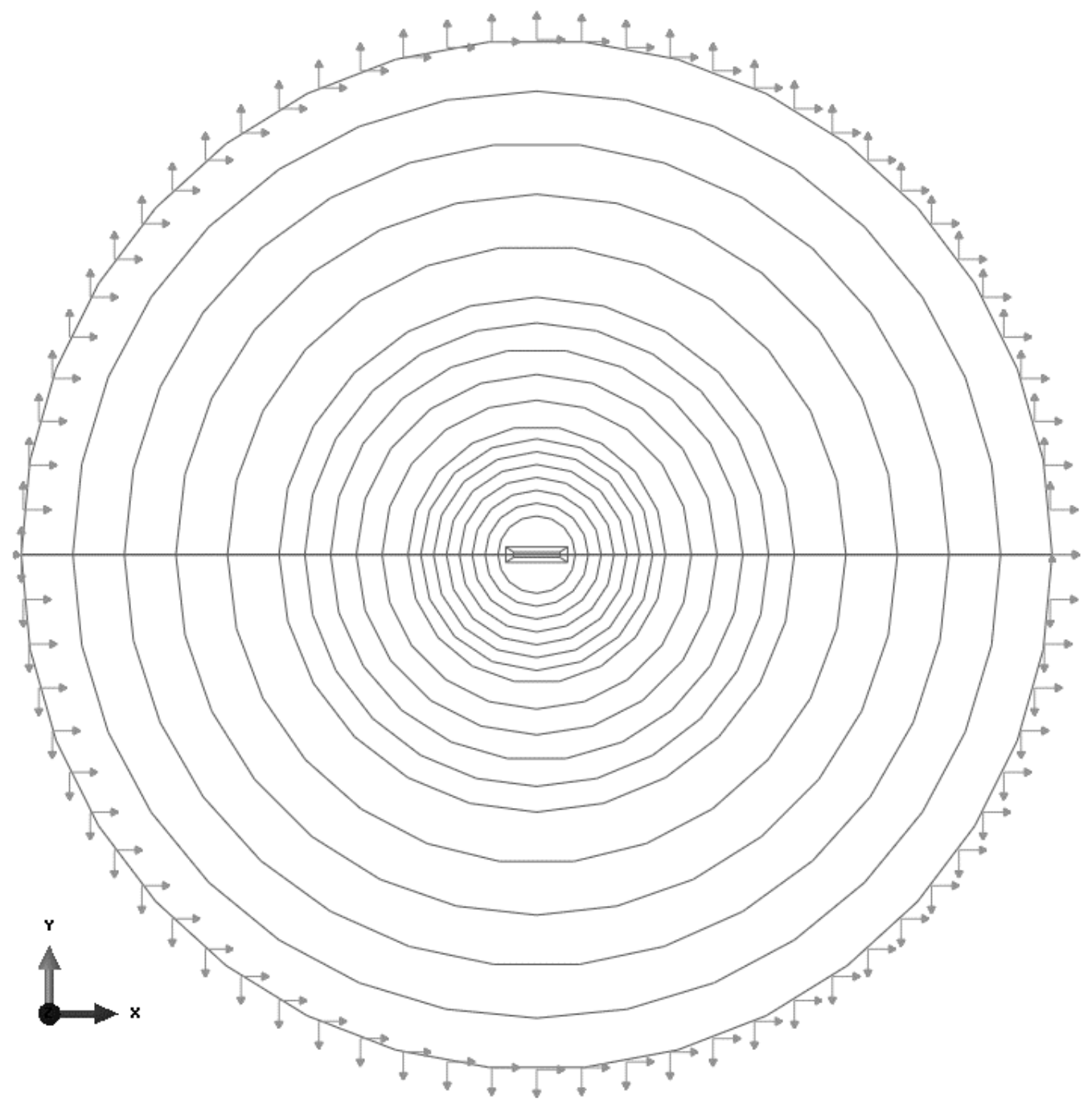

Figure 3.7: Loading conditions- SSY and MBL model-TH steel 


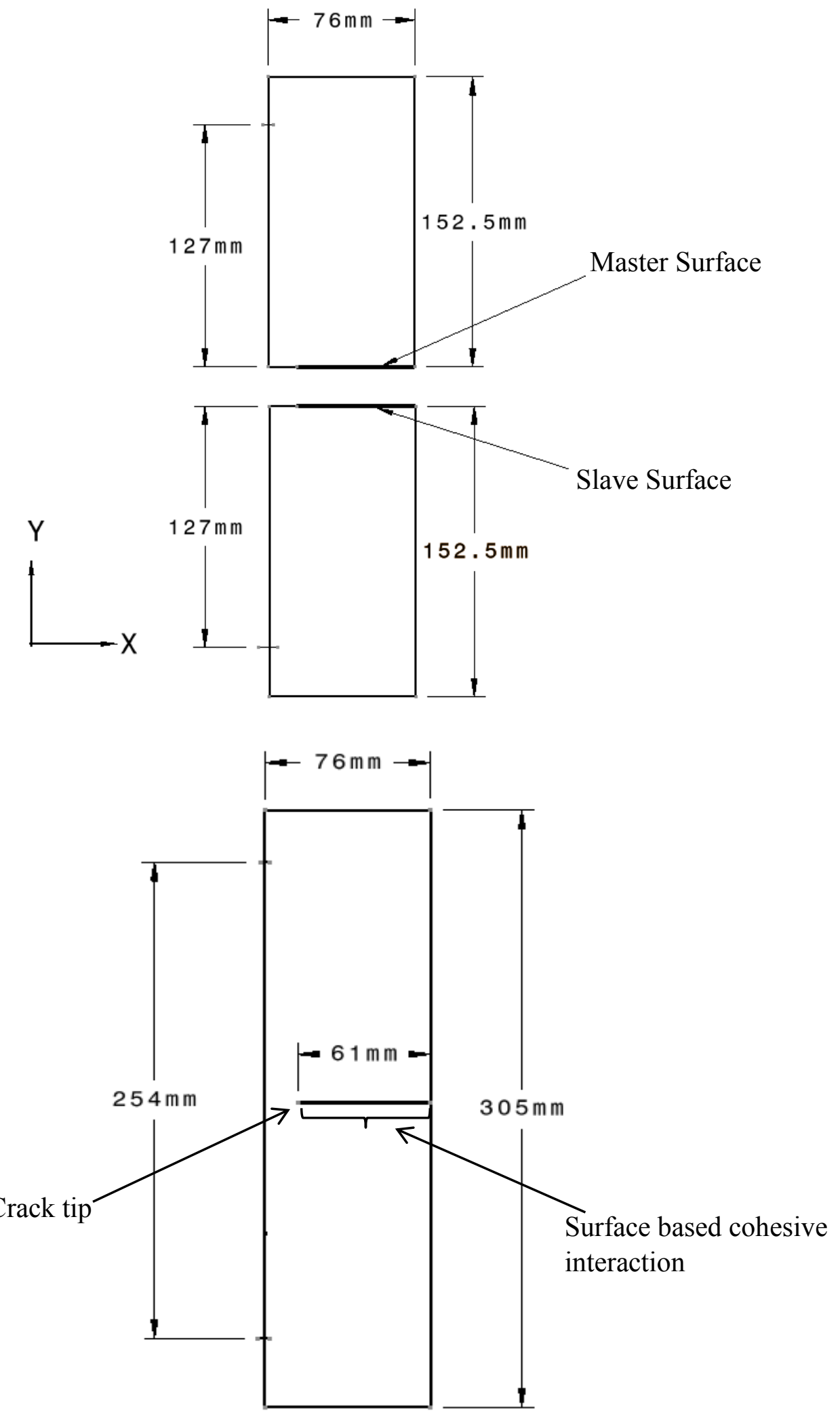

Figure 3.8: Geometry of DWTT specimen - TH steel 


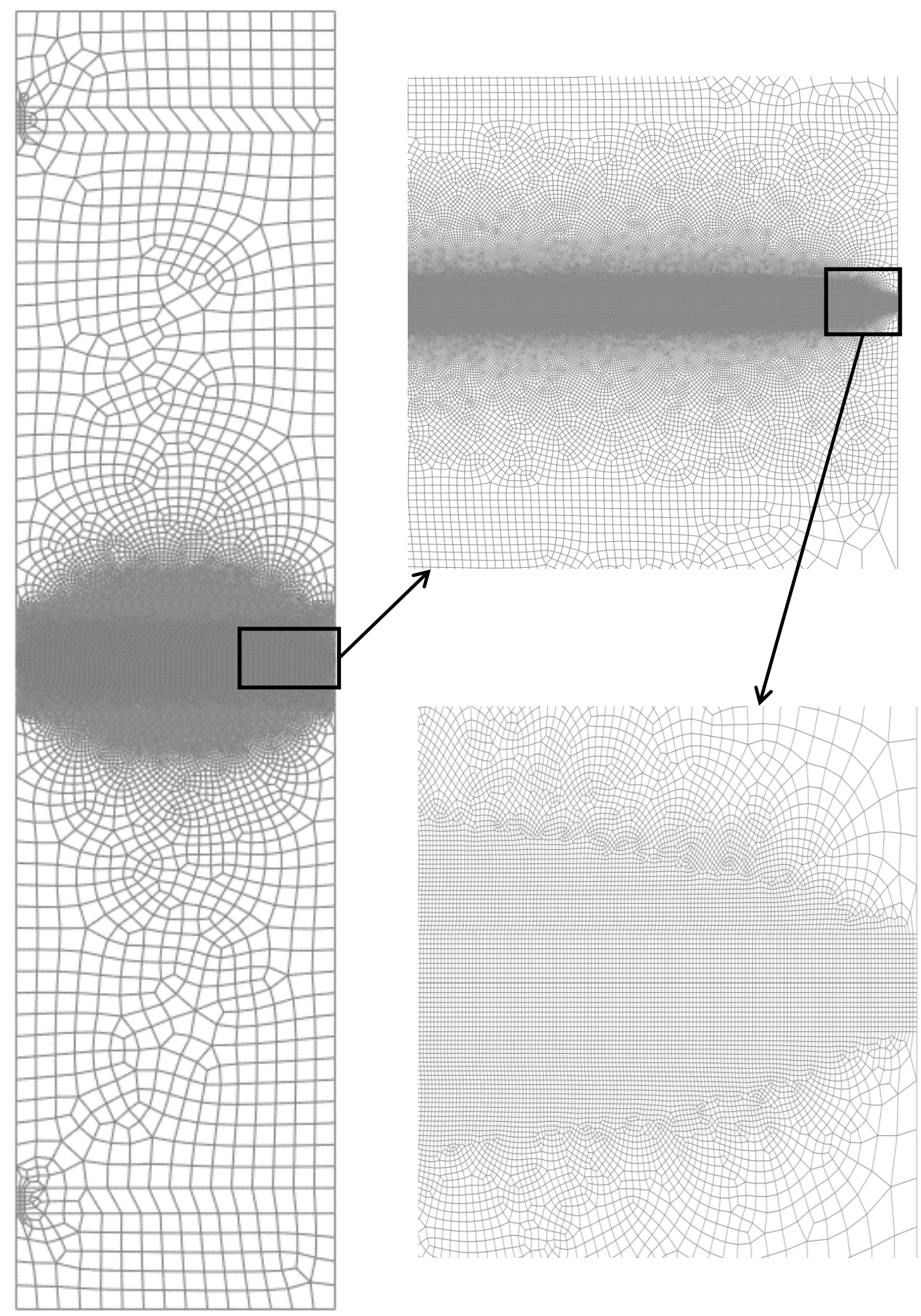

Figure 3.9: Mesh design of DWTT specimen - TH steel 


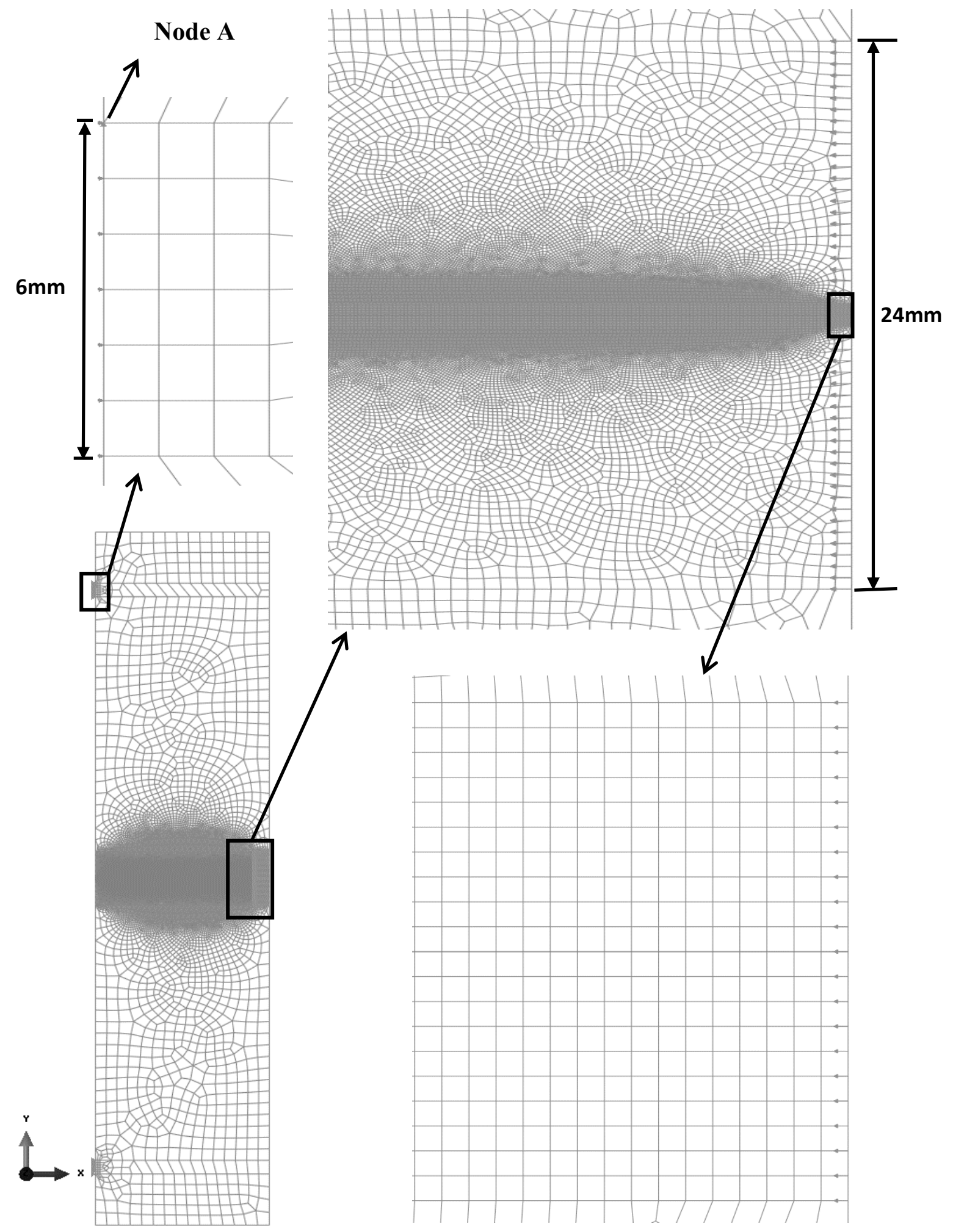

Figure 3.10: Loading conditions of DWTT specimen - TH Steel 


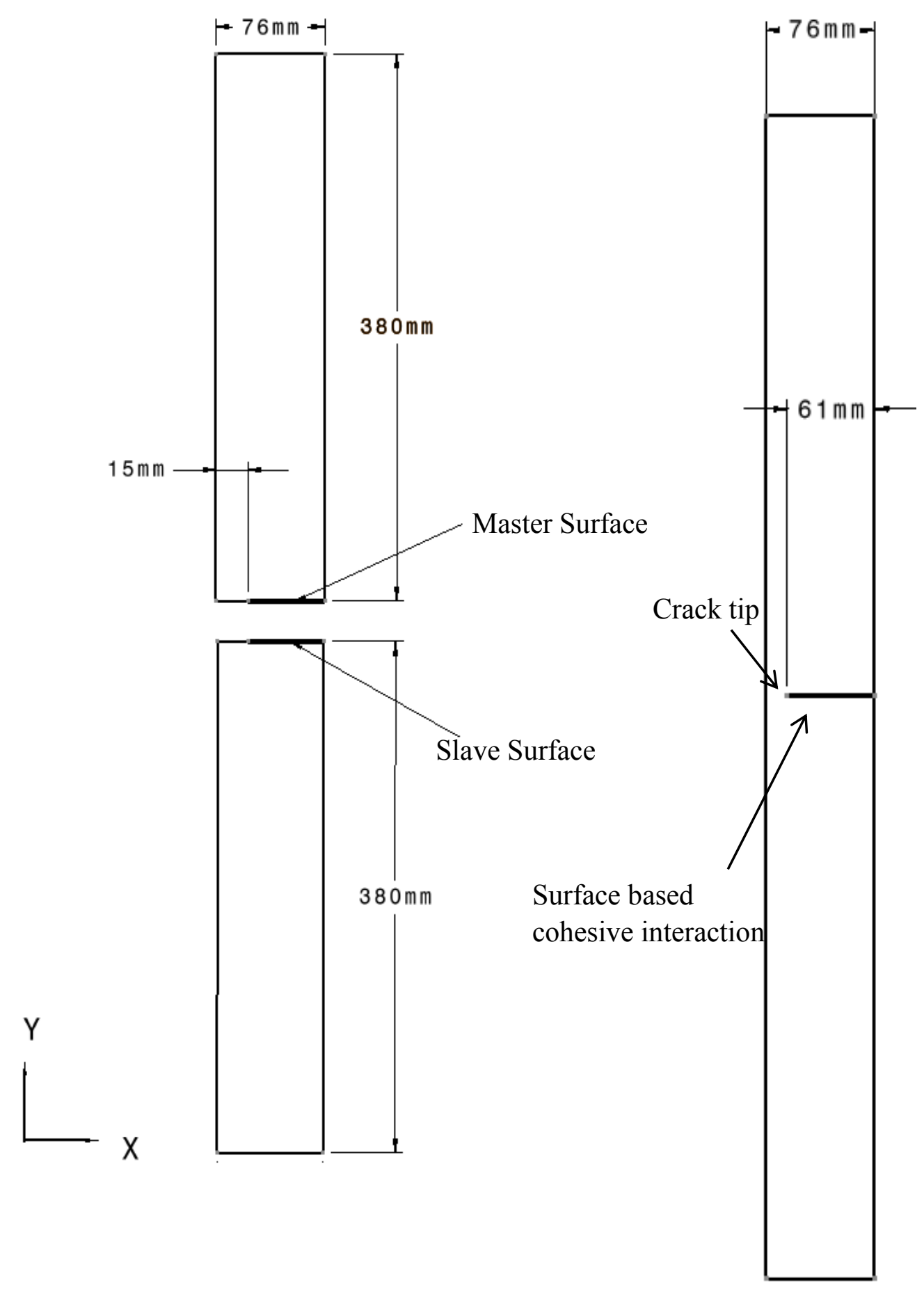

Figure 3.11: Geometry of single edge notched specimen in tension (SENT) - TH Steel 


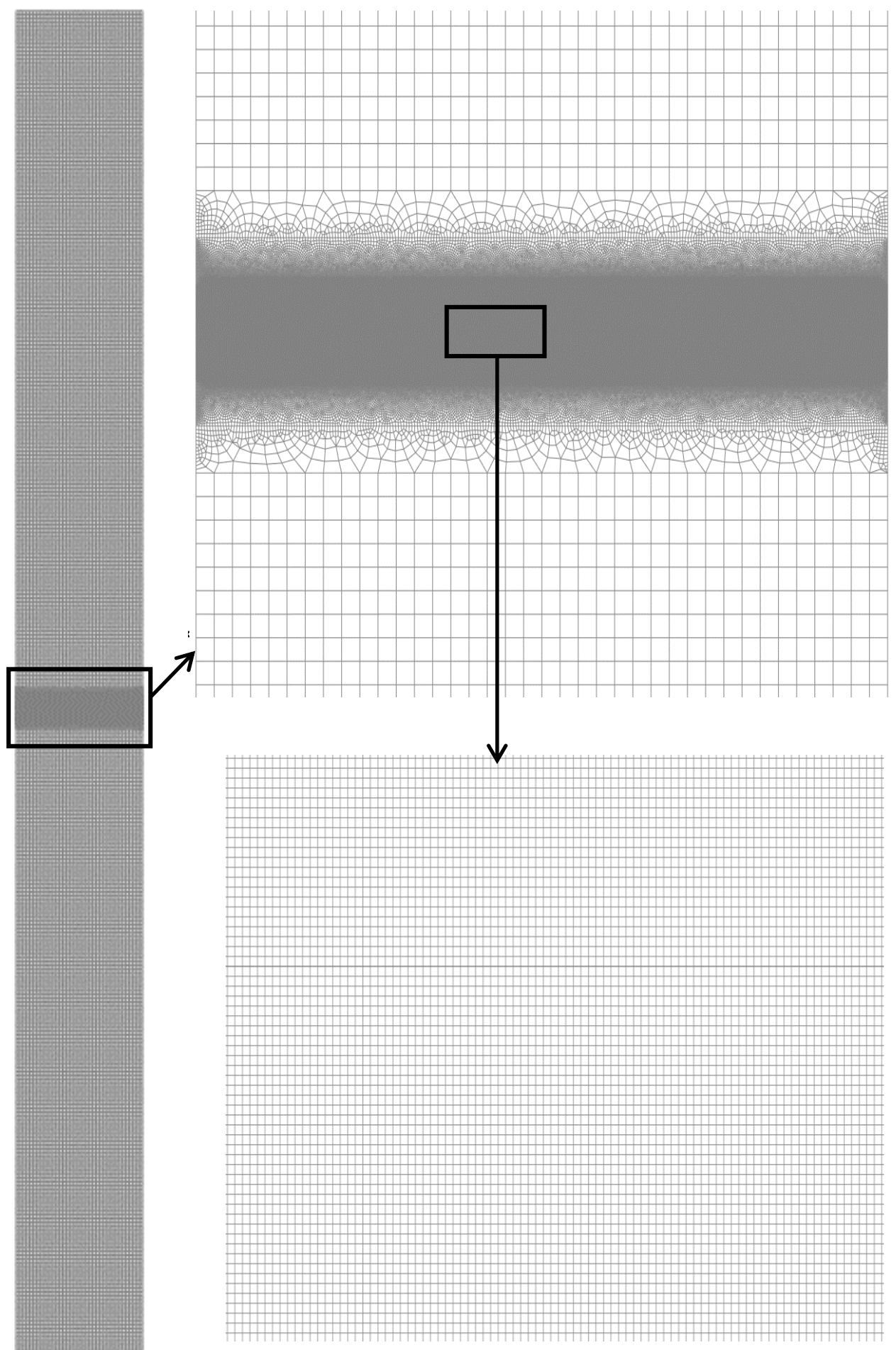

Figure 3.12: Mesh design of SENT- TH steel 


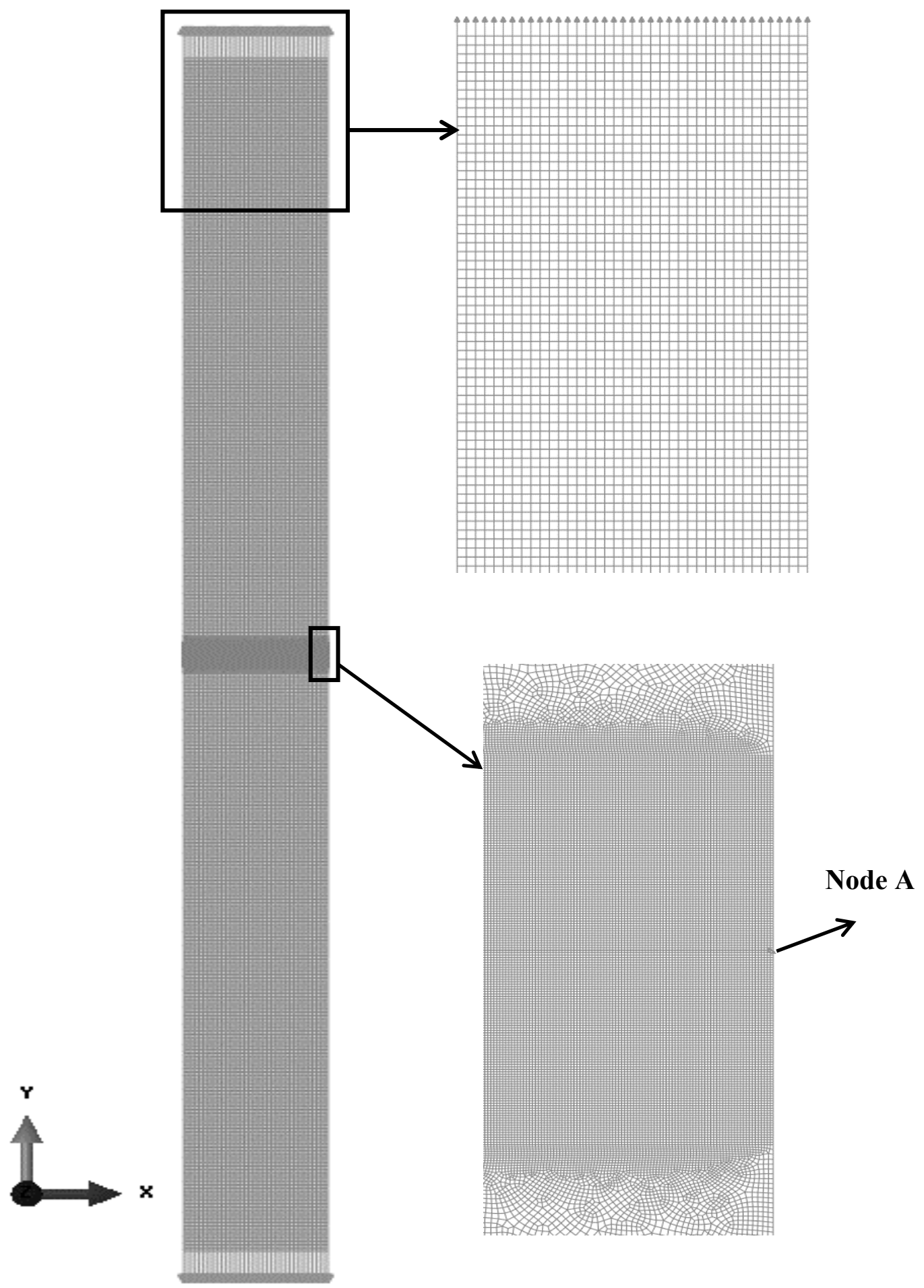

Figure 3.13: Loading conditions of SENT - TH steel 


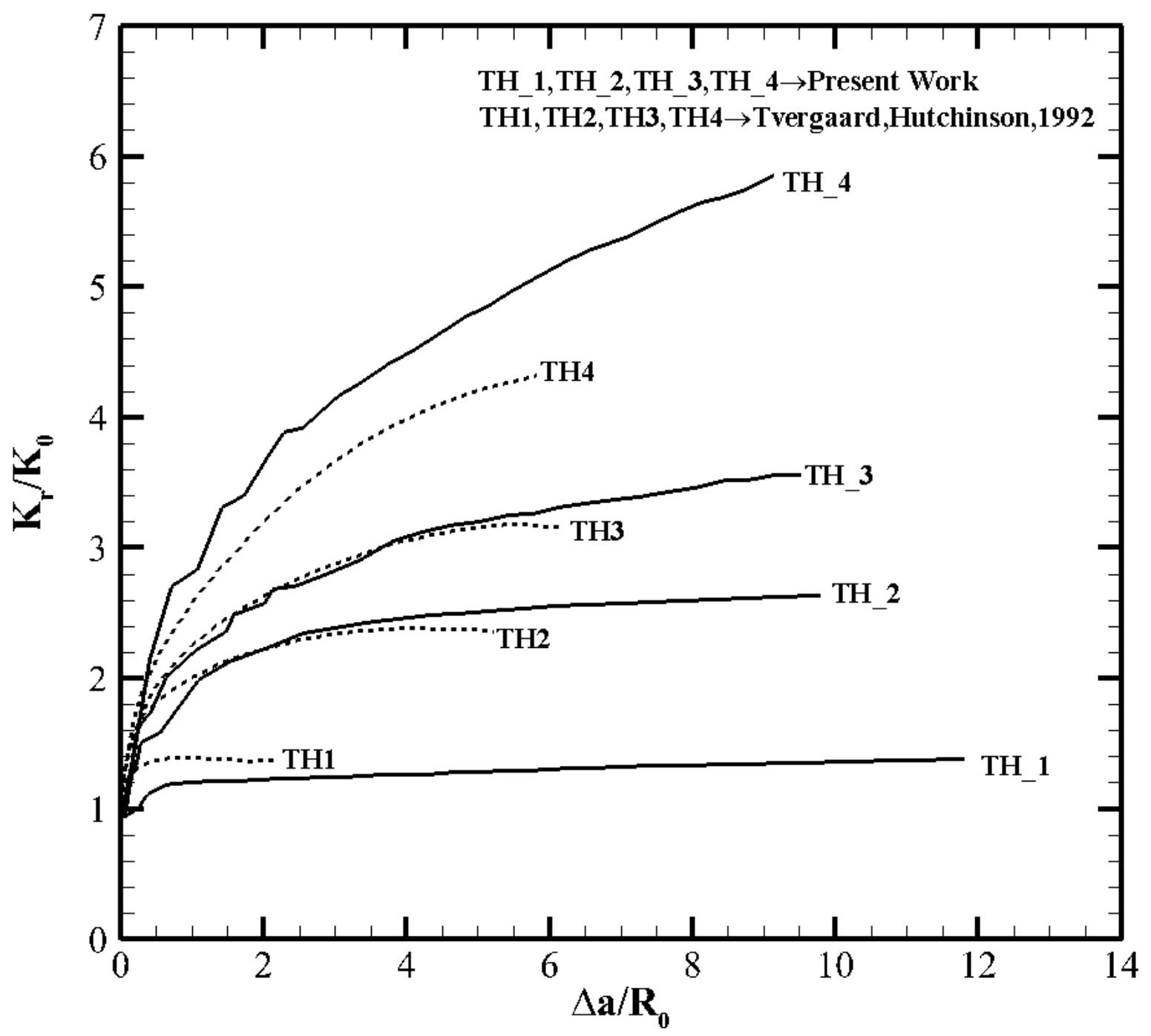

Figure 3.14: Normalized resistance curves of SSY models - TH steel 


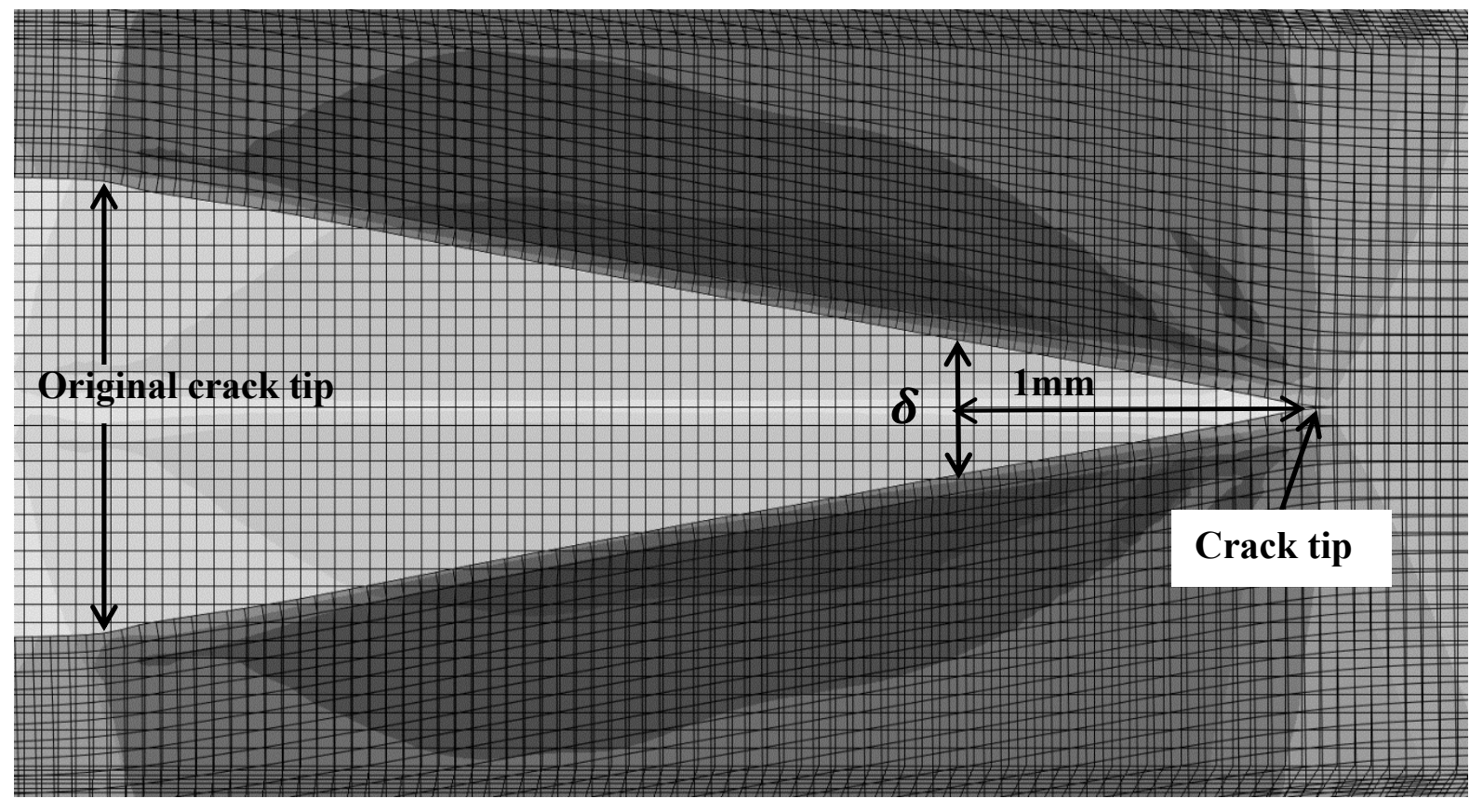

Figure 3.15: Measuring CTOA from FE results

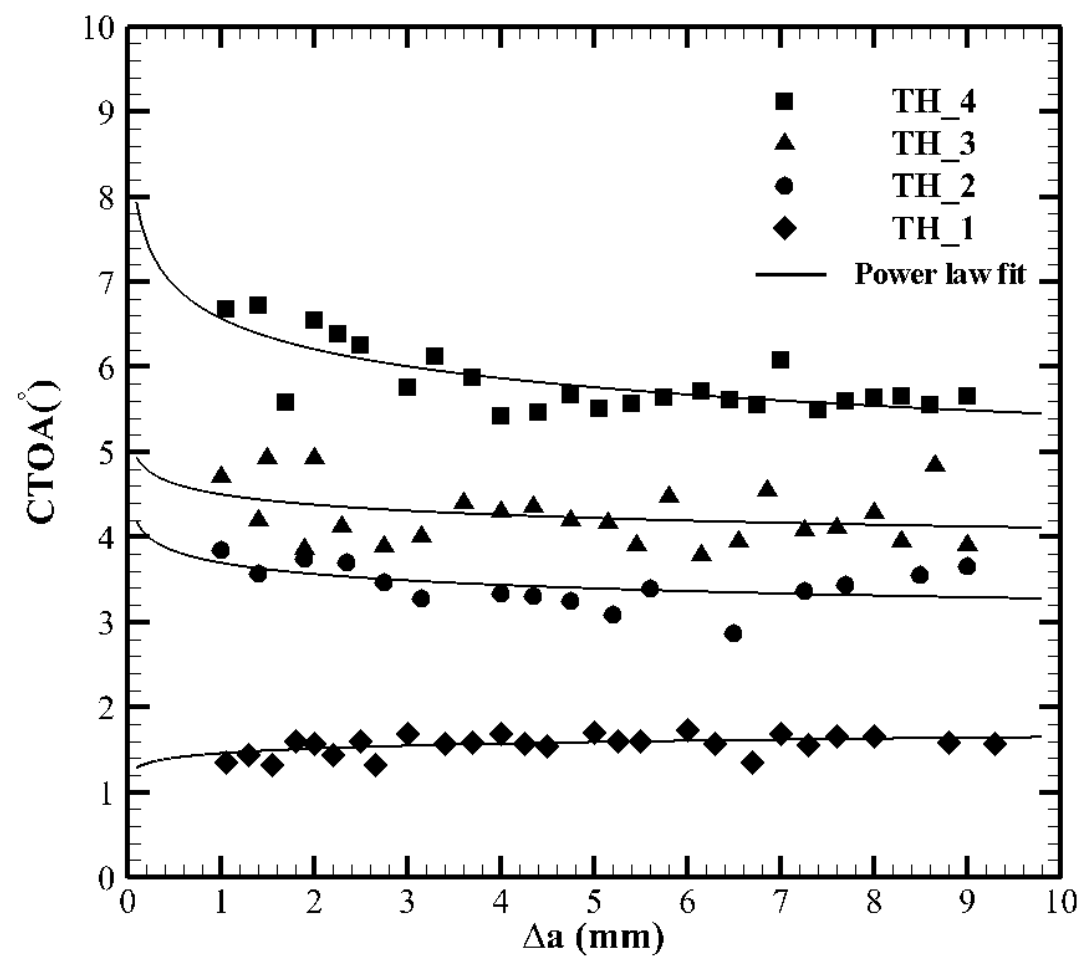

Figure 3.16: CTOA data- SSY model- TH steel 


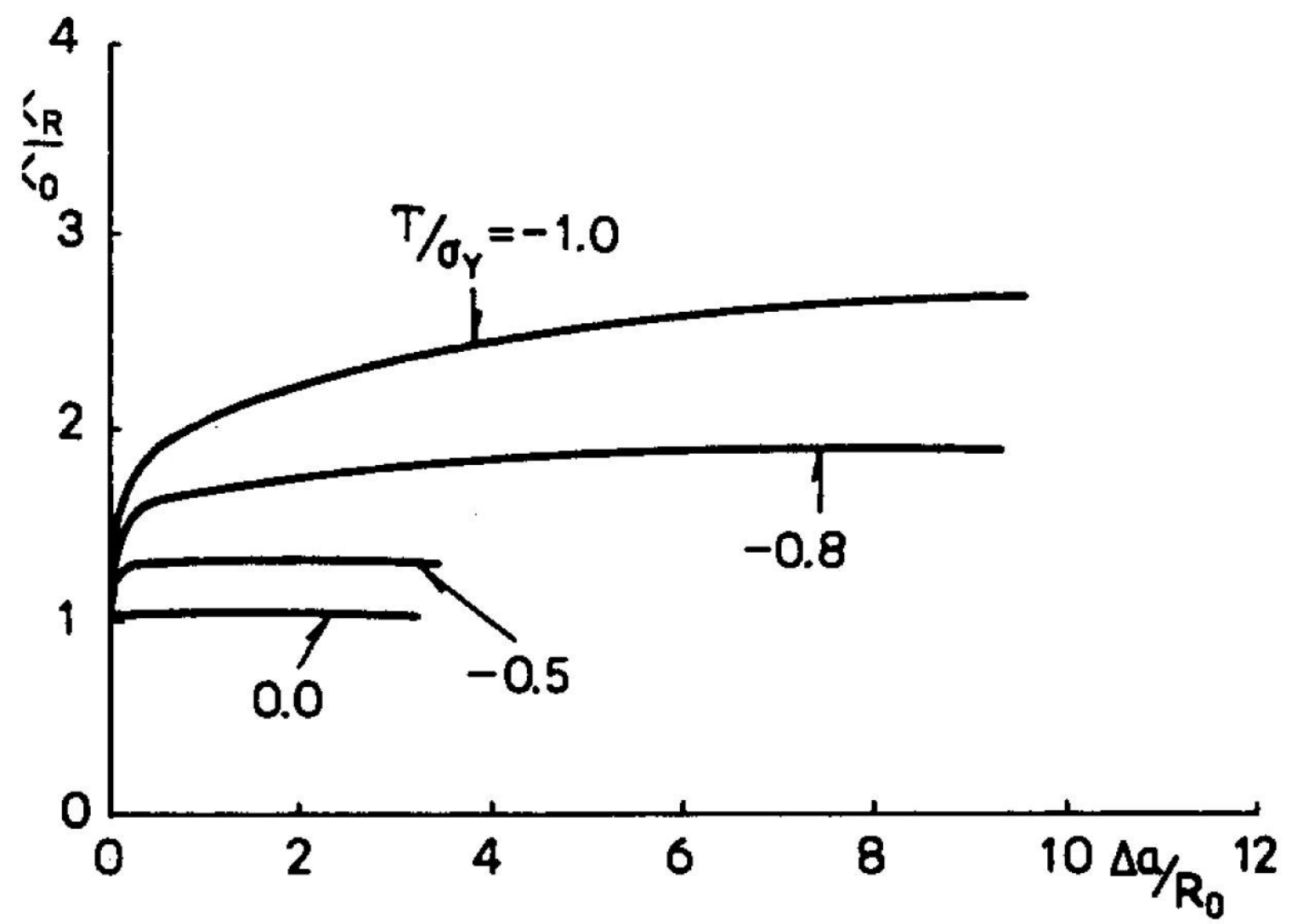

Figure 3.17: Normalized resistance curves - MBL model ( $\widehat{\sigma} / \sigma_{\mathrm{y}}=2.4, \sigma_{\mathrm{y}} / \mathrm{E}=0.003$ and $\mathrm{N}=0.1$ ), (Tvergaard \& Hutchinson, 1994) 


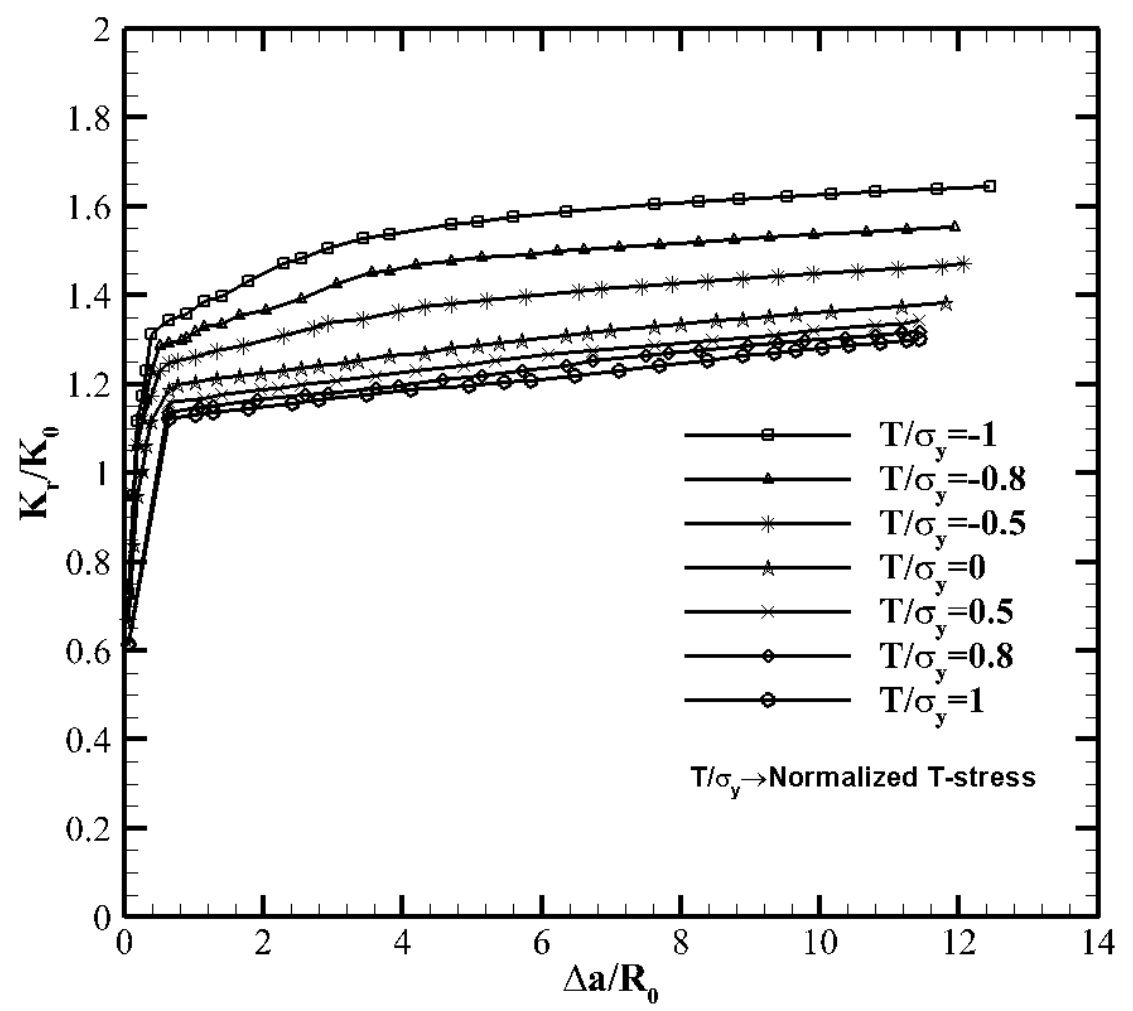

Figure 3.18: Normalized resistance curves - MBL model - TH_1 steel

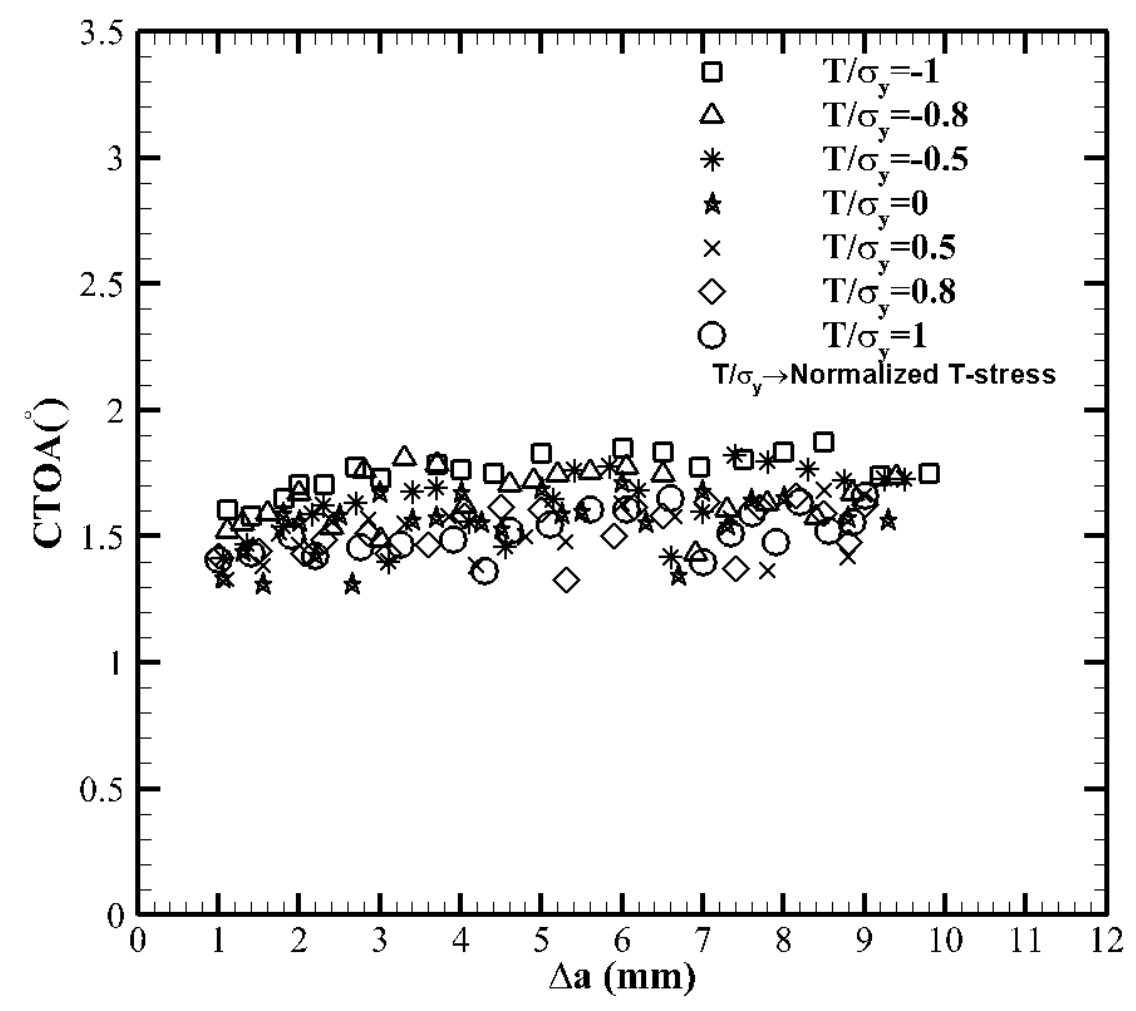

Figure 3.19: CTOA data-MBL model - TH_1 steel 


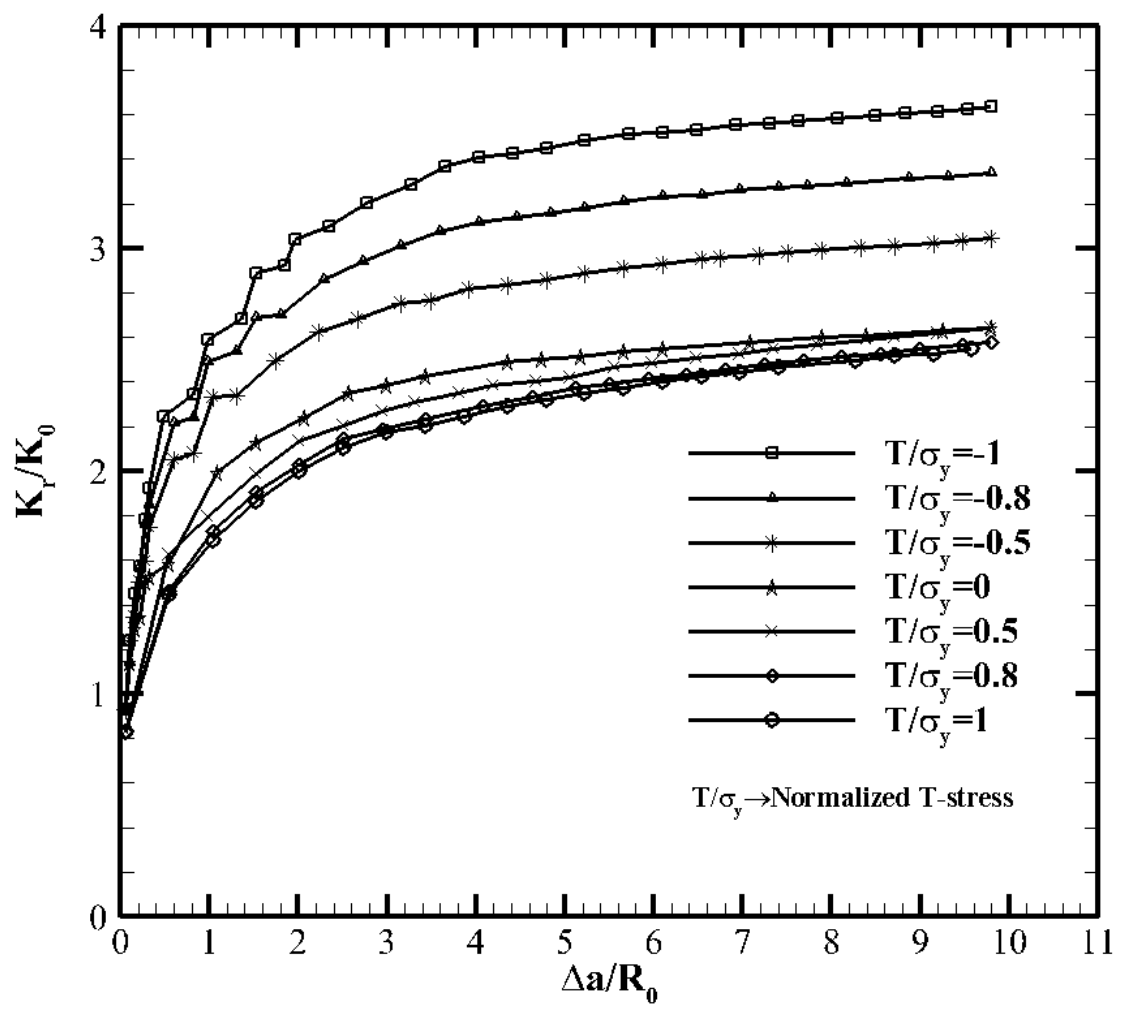

Figure 3.20: Normalized resistance curves -MBL model - TH_2 steel

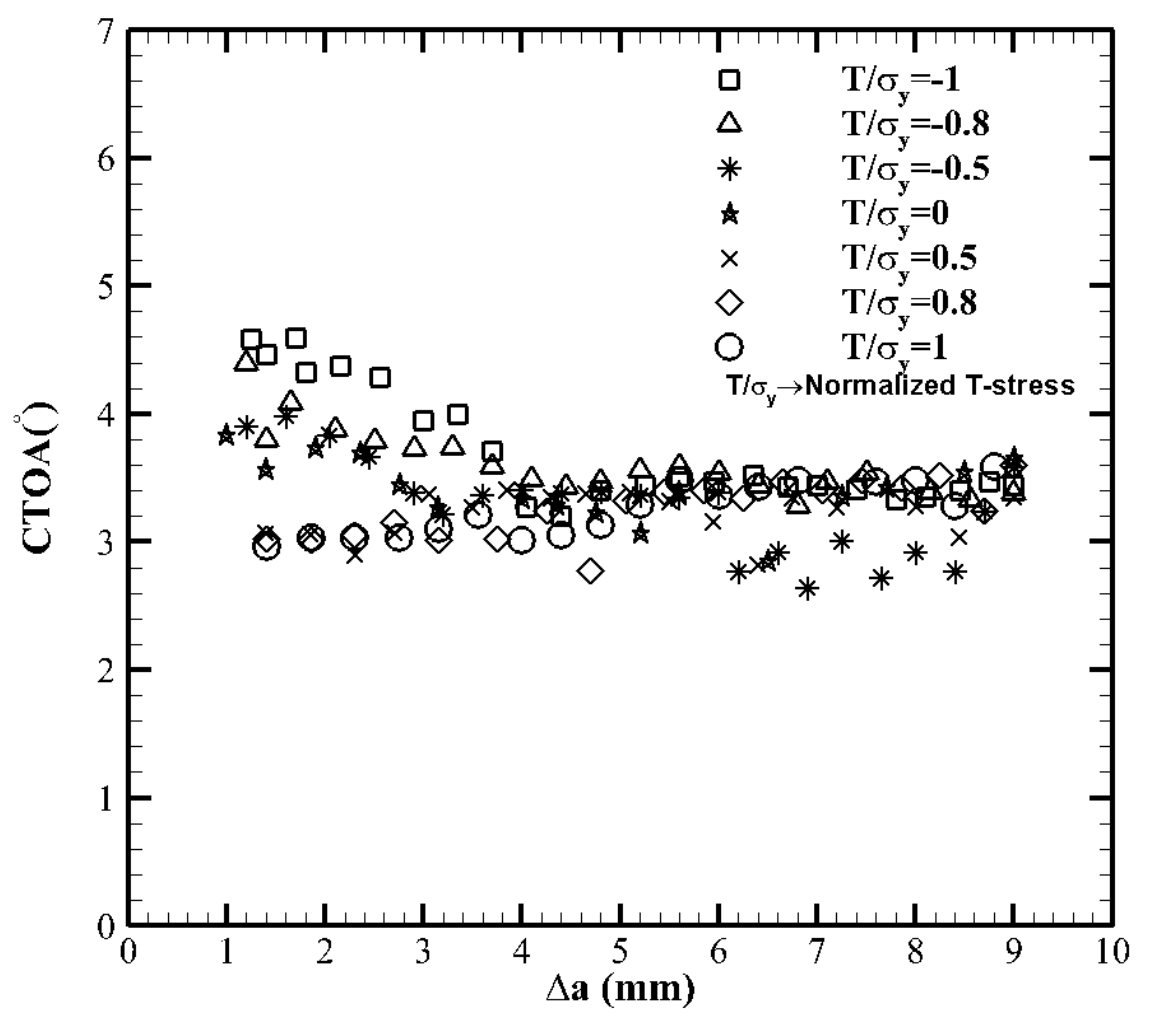

Figure 3.21: CTOA data-MBL model - TH_2 steel 


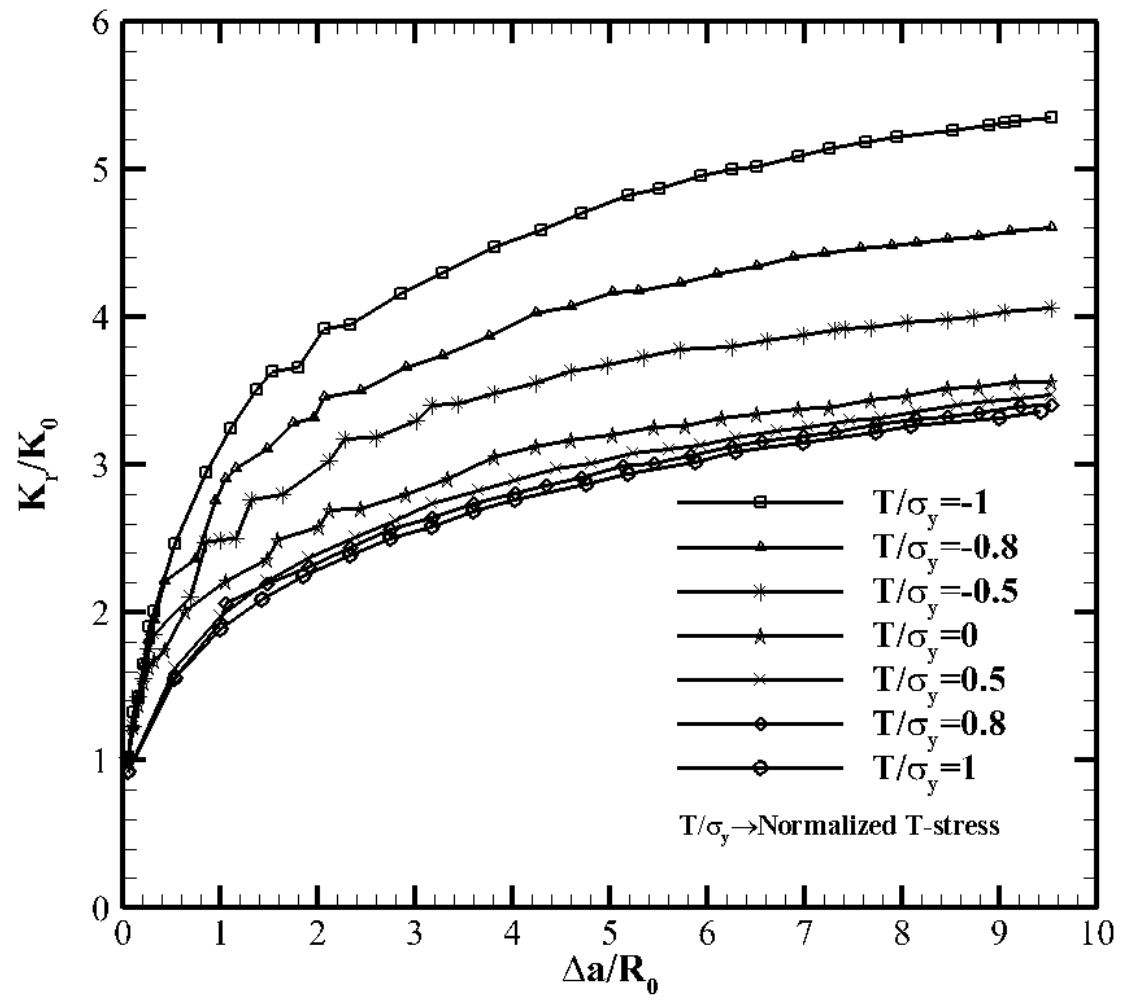

Figure 3.22: Normalized resistance curves $-\mathrm{MBL}$ model $-\mathrm{TH} \_3$ steel

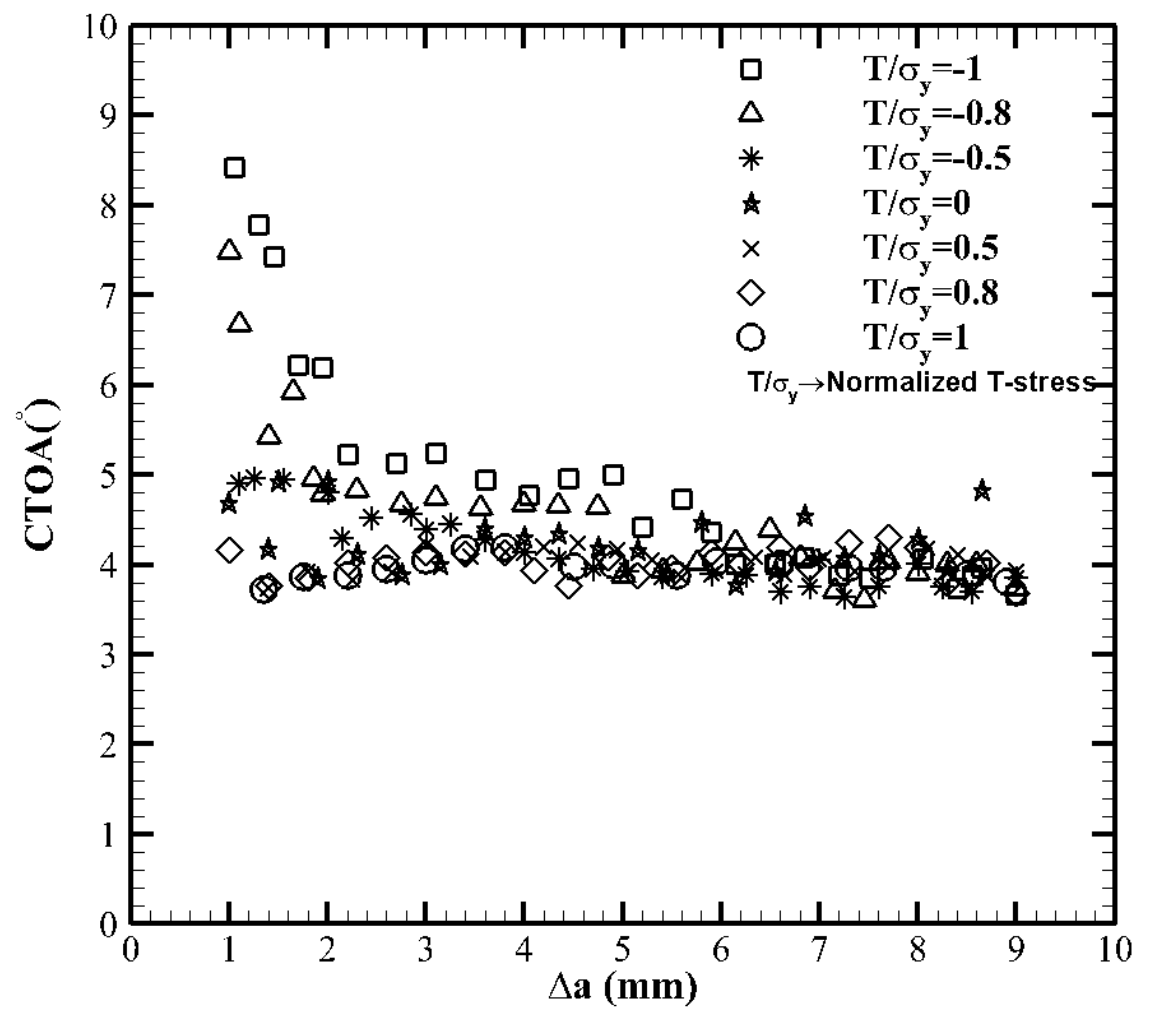

Figure 3.23: CTOA data-MBL model - TH_3 steel 


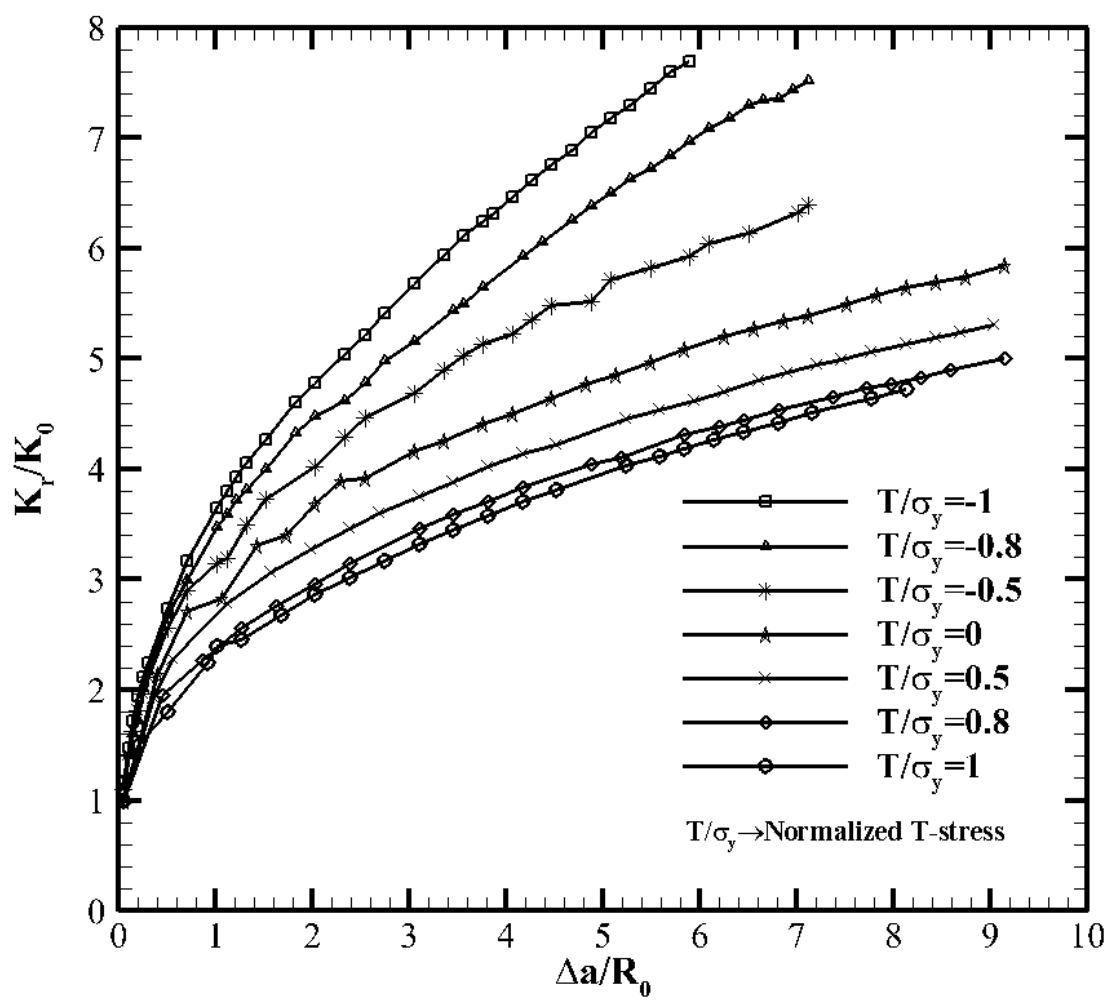

Figure 3.24: Normalized resistance curves $-\mathrm{MBL}$ model $-\mathrm{TH} 44$ steel

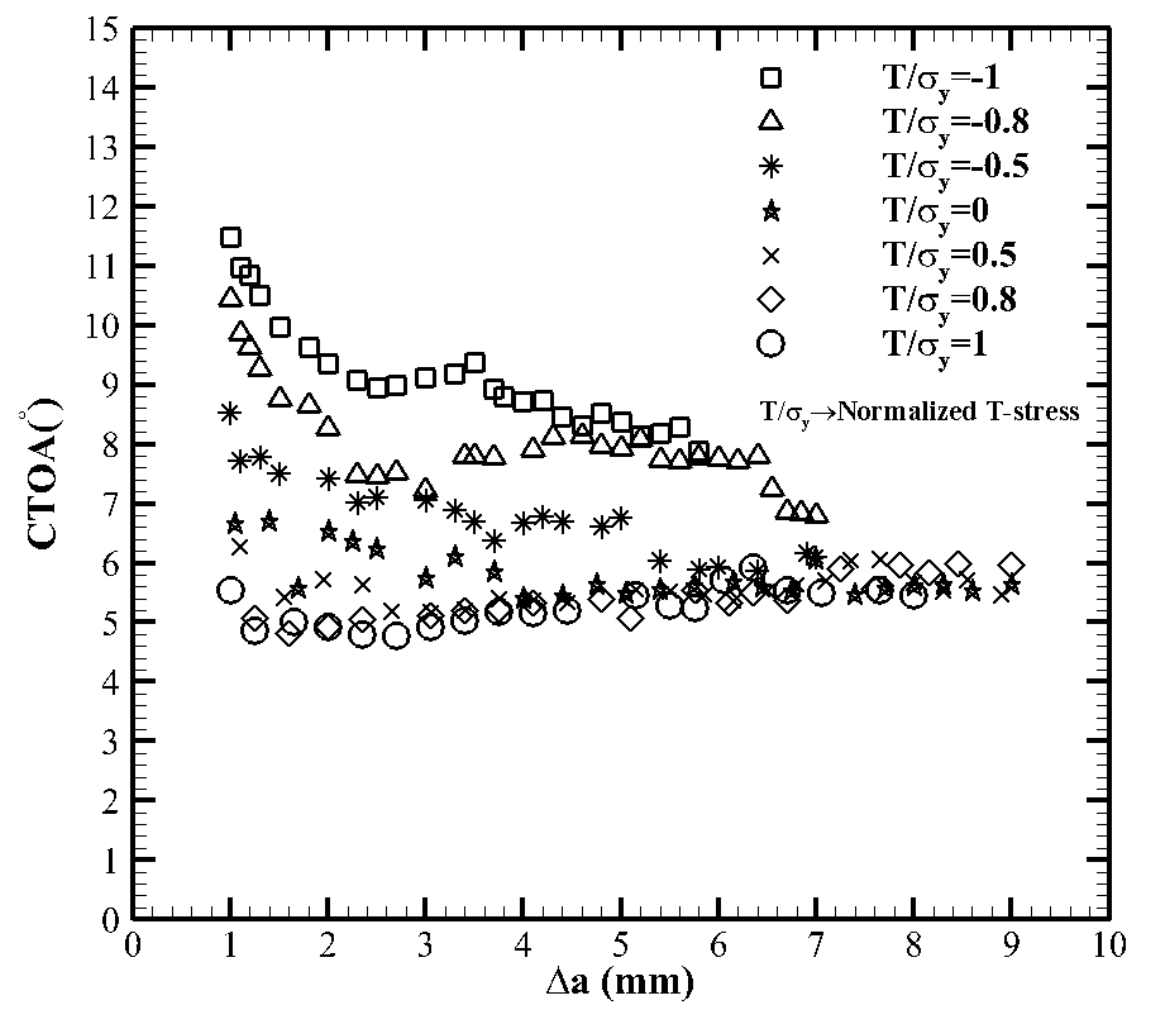

Figure 3.25: CTOA data-MBL model - TH_4 steel 


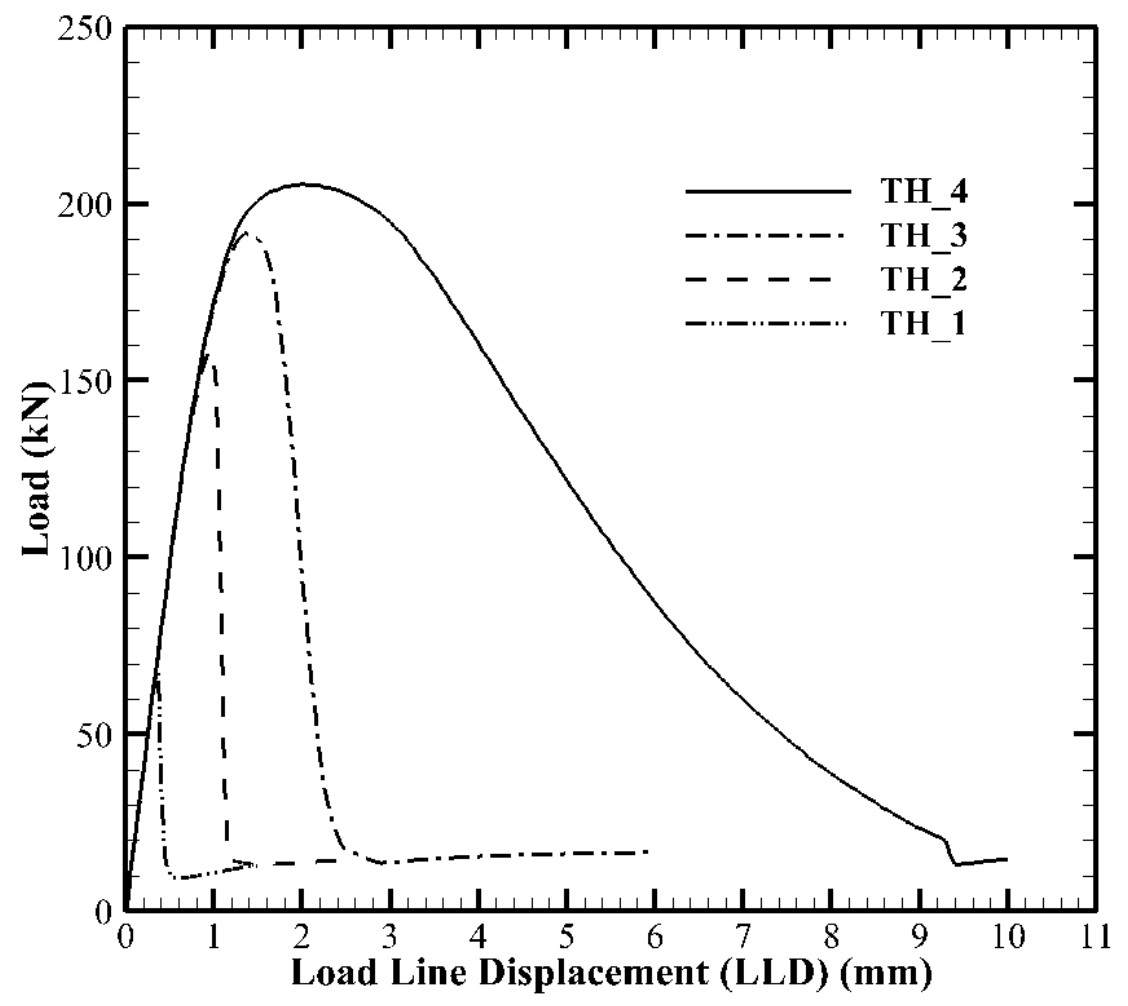

Figure 3.26: Load vs. LLD - DWTT - TH steel

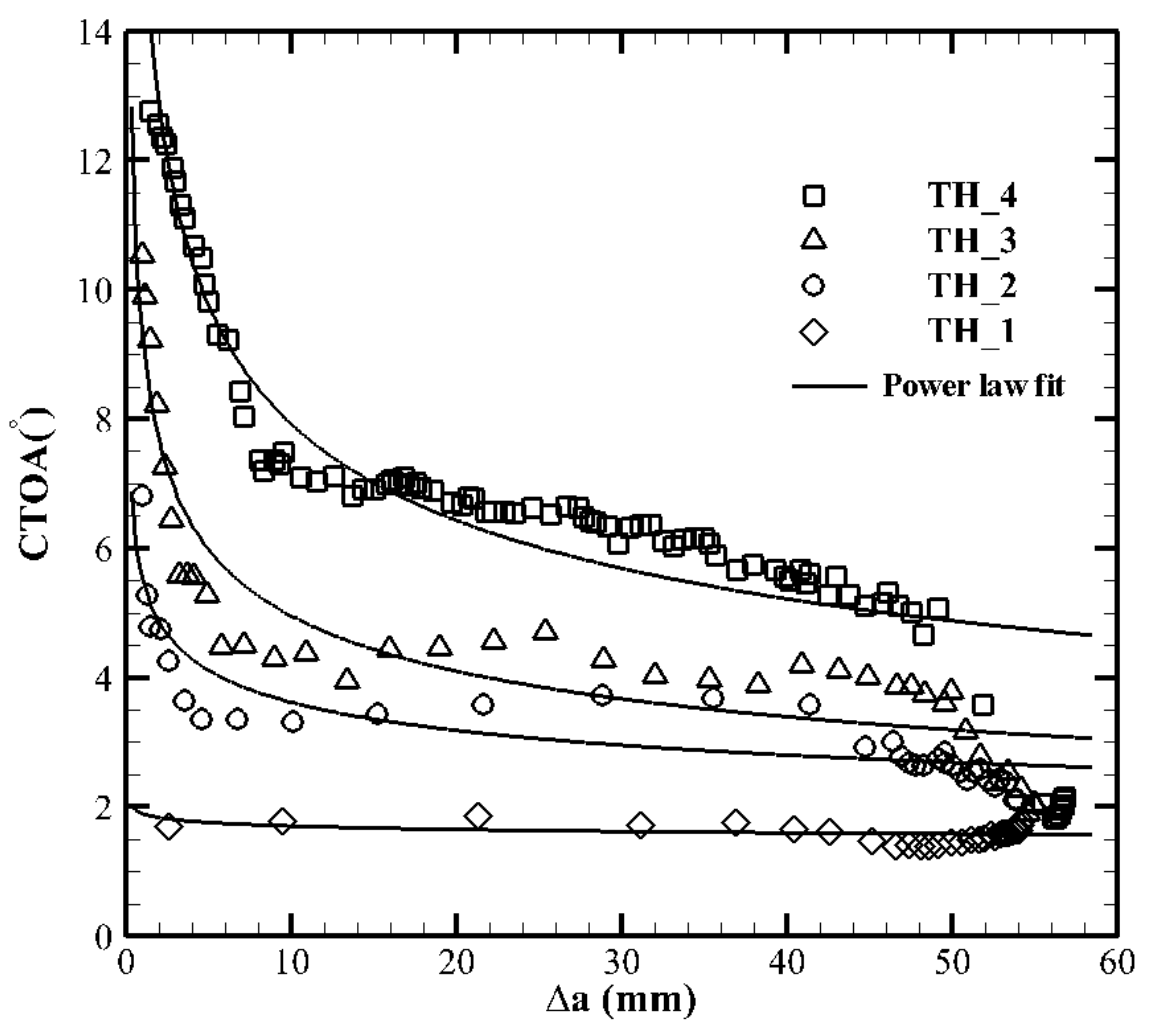

Figure 3.27: CTOA data - DWTT - TH steel 


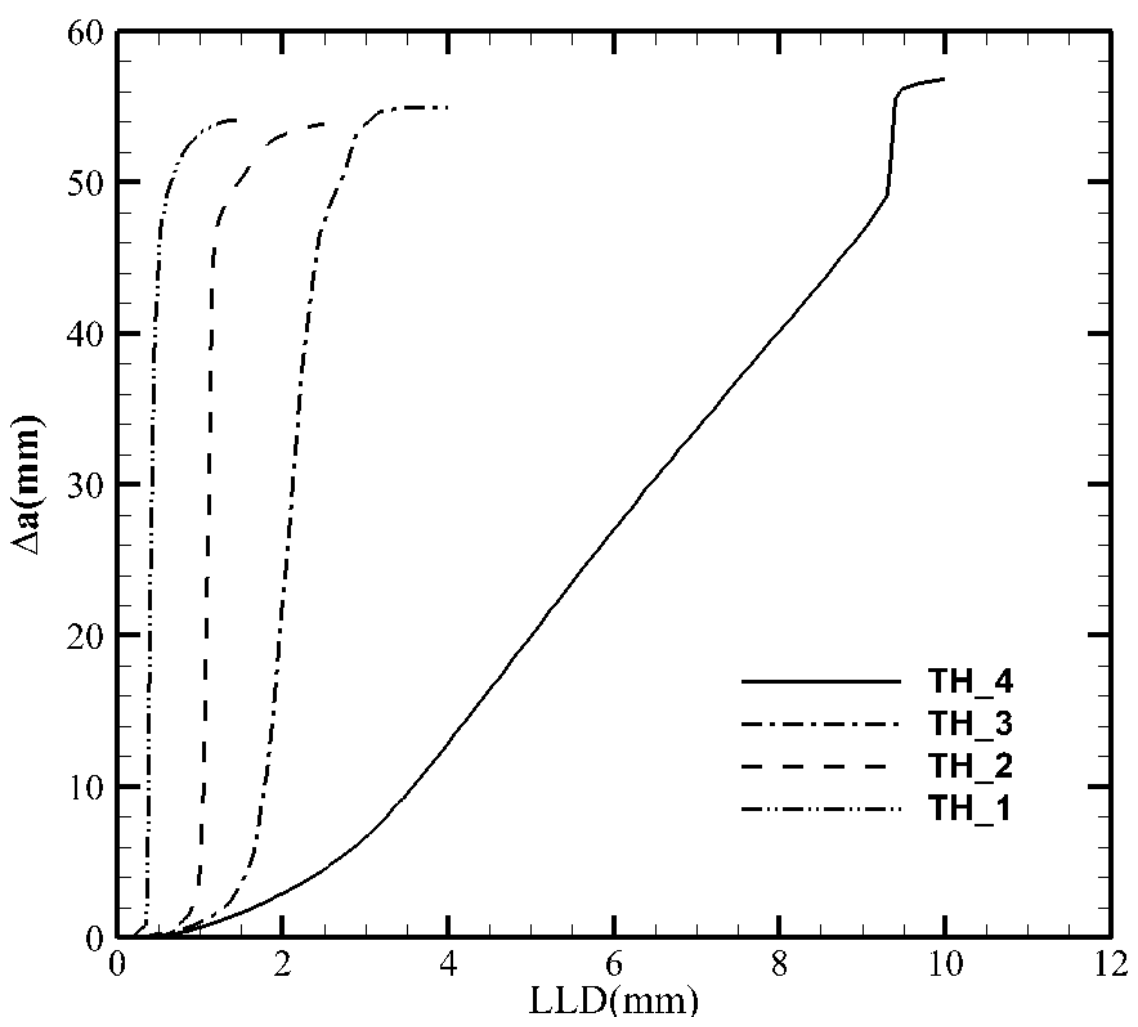

Figure 3.28: $\Delta \mathrm{a}$ vs. LLD - DWTT- TH steel

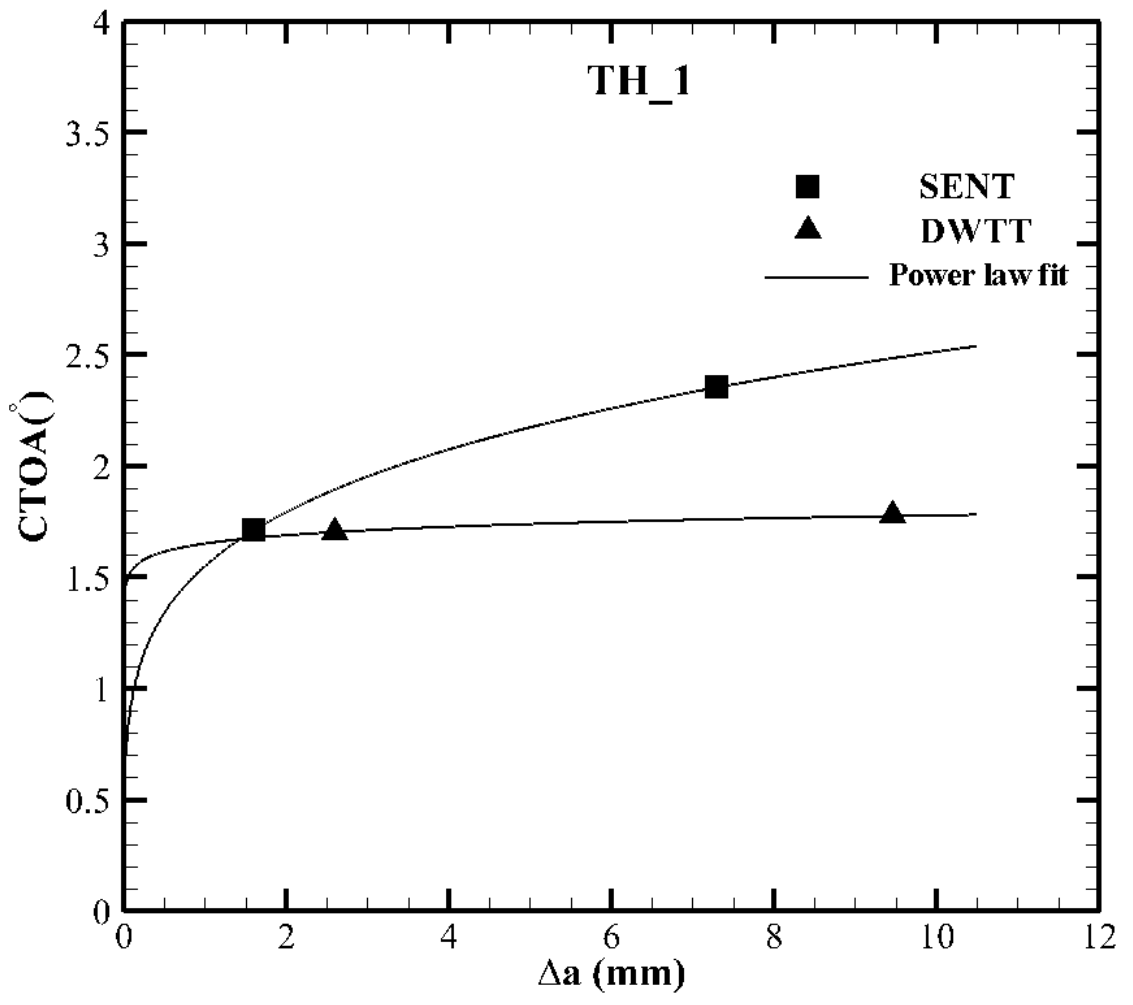

Figure 3.29: CTOA comparison (SENT and DWTT) - TH_1 steel 


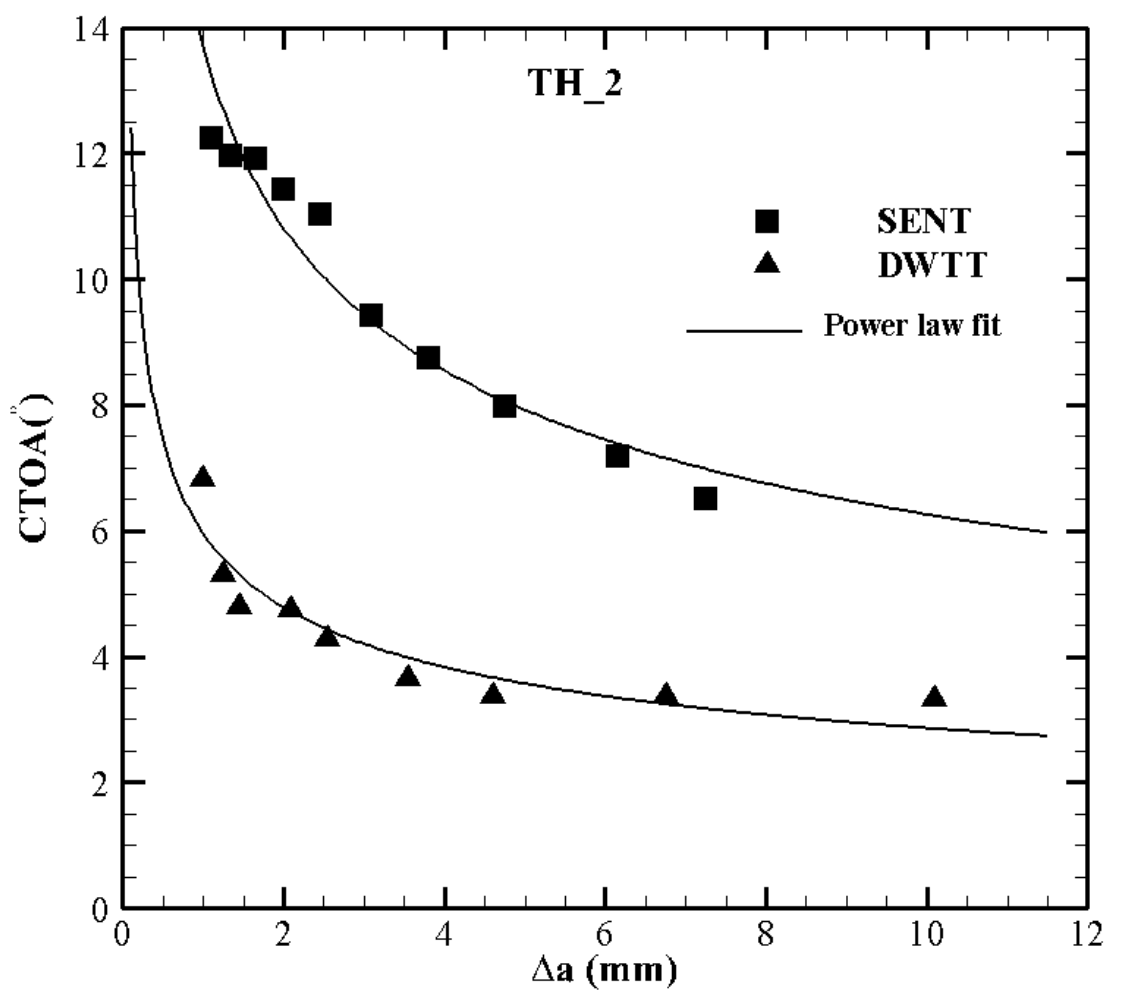

Figure 3.30: CTOA comparison (SENT and DWTT) - TH_2 steel

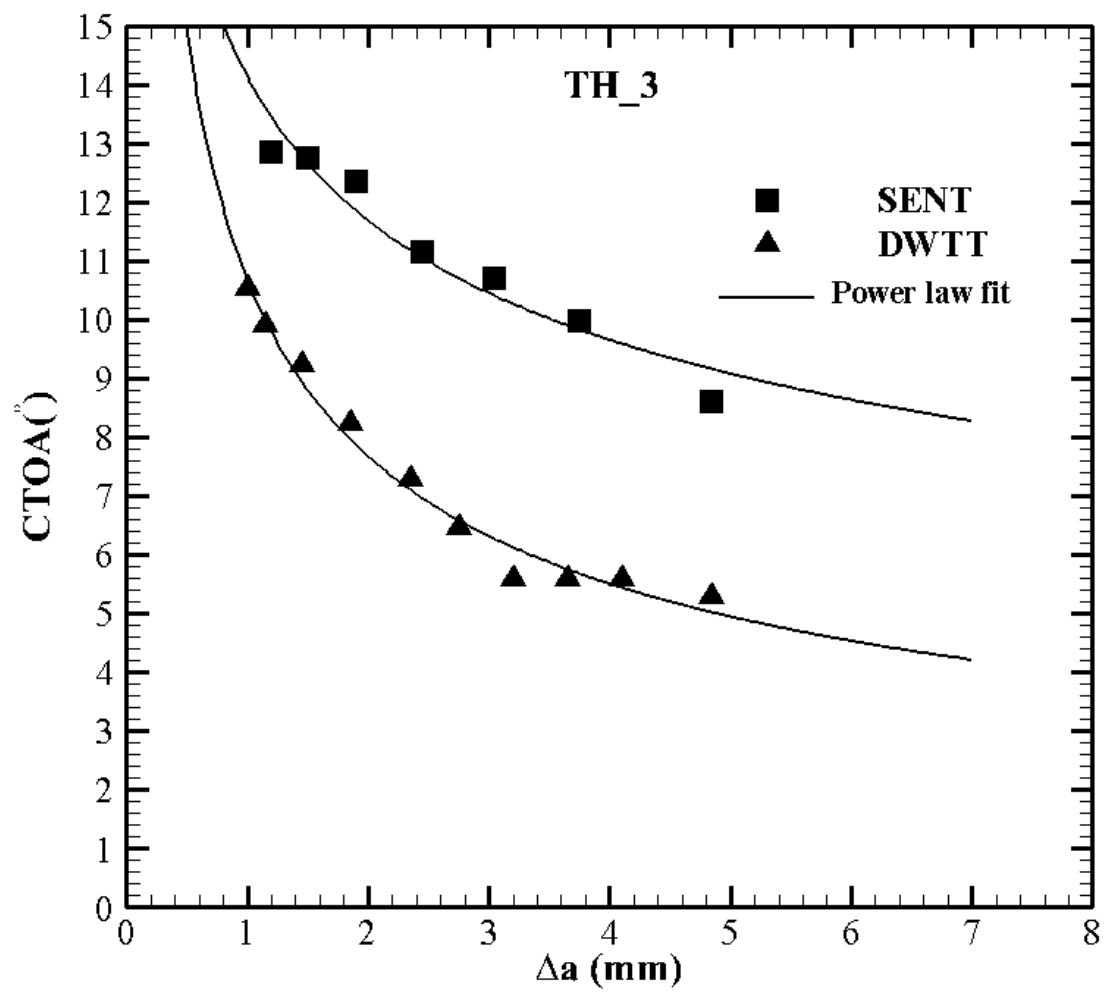

Figure 3.31: CTOA comparison (SENT and DWTT) - TH_3 steel 


\section{Chapter 4}

\section{FE Simulation of Ductile Crack Propagation in C2 Steel}

The C2 steel is identified as one of the high strength and high toughness steels. The real pipeline steel $\mathrm{C} 2$ was indicated by $\mathrm{Xu}$, et al., (2010a,2011), that is recognised as X70 in

the present generation. The C2 steel has a yield strength, a Young's modulus and a Poisson's ratio of $576 \mathrm{MPa}, 195,400 \mathrm{MPa}$ and 0.3 , respectively. The plastic stress-strain data are provided in Table 4.1, which were summarized by Xu (2010a, CANMET-MTL).

In this chapter, the finite element analysis is conducted for three plane strain models; small scale yielding (SSY), modified boundary layer (MBL) and drop weight tear test (DWTT). The exponential traction-separation law is used to study fracture and damage behavior of all three models. All computational analysis is done with the help of the finite element program -ABAQUS/Standard (6.11-2).

\subsection{FE Simulation of the Small Scale Yielding Model}

The geometry, step time definition, mesh design and contact interaction of mode I SSY are same as the described in Chapter 3, Sections 3.1.1, 3.1.3, 3.1.4, 3.1.5. The material properties, cohesive behavior and loading conditions will be changed for C2 steel.

The values of yield strength, Young's Modulus and Poisson's ratio of C2 steel are 576 $\mathrm{MPa}, 195,400 \mathrm{MPa}$ and 0.3 respectively. The stress-plastic strain data are provided in 
Table 4.1 (Xu, CANMET-MTL, 2010a), the values of which are used in ABAQUS/Standard. In Figure 4.1, the true stress-strain curve of C2 steel is presented.

The exponential traction-separation laws as input in contact interaction can be found from

Table 4.2. The SSY model is analysed for three different C2 steels; C2_1, C2_2 and C2_3. The values of $\hat{\sigma} / \sigma_{\mathrm{y}}$ and fracture energy $\left(\Gamma_{0}\right)$ for the surface based cohesive behavior are selected by taking reference of work done by Dunbar (2011). Hence, the values of maximum traction $\hat{\sigma}$ for $\mathrm{C} 2 \_1, \mathrm{C} 2 \_2$ and $\mathrm{C} 2 \_3$ are $3.2 \sigma_{\mathrm{y}}, 3.3 \sigma_{\mathrm{y}}$ and $3.4 \sigma_{\mathrm{y}}$ respectively. The fracture energies are 27.427 $\mathrm{MPa} \cdot \mathrm{mm}, 28.284 \mathrm{MPa} \cdot \mathrm{mm}$ and 29.141 $\mathrm{MPa} \cdot \mathrm{mm}$ for $\mathrm{C} 2 \_1, \mathrm{C} 2 \_2$ and $\mathrm{C} 2 \_3$, respectively. The critical displacement $\left(\delta_{\mathrm{c}}\right)$ is calculated from the Equation 2.19. Figure 4.2 illustrates the three exponential TS laws of C2 steel with the rate of damage evolution $(\alpha)=1$.

The far field displacements in $\mathrm{X}$ and $\mathrm{Y}$ direction are calculated as explained in Section 3.1.6. To propagate the crack through cohesive layers, the value of $K_{r}$ is chosen $\sim 16.8 \cdot \mathrm{K}_{0}^{\mathrm{C} 2}{ }^{3}$.

The crack growth resistance curve and crack tip opening angle (CTOA) are plotted from FE simulation of SSY. The CTOA of SSY is compared with the CTOA of DWTT.

\subsection{FE Simulation of the Modified Boundary Layer Model}

Refer to Section 3.2 for more details of the MBL model. The MBL is studied for the material C2_1 and C2_2. As explained in Section 4.1, refer to Table 4.2 for cohesive behavior of $\mathrm{C}_{2} \_1$ and $\mathrm{C} 2 \_2$. Both materials are examined for different normalized Tstress; $T / \sigma_{y}= \pm 0.5, \pm 0.8$ and \pm 1 . The boundary conditions are found as mentioned in 
Section 3.2.1. To propagate the crack through cohesive layers, the value of $\mathrm{K}_{\mathrm{r}}$ is chosen $\sim 33.6 \cdot K_{0}^{C 2}{ }^{3}$.

The crack growth resistance curves (R-curves) and CTOA data are generated from FE simulations of MBL to review the T-stress effect.

\subsection{FE Simulation of the Drop-Weight Tear Test}

The same steps as explained in Section 3.3 are followed for the geometry, step time definition, mesh design and contact interaction of $\mathrm{C}_{-} \_1$ and $\mathrm{C} 2 \_2$ material. The material properties and cohesive properties are the same as described in Section 4.1. The displacement field of $20 \mathrm{~mm}$ is applied from the 'tup' over the span of $24 \mathrm{~mm}$.

The load vs. LLD is plotted from the simulation and it is compared with the experimental load vs. LLD provided by Xu (2010a, CANMET-MTL). The load vs. LLD was corrected for compliance by Dunbar (2011). The CTOA is also calculated and this calculated CTOA is then compared with the measured experimental CTOA by Xu, et al., (2010b). The crack growth rate $\Delta a$ vs. LLD is plotted to see how long the crack grows.

\subsection{Results and Discussion}

\subsubsection{Small Scale Yielding Model}

\section{Crack Growth Resistance Curves}

The FE analysis is obtained for three sets of material; C2_1, C2_2 and C2_3. The model

parameters like $\hat{\sigma} / \sigma_{y}, \Gamma_{0}, R_{0} . K_{0}$ are found in Table 4.3. The crack length $(\Delta a)$ is normalized by plastic zone size $\left(\mathrm{R}_{0}\right)$ and applied far field stress intensity $\left(\mathrm{K}_{\mathrm{r}}\right)$ is 
normalized by critical stress intensity $\left(\mathrm{K}_{0}\right)$ as described in Section 3.5.1. The values of $\mathrm{K}_{\mathrm{r}} / \mathrm{K}_{0}$ and $\Delta \mathrm{a} / \mathrm{R}_{0}$ are plotted in Figure 4.3.

Figure 4.3 shows that the cohesive elements with higher toughness have higher crack resistance. Therefore, the toughest material C2_3 has the steepest resistance curve and C2_2 and C2_1 have less steep than C2_3.

\section{Crack Tip Opening Angles (CTOA)}

The CTOA is calculated following the same procedure used in Section 3.5.1 and power law fit trend lines are fitted on CTOA results (Tecplot). It can be seen from Figure 4.4 that the material C2_1, C2_2 and C2_3 have CTOA of values $8.3^{\circ}, 14.64^{\circ}$ and $20.42^{\circ}$ respectively, which means the material with higher fracture energy acquire higher CTOA. Thus, the values of CTOA decreases from $\mathrm{C} 2 \_3$ to $22 \_1$.

\subsubsection{Modified Boundary Layer Model}

\section{Crack Growth Resistance Curves}

The R-curves for two materials $\mathrm{C} 2 \_1$ and $\mathrm{C} 2 \_2$ are obtained for cases of the normalized $\mathrm{T}$-stress $\left(\mathrm{T} / \sigma_{\mathrm{y}}\right)$ values $\pm 0.5, \pm 0.8$ and \pm 1 . The R-curves of MBL for $\mathrm{C} 2 \_1$ and $\mathrm{C} 2 \_2$ are plotted with the condition $\left(\mathrm{T} / \sigma_{\mathrm{y}}=0\right)$ in Figure 4.5 and Figure 4.7 respectively. Both Figure 4.5 and Figure 4.7 indicate that there are no significant changes in R-curves with negative T-stress and positive T-stress. The R-curves of positive normalized T-stress having values $+0.5,+0.8$ and +1 are almost same. The R-curve with the normalized Tstress -1 is steepest among all the R-curves. 


\section{Crack Tip Opening Angle (CTOA)}

Figure 4.6 and Figure 4.8 depict the plot of CTOA vs. $\Delta$ a. The CTOA of C2_1 and C2_2 are not varying for negative and positive T-stress.

\subsubsection{Drop-Weight Tear Test}

The finite element analysis of DWTT specimen for C2_1 and C2_2 are performed. The numerical analysis of C2_3 was aborted due to numerical convergence issues in FE solver ABAQUS/Standard 6.11-2.

The numerical load vs. LLD plot is compared with the experimental load vs. LLD of C2 steel in Figure 4.9. The experimental DWTT specimen test was conducted by Xu (2010a)

and it was corrected for compliance by Dunbar (2011). The CTOA obtained from DWTT simulation are compared with the CTOA of SSY. The comparisons also made between numerical CTOA and experimental CTOA provided by Xu, et al., (2010b).

\section{Load vs. Load Line Displacement curves}

The obtained data of load vs. LLD are plotted in Figure 4.9 with the experimental data. The Figure 4.9 shows that neither of the two simulations is able to reach the maximum load of the experimental data. However, the elastic portion of the both material are same until the crack starts to propagate. The $\mathrm{C}_{2} \_1$ material is capable of reaching the maximum applied displacement of $20 \mathrm{~mm}$. But the $\mathrm{C} 2$ _2 material is not able to attain the maximum applied displacement due to numerical instability of the solver. 


\section{Crack Tip Opening Angle}

Figure 4.10 presents the steady state values of CTOA of $\mathrm{C} 2 \_1$ and $\mathrm{C} 2 \_2$ as $6.9^{\circ}$ and

$11.9^{\circ}$ respectively. The experimental measured CTOA values of $\mathrm{C} 2$ steel are $18.5^{\circ}$ using the optical method and $12.4^{\circ}$ using the simplified single-specimen method. Therefore, it can be noticed that the CTOA value of $\mathrm{C}_{2} \_2$ DWTT agrees reasonably well with experimental observations for $\mathrm{C} 2$ material.

In addition, the CTOA of SSY models of C2_1 and C2_2 are $8.3^{\circ}, 14.64^{\circ}$ respectively, which are closer to CTOA of DWTT of C2_1 and C2_2 steels.

\section{Crack Growth Rate}

The crack length $\Delta \mathrm{a}$ and LLD data as a crack growth rate are plotted in Figure 4.11 for C2_1 and C2_2. By analyzing the Figure 4.11, it is found that the crack begins to grow at $0.2 \mathrm{~mm}$ and $0.15 \mathrm{~mm}$ for $\mathrm{C}_{-} \_1$ and $\mathrm{C} 2 \_2$ respectively. The crack attains the length of $57.35 \mathrm{~mm}$ and $30.5 \mathrm{~mm}$ for $\mathrm{C} 2 \_1$ and $\mathrm{C} 2 \_2$ respectively when the simulations were aborted.

At applied displacement of $15 \mathrm{~mm}$, the crack reaches to $43.85 \mathrm{~mm}$ and $30.5 \mathrm{~mm}$ for C2_1 and $\mathrm{C}_{2} \_2$ respectively, which means that the material with less fracture energy propagates fast as compare with the material having high fracture energy.

\subsection{Conclusions}

The two dimensional mode I finite element analysis has been conducted for three models of C2 steel; SSY, MBL and DWTT. The SSY model has been studied for three sets of 
material; C2_1, C2_2 and C2_3. The two models, MBL and DWTT, have been analysed for two sets of C2 steel; C2_1 and C2_2.

By examining R-curves of the SSY models, it can be seen that the material with higher fracture energy and toughness can tolerate high amount of load and hence it has the highest crack resisting energy and CTOA.

From the R-curves and CTOA of MBL, it can be evaluated that the R-curves are not fluctuating significantly for the positive T-stress as well as negative T-stress. The effect of T-stress is not significant on CTOA for different levels of $\mathrm{T} / \sigma_{\mathrm{y}}= \pm 0.5, \pm 0.8, \pm 1$.

The load vs. LLD data from FE simulation of DWTT for C2_1 and C2_2 were compared with the experimental data provided by Xu (2010a, CANMET-MTL). The computed curves are unable to reproduce the experimental curve. The steady state CTOA $\left(11.9^{\circ}\right)$ of C2_2 steel matches reasonably well with the experimental CTOA $\left(12.4^{\circ}\right)$ measured using the S-SSM method published by Xu, et al., (2010b).

In all, by several trial and error of computational analysis, the exponential tractionseparation law chosen for surface based cohesive behavior in this chapter plays a good role to simulate ductile crack propagation for high toughness $\mathrm{C} 2$ steel. The viscosity coefficient $10^{-4}$ helps to protect zig zag crack propagation. 


\begin{tabular}{|c|c|c|c|c|c|c|c|c|c|}
\hline $\begin{array}{l}\text { Stress } \\
(\mathrm{MPa})\end{array}$ & $\begin{array}{l}\text { Plastic } \\
\text { strain }\end{array}$ & $\begin{array}{l}\text { Stress } \\
(\mathrm{MPa})\end{array}$ & $\begin{array}{l}\text { Plastic } \\
\text { strain }\end{array}$ & $\begin{array}{l}\text { Stress } \\
(\mathrm{MPa})\end{array}$ & $\begin{array}{c}\text { Plastic } \\
\text { strain }\end{array}$ & $\begin{array}{l}\text { Stress } \\
(\mathrm{MPa})\end{array}$ & $\begin{array}{c}\text { Plastic } \\
\text { strain }\end{array}$ & $\begin{array}{l}\text { Stress } \\
(\mathrm{MPa})\end{array}$ & $\begin{array}{c}\text { Plastic } \\
\text { strain }\end{array}$ \\
\hline 576 & 0 & 681.6 & 0.06691 & 988.4 & 0.3176 & 1402 & 0.6554 & 1815.4 & 0.9933 \\
\hline 579.6 & .00193 & 684.1 & 0.0689 & 1001 & 0.3275 & 1414 & 0.6654 & 1827.6 & 1.0033 \\
\hline 583.1 & 0.00392 & 686.5 & 0.07089 & 1013 & 0.3374 & 1426 & 0.6753 & 1839.7 & 1.0132 \\
\hline 586.7 & 0.0059 & 688.9 & 0.07287 & 1025 & 0.3474 & 1438 & 0.6852 & 1851.9 & 1.0231 \\
\hline 590.3 & 0.00788 & 691.4 & 0.07486 & 1037 & 0.3573 & 1451 & 0.6952 & 1864.1 & 1.0331 \\
\hline 593.8 & 0.00986 & 693.8 & 0.07685 & 1049 & 0.3672 & 1463 & 0.7051 & 1876.2 & 1.043 \\
\hline 597.4 & 0.01184 & 692.2 & 0.07884 & 1061 & 0.3772 & 1475 & 0.7151 & 1888.4 & 1.0529 \\
\hline 601 & 0.01382 & 698.6 & 0.08082 & 1074 & 0.3871 & 1487 & 0.725 & 1900.5 & 1.0629 \\
\hline 604.5 & 0.01581 & 701.1 & 0.08281 & 1086 & 0.3971 & 1499 & 0.7349 & 1912.7 & 1.0728 \\
\hline 608.1 & 0.01779 & 703.5 & 0.0 & 1098 & 0.407 & 1511 & 0.7449 & 1924.9 & 1.0828 \\
\hline 611.7 & 0.01977 & 705.9 & 0.08679 & 1110 & 0.4169 & 1524 & 0.7548 & 1937 & 1.0927 \\
\hline 615.2 & 0.02175 & 708.6 & 0.08898 & 1122 & 0.4269 & 1536 & 0.7647 & 1949.2 & 1.1026 \\
\hline 618.8 & 0.02373 & 720.8 & 0.09892 & 1134 & 0.4368 & 1548 & 0.7747 & 1961.4 & 1.1126 \\
\hline 622.4 & 0.02571 & 733 & 0.10885 & 1147 & 0.4467 & 1560 & 0.7846 & 1973.5 & 1.1225 \\
\hline 625.9 & 0.0277 & 745.1 & 0.11879 & 1159 & 0.4567 & 1572 & 0.7946 & 1985.7 & 1.1324 \\
\hline 629.5 & 0.02968 & 757.3 & 0.12873 & 1171 & 0.4666 & 1584 & 0.8045 & 1997.8 & 1.1424 \\
\hline 633.1 & 3166 & 769.4 & 0.13867 & 1183 & 0.4766 & 1597 & 0.8144 & 2010 & 1.1523 \\
\hline 636.6 & 0.03364 & 781.6 & 0.1486 & 1195 & 0.4865 & 1609 & 0.8244 & 2022.2 & 1.1623 \\
\hline 640.2 & 0.03562 & 793.8 & 0.15854 & 1207 & 0.4964 & 1621 & 0.8343 & 2034.3 & 1.1722 \\
\hline 643.8 & 0.03761 & 805.9 & & 1220 & 0.5064 & 1633 & & 2046.5 & 1.1821 \\
\hline 647.3 & 03959 & & & 1232 & & 1645 & & 2058.7 & 1.1921 \\
\hline 650 & 0.04107 & 830.3 & 0.18835 & 1244 & 0.5262 & 1657 & 0.8641 & 2070.8 & 1.202 \\
\hline 652.4 & 0.04306 & 842.4 & 0.19829 & 1256 & 0.5362 & 1670 & 0.8741 & 2083 & 1.2119 \\
\hline 654.9 & 0.04505 & 854.6 & 0.20823 & 1268 & 0.5461 & 1682 & 0.884 & 2095.1 & 1.2219 \\
\hline 657.3 & 0.04704 & 866.7 & 0.21817 & 1280 & 0.5561 & 1694 & 0.8939 & 2107.3 & 1.2318 \\
\hline 659.7 & 0.04902 & 878.9 & 0.22811 & 1292 & 0.566 & 1706 & 0.9039 & 2119.5 & 1.2418 \\
\hline 662.2 & 0.05101 & 891.1 & 0.23804 & 1305 & 0.5759 & 1718 & 0.9138 & 2131.6 & 1.2517 \\
\hline 664.6 & & 903.2 & 0.2 & 1317 & & 1730 & 0.9238 & & \\
\hline 667 & 0.05499 & 915.4 & 0.25792 & 1329 & 0.5958 & 1742 & 0.9337 & & \\
\hline 669.5 & 0.05697 & 927.6 & 0.26786 & 1341 & 0.6057 & 1755 & 0.9436 & & \\
\hline 671.9 & 0.05896 & 939.7 & 0.27779 & 1353 & 0.6157 & 1767 & 0.9536 & & \\
\hline 674.3 & 0.06095 & 951.9 & 0.28773 & 1365 & 0.6256 & 1779 & 0.9635 & & \\
\hline 676.8 & 0.06294 & 964 & 0.29767 & 1378 & 0.6356 & 1791 & 0.9734 & & \\
\hline 679.2 & 0.06492 & 976.2 & 0.30761 & 1390 & 0.6455 & 1803 & 0.9834 & & \\
\hline
\end{tabular}

Table 4.1: Stress vs. plastic strain data - C2 steel (input in ABAQUS) 


\begin{tabular}{|c|c|c|c|c|c|c|c|c|c|}
\hline \multicolumn{10}{|c|}{ C2 Steel } \\
\hline \multirow[t]{2}{*}{ Material } & \multicolumn{3}{|c|}{ MaxS Damage (MPa) } & \multirow{2}{*}{$\begin{array}{c}\text { Critical } \\
\text { displacement } \\
\left(\boldsymbol{\delta}_{\mathrm{c}}, \mathrm{mm}\right) \\
\text { Exponential }\end{array}$} & \multirow[t]{2}{*}{$\alpha$} & \multicolumn{3}{|c|}{ Elastic Moduli (MPa) } & \multirow[t]{2}{*}{ V.C. } \\
\hline & Normal & $1^{\text {st }}$ & 2nd & & & $\mathbf{K}_{\mathbf{n n}}$ & $\mathbf{K}_{\mathbf{s s}}$ & $\mathbf{K}_{\mathrm{tt}}$ & \\
\hline C2_1 & 1843.2 & 1382.4 & 1843.2 & 0.02976 & 1 & 10000000 & 3846154 & 3846154 & $10^{-4}$ \\
\hline C2_2 & 1900.8 & 1425.6 & 1425.6 & 0.02976 & 1 & 10000000 & 3846154 & 3846154 & $10^{-4}$ \\
\hline C2_3 & 1958.4 & 1958.4 & 1958.4 & 0.02976 & 1 & 10000000 & 3846154 & 3816154 & $10^{-4}$ \\
\hline
\end{tabular}

Table 4.2: Cohesive properties of three sets of C2 steel

\begin{tabular}{|c|c|c|c|c|c|}
\hline Material & $\widehat{\boldsymbol{\sigma}} / \boldsymbol{\sigma}_{\mathbf{y}}$ & $\begin{array}{c}\mathbf{\Gamma}_{\mathbf{0}} \\
(\mathbf{M P a} \cdot \mathbf{m m})\end{array}$ & $\begin{array}{c}\boldsymbol{\delta}_{\mathbf{c}} \\
(\mathbf{m m})\end{array}$ & $\begin{array}{c}\mathbf{K}_{\mathbf{0}} \\
(\mathbf{M P a} \cdot \sqrt{\mathbf{m m}})\end{array}$ & $\begin{array}{c}\mathbf{R}_{\mathbf{0}} \\
(\mathbf{m m})\end{array}$ \\
\hline C2_1 & 3.2 & 27.427 & 0.02976 & 2426.78 & 1.8834 \\
\hline C2_2 & 3.3 & 28.284 & 0.02976 & 2464.40 & 1.9423 \\
\hline C2_3 & 3.4 & 29.141 & 0.02976 & 2501.46 & 2.0011 \\
\hline
\end{tabular}

Table 4.3: Model parameters - C2 Steel 


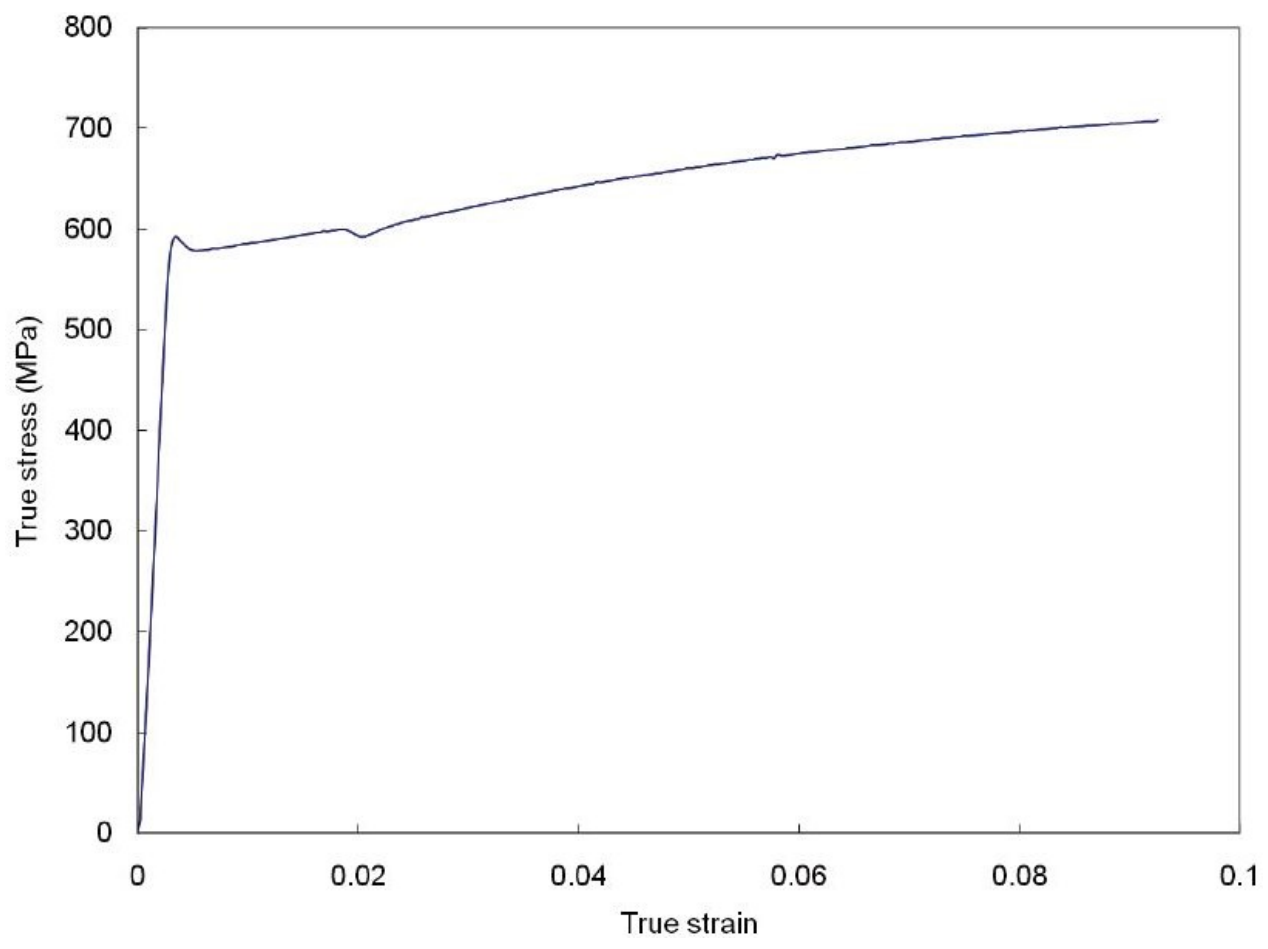

Figure 4.1: True stress-strain curve - C2 steel, (Dunbar, 2011)

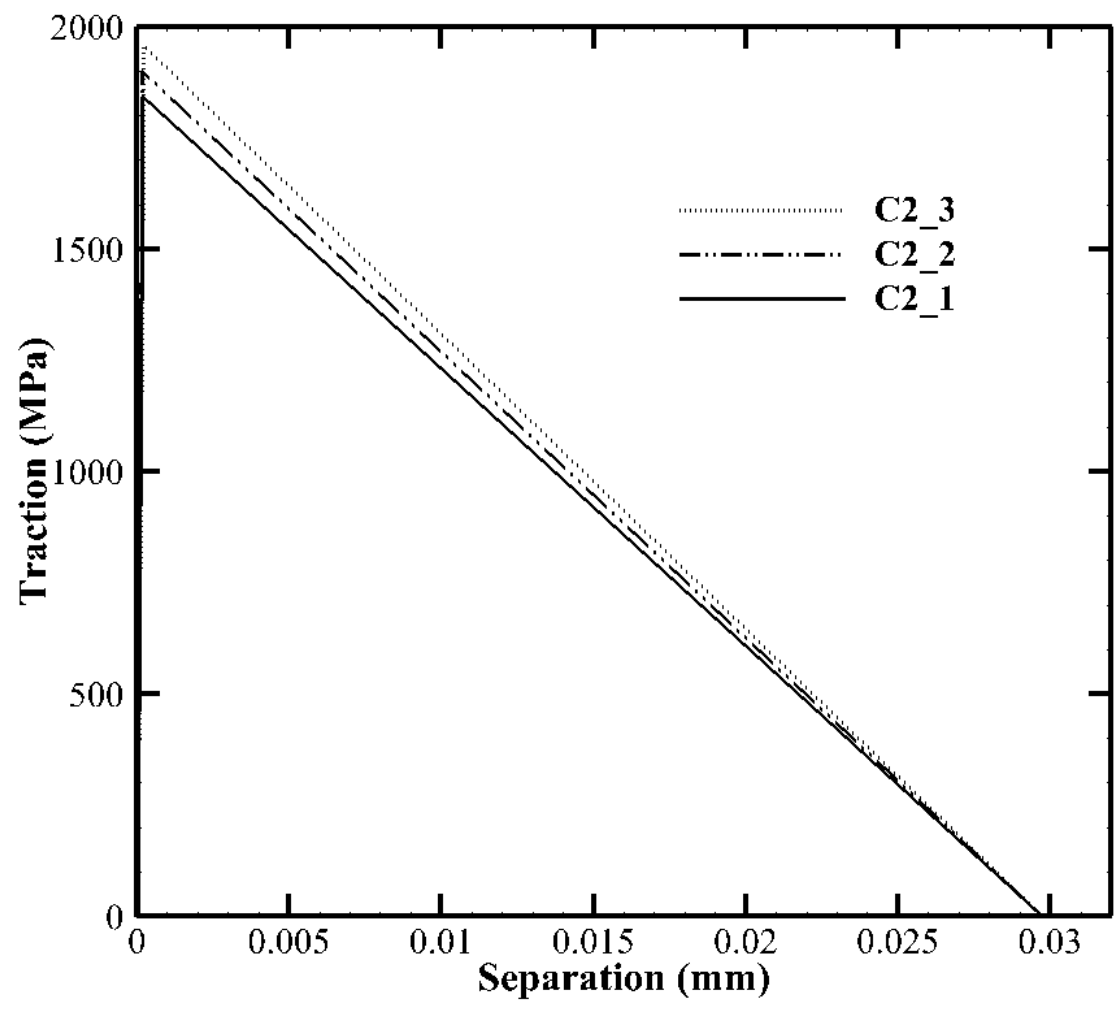

Figure 4.2: Exponential traction-separation laws $(\alpha=1)-\mathrm{C} 2$ steel 


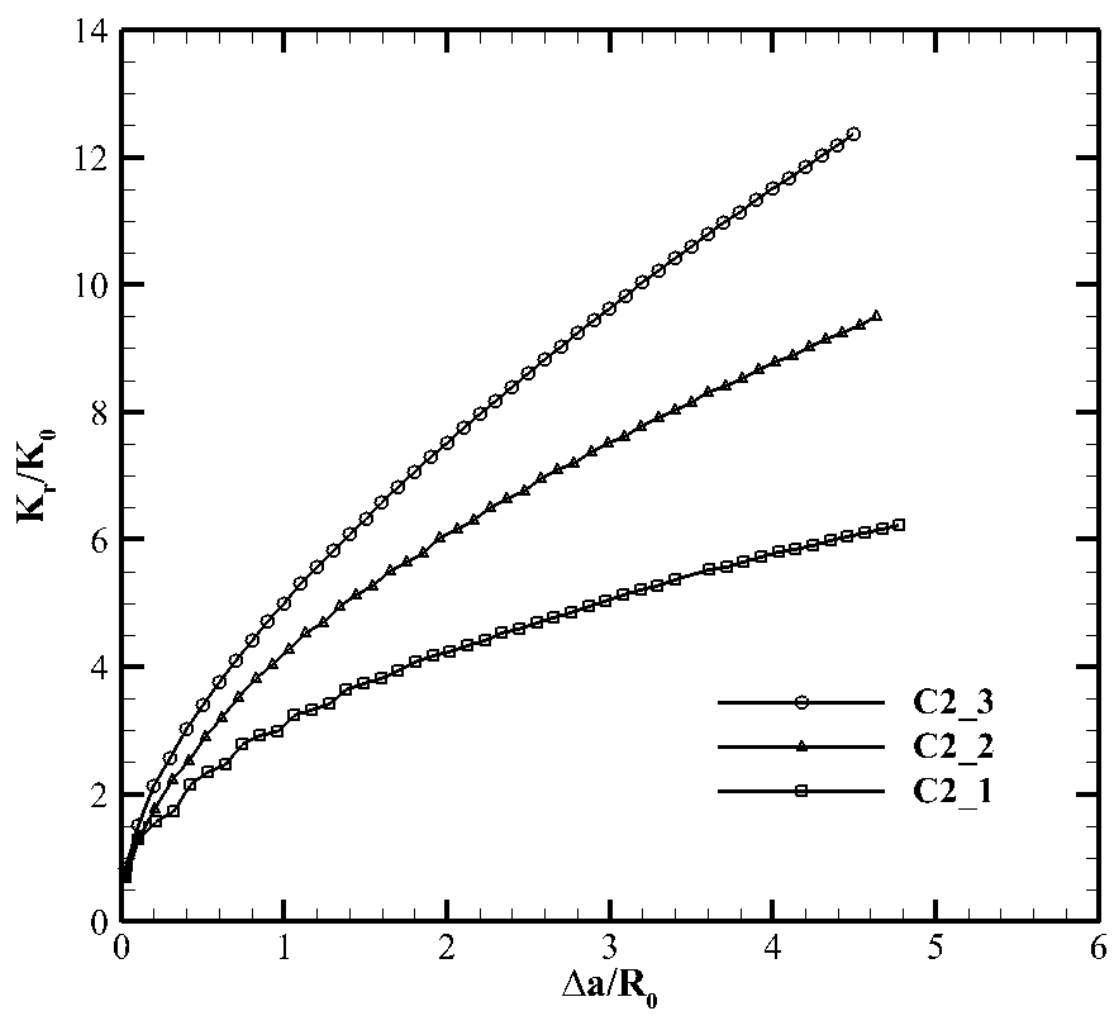

Figure 4.3: Normalized resistance curves of SSY models - C2 steel

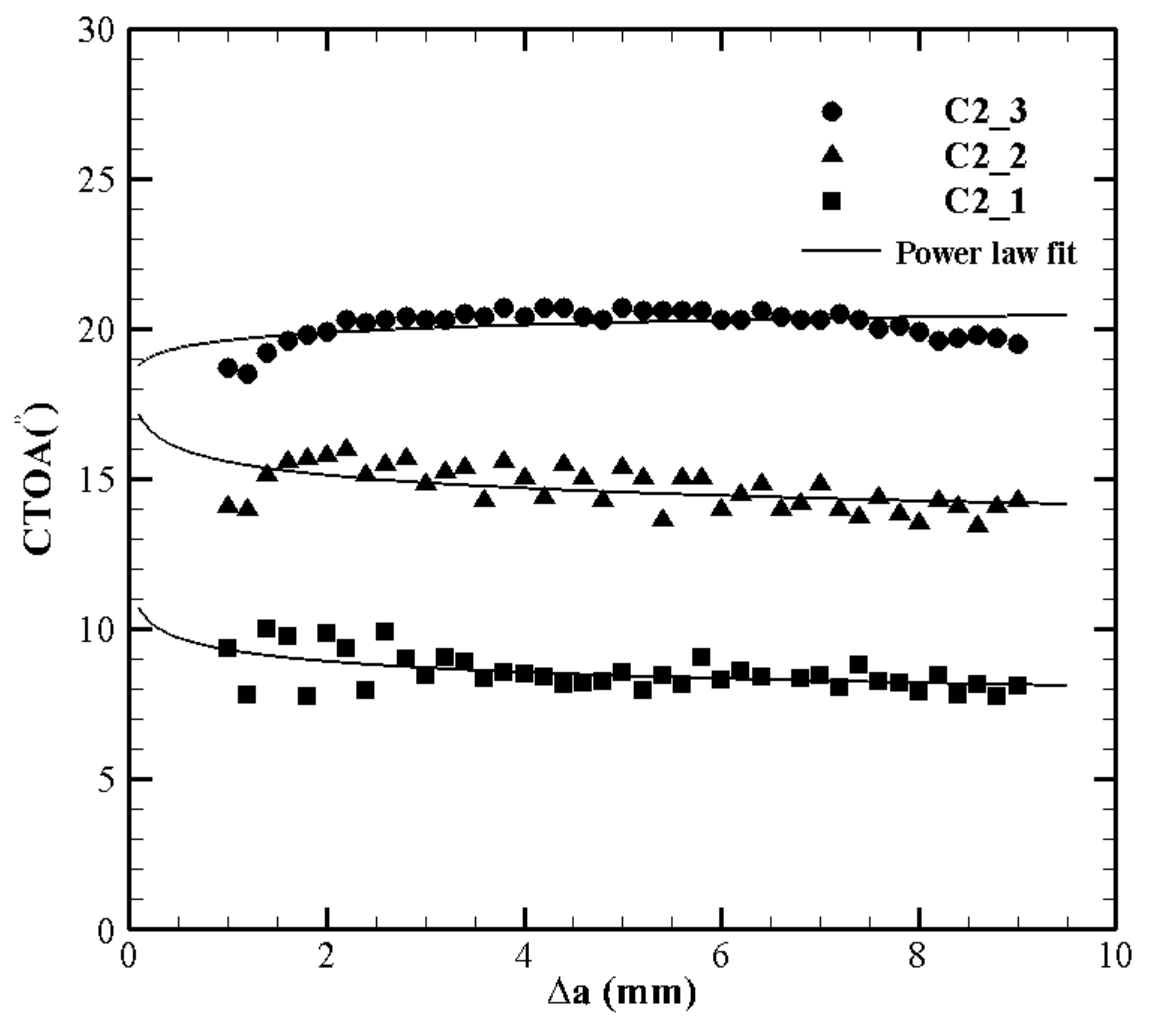

Figure 4.4: CTOA data- SSY model- C2 Steel 


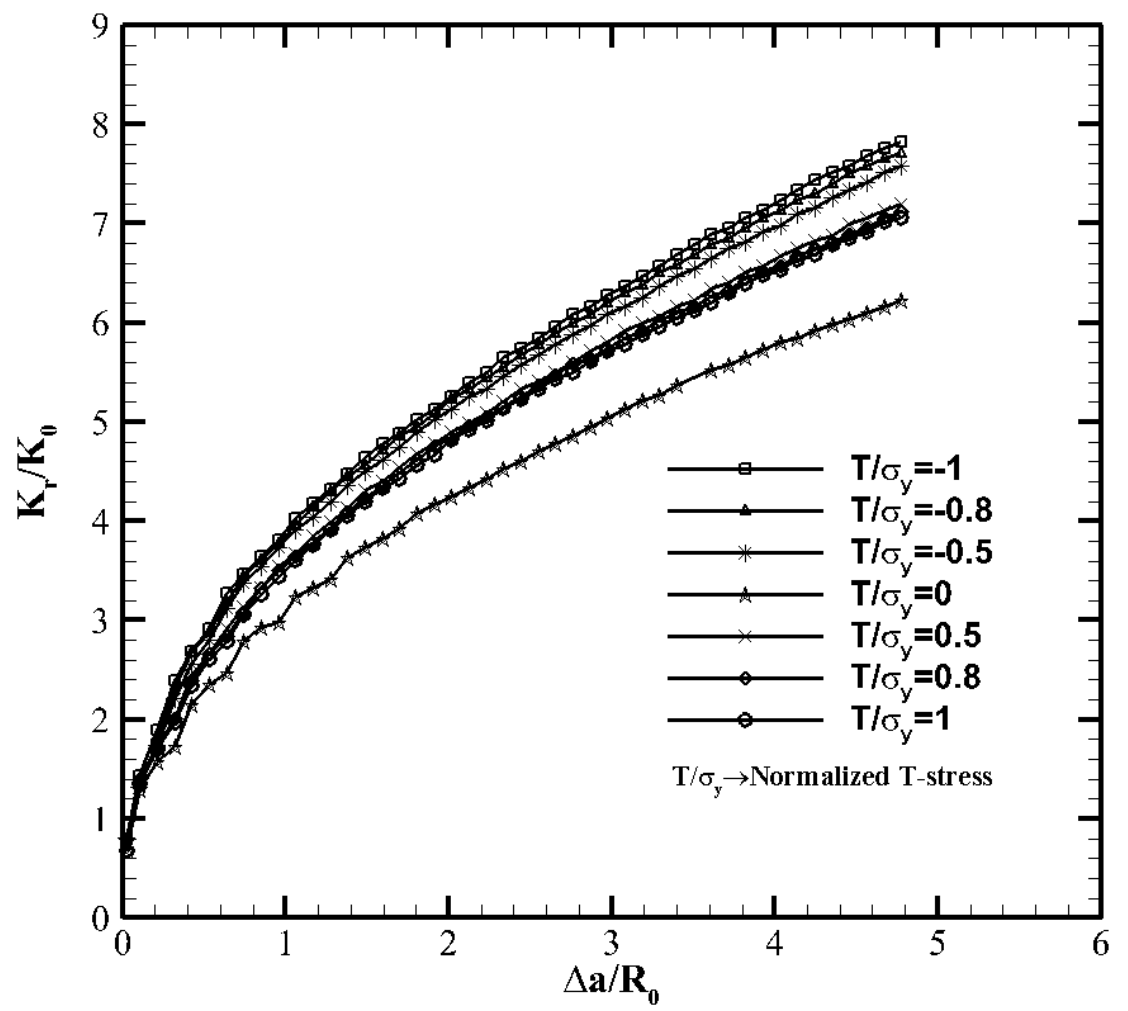

Figure 4.5: Normalized resistance curves $-\mathrm{MBL}$ model $-\mathrm{C} 2 \_1$ steel

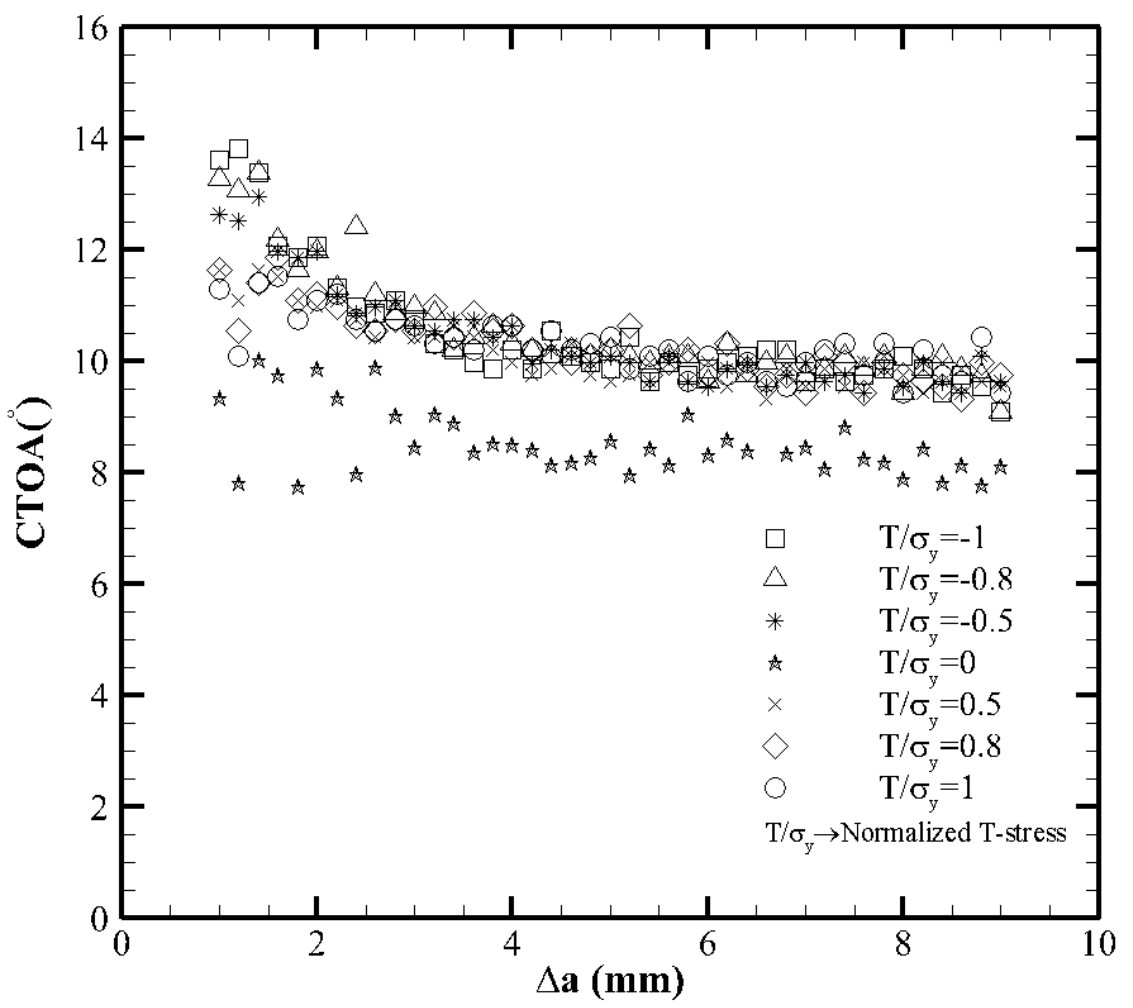

Figure 4.6: CTOA data-MBL model - C2_1 steel 


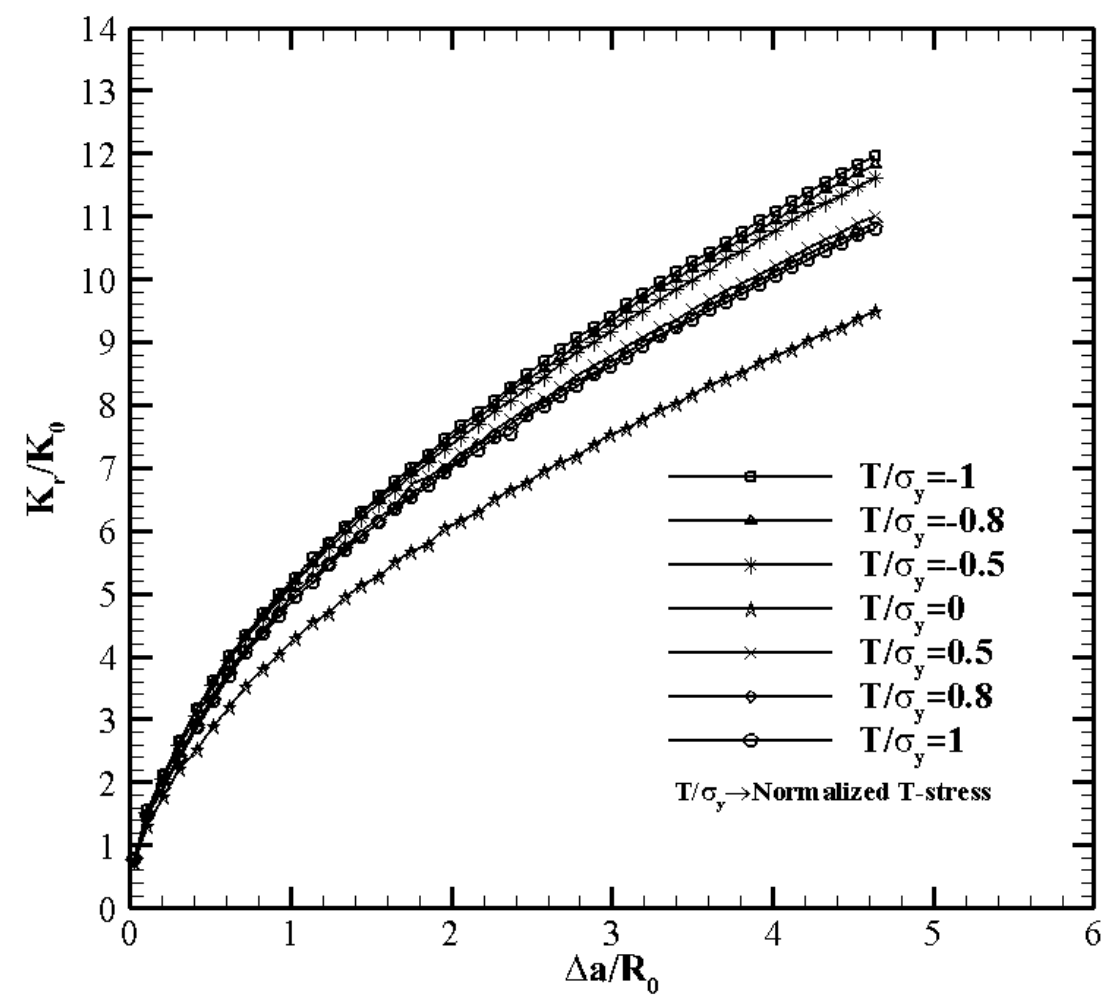

Figure 4.7: Normalized resistance curves -MBL model - C2_2 steel

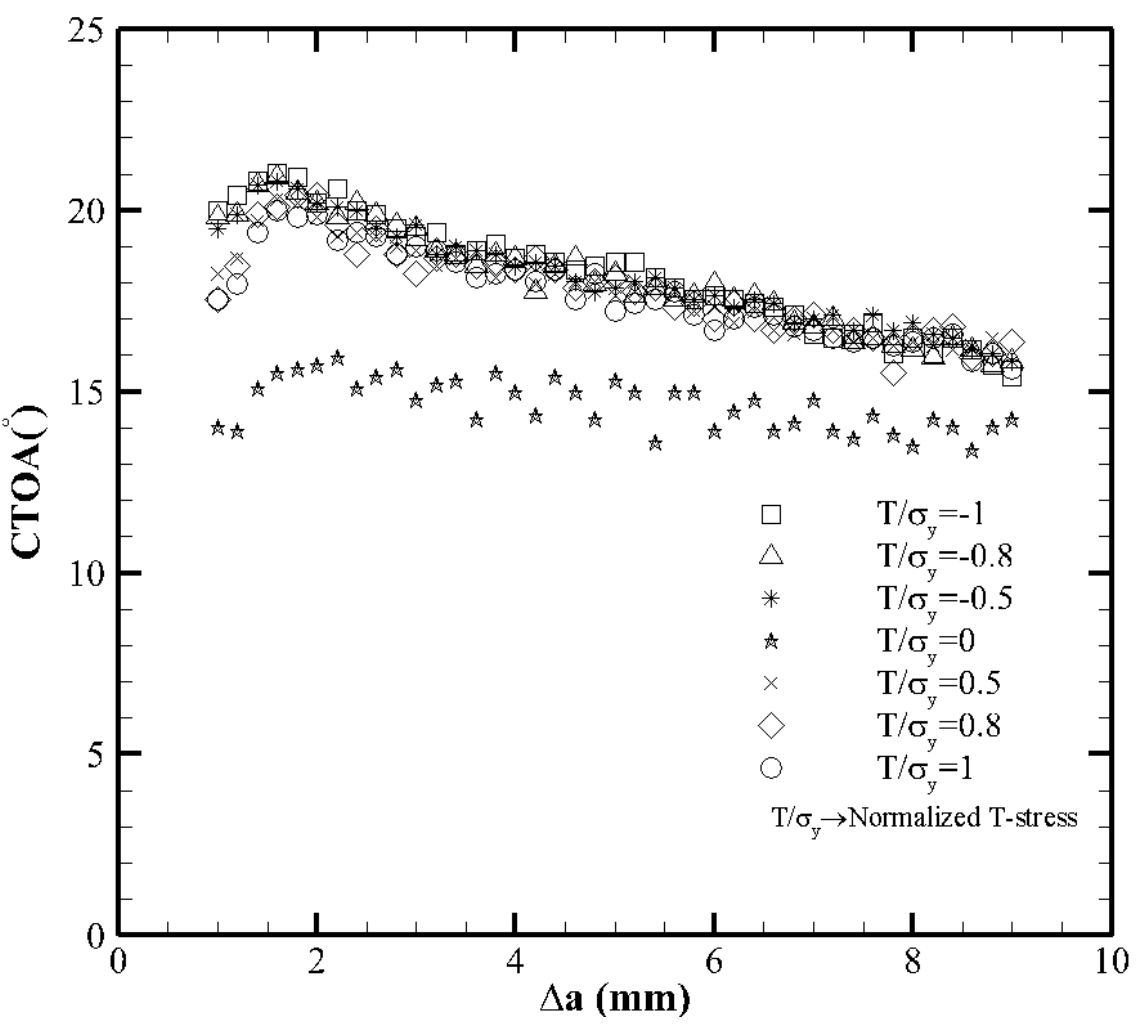

Figure 4.8: CTOA data-MBL model - C2_2 steel 


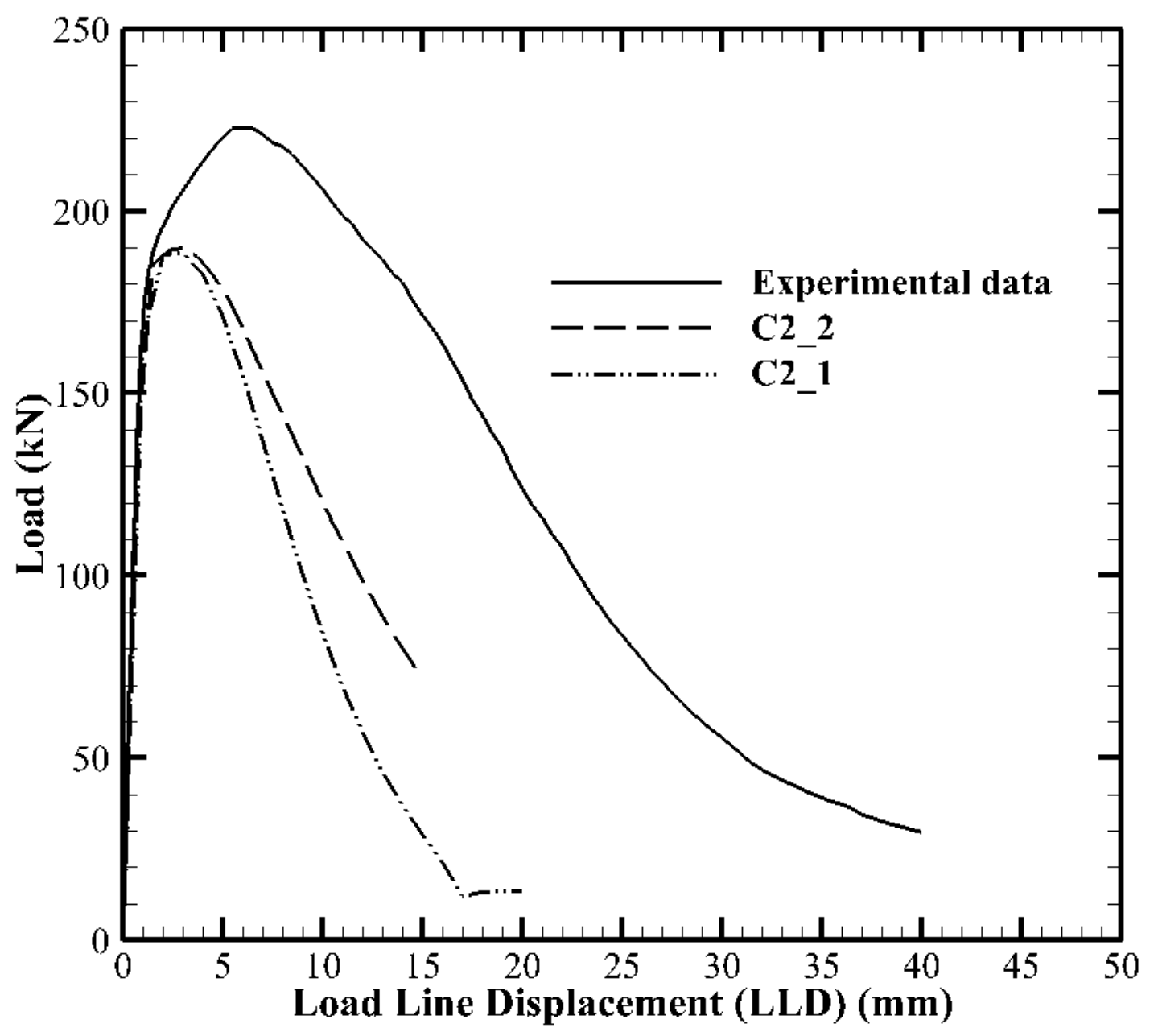

Figure 4.9: Load vs. LLD - DWTT - C2 steel 


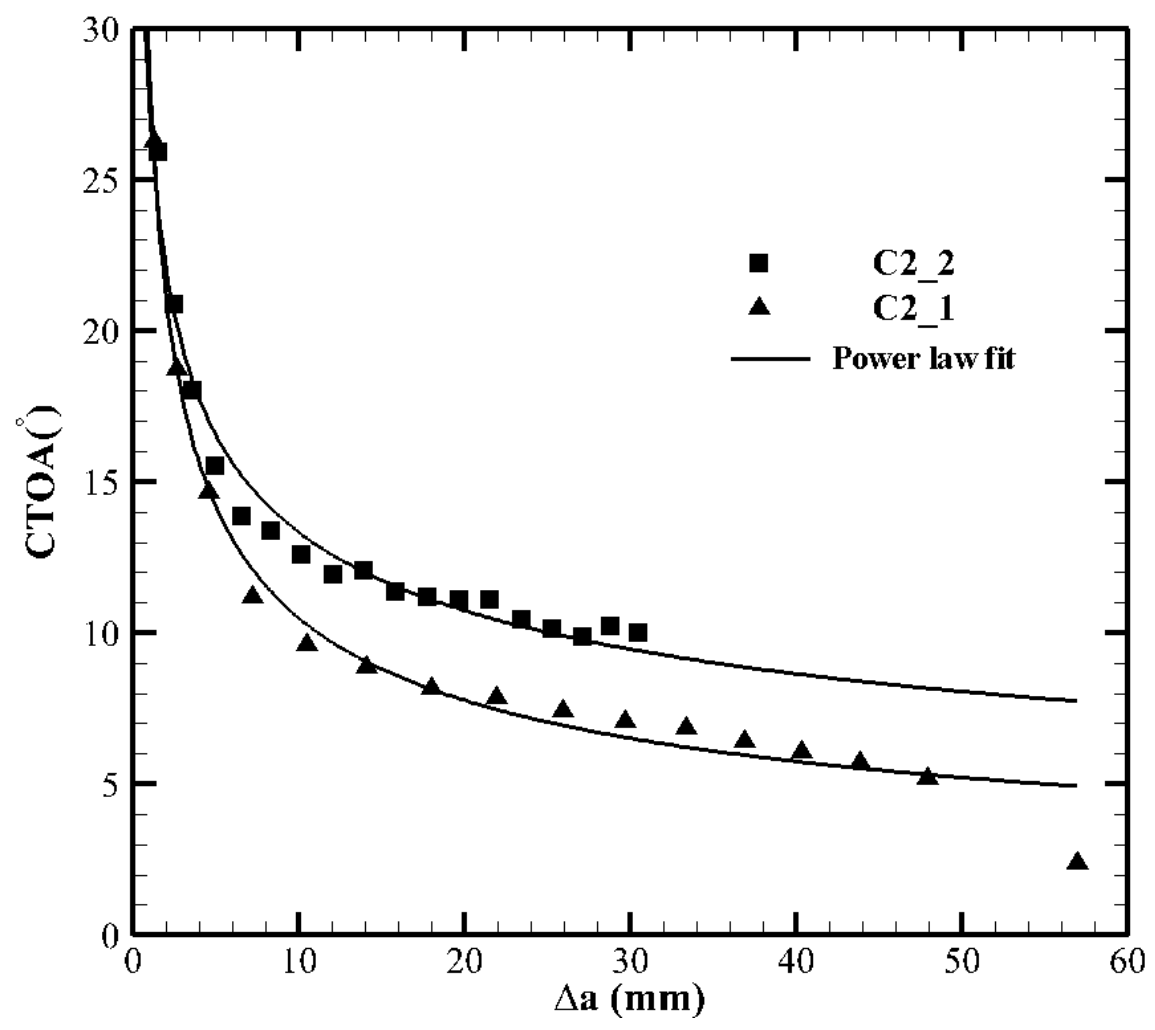

Figure 4.10: CTOA data - DWTT - C2 steel

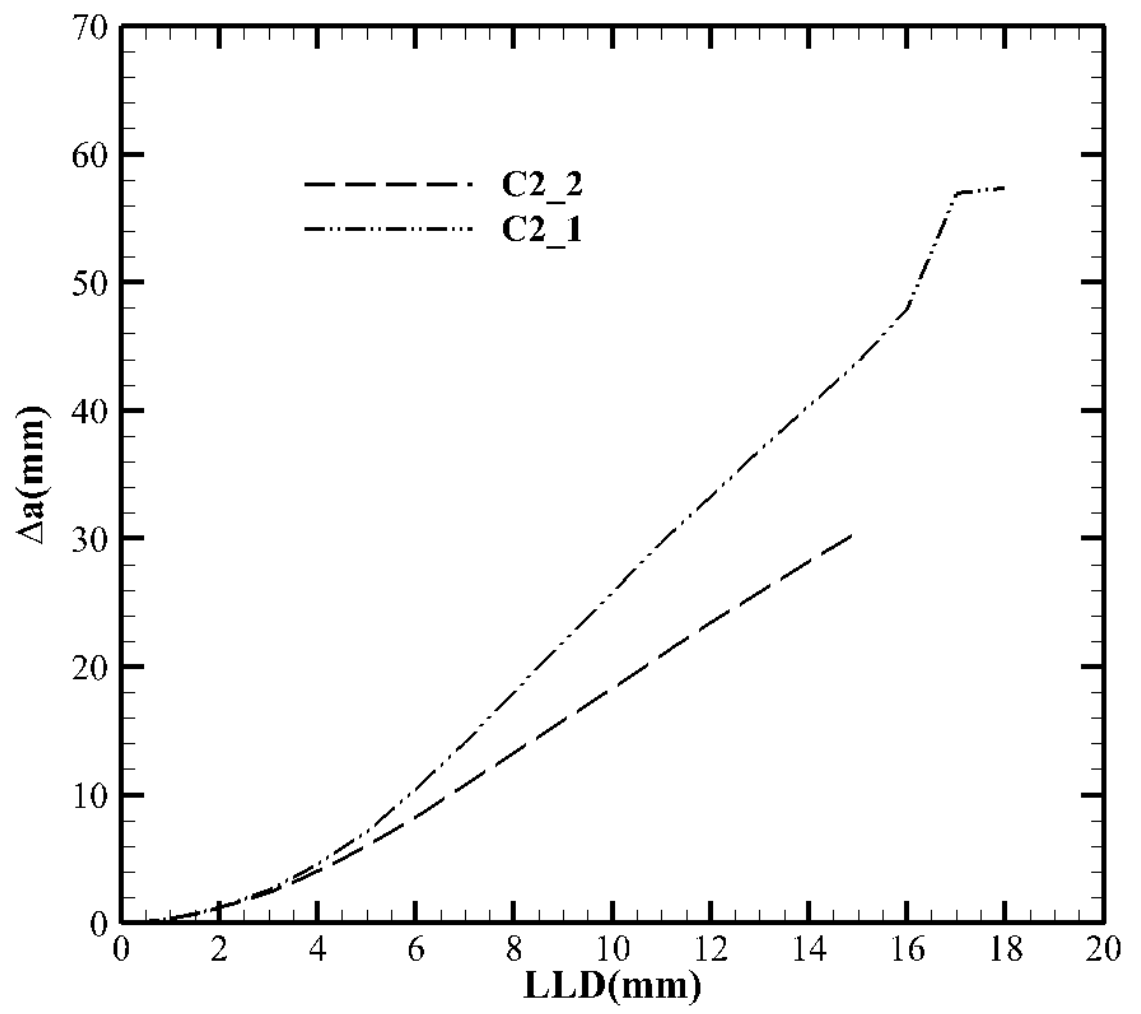

Figure 4.11: $\Delta \mathrm{a}$ vs. LLD - DWTT- C2 steel 


\section{Chapter 5}

\section{FE Simulation of Ductile Crack Propagation in C4 Steel}

In this chapter, the full investigation of $\mathrm{C} 4$ steel is done. C4 or X100 steel is the high strength pipeline steel with a yield strength of $805 \mathrm{MPa}$ and Young's modulus of 203,223 MPa. The metallurgical characterization (chemical composition) and mechanical properties (average transverse tensile and Charpy properties) have been demonstrated in Table 5.1 and Table 5.2, (Xu, et al., 2010b). The true stress-strain curve can be found in Figure 5.3. The stress-plastic strain data used as input for ABAQUS is shown in Table 5.3. The true stress -strain curve data as well as stress-plastic strain data were provided by Xu (2013, CANMET-MTL).

\section{Cohesive Properties}

As explained in Chapter 2, mainly two kinds of traction-separation laws i.e. bilinear and exponential are used in this chapter. The different combinations of $\widehat{\sigma} / \sigma_{\mathrm{y}}$, fracture energy and critical displacement are listed in Table 5.4 and Table 5.5. Six types of cohesive materials namely C4_A, C4_B, C4_C, C4_1, C4_2 and C4_3 are used. Six TS laws; three bilinear and three exponential are shown in Figure 5.1 and

Figure 5.2. 
The focus of this chapter is mainly on the unit cell model, small scale yielding model, modified boundary layer model and drop weight tear test model to analyze the fracture and damage behavior of $\mathrm{C} 4$ steel. All finite element analyses have been performed using ABAQUS 6.11-2.

\subsection{Unit Cell Model}

Before running the simulation of the SSY, MBL and DWTT, the bilinear behavior of the one cohesive element is checked.

The finite element implementation of a single cohesive element is carried out in ABAQUS/Standard 6.11-2 to evaluate the TS behavior of cohesive element.

From Figure 5.4, it can be observed that the length of the element is $0.02 \mathrm{~mm}$ and the width is $0.02 \mathrm{~mm}$. The thickness of the element is automatically chosen to be $1 \mathrm{~mm}$. The element is fixed in the Y-direction at the bottom surface and the left bottom node is fixed in X-direction. The magnitude of the applied ramped displacement is $0.012 \mathrm{~mm}$. In step time definition, the static analysis is done by keeping the maximum number of increment 100 and increment size of time step is 0.01 . The cohesive properties of six sets of $\mathrm{C} 4$ steel are imported from Table 5.4 and Table 5.5. A four node two dimensional cohesive element COH2D4 is used for the mesh design. It can be seen from Table 5.4 that the value of $\hat{\sigma} / \sigma_{\mathrm{y}}$ are chosen in between 3 to 3.5 as suggested in work by Tvergaard \& Hutchinson (1992) and Dunbar (2011) for high strength pipeline steel. 


\subsection{FE Simulation of Small Scale Yielding Model}

The focus of this topic is the prediction of the crack growth resistance curve as well as measurement of the CTOA.

\subsubsection{Geometry}

Figure 5.5 represents the half model of the modified boundary layer of mode I (i.e. Opening) crack propagation. Owing to the symmetry of the model, only a half model is examined. The model is symmetric about the $\mathrm{X}$-axis. The radius $(\mathrm{r})$ of the model is $200 \mathrm{~mm}$. It can be seen from Figure 5.6 that crack tip is introduced at the center of the model (i.e. $\mathrm{x}=\mathrm{y}=0 \mathrm{~mm}$ ). The size $\left(\Delta_{0}\right)$ of the smallest elastic-plastic plane strain element is $0.1 \mathrm{~mm} \times 0.1 \mathrm{~mm}$. The length of cohesive zone, $l_{\text {coh }}$ is $90 \Delta_{0}$ as illustrated in Figure 5.6. The surface-to-surface tie constraint is adopted to assemble semicircle and cohesive zone.

\subsubsection{Material Properties}

The C4 steel has a Young's modulus of 203,223 MPa and Poisson's ratio of 0.3. The stress-plastic strain data for the input in ABAQUS can be found in Table 5.3 (Xu, 2013). The SSY is studied for C4_A, C4_B and C4_C. Cohesive parameters for these three C4 steel have been found in Table 5.4, to introduce bilinear TS law in ABAQUS 6.112/Explicit. Only half of the total fracture energy is inserted due to symmetry of model. Equation 2.16, is used for calculation of the fracture energy. The value of the critical displacement $\left(\delta_{\mathrm{c}}\right)$ is taken $0.012 \mathrm{~mm}$ (for the half model) from trial and error of unit cell model. The mass density is kept $7.85 \times 10^{-6} \mathrm{~kg} / \mathrm{mm}^{3}$ for high strength steel. 


\subsubsection{Mesh Design}

As illustrated in Figure 5.8 and Figure 5.9, the model is developed using cohesive elements as well as plane strain elements. The size of cohesive elements is $0.02 \mathrm{~mm} \times 0.02 \mathrm{~mm}$, while the size of plane strain elements near the crack tip is $0.1 \mathrm{~mm} \times 0.1 \mathrm{~mm}$. As a consequence one plane strain element is connected with 5 cohesive elements. In all, the model comprises $450 \mathrm{COH} 2 \mathrm{D} 4$ elements (a four node two dimensional element) and 23712 CPE4R elements (a four node bilinear plane strain quadrilateral, reduced integration, hourglass control). The maximum degradation is set equal to 1 for $\mathrm{COH} 2 \mathrm{D} 4$ elements. The model consists of 17 concentric semi circles and each semi-circle is divided in 36 parts.

The cohesive segment and the region near the crack tip are meshed with the help of structured (quad) mesh technique however a sweep mesh technique (quad dominated) is applied away from the crack tip. The free mesh technique (quad, advancing front) is employed for the transition from structured mesh to sweep mesh.

\subsubsection{Step Definition and Output}

The dynamic, explicit method was selected to simulate the model. The time period of 1 second is exerted for monotonic increasing displacement. The Nlgeom is kept on to account the non-linearity of the geometry at each increment of the time. In the field an output frequency of 0.0001 seconds is chosen to record the results. The variables SDEG (scalar stiffness degradation) and STATUS ( 1 for active element and 0 for inactive element) are toggled on for the removal of cohesive element after reaching the maximum degradation point. Rather than those, more variables such as, strains (E, PE), stresses 
(misses, misses max), displacement (U) and force (RF) are also requested to write output database files.

\subsubsection{Loading Conditions}

To apply the desired stress intensity, the outer edge of the circle is divided into 36 parts. The nodes are $5^{\circ}$ apart. The nodes are numbered as $0^{\circ}$ at outer right corner of the half model, travel counter clock wise, $180^{\circ}$ at outer left corner of the model as shown in Figure 5.7. The stress intensity factor is applied in terms of displacement in X-direction and Y-direction at each five degree node by using the following equations,

$$
\begin{aligned}
& \mathrm{u}_{\mathrm{x}}=\frac{\mathrm{K}_{\mathrm{r}}}{2 \mu} \sqrt{\frac{\mathrm{r}}{2 \pi}} \cos \left(\frac{\theta}{2}\right)\left[\mathrm{k}-1+2 \sin ^{2}\left(\frac{\theta}{2}\right)\right] \\
& \mathrm{u}_{\mathrm{y}}=\frac{\mathrm{K}_{\mathrm{r}}}{2 \mu} \sqrt{\frac{\mathrm{r}}{2 \pi}} \sin \left(\frac{\theta}{2}\right)\left[\mathrm{k}+1-2 \cos ^{2}\left(\frac{\theta}{2}\right)\right]
\end{aligned}
$$

where, $\mathrm{K}_{\mathrm{r}}$ is the maximum far-field stress intensity factor, $\mu$ is the shear modulus, equals $[\mathrm{E} / 2(1+v)], \mathrm{r}$ is the radius of the semicircle and $\theta$ is the measured counter clockwise angle, $\mathrm{k}=3-4 v, v$ is the Poisson's ratio. Three cases: C4_A, C4_B, C4_C are studied are studied for small scale yielding model (normalized T-stress $=0$ ).

The applied value of $\mathrm{K}_{\mathrm{r}}$ is kept $\sim 37.8 \cdot \mathrm{K}_{0}^{\mathrm{C} 4 \_\mathrm{C}}$, to propagate the crack through cohesive layers. The ramp amplitude is defined as at time zero, the amplitude (displacement) is zero and at time 1 second, the amplitude is 1 .Which means at the completion of 1 second, full displacement will be applied to the model. 


\subsection{FE Simulation of Modified Boundary Layer Model}

The modified boundary layer model has been analysed only for C4_A material. The steps of geometry, material properties, mesh design, step definition and output are same as discussed in Section 5.2.1, 5.2.2, 5.2.3 and 5.2.4 respectively.

\subsubsection{Loading Conditions}

The displacement control boundary conditions is calculated using the following equations,

$$
\begin{aligned}
& \mathrm{u}_{\mathrm{x}}=\frac{\mathrm{K}_{\mathrm{r}}}{2 \mu} \sqrt{\frac{\mathrm{r}}{2 \pi}} \cos \left(\frac{\theta}{2}\right)\left[\mathrm{k}-1+2 \sin ^{2}\left(\frac{\theta}{2}\right)\right]+\frac{1-v}{2} \operatorname{Tr} \cos \theta \\
& \mathrm{u}_{\mathrm{y}}=\frac{\mathrm{K}_{\mathrm{r}}}{2 \mu} \sqrt{\frac{\mathrm{r}}{2 \pi}} \sin \left(\frac{\theta}{2}\right)\left[\mathrm{k}+1-2 \cos ^{2}\left(\frac{\theta}{2}\right)\right]+\frac{(-v)}{2} \operatorname{Tr} \sin \theta
\end{aligned}
$$

where, $K_{r}$ is the maximum far-field stress intensity factor, $\mu$ is the shear modulus, equals $[\mathrm{E} / 2(1+v)], \mathrm{r}$ is the radius of the semicircle and $\theta$ is the measured counter clockwise angle, $k=3-4 v, v$ is the Poisson's ratio, $\mathrm{T}$ is the non-singular stress acting parallel to the crack plane.

The applied value of $\mathrm{K}_{\mathrm{r}}$ is selected $\sim 39 \cdot \mathrm{K}_{0}^{\mathrm{C}}{ }_{-} \mathrm{A}$. The resultant displacements at each node have been calculated for the normalized T-stress $\left(\mathrm{T} / \sigma_{\mathrm{y}}\right)$ values $0, \pm 0.5, \pm 0.8$ and \pm 1 for C4_A steel.

\subsection{Drop-Weight Tear Test Model-Experimental and Numerical}

\section{Analysis}

The drop weight tear test is also known as a three point bend specimen or single edge notched bend specimen. The DWTT is widely used to evaluate toughness and fracture mode (i.e. transition from ductile to brittle) of high strength pipeline steels. In this topic, 
experimental and finite element analysis have been described along with the data collection of load-displacement data, crack tip opening angle (CTOA) and crack propagation rate.

\subsubsection{Experimental Set up and Data Collection of DWTT}

The quasi-static DWTT test of X100 (C4) steel was conducted by Xu (2013). The test set up is shown in Figure 5.10. The specimen is machined from the full thickness flattened pipe section. The simply supported beam has a base of 'anvils' and load is applied gradually at the center of the beam from 'tup'. The ramp rate of the tup is $3 \mathrm{~mm} / \mathrm{min}$ as the test is displacement control. The data collection rate of the testing machine is 4 pts. / sec. The beam is $305 \mathrm{~mm}$ in length, $76.2 \mathrm{~mm}$ in width and $13.7 \mathrm{~mm}$ in depth. The span between the two anvils is $250.4 \mathrm{~mm}$ and original notch depth $14.5 \mathrm{~mm}$.

\section{Load vs. Load Line Displacement plot:}

The Load vs. LLD was recorded by Xu (2013, CANMET MTL). The load is recorded as the reaction forces at corresponding applied displacement. The displacement is the travelling of the top middle point of the beam. But there will be additional elongation due to the testing machine of the DWTT. That difference in elongation can be resolved by calculating load line displacement for the compliance.

The non-dimensional load line compliance for the single edge notched specimen loaded in three point bending is (Anderson, 2011), 


$$
\begin{aligned}
\mathrm{Z}_{\mathrm{LL}}=\frac{\Delta \mathrm{BE}^{\prime}}{\mathrm{P}}= & \frac{\mathrm{S}^{3}\left(1-v^{2}\right)}{\mathrm{W}^{3}}\left[0.25+0.6\left(\frac{\mathrm{W}}{\mathrm{S}}\right)^{2}(1+v)\right]+1.5\left(\frac{\mathrm{s}}{\mathrm{W}}\right)^{2}\left(\frac{\frac{\mathrm{a}}{\mathrm{W}}}{1-\frac{\mathrm{a}}{\mathrm{W}}}\right)^{2}[5.58- \\
& \left.9.57\left(\frac{\mathrm{a}}{\mathrm{W}}\right)+36.82\left(\frac{\mathrm{a}}{\mathrm{W}}\right)^{2}-34.94\left(\frac{\mathrm{a}}{\mathrm{W}}\right)^{3}+12.77\left(\frac{\mathrm{a}}{\mathrm{W}}\right)^{4}\right]
\end{aligned}
$$

where, $\Delta$ is displacement (load line displacement), $\mathrm{B}$ is thickness of the specimen, equals $13.7 \mathrm{~mm}, E^{\prime}$ is Young's modulus (plane strain), equals $E /\left(1-v^{2}\right)=223321.978 \mathrm{MPa}$, $\mathrm{P}$ is a applied load, $\mathrm{S}$ is span between two anvils, equals $250.4 \mathrm{~mm}, v$ is Poisson's ratio, $\mathrm{W}$ is width of the specimen, equals $76.2 \mathrm{~mm}$ and ' $\mathrm{a}$ ' is original notch depth, equals 14.5 mm. By inserting all the values in Equation 5.5, the value of non-dimensional compliance is calculated,

$$
\mathrm{z}_{\mathrm{LL}}=13.058
$$

and hence the desired slope of the graph $(\mathrm{m})=234.304 \mathrm{kN} / \mathrm{mm}$ and compliance is $4.26 \times 10^{-3} \mathrm{~mm} / \mathrm{kN}$.

As a result, the corrected load line displacement (LLD) can be given by:

$$
\mathrm{LLD}^{\text {corrected }}=\mathrm{LLD}^{\text {measured }}-\frac{\mathrm{P}}{\text { Elastic Error Constant }}
$$

In Equation 5.6, the elastic error constant is taken:

Elastic Error constant $=$ Desired slope of the graph - measured (experimental) elastic slope $=234.304-102.04=132.264$.

The plot and data for Load vs. LLD corrected for compliance can be found in Figure 5.11 .

\section{Crack tip opening angle (CTOA):}

As discussed in Section 2.2.1, the crack tip opening angle is measured by the optical method and simplified single specimen method (S-SSM). The values of measured CTOA 
for the C4 material are $19^{\circ}$ with optical method and $10.4^{\circ}$ with S-SSM. These values of CTOA are compared with the FE simulation of DWTT later.

\subsubsection{FE Simulation of DWTT}

The non-linear finite element analysis of a single edge notched bend specimen is performed using ABAQUS 6.11-2/Explicit. In this section, the numerical model has been described by providing information regarding geometry, material properties, mesh, boundary/loading conditions and time steps. The FE simulation without a cohesive layer is executed before analysing the whole model with cohesive behavior. This plane strain elastic-plastic model is appraised to compare Load Vs, LLD data and CTOA to the experimental data provided by Xu (2013, CANMET-MTL).

\subsubsection{Geometry}

As depicted in Figure 5.12, the quasi-static DWTT model comprises the layer of the cohesive segment in between two halves of the model to study crack propagation. The model is rotated by $90^{\circ}$. The half model without the cohesive is $152.5 \mathrm{~mm}$ long, $76.2 \mathrm{~mm}$ wide and $13.7 \mathrm{~mm}$ deep. The length and breadth of the cohesive segment are $61.2 \mathrm{~mm}$ and $0.02 \mathrm{~mm}$ respectively. As a result, the span between the two anvils is $250.42 \mathrm{~mm}$. The specimen contains a pre-crack of $15 \mathrm{~mm}$ in length. The flat crack is designed in order to avoid machined notch to simplify the mesh. All three parts of the model, two halves of the specimen and cohesive part are assembled together using the surface-to-surface tie constraint. The two edges which are connected to cohesive part chosen as master surfaces. Both edges of the cohesive part, top and bottom, are selected as slave surfaces 
as cohesive segment has the finest mesh than two halves of the specimen, (ABAQUS, 2011).

The model has a quasi-static displacement control, not only to make model realistic but also to avert stress singularity at the 'tup', the displacement is applied along length of $12.2 \mathrm{~mm}$, as shown in Figure 5.15.To prevent the rigid body motion in X-direction, the model is constrained in X-direction at the support of anvils.

\subsubsection{Material Properties}

The plastic stress-strain data of C4 (X100) steel can be found in Table 5.3 along with the Young's modulus, yield stress and Poisson's ratio of 203,223 $\mathrm{MPa}, 805 \mathrm{MPa}$ and 0.3

respectively. The mass density is taken $7.85 \times 10^{-6} \mathrm{~kg} / \mathrm{mm}^{3}$. The cohesive parameters for C4_1, C4_2 and C4_3 are listed in Table 5.5. The maximum traction is $3.2 \sigma_{\mathrm{y}}$ for C4_1, C4_2 and C4_3. The maximum displacement $\left(\delta_{c}\right.$, at traction zero) for $\mathrm{C} 4 \_1, \mathrm{C} 4 \_2$, C4_3 are $0.021 \mathrm{~mm}, 0.024 \mathrm{~mm}$ and $0.026 \mathrm{~mm}$. The viscosity coefficient is set equal to $1 \times 10^{-5}$ for damage stabilization of cohesive behavior.

\subsubsection{Mesh}

As illustrated in Figure 5.13 and Figure 5.14, the model is mainly prepared using two types of elements, CPE4R (a four node bilinear plane strain quadrilateral, reduced integration, hourglass control) and COH2D4 (a four node two dimensional element). The sweep (quad) mesh technique is used to produce the cohesive part. The element deletion is kept as 'yes' for cohesive elements. The maximum degradation and linear bulk viscosity are specified as 1 and $1 \times 10^{-5}$ respectively for $\mathrm{COH} 2 \mathrm{D} 4$ elements. The free 
(quad, advancing front) mesh technique is introduced to mesh the rest of the model (two halves of specimen). The size of the cohesive element is slightly different from the modified boundary layer model due to the convergence issue. The cohesive elements are $0.02 \mathrm{~mm}$ wide and $0.03 \mathrm{~mm}$ long. The plane strain elements, which are connected to cohesive layer, are $0.1 \mathrm{~mm} \times 0.1 \mathrm{~mm}$ in size. The mesh is more refined near the crack tip and along direction of crack propagation. The mesh is refined as well at the 'tup' and anvils to avoid complication in meshing and boundary condition. In all, the model comprises 68,991 CPE4R elements and $2040 \mathrm{COH} 2 \mathrm{D} 4$ elements.

\subsubsection{Step Definition and Output}

The ABAQUS 6.11-2 Dynamic, Explicit solver is used for simulation. The Nlgeom (nonlinear geometry) must be "ON" for numerical convergence or to model the non-linearity accurately. The rest of steps are followed as explained in Section 5.2.4.

\subsubsection{Loading Conditions}

Figure 5.15 shows the model with applied boundary conditions. The 'tup' is approximated by applying displacement along the span of $24.02 \mathrm{~mm}$. The displacement is gradually increased from zero to the maximum applied value. The amount of applied displacement is $20 \mathrm{~mm}$ from 'tup'.

The anvils are produced by selecting $6 \mathrm{~mm}$ each side and the movements of those nodes are restricted in X-direction. Hence model will act as a simply supported beam. As shown in Figure 5.15, node A is constrained in the Y-direction to ignore rigid body motion in the Z-direction. 
All loading conditions are assigned on the set of nodes to avoid mesh distortion.

\subsection{Results and Discussion}

\subsubsection{Unit Cell Model}

A cohesive element is able to reproduce the bilinear traction-separation law as expected as shown in Figure 5.16. Hence the same cohesive element size $0.02 \mathrm{~mm} \times 0.02 \mathrm{~mm}$ is used in the models of SSY and MBL. Nevertheless, the different cohesive element size, 0.02 $\mathrm{mm}$ wide and $0.03 \mathrm{~mm}$ long is characterized for drop weight tear test (DWTT) model due to numerical in stability of the software.

\subsubsection{Small Scale Yielding Model}

As discussed in Section 5.2.5, $\mathrm{K}_{\mathrm{I}}$, T field is imposed on small scale yielding model. The ideal small scale yielding models (without T-stress) are examined for $\widehat{\sigma} / \sigma_{\mathrm{y}}$ of $3.2,3.3$ and 3.4 respectively or C4_A, C4_B and C4_C steels.

The crack growth resistance curve (R-curve) and crack tip opening angle have been extracted after post processing of FE simulation in ABAQUS 6.11-2/Explicit.

\section{Crack Growth Resistance Curve (R-curve)}

R-curve is a measure of fracture resistance to the extension of the crack under gradually applied stress intensity factor. The crack growth resistance curve is represented by plotting $K_{r} / K_{o}$ vs. $\Delta a / R_{o}$. Where $K_{r}$ and $K_{o}$ are theoretical applied stress intensity factor and critical stress intensity factor respectively. The displacements in the X-direction at node $0^{\circ}$ are recorded for different time steps. The theoretical applied stress intensity 
factor $\left(\mathrm{K}_{\mathrm{r}}\right)$ can be found by inserting displacement values of $0^{\circ}$ in Equation 5.1. The critical stress intensity (fracture toughness) is the measure of stress intensity factor at which the crack starts to develop. The critical stress intensity $\left(\mathrm{K}_{\mathrm{o}}\right)$ is calculated by,

$$
\mathrm{K}_{0}=\sqrt{\frac{\mathrm{E} \Gamma_{0}}{1-v^{2}}}
$$

The fracture energy $\Gamma_{0}$ can be found by using Equation 2.23.

The cohesive elements are numbered starting from 1 at $(X=0 \mathrm{~mm}, \mathrm{Y}=0 \mathrm{~mm})$ to 450 at $(X=9 \mathrm{~mm}, \mathrm{Y}=0 \mathrm{~mm})$. The length of the crack $(\Delta \mathrm{a})$ is multiplication of the length of the cohesive element and cohesive element number at current crack tip. The current crack tip is predicted as how far the crack tip travels from original position $(\mathrm{X}=0 \mathrm{~mm}, \mathrm{Y}=$ $0 \mathrm{~mm}$ ) of it to the current crack tip position. This travelling is evaluated by counting the number of totally damaged cohesive elements at current crack tip. These totally damaged elements are not eligible to take more traction. Therefore, load carrying capacity vanishes completely at critical separation $\left(\delta_{\mathrm{c}}\right)$. Then the crack length $(\Delta \mathrm{a})$ is normalized by the plastic zone size $\left(\mathrm{R}_{\mathrm{o}}\right)$. The plastic zone size is determined by following equation:

$$
\mathrm{R}_{0}=\frac{1}{3 \pi\left(1-v^{2}\right)} \frac{\mathrm{E} \Gamma_{0}}{\sigma_{\mathrm{y}}^{2}}=\frac{1}{3 \pi}\left(\frac{\mathrm{K}_{\mathrm{o}}}{\sigma_{\mathrm{y}}}\right)^{2}
$$

Hence, Figure 5.17 provides data for the crack growth resistance curve.

Figure 5.17 is the representation of the R-curves of three small scale yielding models, in which T-stress is zero in Equation 5.1. The bilinear traction separation laws are applied with $\widehat{\sigma} / \sigma_{\mathrm{y}}=3.2,3.3,3.4$ and fracture energies $\left(\Gamma_{0}\right.$, for half model $)=15.456 \mathrm{MPa} \cdot \mathrm{mm}$, 15.939 $\mathrm{MPa} \cdot \mathrm{mm}$ and 16.422 $\mathrm{MPa} \cdot \mathrm{mm}$ respectively. It can be observed from Figure 5.17, that the R-curve is steeper for high toughness material (C4_C). This indicates that more energy is required to initiate fracture damage for high toughness material. Hence, the 
amount of fracture resistance decreases from the high plastic zone size $\left(R_{0}\right)$ to the low plastic zone size. The plastic zone size $\left(\mathrm{R}_{\mathrm{o}}\right)$ is smallest for low toughness material (C4_A) and so there is less restriction to crack propagation. The fracture process zone expands by increasing stress intensity. The R-curves show transition from fracture initiation and damage to steady state region. In a steady state region, normalized plastic zone size remains almost constant.

\section{Crack tip opening angle}

As per the International Organization for Standardization (ISO), the crack tip opening angle (CTOA) should be calculated at $1 \mathrm{~mm}$ behind the current crack tip. The crack tip is introduced as the node shared between the element which is removed and the node which is about to remove. After choosing the node which is approximately $1 \mathrm{~mm}$ behind the crack tip, the crack tip opening displacement (CTOD) was measured for that particular node. The trigonometry rule was followed to calculate CTOA, which can be followed by equation,

$$
\mathrm{CTOA}=2 \cdot \tan ^{-1} \frac{\mathrm{CTOD}}{1}
$$

Equation 5.9 is multiplied by 2, to get the CTOA for the full model.

Afterwards, CTOA was measured at different crack length at different interval of time C2_A, C2_B and C2_C. To estimate the steady state CTOA, the trendlines are plotted using power law fit in Tecplot. The graph of CTOA vs. $\Delta \mathrm{a}$ is plotted in Figure 5.18. The measured steady states CTOA results are $12.4^{\circ}, 14.18^{\circ}$ and $17^{\circ}$ for C4_A, C4_B and C4_C respectively. It can be observed that CTOA is increasing by increasing the fracture toughness. 


\subsubsection{Modified Boundary layer model}

The FE simulations of MBL models are inspected for varying level of normalized Tstress such as $0, \pm 0.5, \pm 0.8$ and \pm 1 for C4_A steel.

The procedure to calibrate R-curve and CTOA data is same as discussed in Section 5.5.2 for MBL of C4_A steel.

\section{Crack growth resistance curve (R-curve)}

The computed R-curves with T-stress effect are depicted in Figure 5.19. The R-curves are

plotted for $\mathrm{T} / \sigma_{\mathrm{y}}=0$, negative normalized $\mathrm{T}$-stress $\left(\mathrm{T} / \sigma_{\mathrm{y}}\right)=-1,-0.8,-0.5$ and positive normalized T-stress $\left(\mathrm{T} / \sigma_{\mathrm{y}}\right)=+1,+0.8,+0.5$. The peak $\operatorname{traction}(\hat{\sigma})$ in normal direction is taken as $3.2 \sigma_{\mathrm{y}}$. The fracture energy $\left(\Gamma_{0}\right)$ for half model is plugged in as $15.456 \mathrm{MPa} \cdot \mathrm{mm}$. As shown in Figure 5.19, R-curves are comparatively higher for $T / \sigma_{y}<0$. In all, Rcurves with different $\mathrm{T} / \sigma_{\mathrm{y}}$ values do not differ much from each other.

\section{Crack tip opening angle}

The CTOA can be extracted for modified boundary layer models of C4_A steel with varying values of the normalized T-stress $\left(\mathrm{T} / \sigma_{\mathrm{y}}\right)$ values $0, \pm 0.5, \pm 0.8$ and \pm 1 . The peak traction and fracture energy are $3.2 \sigma_{\mathrm{y}}$ and $15.456 \mathrm{MPa} \cdot \mathrm{mm}$ respectively. The crack tip opening angles (CTOA) are almost the same for $\mathrm{T} / \sigma_{\mathrm{y}}=0, \mathrm{~T} / \sigma_{\mathrm{y}}<0, \mathrm{~T} / \sigma_{\mathrm{y}}>0$. (Refer to Figure 5.20). 


\subsubsection{Drop-Weight Tear Test (DWTT)}

The quasi-static analysis of drop-weight tear test is performed by applying monotonic displacement.

\section{Plane strain elastic plastic model}

As discussed in Section 5.4.2, the plane strain elastic plastic analysis without a cohesive layer is carried out to evaluate the trend of load vs. load line displacement (LLD). This computational data is compared with the experimental Load vs. LLD curve delivered by Xu (2013, CANMET-MTL). The experimental Load vs. LLD data are corrected for compliance. The load line displacements are recorded in the X-direction from the 'tup' at each step time. The reaction forces are measured in X-direction at each node of 'anvils'. The summation of reaction forces is multiplied by thickness of the beam to get the total applied load at each time step. The thickness of the model is $13.7 \mathrm{~mm}$ as mentioned in Section 5.4.2.1.The load can be predicted by:

$$
\mathrm{P}(\mathrm{a})=13.7 \cdot \sum_{\text {anvil nodes }} \mathrm{F}_{\mathrm{X}}^{\text {reaction }}(\mathrm{a})
$$

The numerical data and experimental data of Load vs. LLD are plotted in Figure 5.21.

\section{Load vs. Load Line Displacement}

In Figure 5.22, the numerical results of Load vs. LLD are compared with experimental Load vs. Load. Three curves of computational results C4_1, C4_2 and C4_3 are plotted in Figure 5.22. It can be seen that trend of all three plots is in good agreement with experimental curve until load reaches to its maximum value. The material C4_3 has shown quite close consistency to experimental data. The simulation for C4_1 is aborted 
due to numerical instability after LLD of $3 \mathrm{~mm}$. The constant blunting has been showed for material C4_2 after LLD of $5 \mathrm{~mm}$.

\section{Crack tip opening angle}

As expressed in Section 5.5.2, according to ISO, the crack tip opening angles (CTOA) are measured at $1 \mathrm{~mm}$ behind the current crack tip. The crack tip opening displacement (CTOD) between two surfaces of model is calibrated. Since the FE simulation is accomplished on full scale model of drop-weight tear test (DWTT), the crack tip opening angle (CTOA) is calculated using,

$$
\text { CTOA }=\tan ^{-1} \frac{\mathrm{CTOD}}{1}
$$

Figure 5.23, depicts the plot of CTOA vs. crack length $(\Delta \mathrm{a})$. Using Tecplot, the power law trendlines are plotted on CTOA results to find the steady state value of CTOA. The experimental CTOA, measured by optical method and S-SSM method are $19^{\circ}$ and $10.4^{\circ}$ respectively (Xu, et al., 2010b). It can be observed that the steady state crack tip opening angles of material $\mathrm{C} 4 \_1$ and $\mathrm{C} 4 \_2$ are ranged from $8^{\circ}$ to $10^{\circ}$. The practically measured CTOA of C4_3 steel is $9.3^{\circ}$. The CTOA results show good agreement with experimental CTOA results.

\section{Crack Growth Rate}

From Figure 5.24, a stable ductile fracture growth can be observed for all three materials:

C4_1, C4_2 and C4_3.The crack growth starts at first cohesive element which is 0.03 $\mathrm{mm}$ long. When crack growth starts, the displacements are $0.4658 \mathrm{~mm}, 0.5177 \mathrm{~mm}$ and $0.5337 \mathrm{~mm}$ for C4_1, C4_2 and C4_3 respectively. It can be stated that the material 
which has high fracture energy (the tougher material) will take more amount of applied displacement to develop the crack from its original position. The recorded final crack lengths of all three materials at the end of the simulation are $9.6 \mathrm{~mm}, 14.4 \mathrm{~mm}$ and 44.4 $\mathrm{mm}$ for C4_1, C4_2 and C4_3 respectively. A material C4_3 has shown quite good stable propagation until a crack length of $44.4 \mathrm{~mm}$ with a displacement of $15.8658 \mathrm{~mm}$.

\subsection{Conclusions}

Four models of finite element analysis are conducted for C4 pipe steel. Namely, unit cell, small scale yielding model, modified boundary layer model and drop-weight tear test.

The unit cell analysis shows good agreement to produce bilinear and exponential tractionseparation behaviour for all six sets of materials; C4_A, C4_B, C4_C, C4_1, C4_2 and C4_3.

It can be observed from three sets of small scale yielding model that high toughness material will resist crack propagation more and hence higher value of CTOA for high toughness material. The steady state CTOA $\left(12.4^{\circ}\right)$ for SSY model of C4_A steel is compared with the DWTT simulation of C4_2 steel, as both sets of materials have same fracture energy and peak traction but different shapes of TS law.

In the MBL of C2_A, the resistance curves are slightly different to each other, and CTOA for all positive T-stress, negative $\mathrm{T}$ - stress and without $\mathrm{T}$-stress are almost the same. Therefore, it can be concluded that T-stress does not much affect the CTOA.

The DWTT simulation has different cohesive parameters than the unit cell and small scale yielding model due to convergence problem. After trial and error, the cohesive parameters have been selected for DWTT to reproduce load vs. LLD plot and CTOA 
provided by Xu (2013, CANMET MTL). All three DWTT simulations have same ratio of $\widehat{\sigma} / \sigma_{\mathrm{y}}=3.2$ but different critical displacement $\left(\delta_{\mathrm{c}}\right)$. The material $\mathrm{C} 4{ }_{-} 3$ is able to reproduce comparable load vs. LLD plot. The steady state CTOA of C4 3 is $9.3^{\circ}$, that is quite promising and comparable to experimental (S-SSM) CTOA value $10.4^{\circ}$ delivered by $\mathrm{Xu}$, et al. (2010b). Furthermore, the error between the numerical CTOA results of DWTT for C4_2 steel and SSY model for C4_A steel is 4\%. This difference is expected as the length of cohesive zone of SSY model is not as long as DWTT, hence the CTOA of SSY is not reached yet to the CTOA value of DWTT.

In all, C4_3 material's cohesive parameters are worth enough to reproduce experimental data. 


\begin{tabular}{|lllllllllll|}
\hline Steel & $\mathbf{C}$ & $\mathbf{M n}$ & $\mathbf{S i}$ & $\mathbf{A l}$ & $\mathbf{N b}$ & $\mathbf{T i}$ & $\mathbf{C u}$ & $\mathbf{C r}$ & $\mathbf{N i}$ \\
\hline C4 & 0.06 & 1.75 & 0.06 & 0.012 & 0.045 & 0.008 & 0.28 & 0.028 & 0.13 \\
\hline
\end{tabular}

Table 5.1a

\begin{tabular}{|llllllllll|}
\hline Steel & $\mathbf{P}$ & $\mathbf{S}$ & Mo & Ca & Sn & $\mathbf{B}$ & $\mathbf{N}$ & $\mathbf{C e}$ & $\mathbf{V}$ \\
\hline C4 & 0.036 & 0.036 & $<0.030$ & - & - & - & - & - & $<0.010$ \\
\hline
\end{tabular}

Table 5.1b

Table 5.1: Chemical composition of pipe steel C4 (X100) (wt \%), (Xu et al., 2010b)

\begin{tabular}{|clllllll|}
\hline & YS & UTS & Elongation & $\begin{array}{l}\text { Area } \\
\text { Reduction }\end{array}$ & $\mathbf{N}$ & $\mathbf{Y} / \mathbf{T}$ & CVN \\
& $(\mathbf{M P a})$ & $\mathbf{( M P a )}$ & $\mathbf{( \% )}$ & $\mathbf{( \% )}$ & & $(\mathbf{J})$ \\
\hline $\mathrm{C}_{4}$ & 805 & 853 & 19.7 & 76.3 & 0.050 & 0.94 & 223 \\
\hline
\end{tabular}

Table 5.2: Average transverse tensile and charpy properties of pipe steel C4 (X100), (Xu et al., 2010b) 


\begin{tabular}{|c|c|c|c|c|c|c|c|c|c|}
\hline $\begin{array}{l}\text { Stress } \\
(\mathrm{MPa})\end{array}$ & $\begin{array}{l}\text { Plastic } \\
\text { strain }\end{array}$ & $\begin{array}{l}\text { Stress } \\
(\mathrm{MPa})\end{array}$ & $\begin{array}{l}\text { Plastic } \\
\text { strain }\end{array}$ & $\begin{array}{l}\text { Stress } \\
(\mathrm{MPa})\end{array}$ & $\begin{array}{l}\begin{array}{l}\text { Plastic } \\
\text { strain }\end{array} \\
\end{array}$ & $\begin{array}{l}\text { Stress } \\
(\mathrm{MPa})\end{array}$ & $\begin{array}{l}\text { Plastic } \\
\text { strain }\end{array}$ & $\begin{array}{l}\begin{array}{l}\text { Stress } \\
(\mathrm{MPa})\end{array} \\
\end{array}$ & $\begin{array}{l}\begin{array}{l}\text { Plastic } \\
\text { strain }\end{array} \\
\end{array}$ \\
\hline 805.00000 & 0.00000 & 835.07951 & 0.00893 & 857.66019 & 0.01704 & 876.59876 & 0.02536 & 891.15196 & 0.03428 \\
\hline 806.83960 & 0.00054 & 835.40425 & 0.00916 & 858.16596 & 0.01724 & 877.00069 & 0.02558 & 891.41385 & 0.03450 \\
\hline 809.35842 & 0.00071 & 836.04829 & 0.00937 & 858.34044 & 0.01744 & 877.57526 & 0.02601 & 892.15205 & 0.03471 \\
\hline 810.96172 & 0.00090 & 836.49254 & 0.00958 & 859.32090 & 0.01765 & 878.85140 & 0.02661 & 892.35705 & 0.03494 \\
\hline 811.63377 & 0.00107 & 836.65749 & 0.00978 & 859.76647 & 0.01785 & 879.24279 & 0.02682 & 893.01598 & 0.03538 \\
\hline 812.37882 & 0.00126 & 837.82767 & 0.00998 & 860.64272 & 0.01825 & 879.15086 & 0.02703 & 893.27155 & 0.03559 \\
\hline 813.72953 & 0.00146 & 838.98826 & 0.01041 & 861.02243 & 0.01845 & 879.63610 & 0.02743 & 893.68409 & 0.03582 \\
\hline 814.97422 & 0.00169 & 839.27838 & 0.01060 & 861.52361 & 0.01864 & 880.76968 & 0.02764 & 894.15381 & 0.03604 \\
\hline 814.95677 & 0.00191 & 839.63950 & 0.01079 & 862.41376 & 0.01905 & 881.01690 & 0.02784 & 894.08090 & 0.03626 \\
\hline 815.12503 & 0.00211 & 840.73363 & 0.01098 & 863.06199 & 0.01926 & 881.34312 & 0.02806 & 894.68989 & 0.03648 \\
\hline 816.01887 & 0.00232 & 841.71833 & 0.01120 & 863.66821 & 0.01965 & 881.38907 & 0.02826 & 894.73329 & 0.03692 \\
\hline 816.65826 & 0.00253 & 842.45573 & 0.01160 & 864.72076 & 0.01985 & 882.32212 & 0.02847 & 895.48644 & 0.03714 \\
\hline 817.22329 & 0.00274 & 843.08577 & 0.01179 & 864.89612 & 0.02006 & 882.92022 & 0.02869 & 895.88828 & 0.03736 \\
\hline 817.93728 & 0.00297 & 843.25381 & 0.01199 & 865.19950 & 0.02025 & 883.19229 & 0.02892 & 895.68240 & 0.03759 \\
\hline 818.76970 & 0.00342 & 844.76226 & 0.01220 & 865.78014 & 0.02046 & 883.42692 & 0.02934 & 895.94049 & 0.03780 \\
\hline 819.40691 & 0.00363 & 845.13850 & 0.01240 & 866.01643 & 0.02065 & 884.02318 & 0.02955 & 896.20088 & 0.03802 \\
\hline 819.85237 & 0.00385 & 845.57634 & 0.01261 & 866.44499 & 0.02084 & 883.93766 & 0.02976 & 897.22671 & 0.03824 \\
\hline 820.63303 & 0.00407 & 846.02080 & 0.01282 & 867.16188 & 0.02104 & 885.07603 & 0.02997 & 897.29234 & 0.03870 \\
\hline 821.66890 & 0.00453 & 846.86106 & 0.01302 & 867 & 0.0 & 88 & 0.0 & $89^{\circ}$ & 0.03 \\
\hline 822.32452 & 0.00476 & 847.76967 & 0.01322 & 867.84049 & 0.02143 & 885.38127 & 0.03063 & 897.75151 & 0.03914 \\
\hline 822.76602 & 0.00497 & 848.01817 & 0.01344 & 868.27715 & 0.02163 & 885.90584 & 0.03083 & 898.08298 & 0.03935 \\
\hline 823.48025 & 0.00520 & 848.68811 & 0.01383 & 868.64854 & 0.02182 & 886.63040 & 0.03104 & 898.62949 & 0.03958 \\
\hline 824.19653 & 0.00542 & 849.39344 & 0.01403 & 869.57088 & 0.02203 & 886.96433 & 0.03126 & 898.61771 & 0.03979 \\
\hline 825.69121 & 0.00587 & 849.68968 & 0.01422 & 869.96252 & 0.02225 & 886.88084 & 0.03147 & 898.60817 & 0.04001 \\
\hline 826.01289 & 0.00610 & 850.800 & 0 . & 87 & 0.02245 & 887.27 & 0.03 & 899.00842 & 0.04023 \\
\hline 826.52160 & 0.00631 & 851.10673 & 0.01463 & 870.79585 & 0.02266 & 887.73115 & 0.03189 & 899.48433 & 0.04045 \\
\hline 827.43810 & 0.00653 & 851.47452 & 0.01483 & 871.04161 & 0.02287 & 887.50447 & 0.03210 & 899.97372 & 0.04069 \\
\hline 828.73369 & 0.00698 & 852.11166 & 0.01502 & 871.55323 & 0.02306 & 888.72250 & 0.03232 & 900.23678 & 0.04091 \\
\hline 829.37598 & 0.00719 & 852.95422 & 0.01523 & 872.60320 & 0.02349 & 888.91603 & 0.03254 & 900.31373 & 0.04114 \\
\hline 830.08893 & 0.00741 & 853.66423 & 0.01543 & 872.91686 & 0.02370 & 889.04142 & 0.03276 & 900.57375 & 0.04159 \\
\hline 831.06265 & 0.00762 & 854.28130 & 0.01584 & 873.30042 & 0.02391 & 889.36470 & 0.03297 & 901.17209 & 0.04179 \\
\hline 831.65586 & 0.00785 & 854.99060 & 0.01604 & 873.54214 & 0.02411 & 889.83562 & 0.03319 & 901.59981 & 0.04204 \\
\hline 832.30129 & 0.00807 & 855.42205 & 0.01623 & 874.54768 & 0.02433 & 890.22733 & 0.03340 & 901.38567 & 0.04226 \\
\hline 832.82511 & 0.00830 & 855.85800 & 0.01643 & 874.91620 & 0.02475 & 890.70507 & 0.03363 & 901.58448 & 0.04248 \\
\hline 833.26220 & 0.00850 & 856.70635 & 0.01663 & 875.15598 & 0.02495 & 891.18306 & 0.03386 & 902.05435 & 0.04269 \\
\hline 834.10514 & 0.00872 & 857.28775 & 0.01684 & 875.47673 & 0.02516 & 891.03310 & 0.03407 & 902.41117 & 0.04294 \\
\hline
\end{tabular}

Table 5.3: Stress vs. plastic strain data- C4 steel (input in ABAQUS) 


\begin{tabular}{|c|c|c|c|c|c|c|c|}
\hline \multicolumn{7}{|c|}{ C4 Steel } \\
\hline \multirow{2}{*}{ Material } & \multicolumn{2}{|c|}{$\begin{array}{c}\text { Fracture } \\
\text { MaxS Damage (MPa) } \\
\end{array}$} & $\begin{array}{c}\text { Energy } \\
\text { (MPa-mm) }\end{array}$ & \multicolumn{2}{|c|}{ Elastic Moduli (MPa) } \\
& \multicolumn{2}{|c|}{ 2nd } & Linear & $\mathbf{K}_{\text {nn }}$ & $\mathbf{K}_{\text {ss }}$ & $\mathbf{K}_{\text {tt }}$ \\
\hline C4_A & 2576 & 1932 & 1932 & 15.456 & 10000000 & 3846154 & 3846154 \\
\hline C4_B & 2656.5 & 1992.375 & 1992.375 & 15.939 & 10000000 & 3846154 & 3846154 \\
\hline C4_C & 2737 & 2052.75 & 2052.75 & 16.422 & 10000000 & 3846154 & 3846154 \\
\hline
\end{tabular}

Table 5.4: Cohesive properties of three sets of C4 steel (used in unit cell, SSY and MBL)

\begin{tabular}{|c|c|c|c|c|c|c|c|c|c|}
\hline \multicolumn{10}{|c|}{ C4 Steel } \\
\hline \multirow[t]{2}{*}{ Material } & \multicolumn{3}{|c|}{ MaxS Damage (MPa) } & \multirow{2}{*}{$\begin{array}{c}\text { Critical } \\
\text { displacement } \\
\left(\boldsymbol{\delta}_{\mathbf{c}}, \mathbf{m m}\right) \\
\text { Exponential }\end{array}$} & \multirow[t]{2}{*}{$\alpha$} & \multicolumn{3}{|c|}{ Elastic Moduli (MPa) } & \multirow[t]{2}{*}{ V.C. } \\
\hline & Normal & 1st & $2^{\text {nd }}$ & & & $K_{n n}$ & $\mathbf{K}_{\text {ss }}$ & $\mathbf{K}_{\mathrm{tt}}$ & \\
\hline C4_1 & 2576 & 1932 & 1932 & 0.021 & 1 & 10000000 & 3846154 & 3846154 & $10^{-5}$ \\
\hline C4_2 & 2576 & 1932 & 1932 & 0.024 & 1 & 10000000 & 3846154 & 3846154 & $10^{-5}$ \\
\hline C4_3 & 2576 & 1932 & 1932 & 0.026 & 1 & 10000000 & 3846154 & 3816154 & $10^{-5}$ \\
\hline
\end{tabular}

Table 5.5: Cohesive properties of three sets of C4 steel (used in unit cell and DWTT) 


\begin{tabular}{|c|c|c|c|c|c|c|}
\hline Material & $\widehat{\sigma} / \sigma_{y}$ & $\begin{array}{c}\Gamma_{0} \\
(\mathrm{MPa} \cdot \mathbf{m m})\end{array}$ & $\begin{array}{c}\boldsymbol{\delta}_{\mathbf{c}} \\
(\mathbf{m m})\end{array}$ & $\begin{array}{c}\mathbf{K}_{\mathbf{0}} \\
(\mathbf{M P a} \cdot \sqrt{\mathbf{m m}})\end{array}$ & $\begin{array}{c}\mathbf{R}_{\mathbf{0}} \\
(\mathbf{m m})\end{array}$ & TS law \\
\hline C4_A & 3.2 & 30.912 & 0.024 & 2627.42 & 1.1303 & \multirow{3}{*}{ Bilinear } \\
\hline C4_B & 3.3 & 31.878 & 0.024 & 2668.16 & 1.1656 & \\
\hline C4_C & 3.4 & 32.844 & 0.024 & 2708.28 & 1.2009 & \\
\hline C4_1 & 3.2 & 27.048 & 0.021 & 2457.73 & 0.9890 & \multirow{3}{*}{ Exponential } \\
\hline C4_2 & 3.2 & 30.912 & 0.024 & 2627.42 & 1.1303 & \\
\hline C4_3 & 3.2 & 33.488 & 0.026 & 2734.70 & 1.2245 & \\
\hline
\end{tabular}

Table 5.6: Model parameters - C4 steel 


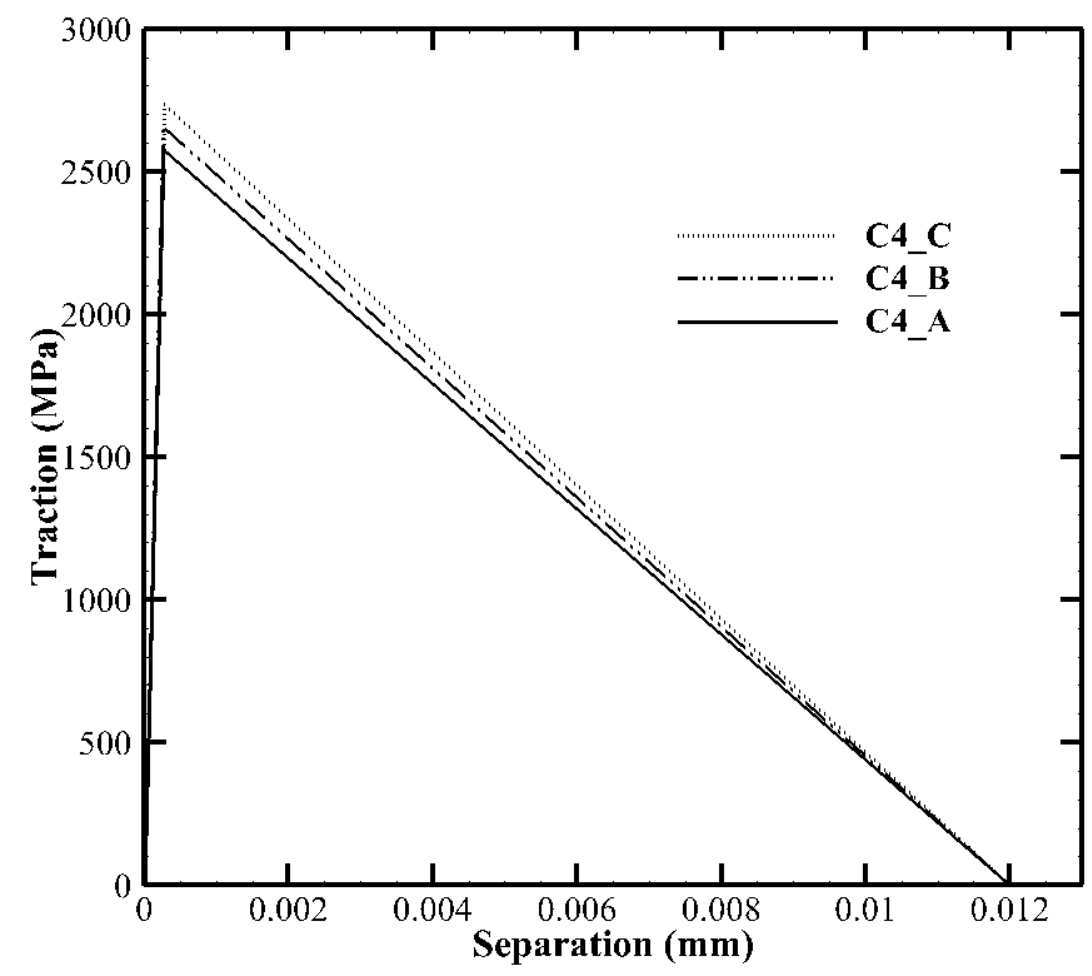

Figure 5.1: Bilinear traction-separation laws - C4 steel (used in unit cell, SSY and MBL)

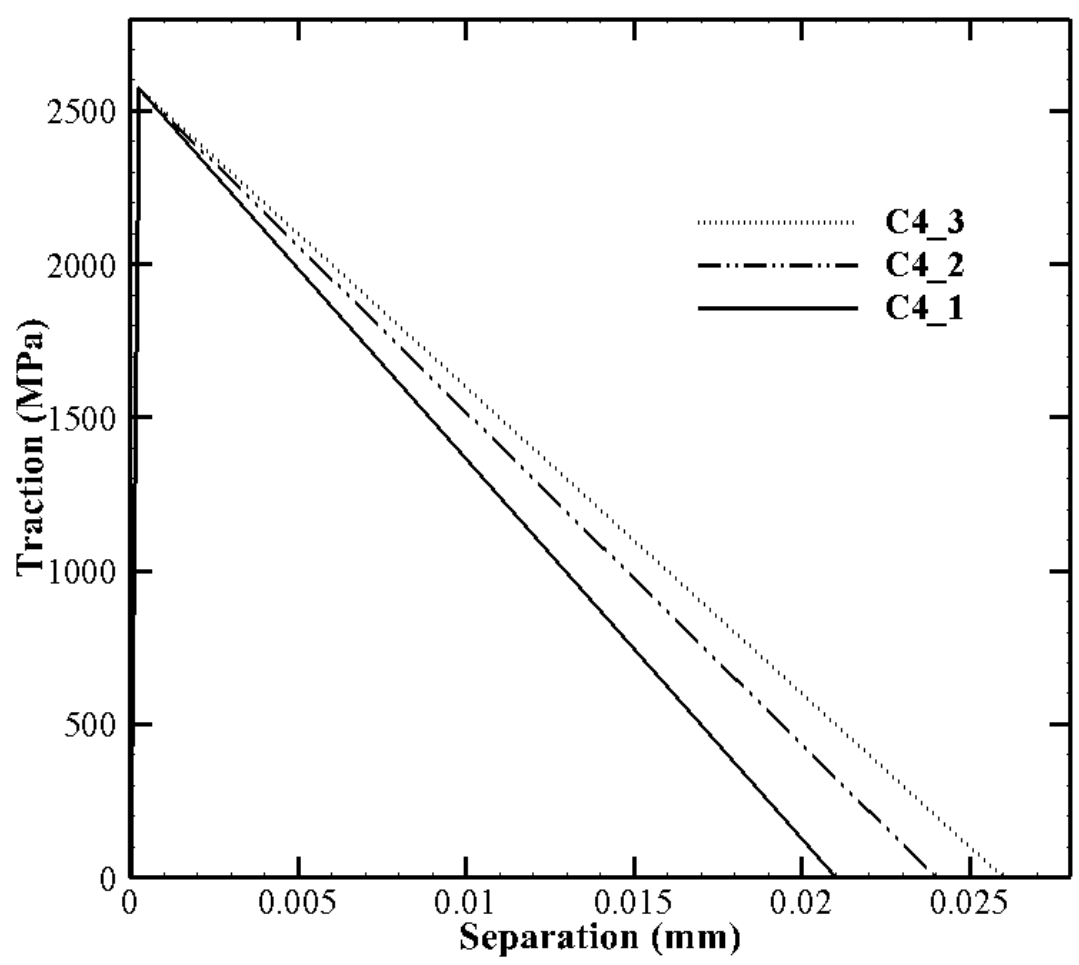

Figure 5.2: Exponential traction-separation laws $(\alpha=1)$ - C4 steel (used in unit cell and DWTT) 


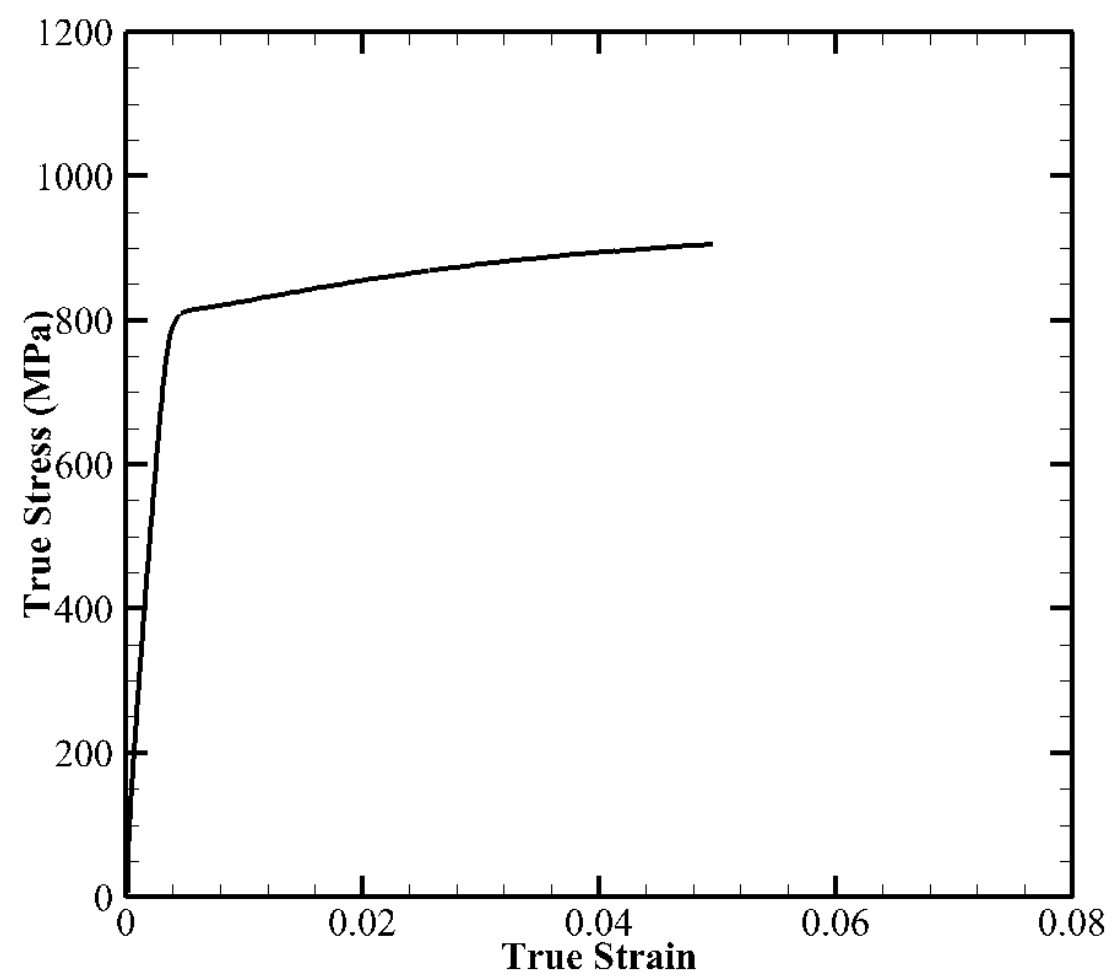

Figure 5.3: True stress-strain curve - C4 steel

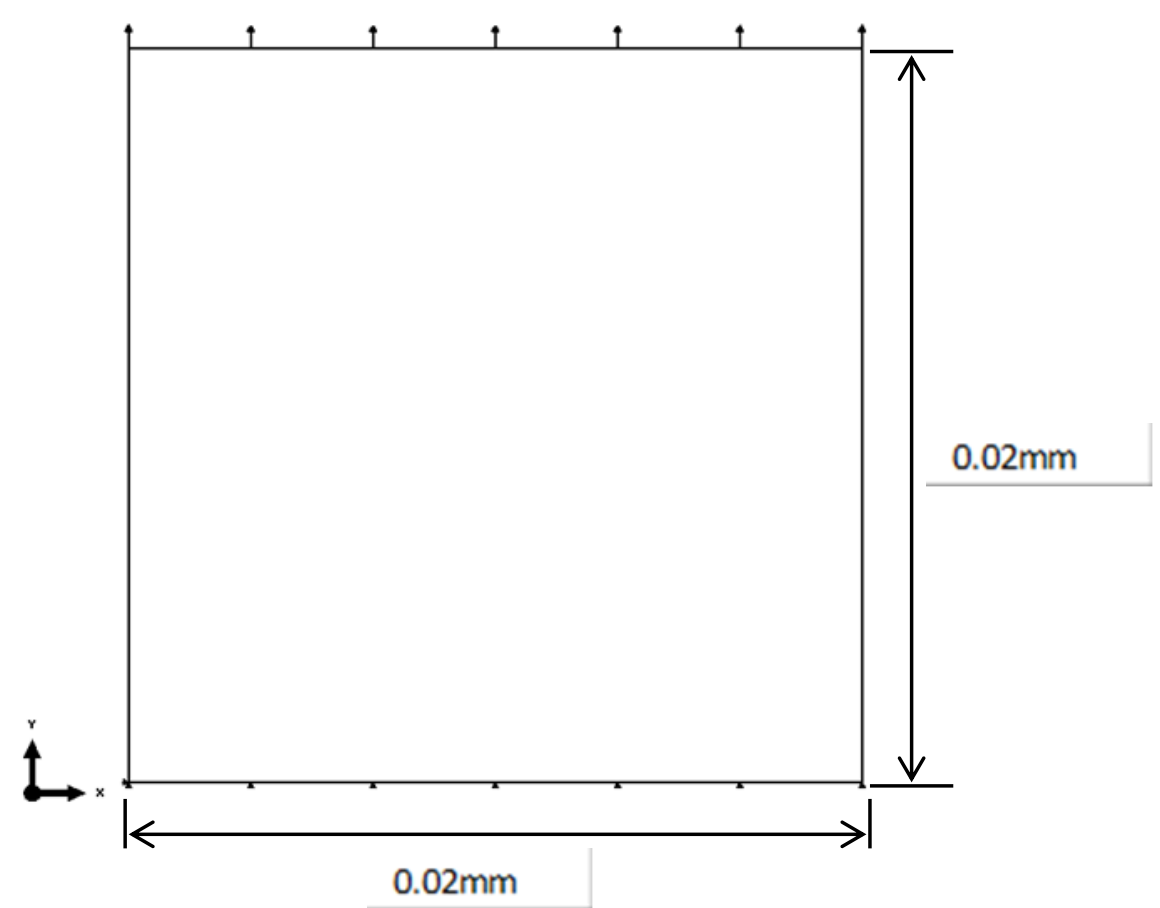

Figure 5.4: Geometry and boundary condition of unit cell model - C4 steel 


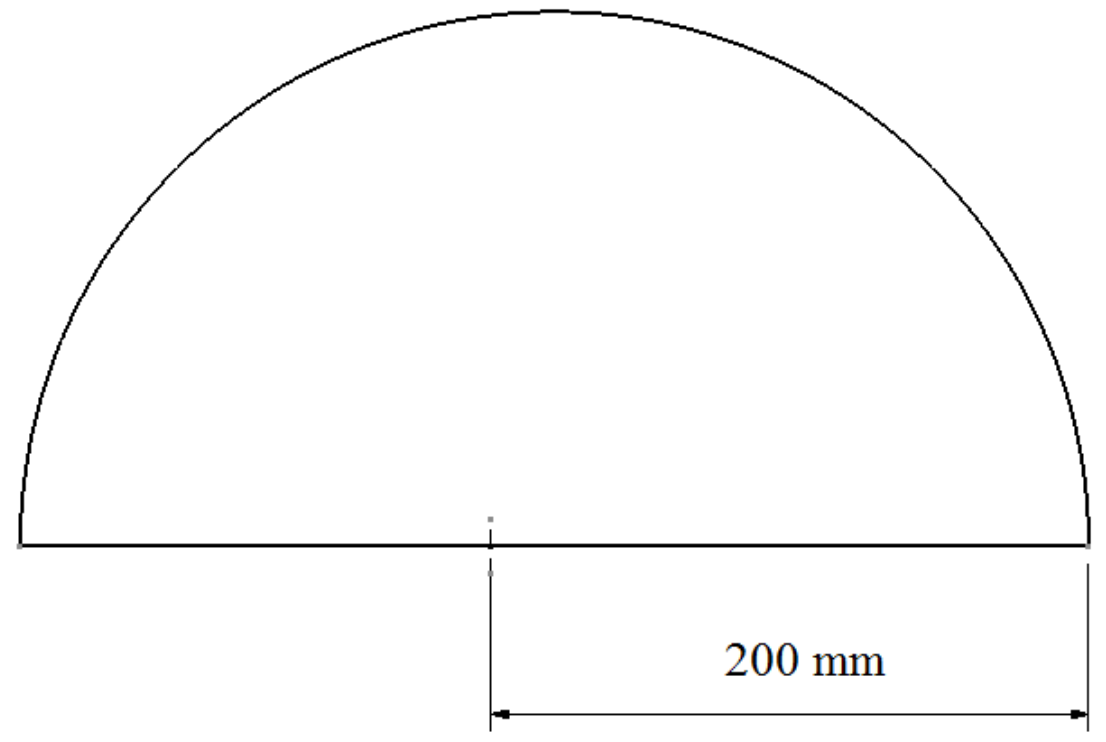

Figure 5.5: Geometry of SSY and MBL model-C4 steel

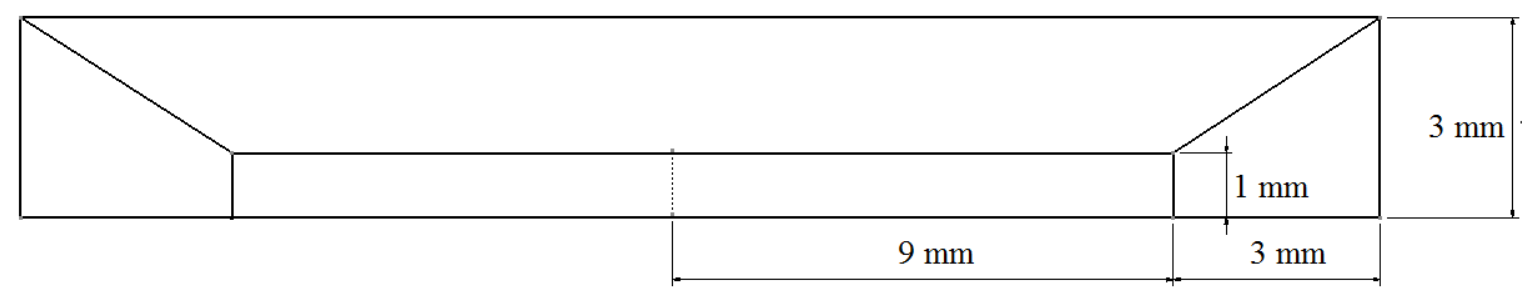

Figure 5.6: Geometry of mesh near crack tip - SSY and MBL model - C4 steel 


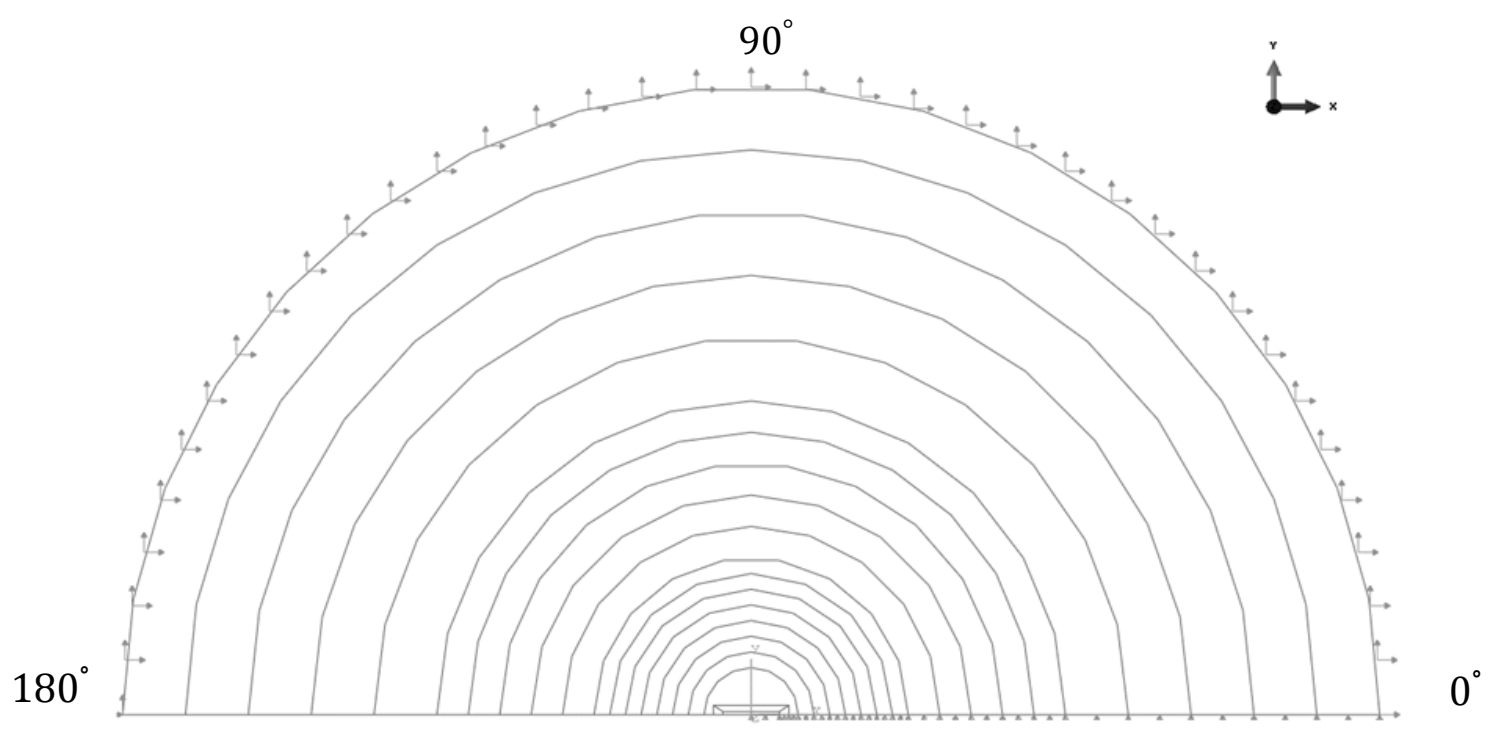

Figure 5.7: Boundary conditions - SSY and MBL model - C4 steel

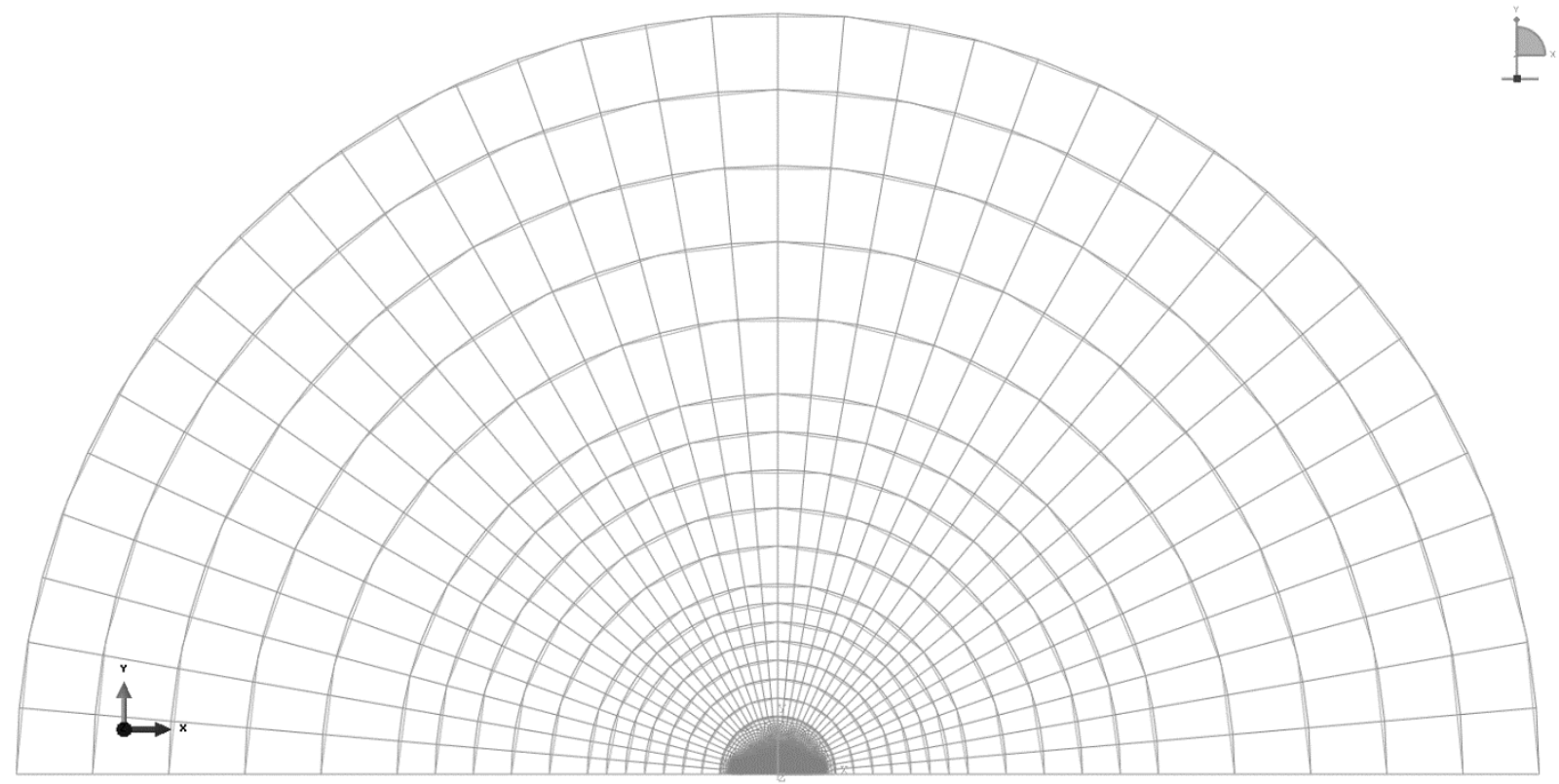

Figure 5.8: Mesh design - SSY and MBL model - C4 steel 


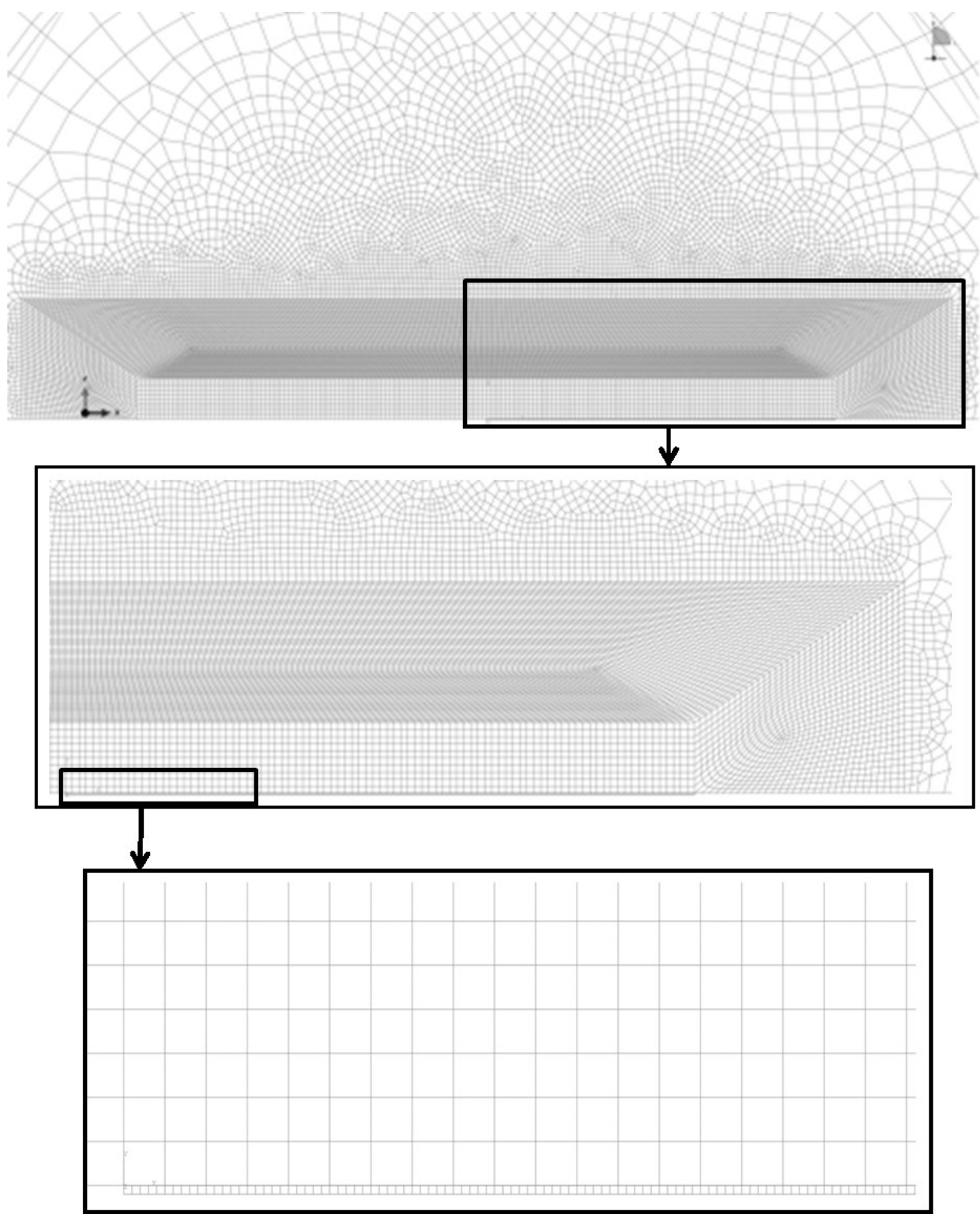

Figure 5.9: Mesh design near crack tip - SSY and MBL model - C4 steel 


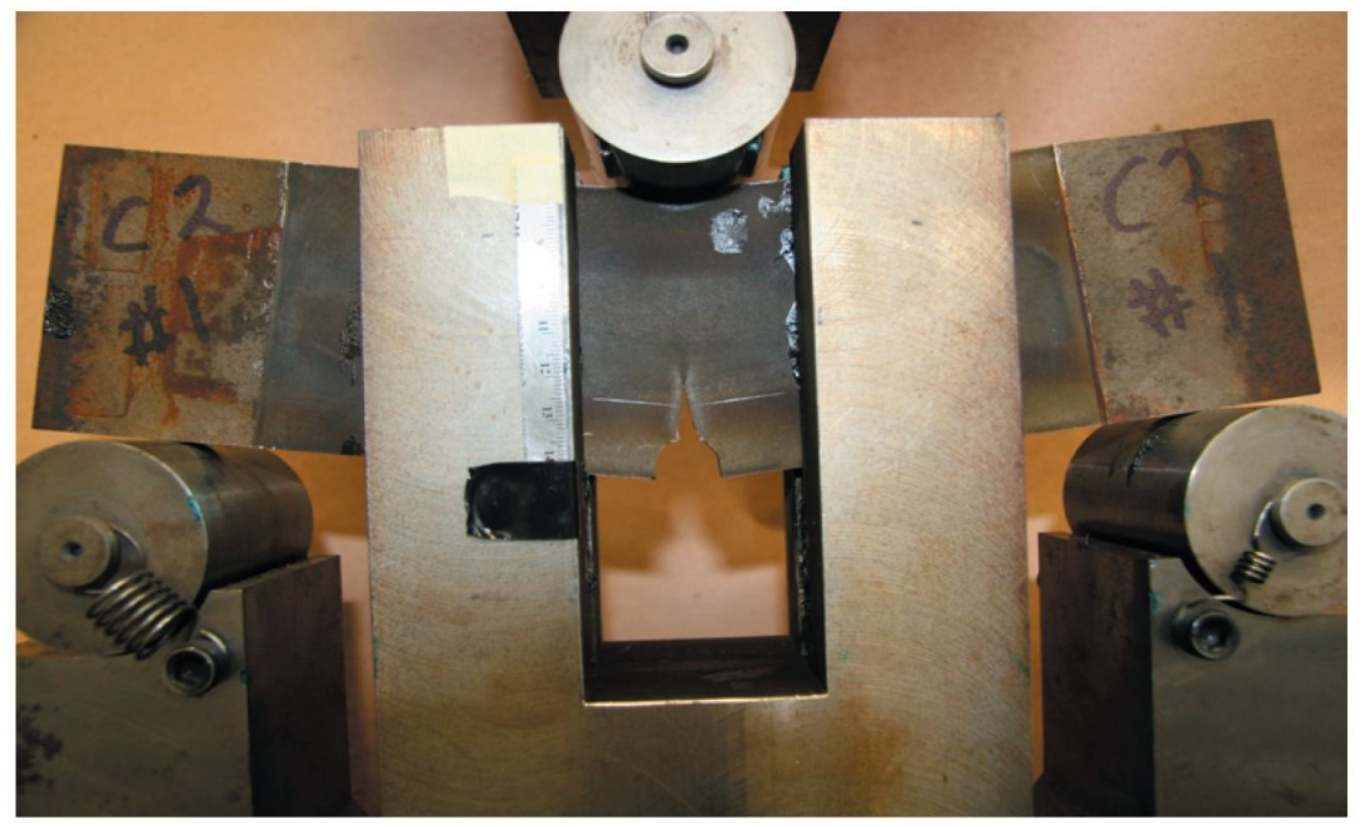

Figure 5.10: Experimental DWTT set up-C4 steel, (Xu et al., 2010b)

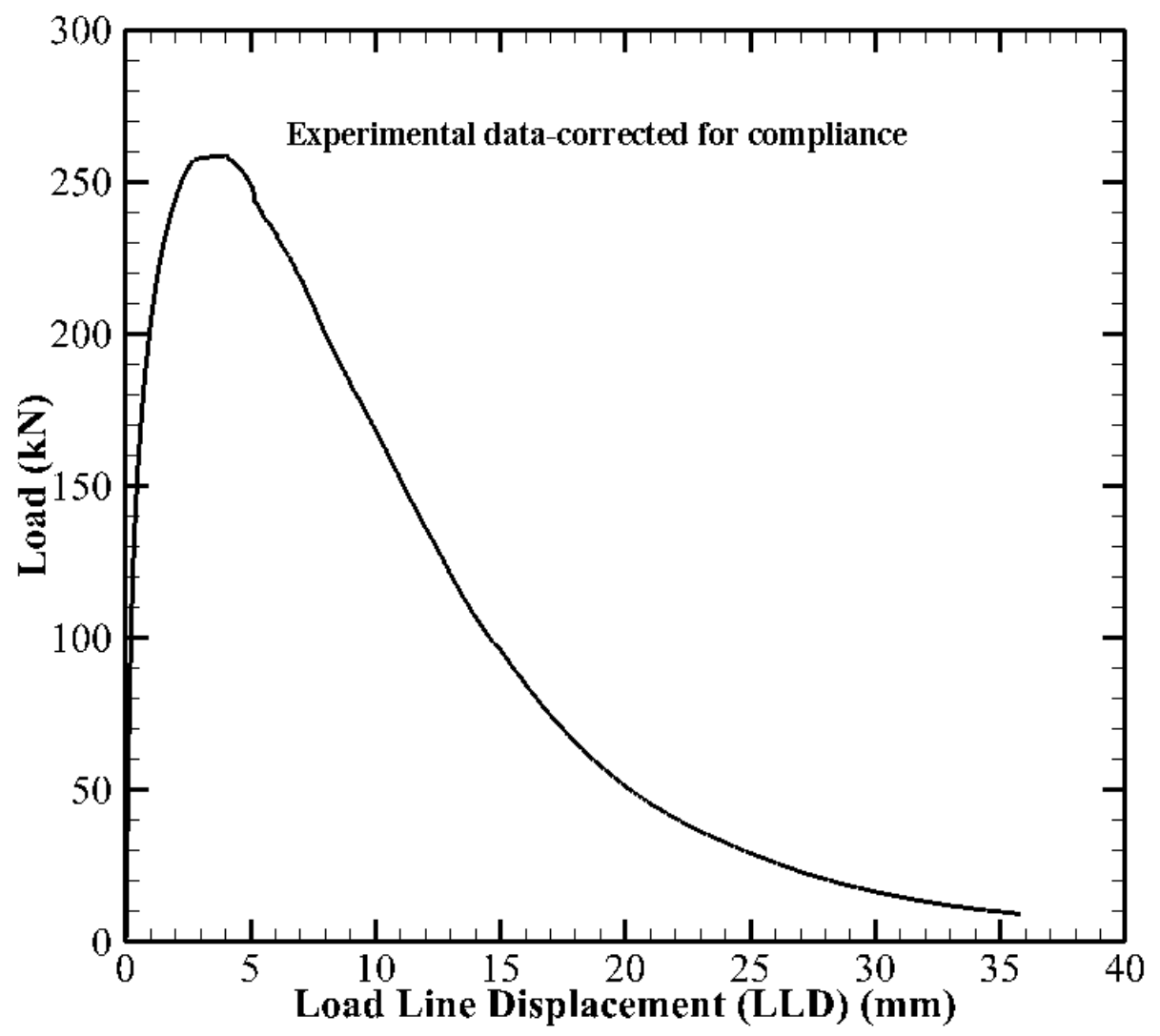

Figure 5.11: Experimental Load vs. LLD-corrected for compliance 


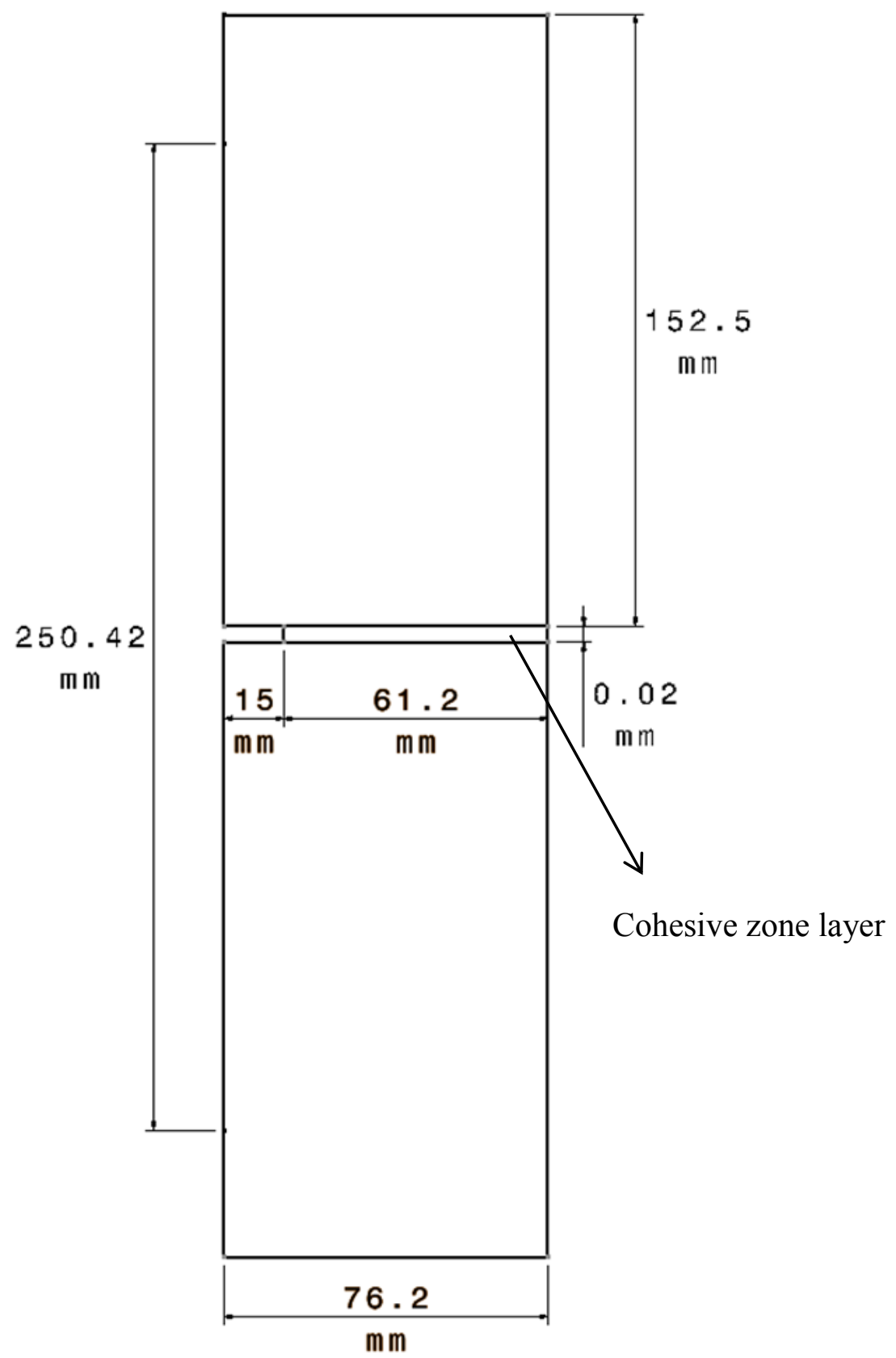

Figure 5.12: Geometry of DWTT specimen - C4 steel 


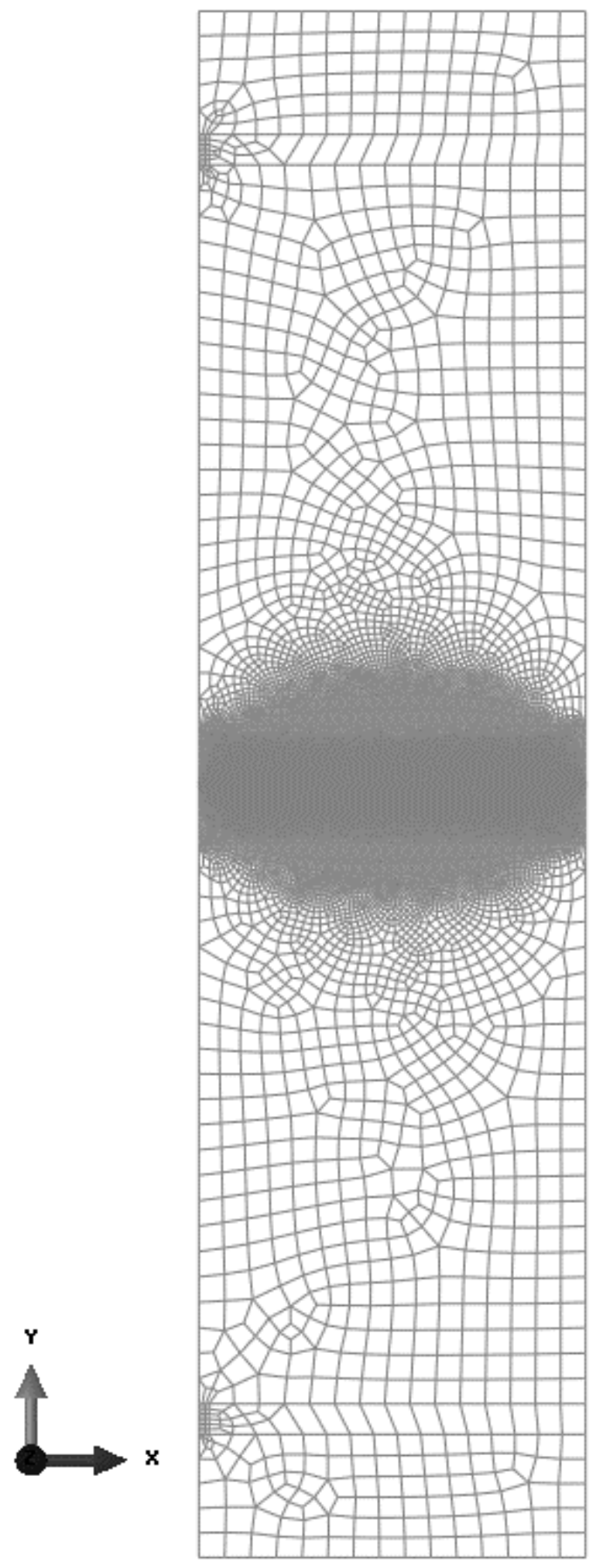

Figure 5.13: Mesh design of DWTT specimen - C4 steel 


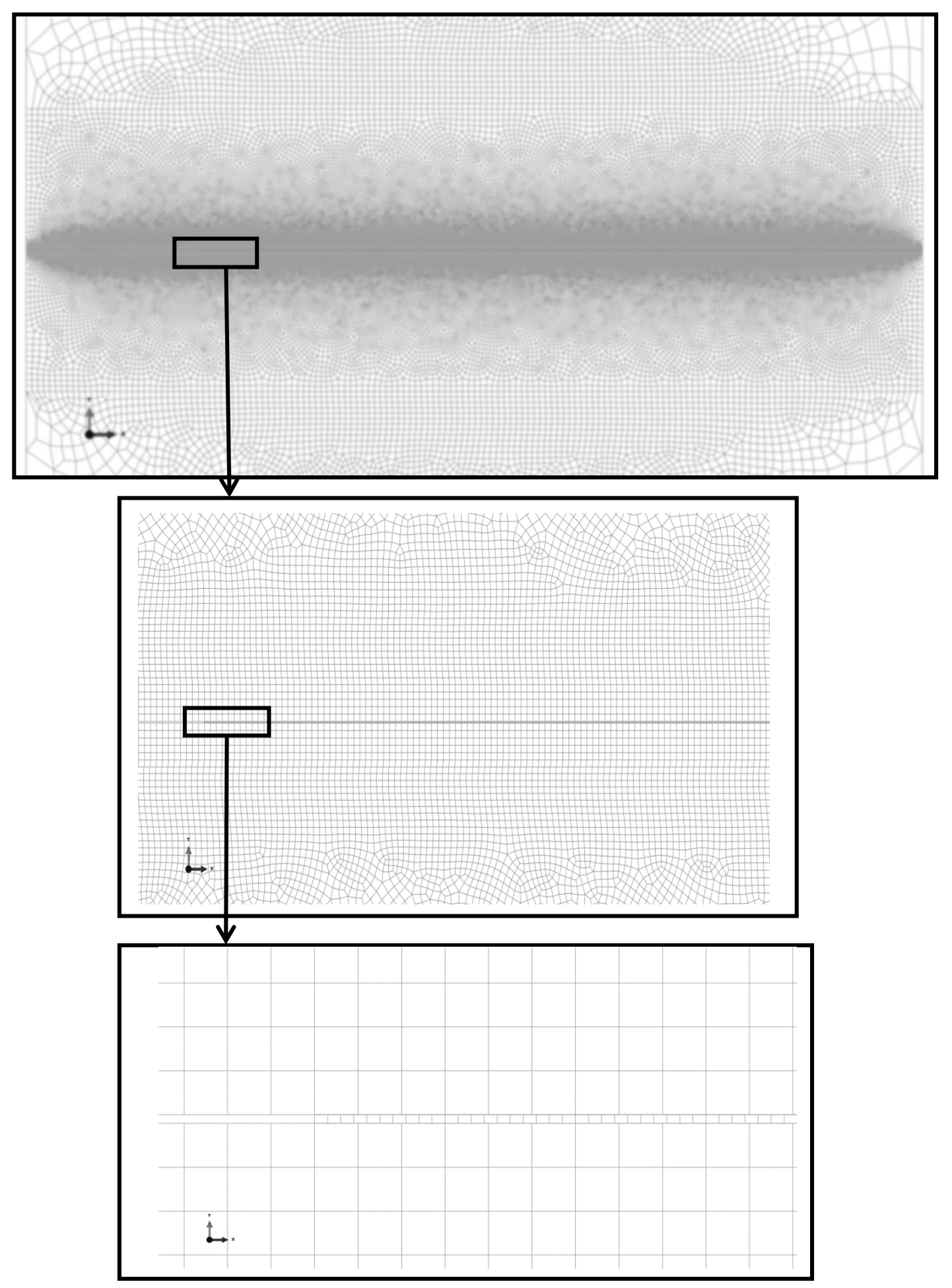

Figure 5.14: Mesh design near crack tip of DWTT specimen - C4 steel 


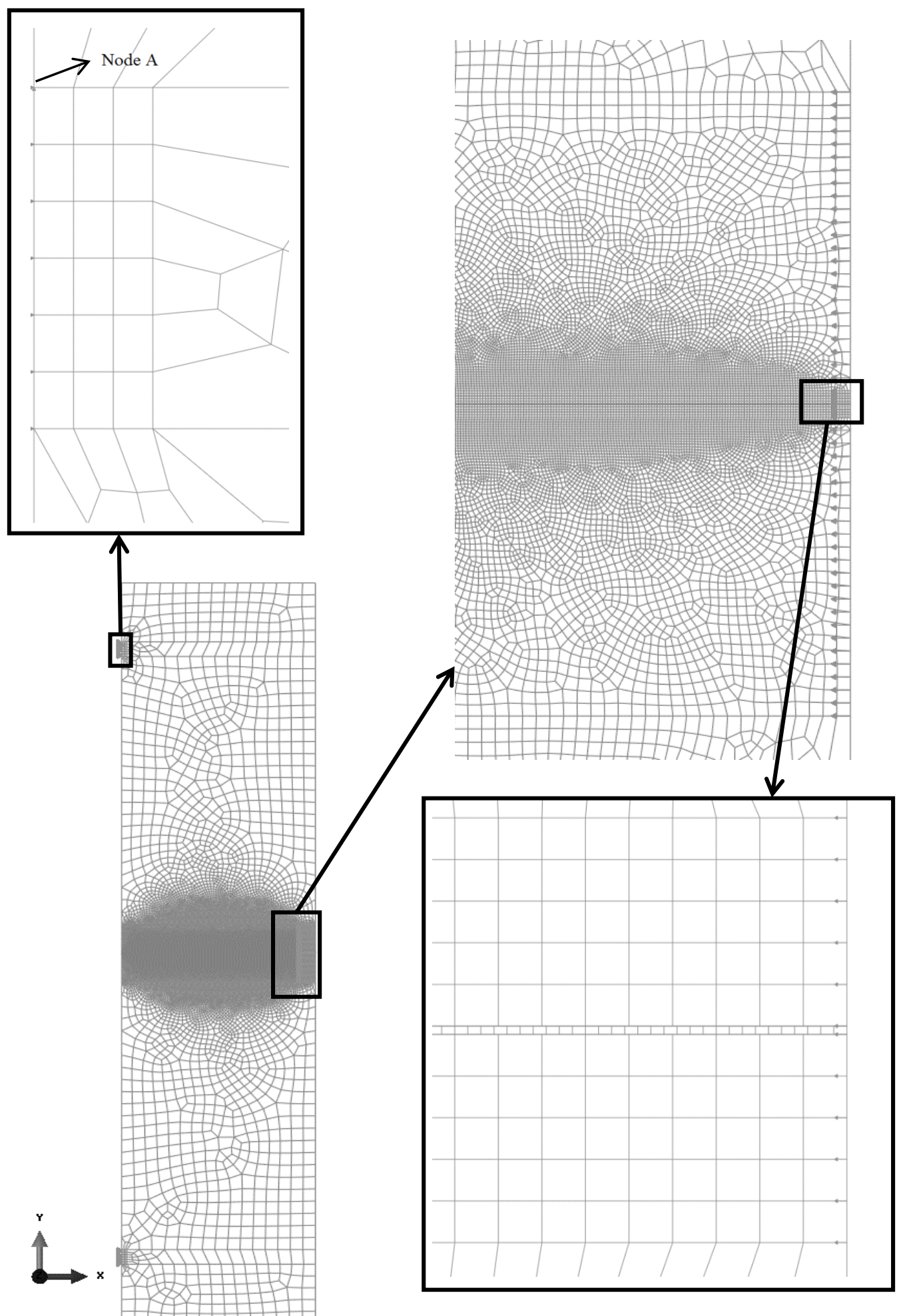

Figure 5.15: Loading conditions of DWTT specimen - C4 steel 


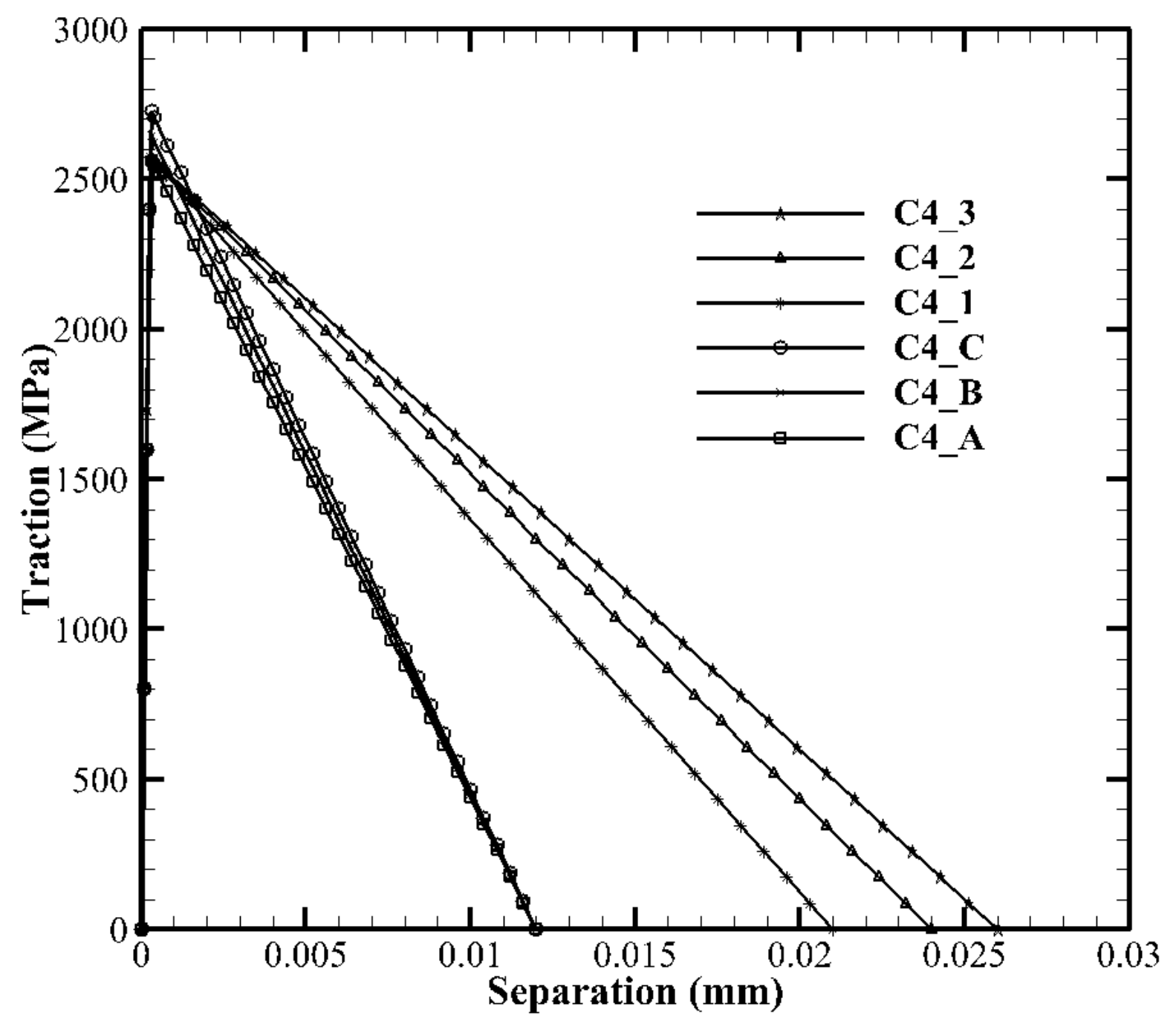

Figure 5.16: Traction-separation laws of unit cell analysis - C4 steel 


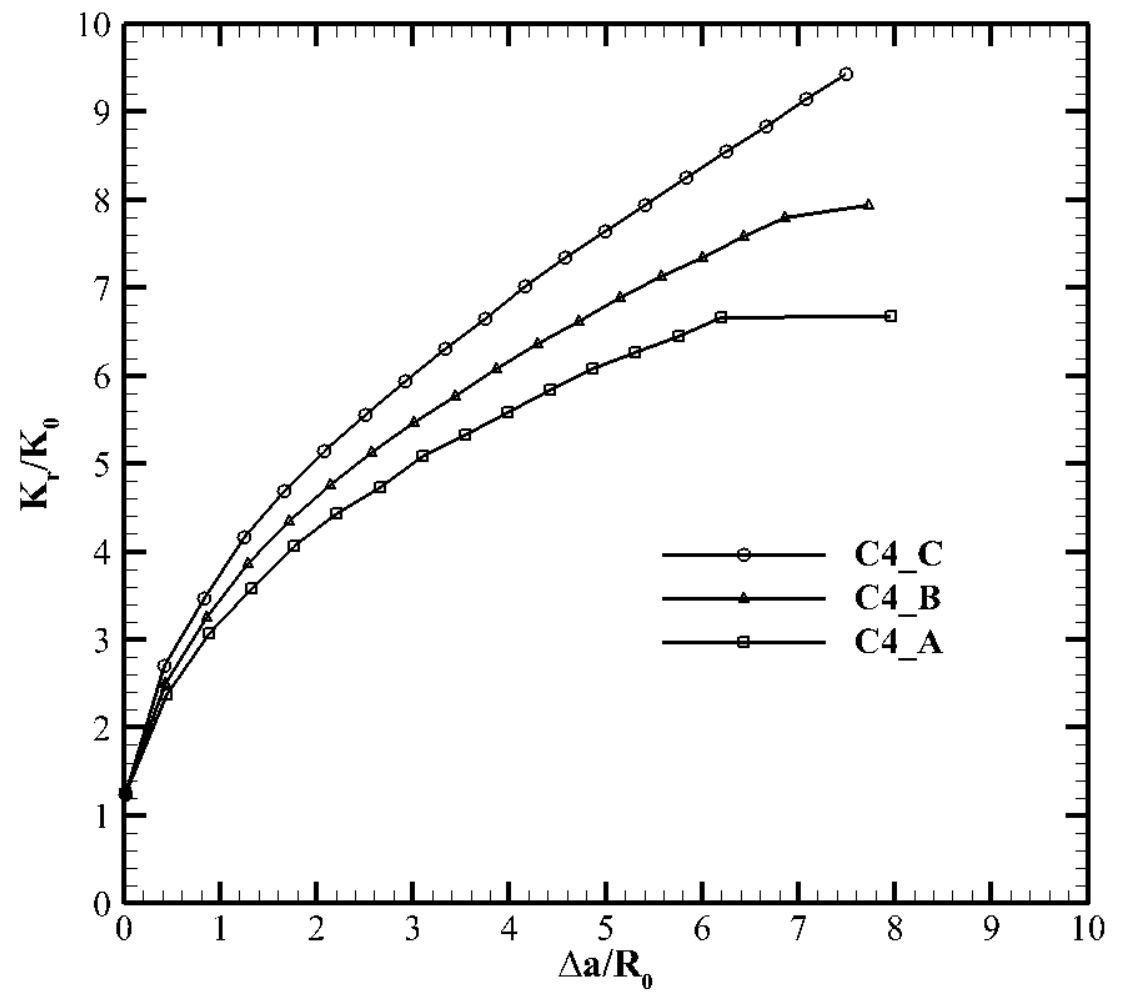

Figure 5.17 Normalized resistance curves of SSY models - C4 Steel

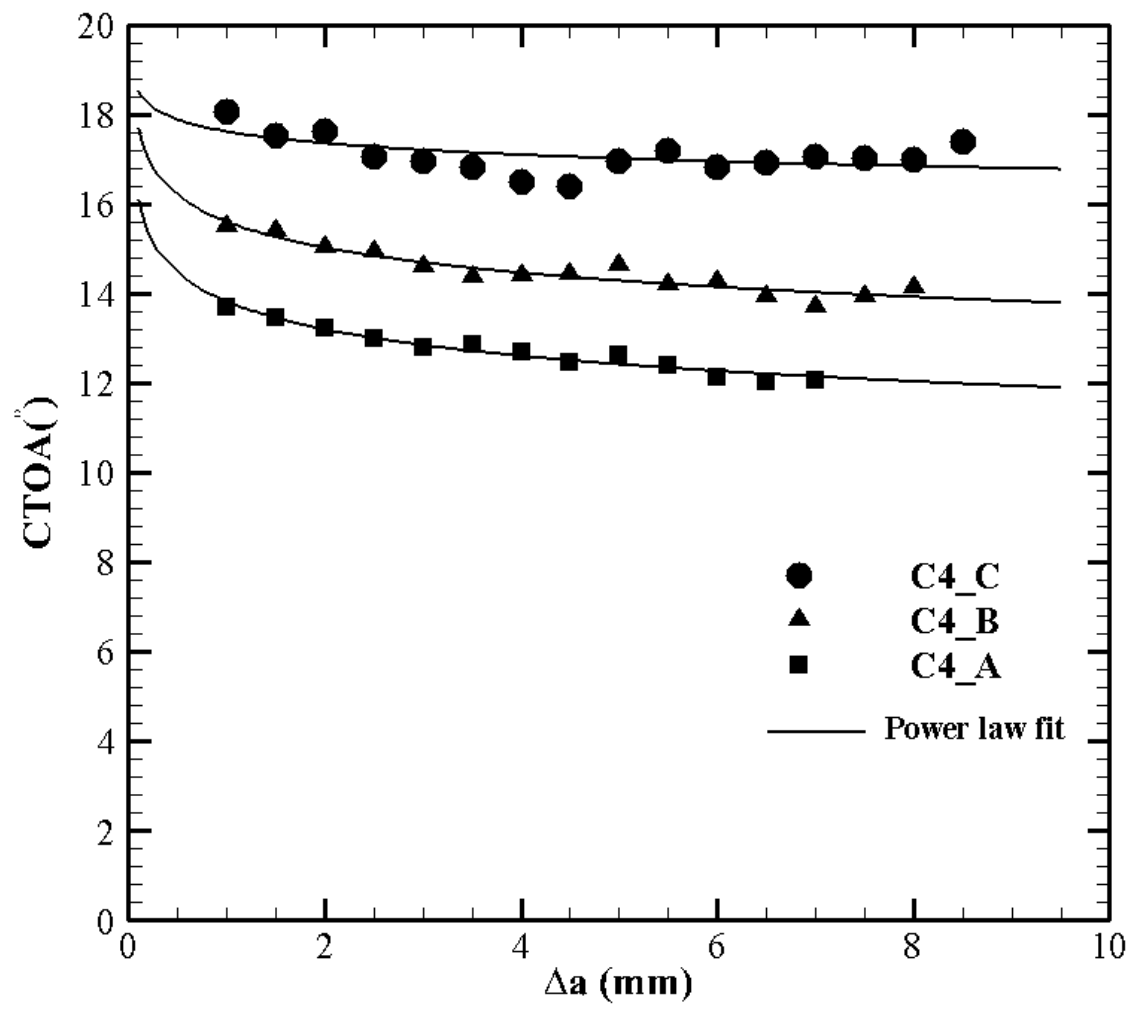

Figure 5.18: CTOA data - SSY model - C4 steel 


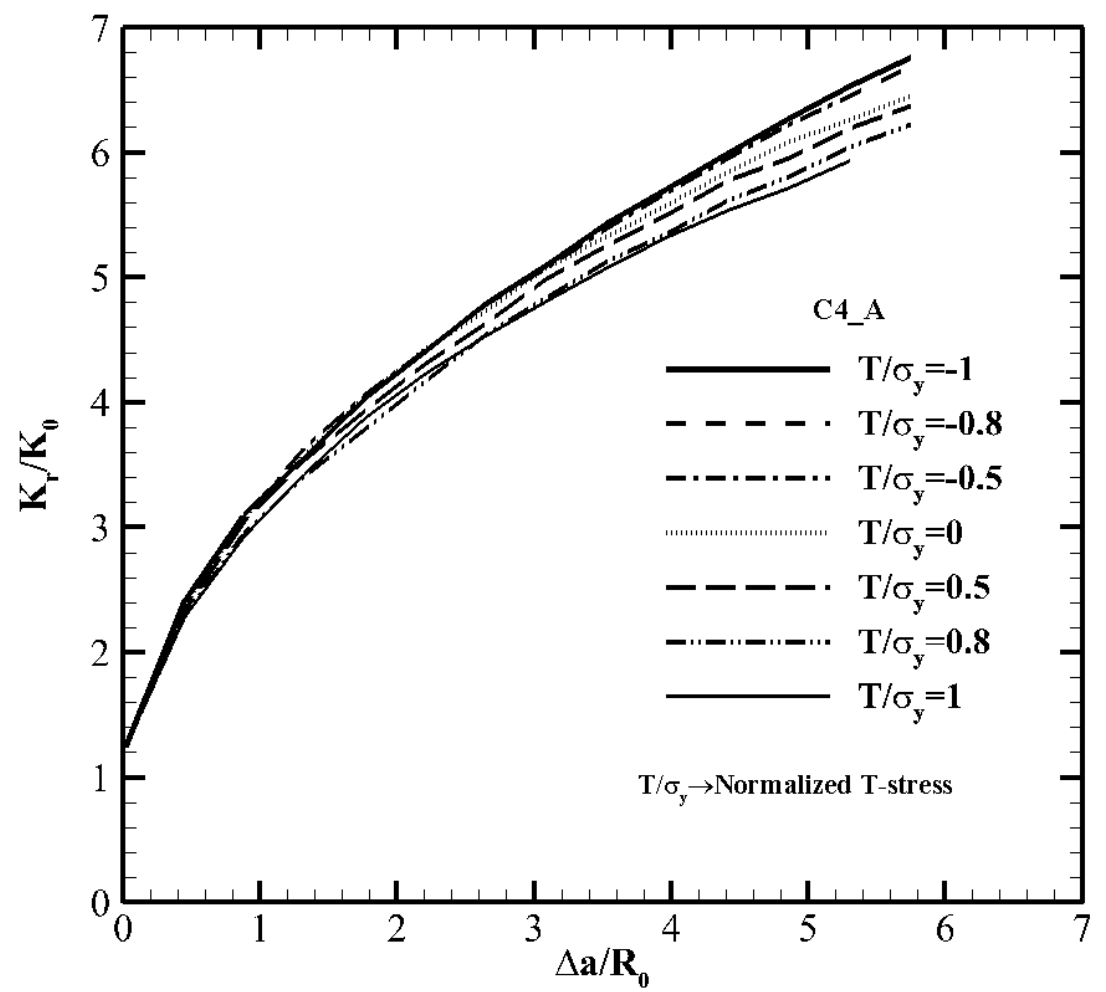

Figure 5.19: Normalized resistance curves -MBL model - C4_A steel

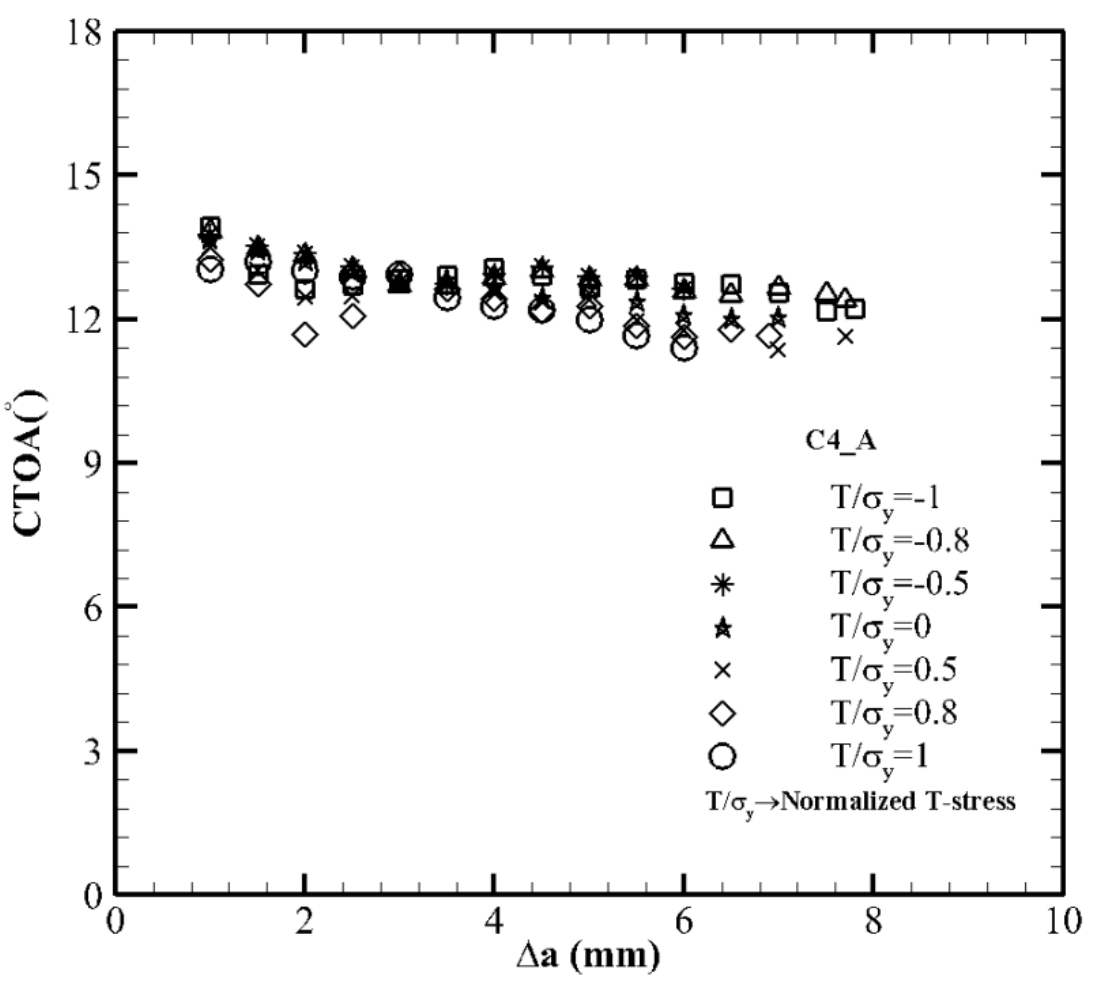

Figure 5.20: CTOA data-MBL model - C4_A steel 


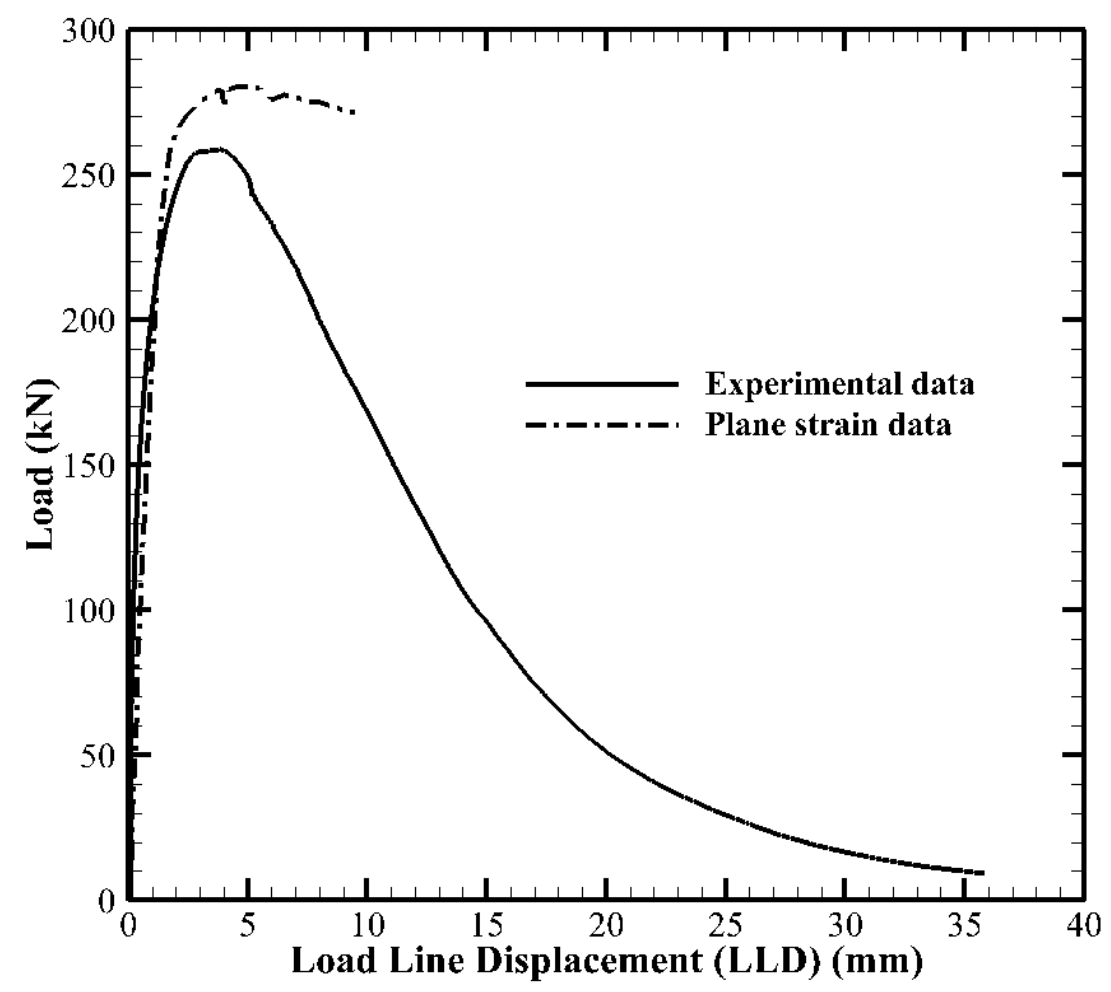

Figure 5.21: Plane strain simulation and experimental data of DWTT - C4 steel

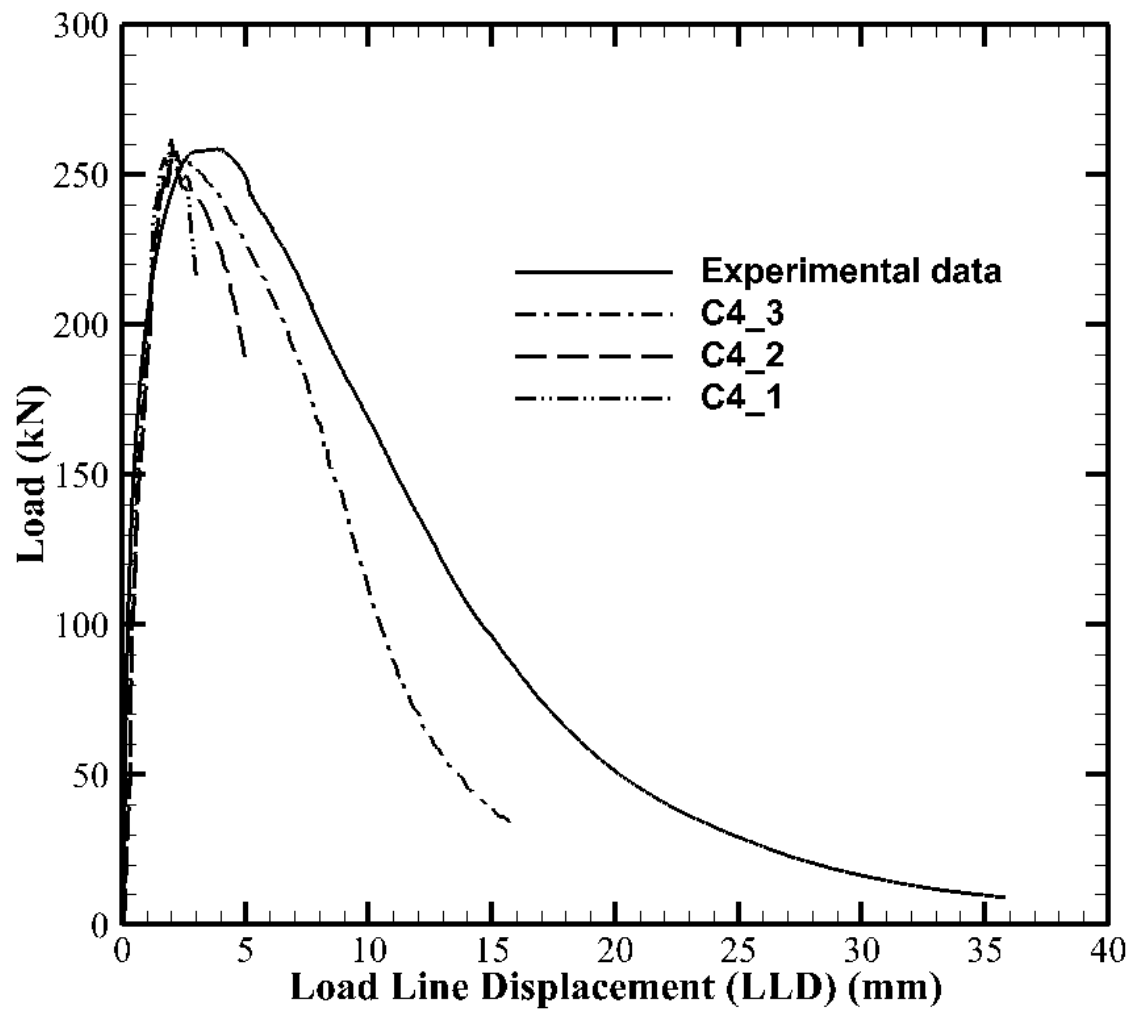

Figure 5.22: Load vs. LLD - DWTT - C4 steel 


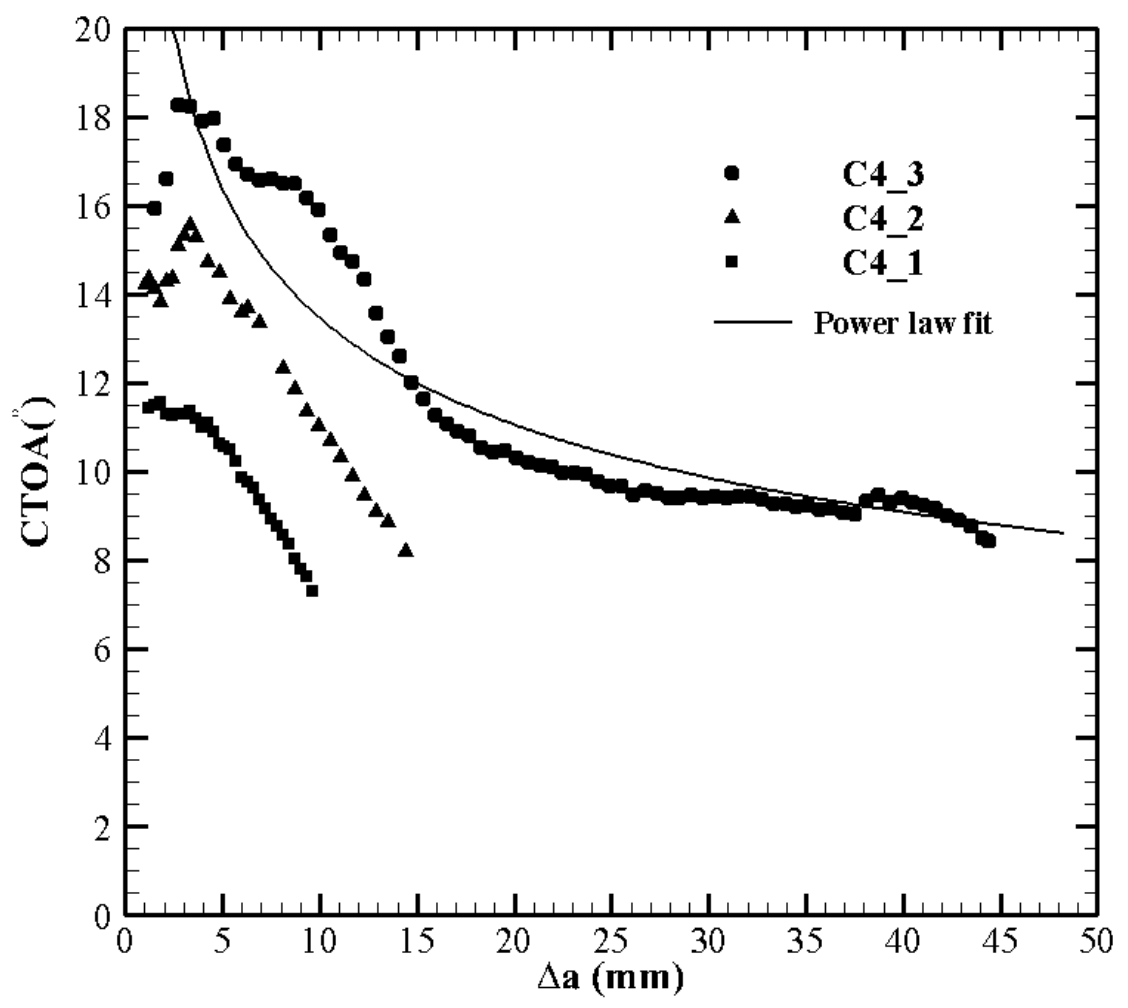

Figure 5.23: CTOA data - DWTT - C4 steel

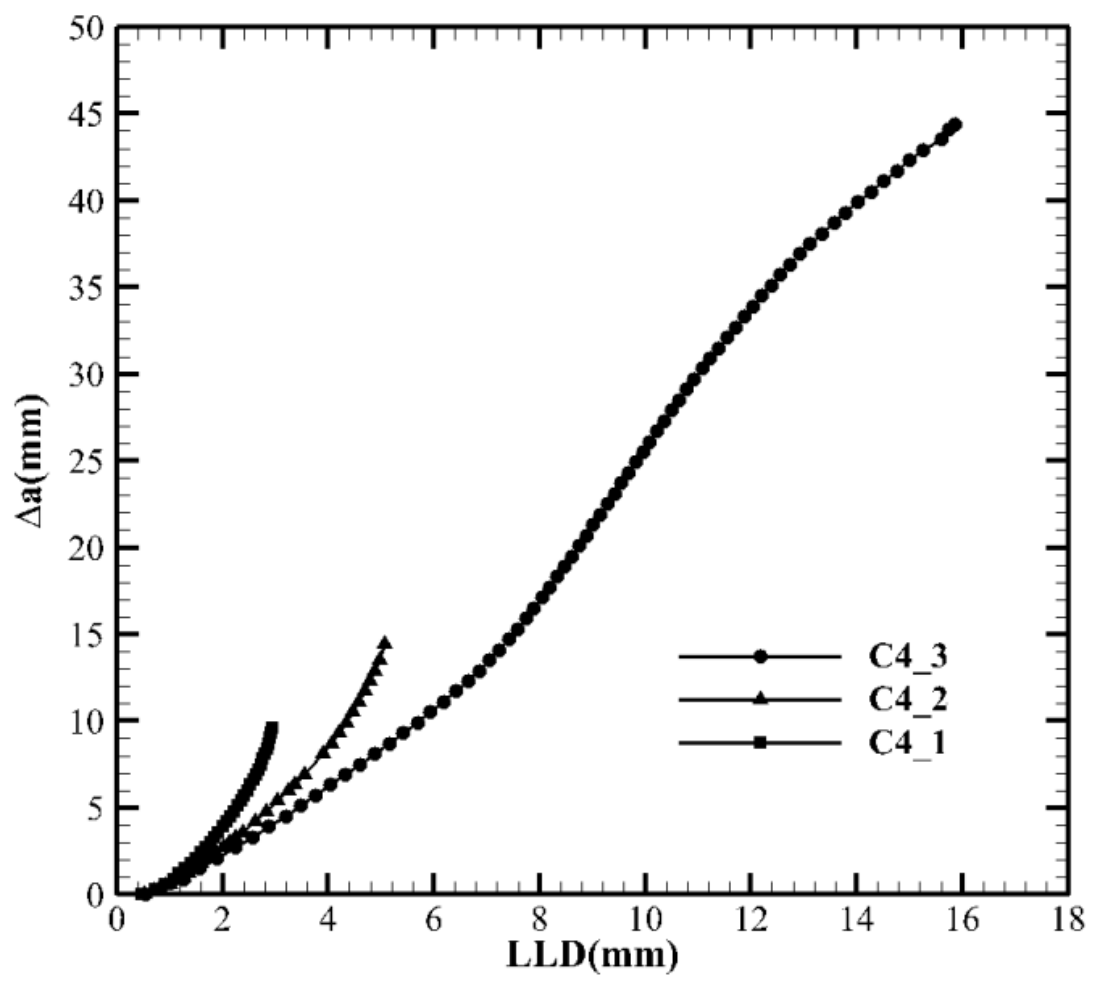

Figure 5.24: $\Delta a$ vs. LLD - DWTT - C4 steel 


\section{Chapter 6}

\section{Conclusions and Future Work}

This chapter summarizes the contribution of each chapter to fulfill the objectives of this work. Also the recommendations for future work are presented in this chapter.

The finite element analysis using cohesive zone model was conducted to study the ductile crack propagation in pipeline steels. Three steels have been used throughout the analysis: TH steel, C2 steel and C4 steel. TH steel was introduced by Tvergaard \& Hutchinson (1992). The other two steels, C2 steel and C4 steel were characterized by Xu in (2010b) and (2013) respectively. The C2 steel and C4 steel are also known as an X70 steel and X100 steel respectively. All finite element simulations have been computed in ABAQUS-6.11.

\subsection{Conclusions}

In Chapter 3, the damage and failure behavior of TH steel has been analyzed using the finite element models of small scale yielding (SSY), modified boundary layer model (MBL), drop-weight tear test (DWTT) and single edge notched specimen in tension (SENT). Four bilinear traction-separation (TS) laws have been used along the surface based cohesive zone modeling for all models. The crack growth resistance curves (Rcurves or $\mathrm{K}_{\mathrm{r}} / \mathrm{K}_{0}$ vs. $\Delta \mathrm{a} / \mathrm{R}_{0}$ ) of SSY have shown good agreement with the results published by Tvergaard \& Hutchinson (1992). The R-curves of MBL for the different 
levels of $\mathrm{T}$-stress $\left(\mathrm{T} / \sigma_{\mathrm{y}}= \pm 0.5, \pm 0.8, \pm 1\right)$ have shown the expected trend of the plot as investigated by Tvergaard \& Hutchinson (1994). Furthermore, it has been observed that, there is no significant effect of the T-stress on CTOA. The load vs. load line displacement (LLD), $\triangle \mathrm{a}$ vs. CTOA and LLD vs. $\Delta \mathrm{a}$ have been plotted for DWTT for sets of TH steel (TH_1-TH_4). The CTOA of DWTT range from $1.6^{\circ}-5^{\circ}$, and are in close agreement with the CTOA measured from SSY. The steady state CTOA data has not been achieved for the SENT, as the simulations have not been converged due to numerical issues. Even though, it can be predicted from the comparison of CTOA of DWTT (positive T-stress) and CTOA of SENT (negative T-stress) that the CTOA is not dependent on T-stress.

In Chapter 4, the same investigation as in Chapter 3 has been performed for $\mathrm{C} 2$ steel. For finite element simulations of SSY, MBL and DWTT, three TS laws have been utilized in surface based cohesive zone modeling. The CTOA data are not affected by the T-stress effect. The R-curves have not fluctuated more for $\mathrm{T}=0, \mathrm{~T}<0$ and $\mathrm{T}>0$. The load vs. LLD plot and CTOA data have been compared to the experimental results provided by $\mathrm{Xu}$, et al., (2010b). The curves of load vs. LLD have not been able to reproduce experimental results. The steady state CTOA data obtained from DWTT of C2_2 is $11.9^{\circ}$ and the CTOA value measured experimentally is $12.4^{\circ}$ (S-SSM). These two values are in good agreement with each other.

In Chapter 5, the full investigation of $\mathrm{C} 4$ steel has been done. The unit cell analysis has been assessed to verify the TS laws. The element based cohesive model has been implemented on SSY, MBL and DWTT. A total of six TS laws have been used for analysis of C4 steel, three TS laws for SSY and MBL and three laws for DWTT. From 
SSY and MBL models, it has been concluded that the T-stress does not much affect the CTOA and R-curves. The steady state CTOA measured from the FE analysis of DWTT of C4_3 steel is $9.3^{\circ}$, while the experimental CTOA measured by Xu (2010) of C4 steel is $10.4^{\circ}$ obtained from the simplified single specimen method. The CTOA value of C4_3 DWTT agrees reasonably well with experimental result. The FE analysis of DWTT of C4_3 has been able to produce quite promising and comparable results to experiment results of load vs. LLD plot and CTOA data provided by Xu (2013).

The simulation of ductile crack propagation using cohesive zone modeling was the aim of this research. The calibration of various CZM was done using different tractionseparation laws. Mainly, three models named SSY, MBL, and DWTT were used for three sets of materials: $\mathrm{TH}$ steel, $\mathrm{C} 2$ steel and $\mathrm{C} 4$ steel. The crack tip opening angles were obtained from all the FE simulations. In all, it is concluded from the results of three steels, that the effect of T-stress (or constraint) on CTOA of MBL is negligible. The CTOA values are transferable from SSY, MBL models to DWTT models for all steels. When properly calibrated, the simulated CTOA values for C2 and C4 steels show good agreement with experimental values for DWTT specimens. Reasonable agreements were also achieved when comparing the load vs. LLD curves between experiments and simulations.

\subsection{Recommendations for Future Work}

The following are the possible ways to proceed this research further:

1. Three dimensional models of SSY, MBL and DWTT could be analyzed in order to improve the results and study the crack tunneling effect. 
2. The single edge notched specimen in tension (SENT) could be implemented in ABAQUS/Explicit using element based cohesive modeling to simulate crack propagation in all three steels: $\mathrm{TH}, \mathrm{C} 2$ and $\mathrm{C} 4$.

3. More models of SSY and DWTT could be simulated with different values of the rate of damage evolution ( $\alpha$ ) of exponential TS law to study the effect of $\alpha$ on Rcurves, fracture energy and CTOA. 


\section{References}

ABAQUS, 2011, Abaqus Analysis User's Manual. Abaqus Online Documentation, Dassault System, Version 6.1.

Available from : http://baribal.cyf-kr.edu.pl:2080/v6.11/books/usb/default.htm

Al-Ani, A. \& Hancock, J., 1991. J-Dominance of short cracks in tension and bending. Journal of the Mechanics and Physics of Solids, 39(1), pp. 23 - 43.

Alfano, G., 2006. On the influence of the shape of the interface law on the application of cohesive-zone models. Composites Science and Technology, 66(6), pp. 723 - 730.

Anderson, T. L., 2011. Fracture Mechanics : Fundamentals and Applications. Florida: CRC Press.

Barenblatt, G., 1962. Mathematical theory of equilibrium cracks. Advance In Applied Mechanics, Volume 7, pp. 56-129.

Carpinteri, A., Gong, B. \& Corrado, M., 2012. Hardening cohesive/overlapping zone model for metallic materials: The size-scale independent constitutive law. Engineering Fracture Mechanics, Volume 82, pp. 29 - 45.

Cerrone, A., Wawrzynek, P., Nonn, A., Paulino, G. H., Ingraffea, A., 2014. Implementation and verification of the Park-Paulino-Roesler cohesive zone model in 3D. Engineering Fracture Mechanics, Volume 120, pp. 26 - 42.

Cornec, A., Scheider, I. \& Schwalbe, K.-H., 2003. On the practical application of the cohesive model. Engineering Fracture Mechanics, 70(14), pp. 1963 - 1987.

Darcis, Ph. P.,McCowan, C. N., McColskey, J. D., Fields, R. J., 2008. Crack tip opening angle measurement through a girth weld in an X100 steel pipeline section. Calgary,Alberta,Canada, 7th International Pilpeline Conference.

Darcis, Ph. P., McCowan, C. N., Windhoff, H., McColskey, J. D., Siewert, T. A., 2008. Crack tip opening angle optical measurement methods in five pipeline steels. Engineering Fracture Mechanics, 75(8), pp. 2453 - 2468.

De Borst, R., 2003. Numerical aspects of cohesive-zone models. Engineering Fracture Mechanics, 70(14), pp. 1743 - 1757. 
Deshpande, V., Needleman, A. \& Giessen, E. V. d., 2003. Scaling of discrete dislocation predictions for near-threshold fatigue crack growth. Acta Materialia, 51(15), pp. 4637 4651.

Ding, P. \& Wang, X., 2012. An estimation method for the determination of the second elastic-plastic fracture mechanics parameters. Engineering Fracture Mechanics, Volume 79 , pp. $295-311$.

Dugdale, D., 1960. Yielding of steel sheets containing slits. Journal of the Mechanics and Physics of Solids, 8(2), pp. 100 - 104.

Dunbar, A. J., 2011. Simulation Of Ductile Crack Propagation in Pipeline Steels Using Cohesive Zone Modeling. Master's Thesis, Carleton University, Ottawa, ON.

Du, Z.-Z. \& Hancock, J., 1991. The effect of non-singular stresses on crack-tip constraint. Journal of the Mechanics and Physics of Solids, 39(4), pp. 555 - 567.

Erdelen-Peppler, M., Gehrmann, R., Junker, G. \& Liessem, A., May 21,2014. Significance of DWT Test in Line Pipe, Duisburg,Germany: Bobbi Middleton.

Harper, P. W. \& Hallett, S. R., 2010. A fatigue degradation law for cohesive interface elements - Development and application to composite materials. International Journal of Fatigue, 32(11), pp. 1774 - 1787.

Hazell, E., 2008. Numerical and experimental studies of shallow cone penetration in clay. PhD Thesis, University of Oxford.

Hillerborg, A., Modéer, M. \& Petersson, P.-E., 1976. Analysis of crack formation and crack growth in concrete by means of fracture mechanics and finite elements. Cement and Concrete Research, 6(6), pp. 773 - 781.

Horsley, D. J., 2003. Background to the use of CTOA for prediction of dynamic ductile fracture arrest in pipelines. Engineering Fracture Mechanics, 70(3-4), pp. 547 - 552.

Ivanco, D. I. V., 2011. Nonlinear Finite Element Analysis. PhD Thesis, Faculty of Mechanical Engineering, Technical University of Kosice, Slovakia. 
Jadhav, D. \& Maiti, S., 2010. Characterization of stable crack growth through AISI 4340 steel using cohesive zone modeling and CTOD/CTOA criterion. Nuclear Engineering and Design, 240(4), pp. 713 - 721.

Larsson, S. \& Carlsson, A., 1973. Influence of non-singular stress terms and specimen geometry on small-scale yielding at crack tips in elastic-plastic materials. Journal of the Mechanics and Physics of Solids, 21(4), pp. 263 - 277.

Li, H. \& Chandra, N., 2003. Analysis of crack growth and crack-tip plasticity in ductile materials using cohesive zone models. International Journal of Plasticity, 19(6), pp. 849 -882 .

Martinelli, A. \& Venzi, S., 1996. Tearing modulus,J-integral,CTOA and crack profile shape obtained from the load-displacement curve only. Engineering Fracture Mechanics, 53(2), pp. 263-277.

McHugh, P., 2007. Non-Linear Finite Element Analysis : Finite Element Solution Schemes I \& II. [PowerPoint Slides], Department of Mechanical and Biomedical Engineering, National University of Ireland, Galway.

Meshii, T., Tanaka, T. \& Lu, K., 2010. T-Stress solutions for a semi-elliptical axial surface crack in a cylinder subjected to mode-I non-uniform stress distributions. Engineering Fracture Mechanics, 77(13), pp. 2467 - 2478.

Nazarali, Q. \& Wang, X., 2011. The effect of T-stress on Crack -Tip Plastic Zones Under Cyclic Mixed - Mode Loading Conditions. Fatigue \& Fracture of Engineering Materials \& Structures, 34(10), pp. 792-803.

Needleman, A., 1987. A continuum model for void nucleation by inclusion debonding. Journal Of Applied Mechanics, 54(3), pp. 525-531.

Newman, J., James, M. \& Zerbst, U., 2003. A review of the CTOA/CTOD fracture criterion. Engineering Fracture Mechanics, 70(3-4), pp. 371 - 385.

Park, K., Paulino, G. H. \& Roesler, J., 2010. Cohesive fracture model for functionally graded fiber reinforced concrete. Cement and Concrete Research, 40(6), pp. 956 - 965.

Petersson, P., 1981. Crack growth and development of fracture zones in plain concrete and similar materials. Dissertation, Report TVBM-1006, Division of Building Materials, Lund Institute of Technology, Denmark. 
Ren, Z. \& Ru, C., 2013. Numerical investigation of speed dependent dynamic fracture toughness of line pipe steels. Engineering Fracture Mechanics, 99(0), pp. 214 - 222.

Rice, J., 1968. A Path Independent Integral and the Approximate Analysis of strain Concentration by Notches and Cracks. ASME Journal of Applied Mechanics, Volume 35, pp. 379-386.

Rice, J. \& Sorensen, E., 1978. Continuing crack-tip deformation and fracture for planestrain crack growth in elastic-plastic solids. Journal of the Mechanics and Physics of Solids, 26(3), pp. 163 - 186.

Rudland, D. L.,Wilkowski, G., Wang, Y. -Y., Horsely, D., Rothwell, B., Glover, A., 2002. Investigation into the use of a single specimen for the determination of dynamic steady state propagation resistance in high toughness line-pipe steels. Calgary,Alberta,Canada, 4th International Pipeline Conference.

Rudland, D.L., Wilkowski, G.M., Feng, Z., Wang, Y.-Y., Horsley, D., Glover, A., 2003. Experimental investigation of CTOA in linepipe steels. Engineering Fracture Mechanics, 70(3-4), pp. 567 - 577.

Ruggieri, C. \& Dotta, F., 2011. Numerical modeling of ductile crack extension in high pressure pipelines with longitudinal flaws. Engineering Structures, 33(5), pp. 1423 1438.

Ruggieri, C. \& Dotta, F., 2011. Numerical modeling of ductile crack extension in high pressure pipelines with longitudinal flaws. Engineering Structures, 33(5), pp. 1423 1438.

Salvini, P. \& Mannucci, A. F. a. G., 2003. Identification of CTOA and fracture process parameters by drop weight test and finite element simulation. Engineering Fracture Mechanics, 70(3-4), pp. 553 - 566.

Scheider, I., Schödel, M., Brocks, W. \& Schönfeld, W., 2006. Crack propagation analyses with CTOA and cohesive model: Comparison and experimental validation. Engineering Fracture Mechanics, 73(2), pp. 252 - 263.

Shim, D.-J., Uddin, M., Wilkowski, G. \& Duan, D.-M., 2013. Simulation of Drop Weight Tear Test (DWTT) using cohesive zone model. Belgium, 6th International Pipeline Technology Conference. 
Siegmund, T. \& Brocks, W., 2000. A numerical study on the correlation between the work of separation and the dissipation rate in ductile fracture. Engineering Fracture Mechanics, 67(2), pp. 139 - 154.

Toshio, N. \& Parks, D. M., 1992. Determination of elastic T-stress along threedimensional crack fronts using an interaction integral. International Journal of Solids and Structures, 29(13), pp. 1597 - 1611.

Trädegård, A., Nilsson, F. \& Östlund, S., 1998. FEM-remeshing technique applied to crack growth problems. Computer Methods in Applied Mechanics and Engineering, 160(1-2), pp. $115-131$.

Tvergaard, V. \& Hutchinson, J. W., 1992. The relation between crack growth resistance and fracture process parameters in elastic-plastic solids. Journal of the Mechanics and Physics of Solids, 40(6), pp. 1377-1397.

Tvergaard, V. \& Hutchinson, J. W., 1994. Effect of T-STRESS on mode I crack growth resistance in a ductile solid. International Journal of Solids and Structures, 31(6), pp. 823 $-833$.

Wang, J. \& Shuai, J., 2012. Measurement and analysis of crack tip opening angle in pipeline steels. Engineering Fracture Mechanics, Volume 79, pp. 36 - 49.

Wang, X., 2009. Two-parameter characterization of elastic-plastic crack front fields: Surface cracked plates under tensile loading. Engineering Fracture Mechanics, 76(7), pp. $958-982$.

$\mathrm{Xu}, \mathrm{S} ., 2010 \mathrm{a}$. Private correspondence between Xu and Dundar regarding experimental results of a DWTT for a C2(X70) steel and it's stress-strain curve.

Xu, S.,Tyson, W. R., Eagleson, R., McCowan, C.N., Drexler, E. S., McColskey, J. D., Darcis, Ph. P., 2010b. Measurement of CTOA of Pipe Steels Using MDCB and DWTT Specimens. Calgary,Alberta,Canada, 8th International Pipeline Conference,IPC201031076.

Xu, S., Tyson, W.R., Simha, C.H.M., 2013. Testing for resistance to fast ductile fracture : measurement of CTOA. Journal of Pipeline Engineering, 12(3), pp. 165-173. 
$\mathrm{Xu}$, S., Bouchard, R. \& Tyson, W. R., 2007. Simplified single-specimen method for evaluating CTOA. Engineering Fracture Mechanics, 74(15), pp. 2459 - 2464.

Xu, S., Eagleson, R., Tyson, W. R. \& Park, D. -Y., 2011. Crack tunneling and crack tip opening angle in drop-weight tear test specimens. International Journal of Fracture, 172(1), pp. 105-112.

$\mathrm{Xu}$, S., Shen, G., Roy, G. \& Tyson, W., 2011. Application Of Plastic Hinge Model to Single-Edge-Notched Bend SE(B) Specimen, Ottawa,ON,Canada: Report No.201101(TR)CANMENT-MTL.

Xu, S. \& Tyson, W. R., 2008. CTOA Measurement of Pipe Steels Using DWTT Specimen. Calgary,Alberta,Canada, 7th International Pipeline Conference, IPC2008-64060.

Xu, S., Tyson, W. R. \& R., B., 2009. Experimental Validation Of Simplified SingleSpeciemen CTOA Method for DWTT specimens. Ottawa,ON, 12th International Conference on Fracture,ICF2009-269.

$\mathrm{Xu}, \mathrm{S} ., 2013$. Private correspondence between $X u$ and Shreya Parmar regarding experimental results of a DWTT for a C4(X100) steel and it's stress-strain curve.

Yamaguchi, T., Okabe, T. \& Yashiro, S., 2009. Fatigue simulation for titanium/CFRP hybrid laminates using cohesive elements. Composites Science and Technology, 69(1112), pp. 1968 - 1973.

Yang, S.-Y., 2006. Analysis of fatigue crack growth in weld specimen using threedimensional cohesive zone model. Key Engineering Materials, Volume 321, pp. 674-677.

Zerbst, U., Heerens, J. \& Schwalbe, K. -H., 1995. Fracture mechanics analysis based on a loacal simulation principle. Fatigue \& Fracture of Engineering Materials \& Structures Ltd, 18(3), pp. 371-376.

Zerbst, U., Heinimann, M., Donne, C. D. \& Steglich, D., 2009. Fracture and damage mechanics modelling of thin-walled structures - An overview. Engineering Fracture Mechanics, 76(1), pp. 5 - 43. 